Universidad deValladolid

PROGRAMA DE DOCTORADO EN QUÍMICA: QUÍMICA DE SÍNTESIS, CATÁLISIS Y MATERIALES AVANZADOS

TESIS DOCTORAL:

\title{
INTERACCIONES SUPRAMOLECULARES DE PORFIRINAS FUNCIONALIZADAS CON MÚLTIPLES SUSTITUYENTES POLIAROMÁTICOS PLANOS Y NO PLANOS CON FULLERENOS
}

Presentada por Sergio Ferrero Martín para optar al grado de Doctor por la Universidad de Valladolid

Dirigida por:

Dr. Celedonio Manuel Álvarez González

Dr. Raúl García Rodríguez 



\section{AGRADECIMIENTOS}

La sección de agradecimientos, en mi humilde opinión, es un reflejo de las experiencias vividas por "el propio doctorando" durante toda esta etapa profesional y académica (a mi parecer un periodo duro y bastante sufrido). Podríamos decir, en cierto modo, que es el "resumen complementario" al obligatorio académico, donde uno hace balance de lo bueno y, porque no decirlo también, de lo malo.

Como dice el refrán "es de bien nacido ser agradecido", y por tanto eso haré, hay que agradecer, decir "gracias", a mucha gente que me ha ayudado, de alguna u otra manera, a lo largo esta larga travesía llamada "tesis doctoral".

Primeramente, quiero agradecer a mis directores de tesis; al Dr. Celedonio M. Alvarez, por confiar en mi desde el primer instante con toda la investigación relacionada con porfirinas ("las porfis"), que finalmente, tan buenos resultados nos han proporcionado (no sin dificultades, claro está). Por enseñarme muchas cosas de diferente indole durante toda mi trayectoria, alguna que otra de sintesis, pero sobre todo en el campo de mi amada Resonancia Magnética Nuclear (RMN). Sin olvidar, por supuesto, su gran carisma y personalidad, siempre dispuesto ayudar cuando ha sido necesario. $Y$ como una breve anécdota, si aquel día ya lejano de hace 7 años no se hubiera pasado por el CENQUIOR para hacerme una visitilla, seguramente yo no estaría escribiendo ahora estas letras y, por ende, usted lector, tampoco leyendo todo este trabajo. A mi gran querido, Dr. Raúl García, no hay palabras de gratitud para expresar todo el apoyo prestado durante mis horas bajas y momentos de flaqueza, es algo que nunca podré olvidar y por ello siempre estaré en deuda contigo. Tu pasión por la enseñanza junto con tu disposición y carácter diligente harán que te conviertas en un docente ejemplar digno de admiración.

Asimismo, me gustaría tener unas palabras para el resto de los profesores integrantes del GIR MIOMeT: Al Dr. Daniel Miguel, por la gran cantidad de buenos consejos científicos aportados en todas las reuniones de grupo y su gran personalidad manifestada siempre en cualquier situación. Es una de las pocas personas que puedo decir, sin miedo a equivocarme, que considero un "sabio", por su infinidad de temas de conocimiento, podríamos decir que es un "ilustrado en pleno siglo XXI". Al Dr. Fernando Villafañe, por las innumerables horas de buenos ratos en el laboratorio, consejos, anécdotas y curiosidades científicas con las que siempre nos amenizaba las largas jornadas de trabajo. Al Dr. Jose M. Martín, uno de los mejores docentes de esta universidad, sabe transmitir y divulgar a la perfección su pasión por la Ciencia y la Química en particular. También a otros profesores que siempre han preguntado por el estado de "la tesis", a la Dra. Camino Bartolomé y al Dr. Jesús A. Miguel, pero en especial al Dr. Jesús M. Martínez de Ilarduya (alias JM), una de las personas más amables que he conocido, siempre dispuesto ayudar, independientemente del momento y de la hora requerida.

A lo largo de todos estos años ha pasado mucha gente por el laboratorio, cada uno dejando, en mayor o menor medida y a su modo, una huella imborrable en mi memoria y a los cuales me gustaría destinar unas palabras. En primer lugar, a nuestro predecesor más ancestral, al Dr. Luis A. García (Luigi) por dejarnos en herencia un gramo de Coranuleno, gracias al cual puede empezar mi investigación (aún hay por ahí algún miligramo guardado). En segundo lugar, a mis coetáneos y compañeros de carrera por los inmensos momentos vividos: a la Dra. Lucía Álvarez, por demostrarme que con determinación y tesón también puede sacarse adelante una tesis doctoral, a pesar de todas las dificultades que puedan plantearse durante el camino. Al Dr. Alberto Diez, una de las personas con la mayor formación académica que tengo el placer de conocer y que siempre me ha brindado buenos consejos desde el comienzo de nuestra amistad. $\Upsilon$, por último, a mi gran estimado Dr. Héctor Barbero, por demostrarme que, con decisión, fuerza de voluntad y carácter es posible alcanzar tus objetivos profesionales marcados y que obtener el título de Doctor ("PhD”), pese a todas las penurias experimentadas en esta etapa formativa-académica, finalmente merece la pena. También tengo que agradecer, su inestimable ayuda en los primeros años de mi investigación, que han resultado cruciales para sacar todo este trabajo adelante. En este apartado me gustaría incluir a un cuasicoetáneo de mi generación, aunque sea de otra rama científica-técnica, al futuro Dr. Eduardo Gutiez, por la gran ayuda aportada solucionando todos nuestros problemas informáticos y siempre dándonos ánimos 
y preocupándose por todos los integrantes del grupo. En tercer lugar, a los relevos generacionales del laboratorio: al futuro Dr. Alvaro García y futura Dra. Adriana Sacristán, que fueron los primeros que pude "fichar" para hacer la tesis. Por el ambiente tan singular y excelente con el que inundáis al laboratorio y por no hacerme sentir sólo en muchos momentos, cuando la presión por terminar me abrumaba y desesperaba. Por todo ello y más, gracias. Os deseo un futuro brillante y no dudo que conseguiréis cualquier meta personal y profesional que os propongáis. $\Upsilon$, por último, a la futura Dra. Nerea Álvarez, mi sucesora directa, aunque aún tiene una larga trayectoria por recorrer, ha evidenciado que posee una enorme paciencia y perseverancia para poder alcanzar las metas "sintéticas" propuestas. Finalmente, a todas aquellas personas que han tenido una estancia más o menos breve por el laboratorio durante todo este tiempo: Dra. Patricia Gómez, futura Dra. Elena Cuellar (por toda la ayuda con mis infructuosos intentos de cristalización), futura Dra. Beatriz Merillas (siempre serás de nuestro grupo, aunque marchaste con los "Físicos"), futuro Dr. José Ángel Quintana, Dra. Pamela Soledad Cuenca, Miguel, Sara, Elena, Luis, Laura, Alba, Luna, David, Cristina, María y Clara. Sin olvidar, por supuesto, a todos los compañeros de Química Orgánica, al futuro Dr. Carlos Díez y Alberto Cherubin. Dentro de este grupo de gente de laboratorio, he de incluir, además, a esa pequeña familia creada en el Quifima: al futuro Dr. Ignacio Pérez, Dr. Marconi Peñas, futuro Dr. Olmo Lozano, futuro Dr. Francisco Villalba y en particular a la Dra. Estela de Domingo, futura Dra. María Barcenilla, Dra. María Pérez y Dra. Estefanía Gioria.

A mis compañeros del Laboratorio de Técnicas Instrumentales (LTI) de la Universidad de Valladolid por su gran disposición cuando se ha requerido de sus servicios científicos: Marta Ozores, Beatriz, Javier y a la Dra. Nora Carrera, pero en especial a Ana Moral, por ser todos estos años mi compañera de batalla en el servicio de RMN de la Universidad de Valladolid.

Al grupo de RMN del Dr. Gareth Morris y Dr. Mathias Nilsson, "Manchester NMR Methodology Group", y a toda la gente que conoci allí, por hacerme sentir uno más dentro de ese grupo de investigación tan único y excepcional: Dr. Guilherme Dal Poggetto (Bart), Dra. Pinelopi Moutzouri, Dr. Aaron Hernandez-Cid, Dr. Peter Kiraly, Dr. Mohammadali Foroozandeh (PSYCHE's father), y fundamentalmente a la Dra. Laura Castañar, por su gran amabilidad y toda la ayuda prestada durante mi primera estancia en el extranjero.

No quiero olvidarme tampoco de mi primera etapa en el servicio de RMN del CENQUIOR, donde tuve mi primer contacto directo con en el apasionante mundo de la Resonancia Magnética Nuclear. En este periodo conocí a un gran número de gente de las que guardo muy personales y cálidos recuerdos: Maite Benito, Araceli Sánchez, Pablo Espina, María José Malo, Dra. María Frutos, Dra. Mayca del Río y Dr. Raúl Benito. Aunque me gustaría mencionar en particular a la Dra. Elisa García y a la Dra. María Luisa Jimeno (May), que me han influenciado de forma decisiva y en parte son responsables de lo que he llegado a convertirme hoy.

A un montón de amigos que siempre se han interesado por mi estado científico-profesional: Ismael, Enrique (Kike), Mariano, Erika, Leticia, Alberto, Sergio, Arturo, Ricardo, Noelia y en particular, a mis queridos Alberto, Lydia y Saray que tan buenos momentos hemos pasado. Mención singular a Alejandra (Álex) por crear el magnífico dibujo que adorna la portada de este trabajo y que además ha sido portada de uno mis artículos en "The Journal of the Organic Chemistry" (JOC). A mi otro gran grupo de amigos que tanto aprecio, por estar siempre apoyándome en todo momento en esta larga etapa de mi vida: Adrián (Dranon), Silvia, Alberto (Moki), Vanesa, Javier (Valli), Jorando (Jordi), Estrella, David (Castro), Blanca, Jose, futura Dra. Cristina Renedo, Ricardo, Guzmán, Lorena, Miguel y al Dr. Antonio Tejerode-Pablos, por demostrarme que también se puede hacer un tesis doctoral, nada más y nada menos que en Japón.

Para terminar, a todos mis familiares y en especial a mis primos David, Mariano y Roberto, que siempre se han preocupado por los avances de mi investigación. Finalmente, como no podría ser de otra manera, a mis queridos padres, Eugenia y José Antonio, y hermano, Jaime; sin su cariño, comprensión y paciencia durante todos estos largos años este trabajo no hubiera sido posible. Por todo ello, gracias de corazón. 
"Confía en el tiempo, que suele dar dulces salidas a muchas amargas dificultades" Miguel de Cervantes Saavedra (1547 - 1616). "La Gitanilla"(1613)

"Las deficiencias de la aptitud nativa son compensables mediante un exceso de trabajo y de atención. Cabría afirmar que el trabajo sustituye al talento, o mejor dicho, crea el talento."

Santiago Ramón y Cajal (1852 - 1934) 



\section{FINANCIACIÓN}

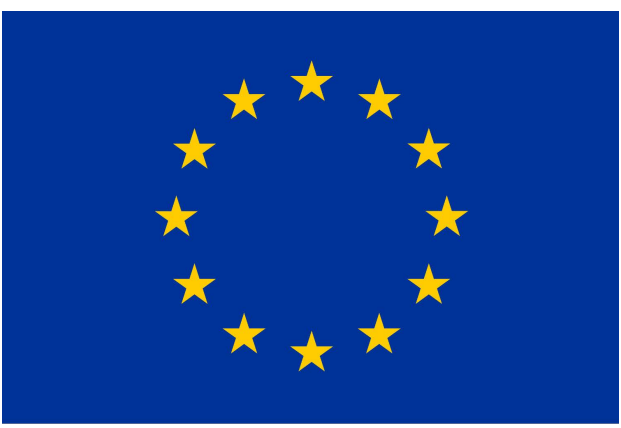

\section{UNIÓN EUROPEA}

Fondo Social Europeo

EL FSE invierte en tu futuro
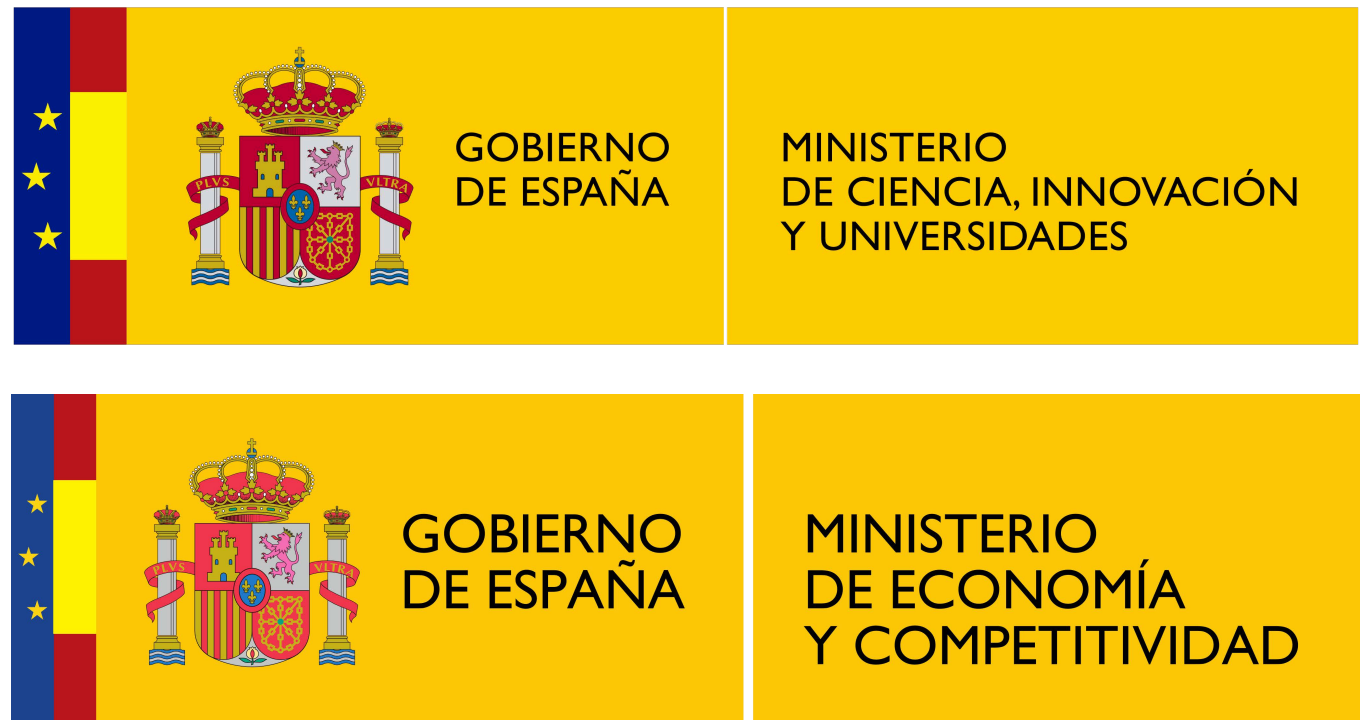

MINISTERIO DE ECONOMÍA Y COMPETITIVIDAD

La presente Tesis Doctoral titulada "Interacciones supramoleculares de porfirinas funcionalizadas con múltiples sustituyentes poliaromáticos planos y no planos con fullerenos" ha sido realizada gracias al apoyo económico del Fondo Social Europeo (FSE), Ministerio de Economía y Competitividad (MINECO, proyecto CTQ 2013-41067-P, PGC 2018-099470-B-100 y RYC-201519035) y al Ministerio de Ciencia, Innovación y Universidades (MCIU, proyecto PGC2018-096880A-I00 y PGC2018-099470-B-I00). 



\section{TESIS PRESENTADA COMO COMPENDIO DE PUBLICACIONES}

De acuerdo con la nueva normativa de la Universidad de Valladolid aprobada por el Consejo de Gobierno el 3 de junio de 2016 (BOCyL n 114, de 15 de junio, págs. 26299 - 26310 y modificación BOCyL no 196, de 10 de octubre de 2019, págs. 45191 - 45194), esta memoria está formada por los apartados exigidos en la misma y se presentan tres artículos publicados, que cuentan con los requisitos necesarios y se listan a continuación (por el orden en el que posteriormente serán tratados):

Artículo I: Dual-Tweezer Behavior of an Octapodal Pyrene Porphyrin-Based System as a Host for Fullerenes.

Publicado en The Journal of Organic Chemistry: Sergio Ferrero, Héctor Barbero, Daniel Miguel, Raúl García-Rodríguez, Celedonio M. Álvarez. J. Org. Chem., 2019, 84, 6183 - 6190. DOI: 10.1021/acs.joc.9b00362.

Artículo II: Octapodal Corannulene Porphyrin-Based Assemblies: Allosteric Behavior in Fullerene Hosting.

Publicado en The Journal of Organic Chemistry: Sergio Ferrero, Héctor Barbero, Daniel Miguel, Raúl García-Rodríguez, Celedonio M. Álvarez. J. Org. Chem., 2020, 85, 4918 - 4926. DOI: 10.1021/acs.joc.0c00072.

Artículo III: Porphyrin-based systems containing polyaromatic fragments: decoupling the synergistic effects in aromatic-porphyrin-fullerene systems.

Publicado en RSC Advances: Sergio Ferrero, Héctor Barbero, Daniel Miguel, Raúl GarcíaRodríguez, Celedonio M. Álvarez. RSC Adv., 2020, 10, 36164 - 36173. DOI: 10.1039/d0ra07407a.

El siguiente listado enumera una serie de artículos y capítulos de libro ordenados cronológicamente en los que el doctorando ha trabajado durante la realización de la tesis doctoral, aunque no formen parte del núcleo de la misma. Dicha lista se encuentra recopilada en el Apartado de Anexos (págs. 133 - 192).

Artículo IV: Synergistic Effect of Tetraaryl Porphyrins Containing Corannulene and Other Polycyclic Aromatic Fragments as Hosts for Fullerenes. Impact of $\mathrm{C}_{60}$ in a Statistically Distributed Mixture of Atropisomers. Celedonio M. Álvarez, Héctor Barbero, Sergio Ferrero, Daniel Miguel. J. Org. Chem. 2016, 81, 6081 - 6086. DOI: 10.1021/acs.joc.6b00454.

Artículo V: Preparation of a Corannulene-functionalized Hexahelicene by Copper(I)catalyzed Alkyne-azide Cycloaddition of Nonplanar Polyaromatic Units. Celedonio M. Álvarez, Héctor Barbero, Sergio Ferrero. J. Vis. Exp., 2016, 115, e53954. DOI:10.3791/53954.

Artículo VI: Affinity modulation of photoresponsive hosts for fullerenes: light-gated corannulene tweezers. Héctor Barbero, Sergio Ferrero, Lucía Álvarez-Miguel, Patricia GómezIglesias, Daniel Miguel and Celedonio M. Álvarez. Chem. Commun., 2016, 52, 12964 - 12967. DOI: $10.1039 / \mathrm{c} 6 \mathrm{cc} 06445 \mathrm{k}$. 
Capítulo de libro: Corannulene-based molecular receptors for fullerenes. Héctor Barbero, Sergio Ferrero, Adriana Sacristán-Martín, Celedonio M. Álvarez. Advances in Chemistry Research. Volume 42. Chapter 4, pp. 165 - 204. Nova Science Publishers, Inc. 2017. ISBN 978-1-53612-9199.

Artículo VII: Synthesis of a Tetracorannulene-perylenediimide That Acts as a Selective Receptor for $\mathrm{C}_{60}$ over $\mathrm{C}_{70}$. Víctor García-Calvo, José V. Cuevas, Héctor Barbero, Sergio Ferrero, Celedonio M. Álvarez, Jesús A. González, Borja Díaz de Greñu, José García-Calvo, Tomas Torroba. Org. Lett. 2019, 21, 5803 - 5807. DOI: 10.1021/acs.orglett.9b01729.

\section{MENCIÓN DE DOCTORADO INTERNACIONAL}

La presente memoria pretende obtener la mención de Doctorado Internacional (artículo 15, RD 99/2011, de 28 de enero, por el que se regulan las enseñanzas oficiales de doctorado, modificado por el RD 195/2016). Para ello, esta tesis incluye toda la documentación requerida. Además, los apartados Índice, Resumen General (págs. 1 - 6) y Conclusiones (págs. 91 - 96), así como todos los Artículos (págs. 97-132) están redactados en inglés. 


\section{LISTA DE ABREVIATURAS}

${ }^{13} \mathrm{C}\left\{{ }^{1} \mathrm{H}\right\}$

$\AA$

$\mathrm{AcO}$

ADN

$\mathrm{B}_{2} \operatorname{pin}_{2}$

BIP

BSSE

${ }^{\mathrm{t}} \mathrm{Bu}$

CNT

COSY

CPD

CRISIS

DCM

DCTB

DDQ

DFT

dppf

DQFCOSY

et al.

Et

FVP

GAFF

HMBC

HOMO

HPLC

HRMS
Carbono 13 desacoplado de protón

Ángstrom

Acetato

Ácido desoxirribonucleico

Diborano de bis-pinacolato

Pulso de inversión de banda ancha (Broadband Inversion Pulse)

Error de Superposición de Bases (Basis Set Superposition Error)

grupo terc-butilo

Nanotubo de carbono (Carbon NanoTubes)

Espectroscopía de Correlación (COrrelation SpectroscopY)

Centro de Proceso de Datos

Compensación de la ineficiencia del reenfoque con barrido de inversión sincronizado (Compesation of Refocusing Inefficiency with Synchronized Inversion Sweep)

Diclorometano

trans-2-[3-(4-terc-butilfenil)-2-metil-2-propeniliden]malononitrilo

2,3-dicloro-5,6-diciano-1,4-benzoquinona

Teoría del Funcional de Densidad (Density Functional Theory)

1,1'-Bis(difenilfosfino)ferroceno

COSY Filtrado a Doble Cuanto (Double Quantum Filtered COSY)

Expresión latina et alii, cuyo significado es "y otros"

Etilo

Pirolización en alto vacío (Flash Vacuum Pyrolysis)

Campo de Fuerzas Generalizado de Amber (Generalized Amber Force Field)

Correlación Heteronuclear de Múltiple Enlace (Heteronuclear MultipleBond Correlation)

Orbital Molecular Ocupado de más Energía (Highest Occupied Molecular Orbital)

Cromatografía Líquida de Alta Eficacia (High Performance Liquid Chromatography)

Espectrometría de Masas de Alta Resolución (High-Resolution Mass Spectrometry) 


\begin{tabular}{|c|c|}
\hline HSQC & $\begin{array}{l}\text { Correlación Heteronuclear a Simple Cuanto (Heteronuclear Single- } \\
\text { Quantum Correlation) }\end{array}$ \\
\hline $\mathrm{Hz}$ & Hercio \\
\hline IR & Infrarrojo (Infrared) \\
\hline ITC & Calorimetría de titulación isotérmica (Isothermal Titration Calorimetry) \\
\hline IUPAC & $\begin{array}{l}\text { Unión Internacional de Química Pura y Aplicada (International Union of } \\
\text { Pure and Applied Chemistry) }\end{array}$ \\
\hline$J$ & Constante de acoplamiento (en RMN) \\
\hline K & Constante de asociación \\
\hline LUMO & $\begin{array}{l}\text { Orbital Molecular No Ocupado de más baja Energía (Lowest Unoccupied } \\
\text { Molecular Orbital) }\end{array}$ \\
\hline MALDI & $\begin{array}{l}\text { Desorción e Ionización por Láser Asistido por Matriz (Matrix-Assisted } \\
\text { Laser Desorption/Ionization) }\end{array}$ \\
\hline MW & Microondas (MicroWave) \\
\hline NBS & N-bromosuccinimida \\
\hline NCIPlot & $\begin{array}{l}\text { Gráfico de Interacciones No Covalentes (Non-Covalent Interactions } \\
\text { Plot) }\end{array}$ \\
\hline PAH & Hidrocarburo Policíclico Aromático (Polycyclic Aromatic Hydrocarbon) \\
\hline PCM & Modelo Continuo Polarizable (Polarizable Continuum Model) \\
\hline PEG & Polietilenglicol (Polyethylene Glycol) \\
\hline PFG & Gradientes de Campo Pulsado (Pulsed Field Gradients) \\
\hline POAV & Vector de eje $\pi$ orbital ( $\pi$-Orbital Axis Vector) \\
\hline ppm & Partes por millón (en RMN) \\
\hline RMN & Resonancia Magnética Nuclear (en inglés, $N M R$ ) \\
\hline ROESY & $\begin{array}{l}\text { Espectroscopía de Efecto nuclear Overhauser en Marco Rotatorio } \\
\text { (Rotating frame nuclear Overhauser Effect SpectroscopY) }\end{array}$ \\
\hline SSR & Suma Cuadrada de los Residuales (Sum Squared Residuals) \\
\hline $\mathrm{S}_{\mathrm{E}} \mathrm{Ar}$ & Sustitución electrófila aromática \\
\hline TLC & Cromatografía en capa fina (Thin Layer Chromatography) \\
\hline TMS & Tetrametilsilano \\
\hline TOF & Tiempo de Vuelo (Time Of Flight) \\
\hline UV & Ultravioleta \\
\hline UV-Vis & Ultravioleta y Visible \\
\hline
\end{tabular}




\section{NOTACIÓN SUPRAMOLECULAR Y EQUILIBRIOS}

A lo largo de esta memoria se han discutido compuestos que presentan la capacidad de formar aductos supramoleculares. Se han denominado en el texto de la siguiente manera:

\section{$\mathbf{G @ H}$}

Donde:

$\mathbf{G}$ es fullereno (Huésped - Guest): $\mathrm{C}_{60}$ o $\mathrm{C}_{70}$.

H es la molécula capaz de establecer interacción supramolecular (Anfitrión - Host)

Y se lee de la siguiente manera: "G contenido en H".

A su vez, los aductos supramoleculares, se definen a través de equilibrios químicos. Se han designado en el texto de la siguiente forma:

\section{$\mathbf{X}: \mathbf{Y}$}

Donde:

$\mathbf{X}$ e $\mathbf{Y}$ son números naturales distintos de 0 .

$\mathbf{X}$ es la molécula Anfitrión - Host.

Y es la molécula Huésped - Guest.

Así, por ejemplo, un equilibrio 1:2 hace referencia a 1 molécula de Host y 2 moléculas de Guest y un equilibrio 2:1 corresponde con 2 moléculas de Host y 1 molécula de Guest. 



\section{ÍNDICE}

1. RESUMEN GENERAL _ _ 1

1.1. GENERAL SUMMARY (Inglés) __ 5

2. INTRODUCCIÓN _ 7

2.1. QUÍMICA SUPRAMOLECULAR _ 9

2.2. NANOMATERIALES DE CARBONO

2.2.1. Fullerenos__ 12

2.3. HIDROCARBUROS POLICÍCICLOS AROMÁTICOS PLANOS _ 14

2.3.1. Pireno 15

2.3.1.1. Interacciones supramoleculares entre fullerenos y pireno _ 16

2.4. HIDROCARBUROS POLICÍCICLOS AROMÁTICOS NO PLANOS _ 17

2.4.1. Coranuleno 18

2.4.1.1. Geometría y propiedades__ 18

2.4.1.2. Métodos de síntesis de coranuleno _ 20

2.4.1.3. Interacciones supramoleculares entre fullerenos y coranuleno _ 22

2.4.1.4. Evolución histórica de sistemas coranulénicos como receptores de fullerenos___ 23

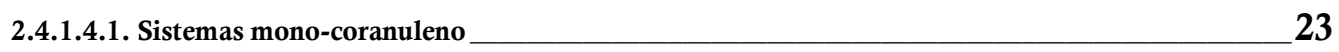

2.4.1.4.2. Sistemas bis-coranuleno

\begin{tabular}{ll}
2.4 .1 .4 .3$. & Sistemas tris-coranuleno \\
\hline
\end{tabular}

$\begin{array}{ll}\text { 2.4.1.4.4. Sistemas tetrakis-coranuleno } & 29\end{array}$

$\begin{array}{ll}\text { 2.4.1.4.5. Polímeros basados en coranuleno } & 30\end{array}$

2.5. SISTEMAS AROMÁTICOS BASADOS EN PORFIRINAS _ 31

2.5.1. Geometría y propiedades _ 32

2.5.2. Métodos de síntesis de porfirinas __ 34

2.5.3. Interacciones supramoleculares entre fullerenos y porfirinas __ 35

3. OBJETIVOS__ 37

3.1. OBJETIVOS GENERALES 39

3.2. OBJETIVOS ESPECÍFICOS_ 39

4. METODOLOGÍA EMPLEADA _ 41

4.1. METODOLOGIA SINTÉTICA___ 43

4.1.1. Métodos de funcionalización___ 43 
4.1.2. Síntesis de precursores planos y no planos 44

4.1.3. Métodos de purificación 44

4.1.3.1. Cromatografía en columna preparativa 44

4.1.3.2. HPLC 44

\subsection{CARACTERIZACIÓN DE COMPUETOS} 45

4.2.1. Espectroscopía de Resonancia Magnética Nuclear de líquidos de alta resolución_ 45

4.2.2. Espectroscopía de Absorción UV-Visible __ 46

4.2.3. Espectrometría de Masas__ 46

4.3. MÉTODOS COMPUTACIONALES

4.4. EVALUACIÓN DE LAS PROPIEDADES DE LOS COMPUESTOS___ 49

4.4.1. Determinación de constantes de asociación __ 49

4.4.2. Estequiometría de los aductos supramoleculares: Modelos de unión __ 51

5. DISCUSIÓN DE RESULTADOS

5.1. PORFIRINAS MESO-OCTAARILSUSTITUIDAS SIMÉTRICAS CON LIGANDOS POLIAROMÁTICOS PLANOS

5.1.1. Artículo I: Dual-Tweezer Behavior of an Octapodal Pyrene Porphyrin-Based System as a Host for Fullerenes __ 57

5.2. PORFIRINAS MESO-OCTAARILSUSTITUIDAS SIMÉTRICAS CON LIGANDOS POLIAROMÁTICOS NO PLANOS 69

5.2.1. Artículo II: Octapodal Corannulene Porphyrin-Based Assemblies: Allosteric Behavior in Fullerene Hosting 69

5.3. PORFIRINAS MESO-TETRAARILSUSTITUIDAS SIMÉTRICAS CON LIGANDOS POLIAROMÁTICOS PLANOS Y NO PLANOS 80

5.3.1. Artículo III: Porphyrin-based systems containing polyaromatic fragments: decoupling the synergistic effects in aromatic-porphyrin-fullerene systems 80

6. CONCLUSIONES 91

6.1. CONCLUSIONES GENERALES 93

6.2. CONCLUSIONES ESPECÍFIFICAS 93

6.3. CONCLUSIONS (Inglés) ___ 95

6.3.1. GENERAL CONCLUSIONS 95

6.3.2. SPECIFIC CONCLUSIONS 95

7. ARTÍCULOS PUBLICADOS 
7.1. Artículo I: Dual-tweezer Behavior of an Octapodal Pyrene Porphyrin-Based System as a Host for Fullerenes 99

7.2. Artículo II: Octapodal Corannulene Porphyrin-Based Assemblies: Allosteric Behavior in Fullerene Hosting 117

7.3. Artículo III: Porphyrin-based systems containing polyaromatic fragments: decoupling the synergistic effects in aromatic-porphyrin-fullerene systems 138 



\section{INDEX}

1. GENERAL SUMMARY (Spanish) ___ 1

1.1. GENERAL SUMMARY (English) _ _ 5

2. INTRODUCTION _ 7

2.1. SUPRAMOLECULAR CHEMISTRY

2.2. CARBON NANOMATERIALS 10

2.2.1. Fullerenes__ 12

2.3.PLANAR POLYCYCLIC AROMATIC HYDROCARBONS 14

2.3.1. Pyrene_ 15

2.3.1.1. Supramolecular interactions between fullerenes and pyrene __ 16

2.4. NON-PLANAR POLYCYCLIC AROMATIC HYDROCARBONS _ 17

2.4.1. Corannulene 18

2.4.1.1. Geometry and properties___ 18

2.4.1.2. Corannulene synthesis__ 20

2.4.1.3. Supramolecular interactions between fullerenes and corannulene __ 22

2.4.1.4. Historical evolution of corannulene-based systems as hosts for fullerenes ___ 23

$\begin{array}{ll}\text { 2.4.1.4.1. Mono-corannulene systems } & 23\end{array}$

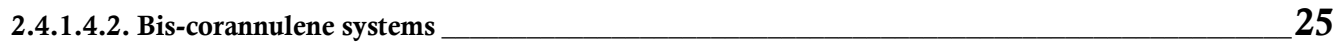

2.4.1.4.3. Tris-corannulene systems __ 29

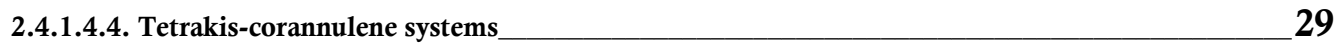

$\begin{array}{ll}2.4 .1 .4 .5 & \text { Corannulene-based polymers } \\ \end{array}$

2.5. AROMATIC PORPHYRIN-BASED SYSTEMS _ 31

2.5.1. Geometry and properties _ 32

2.5.2. Porphyrin synthesis___ 34

2.5.3. Supramolecular interactions between fullerenes and porphyrins _ 35

3. OBJECTIVES 37

3.1. GENERAL OBJECTIVES 39

3.2. SPECIFIC OBJECTIVES 39

4. METHODOLOGY UESED _ 41

4.1. SYNTHETIC METHODOLOGY _ 43

4.1.1. Functionalization methods __ 43 
4.1.2. Planar and non-planar precursors synthesis 44

4.1.3. Purification methods 44

4.1.3.1. Preparative column chromatography 44

4.1.3.2. HPLC 44

4.2. COMPOUND CHARACTERIZATION__ 45

4.2.1. Liquid high-resolution Nuclear Magnetic Resonance spectroscopy _ 45

4.2.2. UV-Visible absorption spectroscopy___ 46

4.2.3. Mass Spectrometry __ 46

4.3. COMPUTACIONAL STUDIES

4.4. PROPERTIES COMPOUND ASSESSMENT _ 49

4.4.1. Binding constants estimation

4.4.2. Stoichiometry of the supramolecular adducts: Binding models __ 51

5. DISCUSSION OF RESULTS

5.1. SYMMETRIC MESO-OCTAARYLSUBSTITUTED PORPHYRINS BEARING PLANAR POLYAROMATIC LIGANDS

5.1.1. Article I: Dual-Tweezer Behavior of an Octapodal Pyrene Porphyrin-Based System as a Host for Fullerenes 57

5.2. SYMMETRIC MESO-OCTAARYLSUBSTITUTED PORPHYRINS BEARING NON-PLANAR POLYAROMATIC LIGANDS 69

5.2.1. Article II: Octapodal Corannulene Porphyrin-Based Assemblies: Allosteric Behavior in Fullerene Hosting 69

5.3. SYMMETRIC MESO-TETRAARYLSUBSTITUTED PORPHYRINS BEARING PLANAR AND NON-PLANAR POLYAROMATIC LIGANDS 80

5.3.1. Article III: Porphyrin-based systems containing polyaromatic fragments: decoupling the synergistic effects in aromatic-porphyrin-fullerene systems 80

6. CONCLUSIONS 91

6.1. GENERAL CONCLUSIONS (Spanish) 93

6.2. SPECIFIC CONCLUSIONS (Spanish) 93

6.3. CONCLUSIONS (English) 95

6.3.1. GENERAL CONCLUSIONS (English) 95

6.3.2. SPECIFIC CONCLUSIONS (English) 95 
7.1. Article I: Dual-tweezer Behavior of an Octapodal Pyrene Porphyrin-Based System as a Host for Fullerenes 99

7.2. Article II: Octapodal Corannulene Porphyrin-Based Assemblies: Allosteric Behavior in Fullerene Hosting 117

7.3. Article III: Porphyrin-based systems containing polyaromatic fragments: decoupling the synergistic effects in aromatic-porphyrin-fullerene systems 138

8. BIBLIOGRAPHY AND NOTES 149 

1. RESUMEN GENERAL 


\section{RESUMEN GENERAL}

El presente trabajo es una recopilación de meso-porfirinas simétricas sustituidas con múltiples hidrocarburos policíclicos aromáticos planos y no planos con capacidad para formar complejos de inclusión con fullerenos. Es bien conocida la capacidad de las porfirinas para promover interacciones supramoleculares con fullerenos, sin embargo, dicha asociación es muy débil en disolución. La presencia de fragmentos aromáticos anclados al núcleo de porfirina con una geometría espacial adecuada puede permitir un efecto sinérgico o cooperativo entre ambas partes, de este modo, se puede incrementar o promover las interacciones supramoleculares resultantes.

La memoria ha sido desglosada en función del tipo de ligando aromático empleado, el número de unidades aromáticas presentes y de la orientación de estas con respecto al anillo de fenileno aromático. Los grupos arilo de las meso-porfirinas presentan sustituciones en disposiciones relativas para o en todas las posiciones meta, dando como resultado compuestos tetraarilsustituidos u octaarilsustituidos simétricos, respectivamente.

De este modo, en el Artículo I, se presentan porfirinas meso-octaarilsustituidas simétricas con sustituyentes poliaromáticos planos de tipo pireno. En este conjunto de compuestos la adecuada geometría de los ocho restos aromáticos permite la participación del núcleo de porfirina promoviendo un efecto sinérgico entre ambas partes. La simple introducción de un metal dentro del núcleo macrocíclico promueve un cambio en el comportamiento de la pinza molecular, modificando su actuación de pinza doble a sencilla frente a la interacción supramolecular con fullerenos. Además, se ha estudiado la utilización de las porfirinas preparadas para el enriquecimiento en mezclas de fullerenos.

En el Artículo II, se presentan porfirinas meso-octaarilsustituidas simétricas con ligandos poliaromáticos no planos de tipo coranuleno. Siguiendo un esquema similar al anterior trabajo, los ocho ligandos coranuleno están dispuestos de tal manera que permiten un gran efecto sinérgico con el núcleo de porfirina, dando como resultado asociaciones supramoleculares realmente excelentes. La presencia de dos centros de unión de fullerenos en la molécula permitió el estudio de posibles efectos alostéricos en estos sistemas.

Finalmente, en el Artículo III se describen porfirinas meso-tetraarilsustituidas simétricas con ligandos poliaromáticos planos (pireno) y no planos (coranuleno). En este caso, la familia de compuestos preparada muestra una disposición de los restos aromáticos en posición para con una orientación alejada del núcleo de porfirina, con el objetivo de eliminar o desacoplar los efectos sinérgicos entre ambas partes. El objetivo de este trabajo es estudiar la repercusión que conlleva la exclusión del núcleo de porfirina en el proceso de reconocimiento supramolecular con fullerenos. Una de las consecuencias observadas es que el sistema puede considerare como dos pinzas moleculares independientes. 


\subsection{GENERAL SUMMARY}

The present work involves a group of symmetric meso-porphyrins bearing planar and nonplanar polycyclic aromatic hydrocarbons with the capability to bind fullerenes. The ability of porphyrins to establish supramolecular interactions with fullerenes is well known; however, these associations are very weak in solution. The presence of aromatic moieties anchored to the porphyrin scaffold with a suitable spatial geometry can enable synergistic or cooperative effects between them; in this way, the resulting supramolecular interactions can be promoted or enhanced.

This thesis is organized according to the aromatic moiety employed, the number of aromatic units present and their relative orientations with respect to the aromatic phenylene ring. The aryl groups of the meso-porphyrins are substituted at the para position or at all of the meta positions, giving symmetric tetraaryl- and octaaryl-substituted systems, respectively.

Symmetric meso-octaaryl-substituted porphyrins containing planar pyrene-type polyaromatic substituents are described in Article I. In this set of compounds, the arrangement of the eight aromatic moieties in a suitable geometry allows the participation of the porphyrin core, promoting a great synergistic effect between both parts. The simple coordination of a metal inside the macrocyclic core promotes a switch from double- to single-tweezer fullerene hosting behavior. Additionally, the use of the prepared porphyrins for the enrichment of fullerene mixtures has been studied.

In Article II, symmetric meso-octaaryl-substituted porphyrins with non-planar corannulene-type polyaromatic ligands are reported. Following a similar scheme to that presented in the previous work, a great synergistic effect with the porphyrin core is achieved via the suitable arrangement of the eight aromatic ligands. As a result, high affinity constants are observed. The presence of two different fullerene binding sites in the molecule allowed the allosteric cooperativity effects of the systems to be assessed.

Finally, symmetric meso-tetraaryl-substituted porphyrins bearing planar pyrene-type and non-planar corannulene-type polyaromatic fragments are described in Article III. In this case, the location of aromatic moieties further from the porphyrin core at the para position avoids or decouples the participation of the porphyrin core among both parts. The main objective of this work is to study the way in which the porphyrin core affects the supramolecular fullerene recognition process. One of the observed consequences of the decoupling effect is that the system can be considered as two independent molecular tweezers. 
2. INTRODUCCIÓN 


\section{INTRODUCCIÓN}

\subsection{QUÍMICA SUPRAMOLECULAR}

La Química Supramolecular ha sido definida recientemente con términos tales como la "Química más allá de la molécula", "Química no molecular" o "Química de enlaces intermoleculares" para referirse a un nuevo tipo de disciplina Química en el que el control termodinámico es la pieza clave para diseñar y preparar nuevas entidades moleculares complejas, formadas a partir de sistemas más sencillos mediante interacciones no covalentes intermoleculares. ${ }^{1}$ Dicho término fue acuñado por Jean-Marie Lehn en $1978^{2}$ por sus estudios previos de compuestos de inclusión y criptandos, ${ }^{3}$ aunque el pionero en proponer las bases para nuevos mecanismos de interacciones especificas fue Emil Fischer en $1894^{4}$ por los sistemas enzima-sustrato. El objetivo principal bajo esta terminología era consolidar y generalizar las áreas de Química de éteres corona, Química anfitrión-huésped (Host-Guest) y la Química de reconocimiento molecular empleadas en la década de los años 60 y $70 .^{5}$

En analogía con las moléculas convencionales, que están constituidas por conexiones entre átomos con enlaces covalentes, las entidades supramoleculares están construidas por unión entre moléculas con interacciones intermoleculares del tipo electrostática, ion- $\pi$, enlace de hidrógeno, apilamiento $\pi$, hidrofóbicas o van der Waals. ${ }^{6}$ Pese a que el intervalo energético implicado en tal proceso puede variar desde cientos a unos valores sumamente pequeños de $\mathrm{kJ} \mathrm{mol}^{-1}(1-200 \mathrm{~kJ}$ $\left.\mathrm{mol}^{-1}\right)$, comparando con las interacciones covalentes de mayor carácter energético $(200-400 \mathrm{~kJ}$ $\mathrm{mol}^{-1}$ ), la estabilidad estructural total resultante es la fuerza impulsora para generar dichas nuevas entidades supramoleculares. Otro factor importante para tener en cuenta es la complementariedad de forma entre las unidades participantes en los eventos de reconocimiento molecular y anfitriónhuésped; siendo de tal relevancia hasta el punto de que facilitaría, o al menos permitiría, la aproximación de los diferentes sistemas para que el evento supramolecular pueda llevarse a cabo.

En la naturaleza, este tipo de interacciones no covalentes juega un papel especialmente relevante, ${ }^{7}$ por ejemplo, en la estructura de doble hélice del $\mathrm{ADN},{ }^{8}$ en el transporte de aniones en

\footnotetext{
${ }^{1}$ (a) J. M. Lehn, Supramolecular Chemistry: Concepts and Perspectives, VCH-Wiley, Weinheim, 1995, (b) G. R. Desiraju, Nature, 2001, 412, 397-400, (c) J. W. Steed, J. L. Atwood, Supramolecular Chemistry, 2nd Edition, John Wiley \& Sons, New York, 2009, (d) R. M. Izatt, J. S. Bradshaw, S. R. Izatt, R. G. Harrison, Macrocyclic and Supramolecular Chemistry: How Izatt-Christensen Award Winners Shaped the Field, Wiley, Oxford, UK, 2016.

2 J. M. Lehn, Pure Appl. Chem., 1978, 50, 871-892.

3 (a) B. Dietrich, J. M. Lehn, J. P. Sauvage, Tetrahedron Lett., 1969, 10, 2885-2888, (b) B. Dietrich, J. M. Lehn, J. P. Sauvage, Tetrahedron Lett., 1969, 10, 2889-2892.

${ }^{4}$ E. Fischer, Ber. Dt. Chem. Ges., 1894, 27, 2985-2993.

${ }^{5}$ (a) C. J. Pedersen, J. Am. Chem. Soc., 1967, 89, 2495-2496, (b) C. J. Pedersen, J. Am. Chem. Soc., 1967, 89, 7017-7036, (c) J. M. Lehn, in Alkali Metal Complexes with Organic Ligands, Springer, Berlin, Heidelberg, 1973, pp. 1-69, (d) D. J. Cram, J. M. Cram, Science, 1974, 183, 803.

${ }^{6}$ H.-J. Schneider, Angew. Chem. Int. Ed., 2009, 48, 3924-3977.

${ }^{7}$ D. Philp, J. F. Stoddart, Angew. Chem. Int. Ed. Engl., 1996, 35, 1154-1196.

${ }^{8}$ (a) J. D. Watson, F. H. C. Crick, Nature, 1953, 171, 737-738, (b) M. H. F. Wilkins, A. R. Stokes, H. R. Wilson, Nature, 1953, 171, 738-740, (c) R. E. Franklin, R. G. Gosling, Nature, 1953, 171, 740-741, (d) C. K. McLaughlin, G. D. Hamblin, H. F. Sleiman, Chem. Soc. Rev., 2011, 40, 5647-5656.
} 
capas lipídicas y membranas celulares ${ }^{9}$ o en el ensamblaje de biomacromoléculas complejas, ${ }^{10}$ entre otros.

En ocasiones, debido al diseño de la molécula anfitriona existe la posibilidad de múltiples centros de unión supramolecular conectados a través de espaciadores, generando el concepto de multivalencia. La presencia de diversos centros receptores puede beneficiarse de efectos cooperativos, ${ }^{11}$ modificando la afinidad receptora de los diferentes centros de interacción. Así, cuando el espaciador físico entre los sitios de unión juega un papel importante en el evento supramolecular, hablamos de alosterismo. Dicho efecto alostérico puede ser positivo, cuando la ocupación del primer centro de unión incrementa la afinidad por el segundo en la molécula anfitriona; o negativo, produciendo efectos completamente contrarios. Este efecto de alosterismo es crítico en organizaciones bioquímicas. Quizás el ejemplo más representativo es el cambio conformacional inducido en la estructura terciaria que sufre el grupo hemo tras la unión de la primera molécula de oxígeno en el sistema hemoglobina, ${ }^{12}$ favoreciendo la unión posterior de otra molécula de oxígeno.

La Química Supramolecular ha proporcionado un total de seis premios Nobel de Química a lo largo de su historia, galardonando en 1987 a Charles Pederson, Donald Cram y Jean-Marie Lehn por el desarrollo y uso de moléculas con interacciones específicas de alta selectividad, ${ }^{13}$ y recientemente en 2016, a Jean-Pierre Sauvage, J. Fraser Stoddart y Bernard L. Feringa por el diseño y construcción de máquinas moleculares. ${ }^{14}$

\subsection{NANOMATERIALES DE CARBONO}

De entre todos los elementos conocidos en la tabla periódica, el carbono quizás es el más versátil de la naturaleza. Es uno de los elementos básicos en los que se sustentan todas las biomoléculas orgánicas para generar la vida en la Tierra. Presenta una diversidad estructural excepcional, reflejada en los diferentes grados de hibridación que puede adoptar ( $\mathrm{sp}, \mathrm{sp}^{2} \mathrm{y} \mathrm{sp}^{3}$ ), dando lugar a diferentes alótropos. Además de los más conocidos por el público en general, diamante y grafito, existen otra variedad que en las últimas tres décadas ha revolucionado la

\footnotetext{
${ }^{9}$ (a) N. H. Evans, P. D. Beer, Angew. Chem. Int. Ed., 2014, 53, 11716-11754, (b) P. A. Gale, J. T. Davis, R. Quesada, Chem. Soc. Rev., 2017, 46, 2497-2519.

10 (a) K. A. Dill, Biochemistry, 1990, 29, 7133-7155, (b) A. C. Steven, W. Baumeister, L. N. Johnson, R. N. Perham, Molecular Biology of Assemblies and Machines, Garland Science, New York, 2016.

${ }^{11}$ (a) J. D. Badjić, A. Nelson, S. J. Cantrill, W. B. Turnbull, J. F. Stoddart, Acc. Chem. Res., 2005, 38, 723-732, (b) C. A. Hunter, H. L. Anderson, Angew. Chem. Int. Ed., 2009, 48, 7488-7499, (c) L. K. S. von Krbek, C. A. Schalley, P. Thordarson, Chem. Soc. Rev., 2017, 46, 2622-2637.

12 (a) G. K. Ackers, M. L. Doyle, D. Myers, M. A. Daugherty, Science, 1992, 255, 54, (b) W. A. Eaton, E. R. Henry, J. Hofrichter, A. Mozzarelli, Nat. Struct. Biol., 1999, 6, 351-358, (c) J. A. Lukin, C. Ho, Chem. Rev., 2004, 104, 1219-1230, (d) S. Nagatomo, M. Nagai, T. Kitagawa, J. Am. Chem. Soc., 2011, 133, 10101-10110. ${ }^{13}$ (a) C. J. Pedersen, Angew. Chem. Int. Ed. Engl., 1988, 27, 1021-1027, (b) D. J. Cram, Angew. Chem. Int. Ed. Engl., 1988, 27, 1009-1020, (c) J.-M. Lehn, Angew. Chem. Int. Ed., 1988, 27, 89-112.

14 (a) J.-P. Sauvage, Angew. Chem. Int. Ed., 2017, 56, 11080-11093, (b) J. F. Stoddart, Angew. Chem. Int. Ed., 2017, 56, 11094-11125, (c) B. L. Feringa, Angew. Chem. Int. Ed., 2017, 56, 11060-11078.
} 
ciencia a nivel nanométrico por sus excelentes propiedades fotovoltaicas, mecánicas, ópticas y detectoras, ${ }^{15}$ son los conocidos como nanoalótropos de carbono. ${ }^{16}$

Estos nanomateriales de carbono pueden clasificarse en función del número de dimensiones que presentan, siendo cero dimensionales (0D) los fullerenos, ${ }^{17}$ en donde las tres dimensiones se encuentran a escala nanométrica, monodimensionales (1D) los nanotubos de carbono $(\mathrm{CNT})^{18}$ y bidimensionales (2D) el grafeno, ${ }^{19}$ donde una y dos dimensión se ubican a escala nanométrica, respectivamente (Figura 1). Todos ellos comparten una hibridación $\mathrm{sp}^{2}$ en el átomo de carbono, pero la estructura final es muy diferente en función de cómo están organizados a nivel atómico, como puede observarse en la Figura 1.

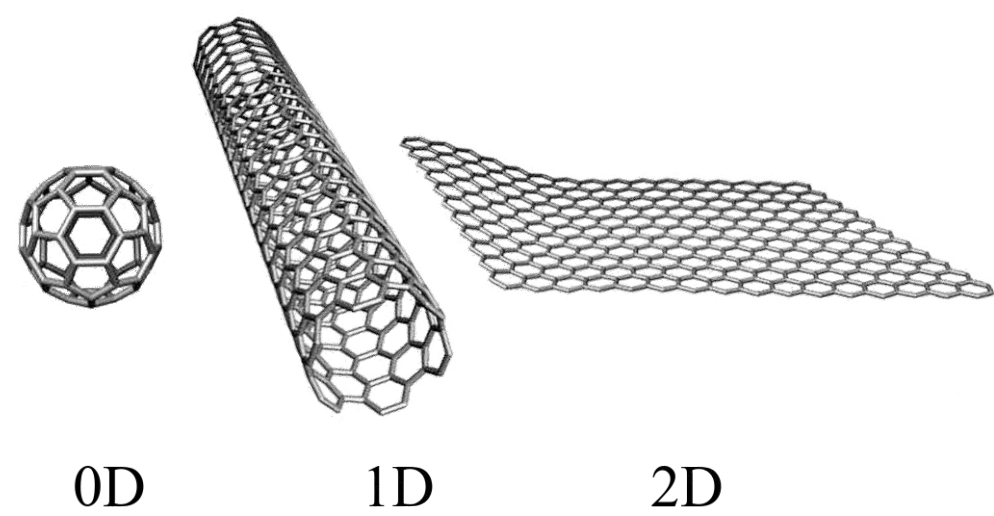

Figura 1. Clasificación de nanoalótropos de carbono basada en su dimensionalidad estructural. De izquierda a derecha: fullereno, nanotubos de carbono y grafeno.

Cuando la estructura muestra exclusivamente una red de monocapas de átomos de carbonos hexagonales en forma de láminas, obtenemos el grafeno. Por otro lado, cuando las hojas de grafeno se enrollan a lo largo de un eje se obtienen nanocilindros, generado los nanotubos de carbono. Sin embargo, la presencia de anillos de otros tamaños, como por ejemplo pentagonales, inducen imperfecciones en el sistema ${ }^{20}$ introduciendo efectos de curvatura. Si la combinación entre hexágonos y pentágonos fuera la adecuada podría adoptarse una disposición esférica como

${ }^{15}$ (a) M. M. J. Treacy, T. W. Ebbesen, J. M. Gibson, Nature, 1996, 381, 678-680, (b) C. Lee, X. Wei, J. W. Kysar, J. Hone, Science, 2008, 321, 385-388, (c) D. M. Guldi, V. Sgobba, Chem. Commun., 2011, 47, 606610, (d) D. Jariwala, V. K. Sangwan, L. J. Lauhon, T. J. Marks, M. C. Hersam, Chem. Soc. Rev., 2013, 42, 2824-2860, (e) F. R. Baptista, S. A. Belhout, S. Giordani, S. J. Quinn, Chem. Soc. Rev., 2015, 44, 4433-4453, (f) A. J. Clancy, M. K. Bayazit, S. A. Hodge, N. T. Skipper, C. A. Howard, M. S. P. Shaffer, Chem. Rev., 2018, 118, 7363-7408.

${ }^{16}$ (a) V. Georgakilas, J. A. Perman, J. Tucek, R. Zboril, Chem. Rev., 2015, 115, 4744-4822, (b) Z. Li, Z. Liu, H. Sun, C. Gao, Chem. Rev., 2015, 115, 7046-7117, (c) Y. Segawa, H. Ito, K. Itami, Nat. Rev. Mater., 2016, 1, 15002.

17 (a) H. W. Kroto, J. R. Heath, S. C. O'Brien, R. F. Curl, R. E. Smalley, Nature, 1985, 318, 162-163, (b) A. Hirsch, M. Brettreich, Fullerenes: Chemistry and Reactions, Wiley-VCH, Weinheim, 2004, (c) N. Martín, Chem. Commun., 2006, 2093-2104.

18 (a) S. lijima, Nature, 1991, 354, 56-58, (b) S. Niyogi, M. A. Hamon, H. Hu, B. Zhao, P. Bhowmik, R. Sen, M. E. Itkis, R. C. Haddon, Acc. Chem. Res., 2002, 35, 1105-1113, (c) S. Reich, C. Thomsen, J. Maultzsch, Carbon Nanotubes-Basic Concepts and Physical Properties, Wiley-VCH, Weinheim, 2004.

${ }^{19}$ (a) K. S. Novoselov, A. K. Geim, S. V. Morozov, D. Jiang, Y. Zhang, S. V. Dubonos, I. V. Grigorieva, A. A. Firsov, Science, 2004, 306, 666-669, (b) M. J. Allen, V. C. Tung, R. B. Kaner, Chem. Rev., 2010, 110, 132145, (c) W. Choi, L. Jo-won, Graphene: synthesis and applications, CRC Press, 2011.

${ }^{20}$ (a) F. Banhart, J. Kotakoski, A. V. Krasheninnikov, ACS Nano, 2011, 5, 26-41, (b) Y. Wei, J. Wu, H. Yin, X. Shi, R. Yang, M. Dresselhaus, Nat. Mater., 2012, 11, 759-763. 
sucede en el caso de los fullerenos. Así, por ejemplo, la presencia de 12 pentágonos y 20 hexágonos dan lugar a la formación del $\mathrm{C}_{60}$.

Los fullerenos son el nanomaterial empleado en esta tesis doctoral con el objetivo de formar interacciones supramoleculares con tales entidades, con lo que serán comentados en detalle en el siguiente Apartado 2.2.1.

\subsubsection{Fullerenos}

En 1985 Kroto et al. ${ }^{17 a}$ descubrieron durante los experimentos de vaporización de grafito por irradiación láser, un sistema estable formado por un grupo de 60 átomos de carbono $\left(\mathrm{C}_{60}\right)$ como componente principal. A su vez, también se detectaron otras unidades de átomos de carbono tanto superiores, tales como las pertenecientes a 70 átomos de carbono $\left(\mathrm{C}_{70}\right)$, como inferiores, correspondientes a la presencia de 20 átomos de carbono $\left(\mathrm{C}_{20}\right)$, pero a un nivel porcentual muy inferior. Para explicar la estabilidad de esta nueva entidad $\left(\mathrm{C}_{60}\right)$, el modelo original propuesto fue un icosaedro truncado, formando un polígono con 60 vértices y 32 caras, de los cuales 12 son pentagonales y 20 hexagonales. Como resultado, la única disposición plausible que pudiera satisfacer el carácter aromático tipo $\mathrm{sp}^{2}$ de la molécula era la de una esfera hueca. Esta curiosa disposición espacial fue acogida con un cierto grado de escepticismo inicial por la comunidad científica de la época, hasta que dicha estructura se confirmó finalmente 5 años más tarde por estudios de espectroscopía de IR, RMN y difracción de rayos $X^{21}$ (Figura 2a).

Además del ya mencionado $\mathrm{C}_{60}$, en esta época primigenia para la nanociencia, Taylor $e t$ $a l .{ }^{21 b}$ fue capaz de confirmar en 1990 mediante experimentos de RMN de ${ }^{13} \mathrm{C}$ la forma elipsoidal del $\mathrm{C}_{70}$ (Figura $2 \mathrm{~b}$ ) propuesta inicialmente por Smalley y colaboradores. ${ }^{22}$

a)

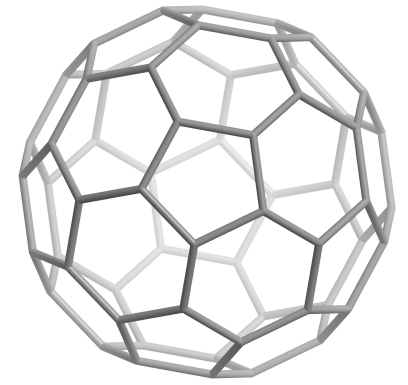

$\mathrm{C}_{60}$ b)

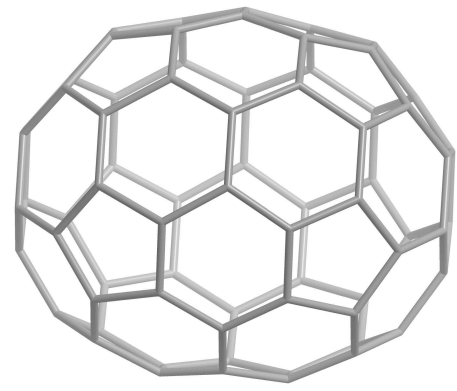

$\mathrm{C}_{70}$

Figura 2. Estructura del $\mathrm{C}_{60}$ y $\mathrm{C}_{70}$ donde puede apreciarse su geometría tridimensional.

Debido a la naturaleza geodésica del $\mathrm{C}_{60}$, los autores decidieron nombrarle Buckminsterfullereno en honor al arquitecto Americano R. Buckminster Fuller, inventor de las cúpulas geodésicas, cuyo edificio más representativo de su obra fue la Biosfera de Montreal. Para facilitar la posterior denominación de estos compuestos, el nombre fullereno $\left(\mathrm{C}_{n}\right)^{23}$ se escogió para toda la familia de jaulas de carbono cerradas que poseen 12 pentágonos y un número $m$ de hexágonos que están regidos por el teorema de poliedros de Euler, ${ }^{24}$ tal que $m=\left(C_{n}-20\right) / 2$, y además, todos los vértices están compartidos por polígonos vecinos. Con el fin de llevar a cabo

\footnotetext{
${ }^{21}$ (a) W. Krätschmer, L. D. Lamb, K. Fostiropoulos, D. R. Huffman, Nature, 1990, 347, 354-358, (b) R. Taylor, J. P. Hare, A. a. K. Abdul-Sada, H. W. Kroto, J. Chem. Soc., Chem. Commun., 1990, 1423-1425.

22 J. R. Heath, S. C. O'Brien, Q. Zhang, Y. Liu, R. F. Curl, F. K. Tittel, R. E. Smalley, J. Am. Chem. Soc., 1985, 107, 7779-7780.

${ }^{23}$ H. W. Kroto, Nature, 1987, 329, 529-531.

${ }^{24}$ L. Euler, Novi Commentarii academiae scientiarum Petropolitanae, 1758, 4, 109-140.
} 
una adecuada identificación, la IUPAC en 2005 publicó una serie de recomendaciones para la numeración de fullerenos de distintos tamaños. ${ }^{25}$ De esta manera, por ejemplo, el $\mathrm{C}_{70}$ se denomina $\left(\mathrm{C}_{70}-\mathrm{D}_{5 \mathrm{~h}(6)}\right)[5,6]$ fullereno, donde el paréntesis indica el contenido de átomos de carbono y el grupo puntual de simetría. El subíndice entre paréntesis (6) seguido del grupo puntal de simetría $\mathrm{D}_{5 \mathrm{~h}}$ indica que el anillo de cinco miembros en el eje de simetría quíntuple está rodeado por anillos de seis miembros. Por último, los números entre corchetes indican los tamaños de anillo del propio fullereno.

Los fullerenos son considerados las nanoestructuras de carbono estables más pequeñas conocidas y yacen en el límite entre moléculas $(1-10 \mathrm{~nm})$ y nanomateriales $(10-100 \mathrm{~nm})$, por todo ello, sus descubridores fueron galardonados con el premio Nobel de Química en 1996. ${ }^{26}$

Aunque inicialmente se pudieron evaluar ciertas propiedades de estos nuevos materiales, su uso en investigación no comenzó hasta la década de los 90 cuando por primera vez se obtuvieron en cantidades macroscópicas. ${ }^{21 a}$ Este tipo de estructuras nanométricas presentan un especial interés en ciencia de materiales, por sus numerosas y singulares propiedades fotovoltaicas, electroquímicas, fotofísicas y de óptica no lineal. ${ }^{27}$ Cabe resaltar, que los fullerenos exhiben una capacidad aceptora de electrones excepcional, ${ }^{28}$ por lo que son usados en conversores de energía solar. ${ }^{29}$ Por ser una esfera hueca, es capaz de encapsular metales en su interior, creando materiales aceptores con valores energéticos de LUMO cercanos al donador. Este es el caso de los conocidos como fullerenos endoédricos. ${ }^{30}$ Por otro lado, el dopado de fullerenos con metales alcalinos, proporciona materiales superconductores. ${ }^{31}$

Sin embargo, uno de los mayores problemas que presentan estos materiales, es su baja solubilidad en la mayoría de los disolventes orgánicos convencionales, ${ }^{32}$ limitando su uso en aplicaciones prácticas. Pese a ello, este obstáculo puede superarse mediante funcionalización química o estableciendo interacciones no covalentes de tipo supramolecular. En cualquiera de los casos, la mayoría de las propiedades originales de los fullerenos previamente mencionadas se retienen.

Uno de los mayores retos actuales es el desarrollo y exploración de nuevas metodologías que posibiliten controlar las fuerzas supramoleculares que permitan mejoras en la formación de

${ }^{25}$ F. Cozzi, W. H. Powell, C. Thilgen, Pure Appl. Chem., 2005, 77, 843-923.

${ }^{26}$ (a) R. F. Curl, Angew. Chem. Int. Ed. Engl., 1997, 36, 1566-1576, (b) H. W. Kroto, Angew. Chem. Int. Ed. Engl., 1997, 36, 1578-1593, (c) R. E. Smalley, Angew. Chem. Int. Ed. Engl., 1997, 36, 1594-1601.

27 (a) N. S. Sariciftci, L. Smilowitz, A. J. Heeger, F. Wudl, Science, 1992, 258, 1474-1476, (b) L. W. Tutt, A. Kost, Nature, 1992, 356, 225-226, (c) L. Echegoyen, L. E. Echegoyen, Acc. Chem. Res., 1998, 31, 593-601, (d) D. M. Guldi, M. Prato, Acc. Chem. Res., 2000, 33, 695-703, (e) S. Collavini, J. L. Delgado, Sustainable Energy Fuels, 2018, 2, 2480-2493.

28 (a) D. M. Guldi, Chem. Commun., 2000, 321-327, (b) S. Kirner, M. Sekita, D. M. Guldi, Adv. Mater., 2014, 26, 1482-1493, (c) A. Zieleniewska, F. Lodermeyer, A. Roth, D. M. Guldi, Chem. Soc. Rev., 2018, 47, 702714.

${ }^{29}$ (a) J. L. Segura, N. Martín, D. M. Guldi, Chem. Soc. Rev., 2005, 34, 31-47, (b) S. Günes, H. Neugebauer, N. S. Sariciftci, Chem. Rev., 2007, 107, 1324-1338, (c) Y. Shen, T. Nakanishi, Phys. Chem. Chem. Phys., 2014, 16, 7199-7204, (d) M. Rudolf, S. V. Kirner, D. M. Guldi, Chem. Soc. Rev., 2016, 45, 612-630.

${ }^{30}$ (a) S. Stevenson, G. Rice, T. Glass, K. Harich, F. Cromer, M. R. Jordan, J. Craft, E. Hadju, R. Bible, M. M. Olmstead, K. Maitra, A. J. Fisher, A. L. Balch, H. C. Dorn, Nature, 1999, 401, 55-57, (b) A. A. Popov, S. Yang, L. Dunsch, Chem. Rev., 2013, 113, 5989-6113, (c) S. Yang, T. Wei, F. Jin, Chem. Soc. Rev., 2017, 46, 50055058, (d) T. Wang, C. Wang, Small, 2019, 15, 1901522.

${ }^{31}$ (a) R. C. Haddon, Acc. Chem. Res., 1992, 25, 127-133, (b) M. Capone, M. Fabrizio, C. Castellani, E. Tosatti, Science, 2002, 296, 2364-2366.

32 (a) R. S. Ruoff, D. S. Tse, R. Malhotra, D. C. Lorents, J. Phys. Chem., 1993, 97, 3379-3383, (b) K. N. Semenov, N. A. Charykov, V. A. Keskinov, A. K. Piartman, A. A. Blokhin, A. A. Kopyrin, J. Chem. Eng. Data, 2010, 55, 13-36. 
aductos de inclusión con fullerenos. En los últimos años, se han hecho enormes avances en este campo como se refleja por la gran cantidad de revisiones bibliografías que existen al respecto. ${ }^{33}$

Esta tesis doctoral está centrada en la formación de aductos supramoleculares con fullerenos, aprovechando para ello, las interacciones de apilamiento $\pi$ no covalentes que surgen entre los fullerenos y los fragmentos de tipo poliaromáticos planos y no planos. Estos compuestos poliaromáticos se describen en los Apartados 2.3 y 2.4 .

\subsection{HIDROCARBUROS POLICÍCICLOS AROMÁTICOS PLANOS}

Los hidrocarburos policíclicos aromáticos (PAH) planos son una clase de derivados orgánicos que están formados exclusivamente por átomos de carbono e hidrógeno. Están caracterizados por la fusión de dos o más anillos bencénicos unidos de forma lineal, grupal o angular, pero siempre de tal manera que puedan permitir mantener la planaridad en toda la entidad molecular. De entre los ejemplos más simples se encuentran aquellos formados por la unión de dos unidades aromáticas (naftaleno, Figura 3b) o de tres unidades, conocidos como antraceno y fenantreno (Figura $3 \mathrm{a} \mathrm{y} \mathrm{g,} \mathrm{respectivamente).} \mathrm{Cuando} \mathrm{seis} \mathrm{unidades} \mathrm{bencénicas} \mathrm{están} \mathrm{fusionadas}$ entorno a un anillo hexagonal central, dan lugar al coroneno o [6]circuleno (Figura 3e).<smiles>c1ccc2cc3ccccc3cc2c1</smiles>

a<smiles>c1ccc2ccccc2c1</smiles>

b

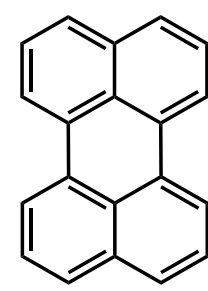

C<smiles>c1ccc2c(c1)c1ccccc1c1ccccc21</smiles>

d<smiles>c1cc2ccc3ccc4ccc5ccc6ccc1c1c2c3c4c5c61</smiles>

e<smiles>Fc1cc2ccc3cccc4ccc(c1)c2c34</smiles><smiles>c1ccc2c(c1)ccc1ccccc12</smiles>

g

Figura 3. Algunos ejemplos representativos de PAH planos: (a) Antraceno, (b) Naftaleno, (c) Perileno, (d) Trifenileno, (e) Coroneno o [6]circuleno, (f) Pireno y (g) Fenantreno.

Cabe resaltar, el interés reciente por la síntesis de compuestos que presentan un número elevado de anillos fusionados, ya que éstos pueden considerarse derivados de nanografeno. ${ }^{34}$

\footnotetext{
${ }_{33}$ (a) F. Diederich, M. Gómez-López, Chem. Soc. Rev., 1999, 28, 263-277, (b) E. M. Pérez, N. Martín, Chem. Soc. Rev., 2008, 37, 1512-1519, (c) S. S. Babu, H. Mohwald, T. Nakanishi, Chem. Soc. Rev., 2010, 39, 40214035, (d) N. Martín, E. M. Pérez, Pure Appl. Chem., 2010, 82, 523-533, (e) D. Canevet, E. M. Pérez, N. Martín, Angew. Chem. Int. Ed., 2011, 50, 9248-9259, (f) S. Selmani, D. J. Schipper, Chem. Eur. J., 2019, 25, 6673-6692, (g) S. Toyota, E. Tsurumaki, Chem. Eur. J., 2019, 25, 6878-6890.

${ }^{34}$ (a) Y. Chen, T. Marszalek, T. Fritz, M. Baumgarten, M. Wagner, W. Pisula, L. Chen, K. Müllen, Chem. Commun., 2017, 53, 8474-8477, (b) S. Grätz, D. Beyer, V. Tkachova, S. Hellmann, R. Berger, X. Feng, L. Borchardt, Chem. Commun., 2018, 54, 5307-5310, (c) K. Xu, J. I. Urgel, K. Eimre, M. Di Giovannantonio, A. Keerthi, H. Komber, S. Wang, A. Narita, R. Berger, P. Ruffieux, C. A. Pignedoli, J. Liu, K. Müllen, R. Fasel, X. Feng, J. Am. Chem. Soc., 2019, 141, 7726-7730.
} 
Una propiedad intrínseca de estos compuestos es su aromaticidad, y por ello tienen una gran tendencia a establecer interacciones supramoleculares de apilamiento $\pi$ ( $\pi$ stacking). Este tipo de interacciones se ha utilizado en muy diversas aplicaciones, ${ }^{35}$ como por ejemplo en la formación de cristales líquidos, entre otras. Por otro lado, los PAH planos han sido enormemente estudiados por los problemas vinculados a la salud. ${ }^{36}$ Existen numerosos estudios relacionados con la capacidad de estos compuestos de inducir mutaciones oncogénicas.

En la presente tesis doctoral se estudian compuestos derivados del hidrocarburo policíclico aromático plano de tipo pireno y por ello se comenta con más detalle en el siguiente Apartado 2.3.1.

\subsubsection{Pireno}

El nombre "pireno" procede del griego $\pi v \rho$ (pir), cuyo significado es fuego en castellano, debido a que podía obtenerse a través de reacciones de sustancias orgánicas con fuego. Es el perifusionado PAH plano más pequeño existente y se obtiene principalmente por combustión incompleta de materiales orgánicos (carbón, petróleo, aceite y madera). Fue descubierto por Laurent en el residuo obtenido durante la destilación del alquitrán de hulla en $1837 .{ }^{37}$

El pireno es susceptible de sufrir sustituciones electrofílicas aromáticas $\left(\mathrm{S}_{\mathrm{E}} \mathrm{Ar}\right)$ preferentemente en las posiciones 1-, 3-, 6- y 8- (mostradas en rojo en la Figura 4). Controlando las condiciones de reacción pueden obtenerse desde derivados mono hasta tetrasustituidos en las posiciones previamente indicadas, como sucede en la introducción de restos bromados. ${ }^{38}$ Estas especies sustituidas de pireno constituyen los precursores más utilizados para la introducción de restos pireno en diversas arquitecturas moleculares debido a que el átomo de bromo en el enlace $\mathrm{C}-\mathrm{Br}$ puede convertirse fácilmente en un enlace $\mathrm{C}-\mathrm{C}, \mathrm{C}-\mathrm{N}$ u otro grupo.

El pireno y sus derivados presentan unas propiedades fotoquímicas relevantes, por esa razón ha sido ampliamente usado como cromóforo y semiconductor en ciencia de materiales, siendo utilizado para la obtención de sensores, geles luminiscentes y dispositivos optoelectrónicos orgánicos, ${ }^{35 b, 39}$ así como, marcador en ácidos nucleicos. ${ }^{40}$

\footnotetext{
35 (a) K. Suzuki, K. Takao, S. Sato, M. Fujita, J. Am. Chem. Soc., 2010, 132, 2544-2545, (b) T. M. FigueiraDuarte, K. Müllen, Chem. Rev., 2011, 111, 7260-7314, (c) T. Wöhrle, I. Wurzbach, J. Kirres, A. Kostidou, N. Kapernaum, J. Litterscheidt, J. C. Haenle, P. Staffeld, A. Baro, F. Giesselmann, S. Laschat, Chem. Rev., 2016, 116, 1139-1241, (d) F. Würthner, C. R. Saha-Möller, B. Fimmel, S. Ogi, P. Leowanawat, D. Schmidt, Chem. Rev., 2016, 116, 962-1052.

${ }^{36}$ (a) W. P. Ronald, J. Toxicol. Cut. \& Ocular Toxicol., 2000, 19, 55-67, (b) W. M. Baird, L. A. Hooven, B. Mahadevan, Environ.Mol.Mutagen., 2005, 45, 106-114.

${ }^{37}$ A. Laurent, Ann. Chim. Phys., 1837, 66, 136.

${ }^{38}$ X. Feng, J.-Y. Hu, C. Redshaw, T. Yamato, Chem. Eur. J., 2016, 22, 11898-11916.

${ }^{39}$ (a) J. R. Moffat, D. K. Smith, Chem. Commun., 2011, 47, 11864-11866, (b) D. Mandal, T. Kar, P. K. Das, Chem. Eur. J., 2014, 20, 1349-1358, (c) O. Karagollu, M. Gorur, F. Gode, B. Sennik, F. Yilmaz, Macromol. Chem. Phys., 2015, 216, 939-949, (d) Y. Sun, Y. Wu, C. Yu, L. Zhang, G. Song, Z. Yao, ACS Appl. Nano Mater., 2019, 2, 3453-3458.

${ }^{40}$ (a) V. L. Malinovskii, D. Wenger, R. Häner, Chem. Soc. Rev., 2010, 39, 410-422, (b) A. O. Krasheninina, S. D. Novopashina, K. E. Apartsin, G. A. Venyaminova, Molecules, 2017, 22, 2108.
} 


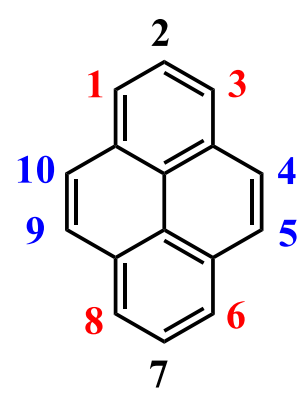

Figura 4. Estructura y numeración del pireno. Las posiciones 4-, 5-, 9- y 10- , mostradas en azul, son conocidas como la región K. Las posiciones 1-, 3-, 6- y 8- , indicadas en rojo, son las regiones propensas a sustituciones electrofílicas aromáticas.

Por su naturaleza aromática plana, diversos compuestos que contienen pireno se han usado para producir interacciones supramoleculares con nanoalótropos de carbono, en particular con fullerenos, tal y como se detalla en el Apartado 2.3.1.1.

\subsubsection{Interacciones supramoleculares entre fullerenos y pireno}

Debido a la presencia de una gran superficie aromática plana, el pireno es capaz de interaccionar mediante apilamiento $\pi$ con nanomateriales de carbono que muestran cierta similitud estructural con él, es decir, con unidades que posean una red aromática plana o pseudoplana, tales como grafeno y nanotubos de carbono de gran diámetro. Por esta razón, las estructuras con motivos de pireno han sido muy explotadas con esos fines, existiendo numerosos ejemplos en la bibliografía. ${ }^{41}$

Por otra parte, para facilitar la formación de aductos supramoleculares de inclusión con fullerenos, es recomendable una adecuación geométrica entre los sistemas anfitrión-huésped (Host-Guest) concurrentes. En este aspecto, la extensión aromática plana del pireno no es capaz de complementar la superficie esférica perteneciente al Buckminsterfullereno, en consecuencia, el evento supramolecular no estará favorecido. Por ese motivo, el trabajo existente al respecto no es muy extenso, de hecho, sólo pueden encontrarse un par de ejemplos en la bibliografía basados en pinzas moleculares ${ }^{42}$ y en complejas cajas o jaulas, ${ }^{43}$ algunas de ellas utilizando la propiedad de autoensamblaje que presentan ciertos compuestos organometálicos.

\footnotetext{
${ }^{41}$ Algunos ejemplos seleccionados: (a) Y.-L. Zhao, J. F. Stoddart, Acc. Chem. Res., 2009, 42, 1161-1171, (b) J. A. Mann, J. Rodríguez-López, H. D. Abruña, W. R. Dichtel, J. Am. Chem. Soc., 2011, 133, 17614-17617, (c) D. Parviz, S. Das, H. S. T. Ahmed, F. Irin, S. Bhattacharia, M. J. Green, ACS Nano, 2012, 6, 8857-8867, (d) C. B. KC, G. N. Lim, F. D'Souza, Angew. Chem. Int. Ed., 2015, 54, 5088-5092, (e) A. López-Moreno, E. M. Pérez, Chem. Commun., 2015, 51, 5421-5424, (f) A. de Juan, A. López-Moreno, J. Calbo, E. Ortí, E. M. Pérez, Chem. Sci., 2015, 6, 7008-7014, (g) M. Garrido, J. Calbo, L. Rodríguez-Pérez, J. Aragó, E. Ortí, M. A. Herranz, N. Martín, Chem. Commun., 2017, 53, 12402-12405, (h) B. K. Billing, Mayank, P. K. Agnihotri, N. Singh, Analyst, 2018, 143, 3343-3352, (i) M. Garrido, M. K. Volland, P. W. Münich, L. Rodríguez-Pérez, J. Calbo, E. Ortí, M. Á. Herranz, N. Martín, D. M. Guldi, J. Am. Chem. Soc., 2020, 142, 1895-1903.

42 (a) K. Mulla, H. Shaik, D. W. Thompson, Y. Zhao, Org. Lett., 2013, 15, 4532-4535, (b) M. Park, K.-I. Hong, M. Kang, T.-W. Kim, H. Lee, W.-D. Jang, K.-U. Jeong, ACS Nano, 2019, 13, 6101-6112.

43 (a) T. K. Ronson, A. B. League, L. Gagliardi, C. J. Cramer, J. R. Nitschke, J. Am. Chem. Soc., 2014, 136, 15615-15624, (b) T. K. Ronson, W. Meng, J. R. Nitschke, J. Am. Chem. Soc., 2017, 139, 9698-9707, (c) V. Martínez-Agramunt, D. G. Gusev, E. Peris, Chem. Eur. J., 2018, 24, 14802-14807, (d) V. Martínez-Agramunt, T. Eder, H. Darmandeh, G. Guisado-Barrios, E. Peris, Angew. Chem. Int. Ed., 2019, 58, 5682-5686, (e) V. Martínez-Agramunt, E. Peris, Inorg. Chem., 2019, 58, 11836-11842.
} 
En esta memoria en los Artículos I y III se han desarrollado arquitecturas moleculares que contienen pireno como restos PAH plano en distintas orientaciones espaciales y se ha estudiado su interacción con fullerenos.

\subsection{HIDROCARBUROS POLICÍCICLOS AROMÁTICOS NO PLANOS}

Una clase especial de PAH son aquellos que divergen de la estructura común plana previamente comentada y son aquellos que presentan anillos aromáticos en disposiciones espaciales retorcidas o torsionadas. ${ }^{44}$ Esto proporciona moléculas aromáticas $\pi$-conjugadas con geometrías no planas o curvadas. Una manera de liberar la tensión interna generada es mediante la deformación de enlaces y ángulos, dando como resultado un alejamiento de la planaridad de los sistemas bencénicos. La magnitud de la curvatura en estas moléculas puede evaluarse a partir de medidas geométricas locales, tales como, torsión de enlace, ángulos de piramidalización, coordenadas de anillo plegado o profundidad del sistema. Además, la curvatura es la responsable de las propiedades ópticas, electrónicas, magnéticas y quirales de estos compuestos, ${ }^{45}$ como por ejemplo la presencia de quiralidad axial en el caso de los helicenos (Figura 5b).

La formación de PAH no planos puede producirse debido a la presencia de anillos fusionados dispuestos de tal manera que conducen a una congestión estérica proyectada por los residuos aromáticos vecinos, como en el caso de los [n]helicenos ${ }^{46}$ (siendo $\mathrm{n}$ el número de anillos). En estos compuestos la exclusiva fusión en orto helicoidal de anillos produce la formación de una estructura en forma de hélice que hace honor a su nombre. También este efecto de curvatura puede originarse por la incorporación de anillos de otros tamaños en el sistema, así como la existencia de anillos pentagonales o heptagonales, dando lugar al [5]circuleno o coranuleno ${ }^{47}$ (Figura 5a) y
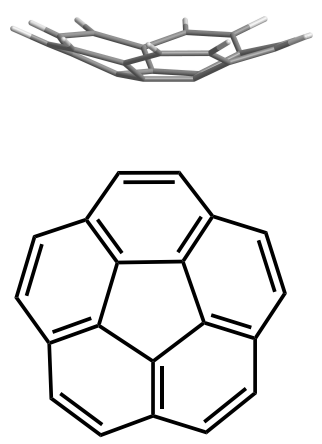

a
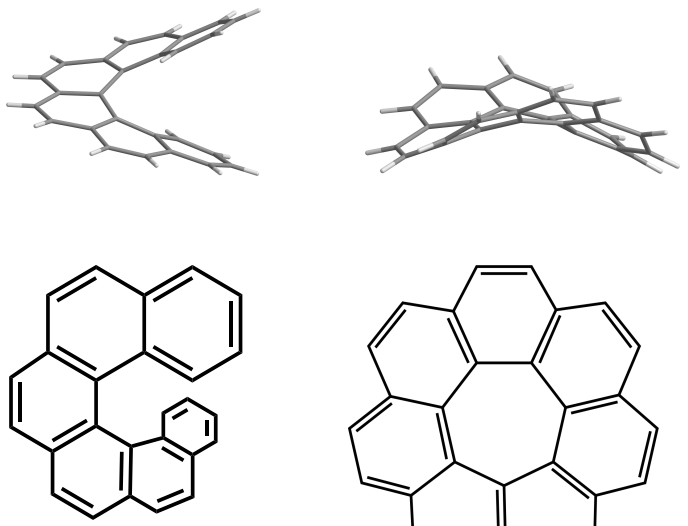

b

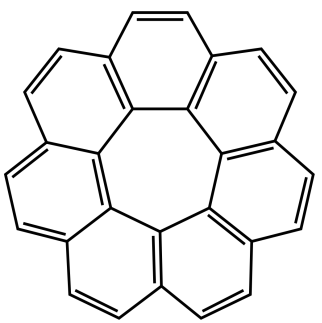

C
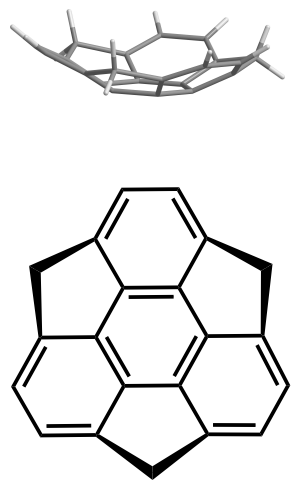

d

Figura 5. Ejemplos representativos de PAH no planos: (a) [5]circuleno o coranuleno, (b) [6]heliceno, (c) [7]circuleno, (d) Sumaneno. En la parte superior está representado su disposición tridimensional.

44 (a) R. A. Pascal, Chem. Rev., 2006, 106, 4809-4819, (b) M. Ball, Y. Zhong, Y. Wu, C. Schenck, F. Ng, M. Steigerwald, S. Xiao, C. Nuckolls, Acc. Chem. Res., 2015, 48, 267-276.

45 (a) M. Gingras, Chem. Soc. Rev., 2013, 42, 1051-1095, (b) M. Rickhaus, M. Mayor, M. Juríček, Chem. Soc. Rev., 2017, 46, 1643-1660, (c) E. Nestoros, M. C. Stuparu, Chem. Commun., 2018, 54, 6503-6519.

${ }^{46}$ M. S. Newman, D. Lednicer, J. Am. Chem. Soc., 1956, 78, 4765-4770.

${ }^{47}$ (a) W. E. Barth, R. G. Lawton, J. Am. Chem. Soc., 1966, 88, 380-381, (b) R. G. Lawton, W. E. Barth, J. Am. Chem. Soc., 1971, 93, 1730-1745. 
[7] circuleno $^{48}$ (Figura 5c), respectivamente. No debe confundirse el coranuleno (Figura 5a) con el coroneno (Figura 3e) que es un PAH de tipo plano.

Debido a la geometría tridimensional curvada no completa de ciertas estructuras, tales como el coranuleno (Figura 5a) y sumaneno ${ }^{49}$ (Figura 5d), se catalogan como poliarenos geodésicos abiertos ${ }^{50}$ o buckybowls. Dicha denominación procede a que su forma se asemeja a la superficie terrestre. Por otro parte, los poliarenos geodésicos que sí presentan formas cerradas o completas, son conocidos como buckyballs, siendo los fullerenos previamente mencionados los ejemplos más representativos.

El coranuleno es el PAH no plano central de esta tesis doctoral por lo que se comenta en detalle en el siguiente Aparatado 2.4.1.

\subsubsection{Coranuleno}

El [5]circuleno o coranuleno $\left(\mathrm{C}_{20} \mathrm{H}_{10}\right)$ fue el primer hidrocarburo policíclico aromático sintetizado con geometría curvada, concebido en la universidad de Michigan por Barth y Lawton en $1966 .{ }^{47 a}$ Prestando atención a la línea temporal, esta forma espacial poco convencional para sistemas $\pi$ se descubrió dos décadas antes a la aparición de los fullerenos (1985). ${ }^{17 a}$

El nombre sistemático para esta molécula es dibenzo[ghi,mno]fluoranteno, aunque sus descubridores acuñaron el nombre trivial "coranuleno", cuya raíz etimológica deriva del latín: cor y annula, significando corazón y anillo, respectivamente en castellano. Además, dicho nombre se escogió para conectar su relación con el [6]circuleno o coroneno (Figura 3e), aunque a diferencia del coranuleno éste es plano.

\subsubsection{Geometría y propiedades}

Desde el punto de vista químico, el coranuleno está constituido por un anillo central de ciclopentano rodeado por la fusión de cinco anillos bencénicos, generando por ello una tensión inusual debido a los requisitos geométricos impuestos por los ángulos de enlace, cuyos valores están alejados de los convencionales para derivados aromáticos planos $\left(120^{\circ}\right.$ frente a $158^{\circ}$ promedio para el coranuleno). ${ }^{51}$ Como resultado final, para liberar esa energía de tensión, el coranuleno adopta una geometría tridimensional curvada en forma de cuenco (Figura 5a superior). Por otro lado, desde una perspectiva estructural puede considerarse como un fragmento constitutivo del Buckminsterfullereno, como puede observarse en una de las caras del $\mathrm{C}_{60}$ representadas en la Figura 2a.

El coranuleno posee un grupo de simetría poco común $\mathrm{C}_{5 \mathrm{v}}$, donde sólo hay tres átomos de carbono químicamente diferentes y cuatro tipos distintos de enlaces carbono-carbono denominados como "Rim", "Flank", "Spoke" y "Hub" (Figura 6). ${ }^{51}$

\footnotetext{
${ }^{48}$ K. Yamamoto, T. Harada, M. Nakazaki, T. Naka, Y. Kai, S. Harada, N. Kasai, J. Am. Chem. Soc., 1983, 105, 7171-7172.

${ }^{49}$ G. Mehta, S. R. Shahk, K. Ravikumarc, J. Chem. Soc., Chem. Commun., 1993, 1006-1008.

50 (a) P. W. Rabideau, A. Sygula, Acc. Chem. Res., 1996, 29, 235-242, (b) L. T. Scott, H. E. Bronstein, D. V. Preda, R. B. M. Ansems, M. S. Bratcher, S. Hagen, Pure \& Appl. Chem., 1999, 71, 209-219, (c) V. M. Tsefrikas, L. T. Scott, Chem. Rev., 2006, 106, 4868-4884.

51 (a) A. Borchardt, A. Fuchicello, K. V. Kilway, K. K. Baldridge, J. S. Siegel, J. Am. Chem. Soc., 1992, 114, 1921-1923, (b) M. A. Petrukhina, K. W. Andreini, J. Mack, L. T. Scott, J. Org. Chem., 2005, 70, 5713-5716, (c) S. Grabowsky, M. Weber, Y.-S. Chen, D. Lentz, M. Schmidt Bernd, M. Hesse, P. Luger, Z. Naturforsch. B, 2010, 65, 452.
} 

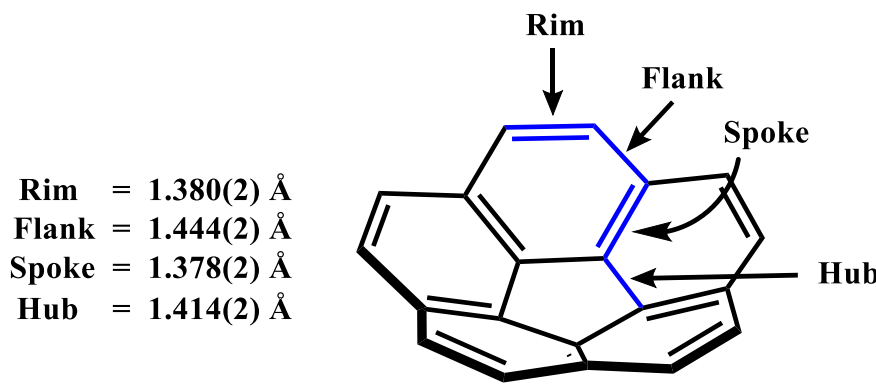

Figura 6. Clasificación de los distintos tipos de enlaces presentes en el coranuleno junto con las distancias determinadas mediante difracción de rayos X.

El grado de curvatura es analizado por datos cristalográficos de rayos $\mathrm{X}$, mostrando una profundidad del cuenco entre la distancia "Hub-Rim" de $0.87 \AA^{52}$ y por el ángulo de piramidalización, calculada por el método $\mathrm{POAV}^{53}$ para el carbono del anillo central de cinco miembros ("Hub") de $8.3^{\circ}$, en contraste con los $11.6^{\circ}$ para el $\mathrm{C}_{60} .{ }^{54} \mathrm{Un}$ efecto directo de la curvatura es una disminución importante de la energía del LUMO y sin cambios relevantes en lo que concierne a la energía del HOMO, incrementando por tanto sus propiedades electrónicas aceptoras y aumentando la reactividad hacia cicloadiciones.

Una consecuencia resultante de su apariencia especial en forma de cuenco es la presencia de las caras cóncava y convexa en esta entidad, existiendo una diferencia de densidades electrónicas entre ambas y manifestando por ello un momento dipolar permanente de $2.07 \mathrm{D}$, que ha sido calculado mediante espectroscopía de rotación. ${ }^{55}$ Por este motivo, el coranuleno puede considerarse como la capa polar del Buckminsterfullereno.

La rigidez de este buckybowl se evalúa por la interconversión entre las dos caras, estando vinculado a un proceso dinámico fluxional conocido como bowl-to-bowl inversion. Este fenómeno no es posible estudiarlo en el coranuleno prístino mediante RMN debido a la rápida inversión existente entre caras. Sin embargo, el uso de derivados de coranuleno adecuadamente sustituidos, ha permitido calcular mediante experimentos de RMN de temperatura variable una barrera energética en el intervalo de $10.2-11.3 \mathrm{kcal} \cdot \mathrm{mol}^{-1} .^{56}$

La reactividad del coranuleno es similar a la de sus congéneres PAH planos, pero con alguna peculiaridad debido a su curvatura. El coranuleno es susceptible de llevar a cabo tanto reacciones de sustitución en las posiciones externas ("Rim") como reacciones de adición en las posiciones internas pertenecientes al anillo de cinco miembros ("Hub"). ${ }^{57}$ Este hecho permite obtener derivados de coranuleno con una gran variedad de grupos funcionales lo que ha permitido

52 J. C. Hanson, C. E. Nordman, Acta Crystallogr. Sect. B, 1976, 32, 1147-1153.

53 (a) R. C. Haddon, L. T. Scott, Pure Appl. Chem., 1986, 58, 137-142, (b) R. C. Haddon, Acc. Chem. Res., 1988, 21, 243-249, (c) R. C. Haddon, J. Am. Chem. Soc., 1990, 112, 3385-3389.

${ }^{54}$ M. A. Petrukhina, Y. Sevryugina, A. Y. Rogachev, E. A. Jackson, L. T. Scott, Angew. Chem. Int. Ed., 2006, 45, 7208-7210.

55 F. J. Lovas, R. J. McMahon, J.-U. Grabow, M. Schnell, J. Mack, L. T. Scott, R. L. Kuczkowski, J. Am. Chem. Soc., 2005, 127, 4345-4349.

56 (a) L. T. Scott, M. M. Hashemi, M. S. Bratcher, J. Am. Chem. Soc., 1992, 114, 1920-1921, (b) A. Sygula, A. H. Abdourazak, P. W. Rabideau, J. Am. Chem. Soc., 1996, 118, 339-343, (c) T. J. Seiders, K. K. Baldridge, E. L. Elliott, G. H. Grube, J. S. Siegel, J. Am. Chem. Soc., 1999, 121, 7439-7440, (d) T. J. Seiders, K. K. Baldridge, G. H. Grube, J. S. Siegel, J. Am. Chem. Soc., 2001, 123, 517-525, (e) M. Yanney, F. R. Fronczek, W. P. Henry, D. J. Beard, A. Sygula, Eur. J. Org. Chem., 2011, 2011, 6636-6639, (f) M. Juríček, N. L. Strutt, J. C. Barnes, A. M. Butterfield, E. J. Dale, K. K. Baldridge, J. F. Stoddart, J. S. Siegel, Nat. Chem., 2014, 6, 222-228.

57 (a) C. Dubceac, A. S. Filatov, A. V. Zabula, A. Y. Rogachev, M. A. Petrukhina, Chem. Eur. J., 2015, 21, 14268-14279, (b) L. T. Scott, Chem. Soc. Rev., 2015, 44, 6464-6471. 
alterar sus propiedades físicas y químicas, siendo por tanto un candidato óptimo para futuras aplicaciones en ciencia de materiales. ${ }^{45 c, 58}$ En particular, es destacable la gran cantidad de trabajos existentes que contienen derivados con grupos electroatractores por sus excelentes propiedades electrónicas, ${ }^{59}$ así por ejemplo, la presencia de grupos $-\mathrm{CF}_{3}$ incrementa la afinidad electrónica del núcleo de coranuleno.

La molécula de coranuleno puede reaccionar con metales alcalinos, obteniéndose carbaniones reducidos que pueden ser estabilizados mediante la formación de agregados supramoleculares. ${ }^{60}$ Por otro lado también es capaz de formar derivados catiónicos, ${ }^{57,61}$ empero éstos han sido menos estudiados. También es bien conocida su habilidad para formar complejos tipo $\sigma^{62}$ y $\pi$ con metales de transición. Con respecto a esta última forma de coordinación, puede distinguirse complejación de tipo exo y endo debido a la presencia de las dos caras bien diferenciadas cóncava y convexa. ${ }^{63}$

\subsubsection{Métodos de síntesis de coranuleno}

Barth y Lawton tomando como punto de partida acenafteno consiguieron obtener el coranuleno con un rendimiento global del $0.4 \%$ tras una ardua y larga síntesis lineal de 17 pasos. Aunque los detalles de la síntesis no se publicaron hasta 5 años más tarde.$^{47}$ La clave principal residió en la introducción de la tensión intramolecular responsable de la deformación del sistema lo más tarde posible dentro de la estrategia sintética.

Posteriormente, emergieron las técnicas de pirolisis en alto vacío (en inglés Flash Vacuum Pyrolysis, FVP) ${ }^{50 \mathrm{c}}$ para la obtención de buckybowls, obteniendo una mejora en los rendimientos

58 (a) R.-Q. Lu, W. Xuan, Y.-Q. Zheng, Y.-N. Zhou, X.-Y. Yan, J.-H. Dou, R. Chen, J. Pei, W. Weng, X.-Y. Cao, RSC Adv., 2014, 4, 56749-56755, (b) R. Chen, R.-Q. Lu, P.-C. Shi, X.-Y. Cao, Chin. Chem. Lett., 2016, 27, 1175-1183, (c) X. Li, D. Sun, X. Li, D. Zhu, Z. Jia, J. Jiao, K. Wang, D. Kong, X. Zhao, L. Xu, Q. Zhao, D. Chen, X. Feng, Biomater. Sci., 2017, 5, 849-859, (d) X. Gu, X. Zhang, H. Ma, S. Jia, P. Zhang, Y. Zhao, Q. Liu, J. Wang, X. Zheng, J. W. Y. Lam, D. Ding, B. Z. Tang, Adv. Mater., 2018, 30, 1801065, (e) A. M. Rice, E. A. Dolgopolova, B. J. Yarbrough, G. A. Leith, C. R. Martin, K. S. Stephenson, R. A. Heugh, A. J. Brandt, D. A. Chen, S. G. Karakalos, M. D. Smith, K. B. Hatzell, P. J. Pellechia, S. Garashchuk, N. B. Shustova, Angew. Chem. Int. Ed., 2018, 57, 11310-11315, (f) M. Saito, H. Shinokubo, H. Sakurai, Mater. Chem. Front., 2018, 2, 635-661, (g) S. Du, H. Wang, Y. Yang, X. Feng, X. Shao, C. Chipot, W. Cai, J. Phys. Chem. C, 2019, 123, 922-930, (h) X. Guo, D. Lu, D. Zhang, J. Deng, X. Zhang, Z. Wang, L. Xiao, Y. Zhao, Mater. Sci. Eng. C, 2020, 106, 110227.

${ }^{59}$ Citas en el interior: (a) B. M. Schmidt, D. Lentz, Chem. Lett., 2014, 43, 171-177, (b) A. Haupt, D. Lentz, Chem. Eur. J., 2019, 25, 3440-3454.

60 (a) N. J. Sumner, S. N. Spisak, A. S. Filatov, A. Y. Rogachev, A. V. Zabula, M. A. Petrukhina, Organometallics, 2014, 33, 2874-2878, (b) A. V. Zabula, S. N. Spisak, A. S. Filatov, A. Y. Rogachev, M. A. Petrukhina, Acc. Chem. Res., 2018, 51, 1541-1549, (c) M. A. Petrukhina, Dalton Trans., 2019, 48, 51255130.

61 (a) J. Li, A. Y. Rogachev, Phys. Chem. Chem. Phys., 2016, 18, 11781-11791, (b) J. Li, G. da Silva Ramos, A. Yu Rogachev, J. Comput. Chem., 2016, 37, 2266-2278, (c) S. Liu, A. Y. Rogachev, ChemPhysChem, 2018, 19, 2579-2588.

62 (a) H. B. Lee, P. R. Sharp, Organometallics, 2005, 24, 4875-4877, (b) H. Choi, C. Kim, K.-M. Park, J. Kim, Y. Kang, J. Ko, J. Organomet. Chem., 2009, 694, 3529-3532, (c) R. Maag, B. H. Northrop, A. Butterfield, A. Linden, O. Zerbe, Y. M. Lee, K.-W. Chi, P. J. Stang, J. S. Siegel, Org. Biomol. Chem., 2009, 7, 4881-4885, (d) M. Yamada, S. Tashiro, R. Miyake, M. Shionoya, Dalton Trans., 2013, 42, 3300-3303, (e) J. W. Facendola, M. Seifrid, J. Siegel, P. I. Djurovich, M. E. Thompson, Dalton Trans., 2015, 44, 8456-8466, (f) R. D. Adams, P. Dhull, M. Pennachio, M. A. Petrukhina, M. D. Smith, Chem. Eur. J., 2019, 25, 4234-4239.

63 (a) P. A. Vecchi, C. M. Alvarez, A. Ellern, R. J. Angelici, A. Sygula, R. Sygula, P. W. Rabideau, Angew. Chem. Int. Ed., 2004, 43, 4497-4500, (b) P. A. Vecchi, C. M. Alvarez, A. Ellern, R. J. Angelici, A. Sygula, R. Sygula, P. W. Rabideau, Organometallics, 2005, 24, 4543-4552, (c) M. A. Petrukhina, L. T. Scott, Dalton Trans., 2005, 2969-2975, (d) M. A. Petrukhina, Angew. Chem. Int. Ed., 2008, 47, 1550-1552, (e) A. S. Filatov, M. A. Petrukhina, Coord. Chem. Rev., 2010, 254, 2234-2246. 
globales para el coranuleno y derivados. ${ }^{56 a, 64}$ De esta manera, Scott consiguió mediante sólo tres etapas un rendimiento global del $26 \% .{ }^{65}$ Pese a lograr un gran rendimiento en pocos pasos de síntesis, las limitaciones prácticas impuestas por este método en particular (temperaturas muy elevadas $500-1000{ }^{\circ} \mathrm{C}$ y alto vacío), promovieron el desarrollo de alternativas sintéticas en disolución bajo condiciones más suaves.

En la década de los 90 el grupo de Siegel realizó una mejora reduciendo el número de etapas sintéticas en fase condensada. La metodología empleada en este caso consistió en partir de 2,7-dimetilnaftaleno como núcleo principal sobre el que posteriormente se van construyendo el resto de los anillos aromáticos. ${ }^{51 a, 66}$ Aunque el avance más significativo en este campo fue alcanzado por Sygula y Rabideau a principios de los 2000, logrando obtener de forma casual el 1,2,5,6-tetrabromocoranuleno con un rendimiento elevado (80\%) (Esquema 1). Este compuesto se obtiene mediante una doble sustitución nucleófila intramolecular partiendo del 1,6,7,10tetrakis(dibromometilen)fluoranteno. ${ }^{67}$

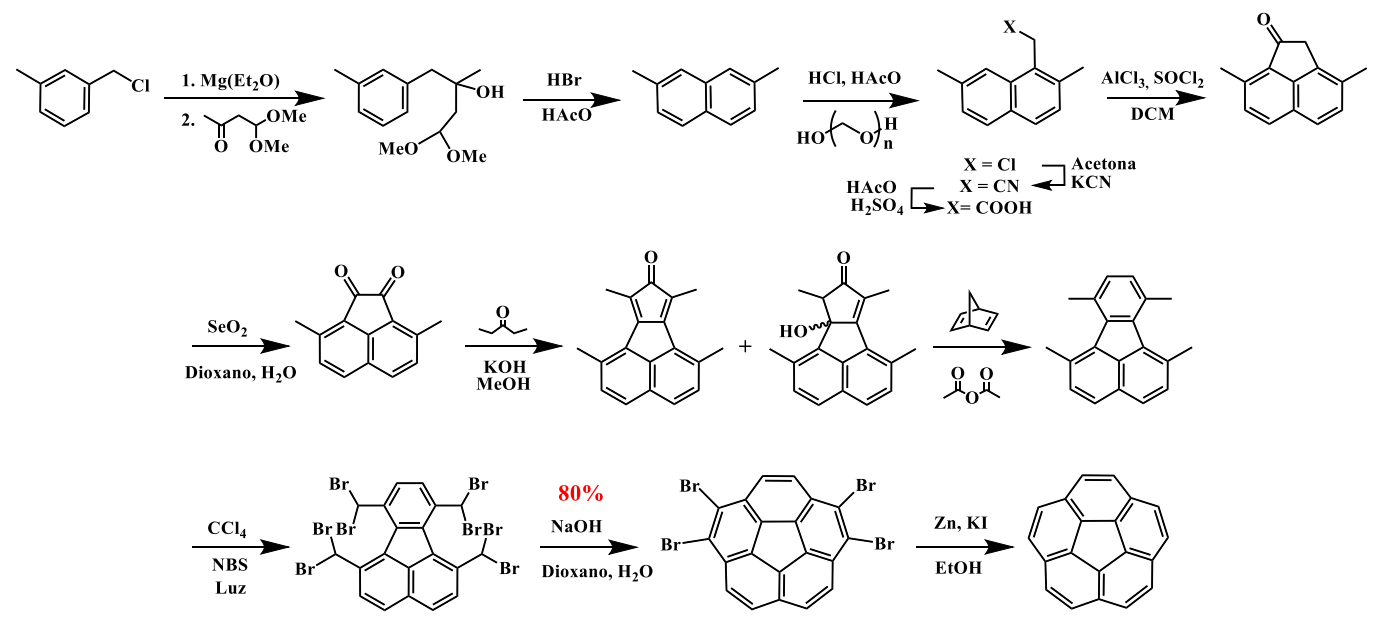

Esquema 1. Síntesis de coranuleno optimizada por el grupo de Sygula.

La última modificación moderna en la síntesis de coranuleno, siendo la más utilizada actualmente, fue introducida por Siegel en $2012 .{ }^{68}$ En esta nueva estrategia, el anillo central pentagonal se obtiene en un único paso. Para ello, tras la síntesis del 2,7-dimetilnaftaleno en la segunda etapa de reacción, se lleva a cabo una doble acilación de Friedel-Crafts con el cloruro de oxalilo, obteniendose en este punto una mezcla dos dicetonas en relación 2:1 para el regioisómero deseado (Esquema 2). Se ha demostrado que la eliminación del isómero no deseado (compuesto azul Esquema 2) puede realizarse mediante una simple derivatización con un reactivo de Girard ${ }^{69}$ y subsiguiente extracción con agua.

64 (a) P. W. Rabideau, A. H. Abdourazak, H. E. Folsom, Z. Marcinow, A. Sygula, R. Sygula, J. Am. Chem. Soc., 1994, 116, 7891-7892, (b) G. Mehta, G. Panda, Tetrahedron Lett., 1997, 38, 2145-2148.

65 (a) L. T. Scott, M. M. Hashemi, D. T. Meyer, H. B. Warren, J. Am. Chem. Soc., 1991, 113, 7082-7084, (b) L. T. Scott, P.-C. Cheng, M. M. Hashemi, M. S. Bratcher, D. T. Meyer, H. B. Warren, J. Am. Chem. Soc., 1997, 119, 10963-10968.

66 (a) A. Borchardt, K. Hardcastle, P. Gantzel, J. S. Siegel, Tetrahedron Lett., 1993, 34, 273-276, (b) T. J. Seiders, K. K. Baldridge, J. S. Siegel, J. Am. Chem. Soc., 1996, 118, 2754-2755, (c) T. J. Seiders, E. L. Elliott, G. H. Grube, J. S. Siegel, J. Am. Chem. Soc., 1999, 121, 7804-7813.

${ }^{67}$ (a) A. Sygula, P. W. Rabideau, J. Am. Chem. Soc., 2000, 122, 6323-6324, (b) G. Xu, A. Sygula, Z. Marcinow, P. W. Rabideau, Tetrahedron Lett., 2000, 41, 9931-9934, (c) A. Sygula, G. Xu, Z. Marcinow, P. W. Rabideau, Tetrahedron, 2001, 57, 3637-3644.

${ }^{68}$ A. M. Butterfield, B. Gilomen, J. S. Siegel, Org. Process Res. Dev., 2012, 16, 664-676.

69 (a) A. Girard, G. Sandulesco, Helv. Chim. Acta, 1936, 19, 1095-1107, (b) H. B. Henbest, Nature, 1946, $158,950-950$. 


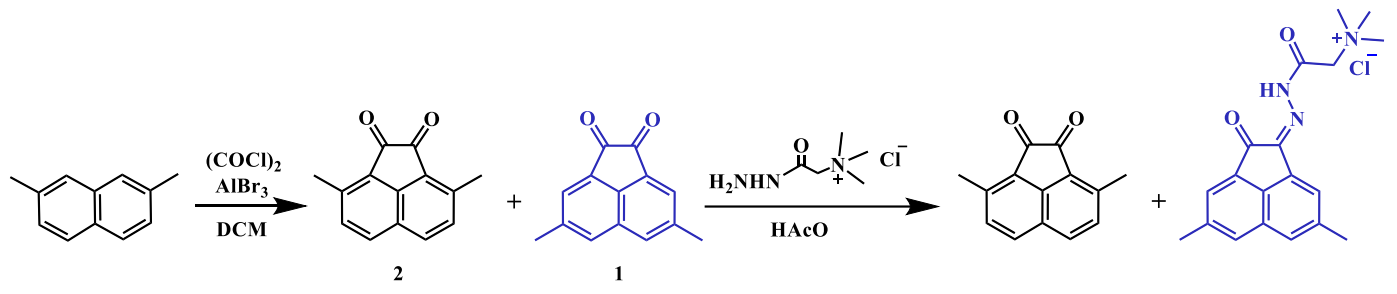

Esquema 2. Última variante introducida en la síntesis moderna de coranuleno. El regioisómero no deseado reacciona de forma específica con el reactivo de Girard generado un derivado que es soluble en agua, facilitando de este modo la obtención del compuesto de interés. La relación de regioisómeros se encuentra indicado debajo del compuesto dicetónico.

Esta variante, pese a tener una mezcla de isómeros que hay que separar en cierto punto, ha conseguido eliminar varias etapas sintéticas posteriores compensando dicha limitación anterior (12 etapas correspondientes a la síntesis mostrada en el Esquema 1 frente a las 8 de la síntesis moderna). El rendimiento global alcanzado es del 8.7\%, mejorando con creces la síntesis original de 1966. Este método ha permitido obtener coranuleno en escala de kilogramos, facilitando así su comercializaron y accesibilidad a grupos de investigación en todo el mundo.

Finalmente, también se han llevado a cabo intentos para obtener derivados de coranuleno o de otros PAH no planos mediante acoplamientos carbono-carbono catalizados por metales, gracias a los avances en el campo de la Química Organometálica. ${ }^{70}$ Por ejemplo, es posible convertir un sistema plano de tipo fluoranteno debidamente sustituido con bromos en un derivado de coranuleno mediante una reacción de tipo Heck. ${ }^{70 a}$

\subsubsection{Interacciones supramoleculares entre fullerenos y coranuleno}

Como se ha comentado en el Apartado 2.1, la complementariedad de forma entre los integrantes anfitrión-huésped es uno de los puntos relevantes para el éxito de la interacción supramolecular. De este modo, PAH planos como el pireno presenta serias dificultades para interaccionar con fullerenos (Apartado 2.3.1.1). Por razones geométricas, el sistema plano no es capaz de interaccionar de forma eficiente con una estructura esférica como es el Buckminsterfullereno. En cambio, el coranuleno al ser un sistema tridimensionalmente curvado es más propenso a formar interacciones supramoleculares con organizaciones nanométricas geométricamente similares, tales como los fullerenos $\left(\mathrm{C}_{60} \mathrm{y} \mathrm{C}_{70}\right)$. Este buckybowl posee un menor grado de curvatura que el $\mathrm{C}_{60}$ debido a la presencia de un menor número de anillos pentagonales, posibilitando al coranuleno envolver o abrazar al Buckminsterfullereno eficientemente. Esto se traduce en una perfecta complementariedad entre superficies cóncavas y convexas de los sistemas participantes. El resultado final es un mayor grado de afinidad mutuo por una mejora en las interacciones del apilamiento $\pi$. Este hecho, junto con la existencia de un momento dipolar permanente que aumenta las interacciones electrostáticas intermoleculares, hacen de la molécula de coranuleno un candidato ideal como receptor de fullerenos (Figura 7). Además, no hay que olvidar que existen otros factores energéticos que también pueden influenciar de forma decisiva

\footnotetext{
70 (a) H. A. Reisch, M. S. Bratcher, L. T. Scott, Org. Lett., 2000, 2, 1427-1430, (b) Z. Marcinow, A. Sygula, A. Ellern, P. W. Rabideau, Org. Lett., 2001, 3, 3527-3529, (c) H. A. Wegner, L. T. Scott, A. de Meijere, J. Org. Chem., 2003, 68, 883-887, (d) D. Kim, J. L. Petersen, K. K. Wang, Org. Lett., 2006, 8, 2313-2316, (e) C.-N. Feng, Y.-C. Hsieh, Y.-T. Wu, Chem. Rec., 2015, 15, 266-279.
} 
en las interacciones intermoleculares, como son: fuerzas de van der Waals, energía de inducción, procesos de transferencia de carga o desolvatación. ${ }^{33 b, 71}$

a)

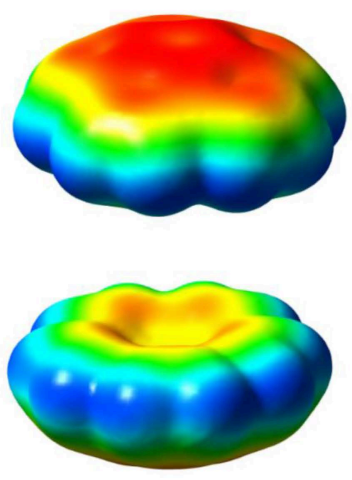

b)

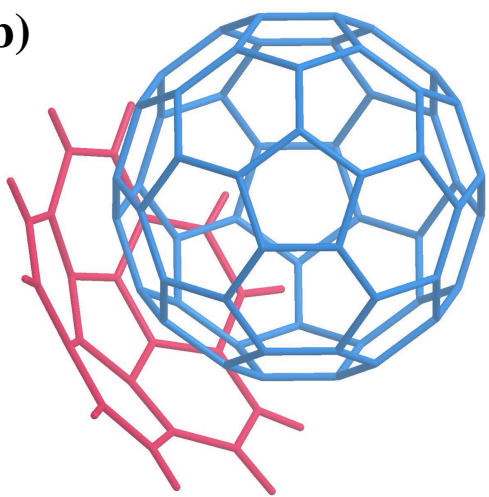

Figura 7. (a) Mapa del potencial electrostático de las diferentes caras cóncava-convexa, indicando la existencia del momento dipolar del coranuleno. (b) Representación donde puede apreciarse la complementariedad de superficies entre el $\mathrm{C}_{60} \mathrm{y}$ el coranuleno.

En esta memoria en los Artículos II y III se han desarrollado arquitecturas moleculares que contienen restos PAH no planos derivados de coranuleno en distintas posiciones espaciales y se ha estudiado su interacción con fullerenos. Además, el número de unidades coranuleno presentes en ambos trabajos es distinto y se ha estudiado su repercusión en las interacciones supramoleculares resultantes.

\subsubsection{Evolución histórica de sistemas coranulénicos como receptores de fullerenos}

En este apartado se resumen la evolución de los distintos sistemas descritos en la bibliografía que contienen restos de coranuleno. La sección se ha dividido atendiendo al número de unidades de coranuleno presentes.

\subsection{Sistemas mono-coranuleno}

Pese a los propicios factores para la interacción con $\mathrm{C}_{60}$, la formación del complejo de inclusión entre coranuleno prístino y $\mathrm{C}_{60}$ nunca se ha podido observar en disolución, ya que la interacción resultante es demasiado débil. Sin embargo, existen trabajos experimentales y teóricos desarrollados en fase gas que sugieren que esta interacción es energéticamente favorable (19.5 $\left.\mathrm{kcal} \cdot \mathrm{mol}^{-1}\right){ }^{72}$ Sólo existe un ejemplo peculiar en disolución, donde un fullereno endoédrico que contiene un ion de litio $\left(\mathrm{Li}^{+} @ \mathrm{C}_{60}\right)$ es capaz de interaccionar con coranuleno. La formación del complejo es debida a procesos de transferencia de carga y la constate de asociación obtenida es bastante pequeña $\left(\mathrm{K}=19 \mathrm{M}^{-1}\right.$, benzonitrilo) ${ }^{73}$ Esta baja o casi nula afinidad en disolución puede ser atribuida a factores de solvatación y penalizaciones entrópicas relacionadas con la formación del complejo supramolecular. ${ }^{74}$

${ }^{71}$ E. M. Pérez, N. Martín, Chem. Soc. Rev., 2015, 44, 6425-6433.

72 (a) H. Becker, G. Javahery, S. Petrie, P. C. Cheng, H. Schwarz, L. T. Scott, D. K. Bohme, J. Am. Chem. Soc., 1993, 115, 11636-11637, (b) A. Sygula, S. Saebø, Int. J. Quantum Chem, 2009, 109, 65-72, (c) P. A. Denis, Chem. Phys. Lett., 2011, 516, 82-87, (d) T. Janowski, P. Pulay, A. A. Sasith Karunarathna, A. Sygula, S. Saebø, Chem. Phys. Lett., 2011, 512, 155-160.

${ }^{73}$ M. Yamada, K. Ohkubo, M. Shionoya, S. Fukuzumi, J. Am. Chem. Soc., 2014, 136, 13240-13248.

${ }^{74}$ M. R. Kennedy, L. A. Burns, C. D. Sherrill, J. Phys. Chem. A, 2012, 116, 11920-11926. 
No fue hasta el año 2012 cuando el grupo de Soctt observó en estado sólido la cocristalización entre ambas especies. ${ }^{75}$ Otros trabajos posteriores con fines optoelectrónicos también muestran ejemplos de cocristalización. ${ }^{76}$ Otro ejemplo en estado sólido fue obtenido por el grupo Siegel, logrando sobre una superficie de $\mathrm{Cu}(110)$ en ultra alto vacío la formación de un complejo coranuleno- $\mathrm{C}_{60}{ }^{77}$

Los casos donde sí ha sido posible demostrar la interacción supramolecular en disolución, están basados en estrategias de funcionalización de mono-coranuleno en las posiciones "Rim". La finalidad de estas funcionalizaciones es incrementar la superficie $\pi$ activa para mejorar el contacto entre las especies implicadas. ${ }^{78}$ Además, la decoración con grupos ricos en electrones mejora las interacciones electrostáticas aprovechando las cualidades aceptoras de los fullerenos.

De este modo, Scott y colaboradores fueron los pioneros sintetizando una familia de tetray penta- derivados de coranuleno con grupos tioéteres que mostraron interacciones favorables ( $\mathbf{1}$, Figura 8a). Mediante una valoración por RMN usando tolueno- $d_{8}$ como disolvente, se pudieron calcular las constantes de asociación para estos compuestos frente a $\mathrm{C}_{60}$, obteniéndose valores aceptables $\left(\mathrm{K} \sim 10^{2} \mathrm{M}^{-1}\right.$, estequiometría $\left.1: 1\right){ }^{79}$

a)

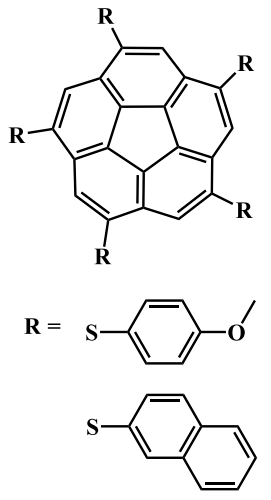

1 b)

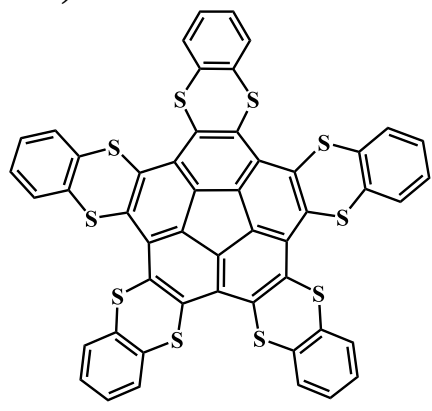

2 c)

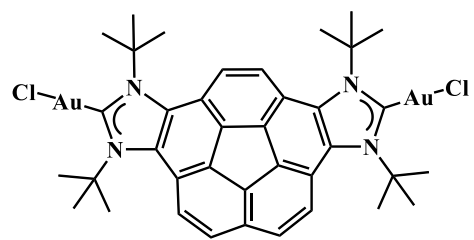

3

Figura 8. Ejemplos seleccionados conteniendo una única unidad de coranuleno que han presentado constantes de asociación observables en disolución.

Unos años más tarde, el mismo grupo de investigación consiguió alcanzar la decafuncionalización de coranuleno con grupos sulfuro, obteniendo un compuesto especialmente rico en densidad electrónica (2, Figura 8b). ${ }^{80} \mathrm{El}$ análisis de la estructura cristalina de rayos X reveló que este derivado adoptaba una conformación que los autores denominaron Venus flytrap (inspirada en la famosa planta atrapamoscas Dionaea muscipula), mostrando una geometría óptima para encapsular fullerenos. Este hecho se confirmó por estudios de valoración de RMN dando lugar a valores de constantes moderadas $\left(\mathrm{K}=10^{3} \mathrm{M}^{-1}\right.$, estequiometría 1:1, $\left.\mathrm{CS}_{2}\right)$.

\footnotetext{
75 L. N. Dawe, T. A. AlHujran, H.-A. Tran, J. I. Mercer, E. A. Jackson, L. T. Scott, P. E. Georghiou, Chem. Commun., 2012, 48, 5563-5565.

${ }^{76}$ Y. Wang, Y. Li, W. Zhu, J. Liu, X. Zhang, R. Li, Y. Zhen, H. Dong, W. Hu, Nanoscale, 2016, 8, 14920-14924.

77 W. Xiao, D. Passerone, P. Ruffieux, K. Aït-Mansour, O. Gröning, E. Tosatti, J. S. Siegel, R. Fasel, J. Am. Chem. Soc., 2008, 130, 4767-4771.

${ }^{78}$ S. Lampart, L. M. Roch, A. K. Dutta, Y. Wang, R. Warshamanage, A. D. Finke, A. Linden, K. K. Baldridge, J. S. Siegel, Angew. Chem., 2016, 128, 14868-14872.

${ }^{79}$ S. Mizyed, P. E. Georghiou, M. Bancu, B. Cuadra, A. K. Rai, P. Cheng, L. T. Scott, J. Am. Chem. Soc., 2001, 123, 12770-12774.

80 (a) M. Bancu, A. K. Rai, P. Cheng, R. D. Gilardi, L. T. Scott, Synlett, 2004, 2004, 173-176, (b) P. E. Georghiou, A. H. Tran, S. Mizyed, M. Bancu, L. T. Scott, J. Org. Chem., 2005, 70, 6158-6163.
} 
El primer ejemplo importante en todo este campo fue realizado recientemente por el grupo de Peris en 2017 (3, Figura 8c). ${ }^{81}$ Este derivado de mono-coranuleno está constituido por dos carbenos de oro di-N-heterocíclico que exhiben una perfecta complementariedad con la superficie del fullereno. Este trabajo está avalado por extensos cálculos DFT y valoraciones en tolueno por las técnicas de RMN e ITC, dando como resultado una sorprendente estequiometria 3:1 y un valor de constante razonablemente alta del orden de $10^{3} \mathrm{M}^{-1}$ para cada evento supramolecular.

A la vista de los resultados obtenidos con una única unidad de coranuleno, es razonable pensar que incrementando el número unidades produciría un aumento en las fuerzas responsables de las interacciones supramoleculares. De esta manera es posible superar las penalizaciones debidas a factores de solvatación y entrópicos para obtener constantes de asociación más elevadas. Con esta mentalidad han sido desarrollados diversos sistemas multi-coranuleno que se comentaran en los siguientes apartados.

\subsection{Sistemas bis-coranuleno}

Los sistemas que contienen dos unidades de coranuleno, concretamente aquellos dispuestos con geometría espacial en forma de pinza, han sido ampliamente explotados. Existe un gran número de trabajos al respecto siendo el grupo de Sygula quién ha aportado un mayor número de ejemplos.

El primer sistema bis-coranuleno fue desarrollado por Sygula et al. en 2003. Sin embargo, mostró resultados negativos para asociación con fullerenos. La razón de esto se debe a que tal y como se demostró por difracción de rayos X, la conformación bis-exo de la molécula no era la adecuada para formar una interacción supramolecular. ${ }^{82}$

Ese mismo grupo de investigación cuatro años más tarde, logró alcanzar el primer éxito importante marcando un hito en el campo de la Química Supramolecular entre el coranuleno y Buckminsterfullereno. Los autores obtuvieron la primera pinza molecular capaz de establecer fuertes complejos de inclusión con fullerenos. ${ }^{83}$ Haciendo uso de recciones de tipo Diels-Alder consiguieron una estructura que contenía dos unidades de coranuleno fusionadas a un armazón de tetrabenzociclooctatetraeno que bautizaron como Buckycatcher I (4, Figura 9a). Los análisis preliminares de RMN realizados en tolueno- $d_{8}$, dieron como resultado un formidable valor para la $\mathrm{K}$ de $8.6 \cdot 10^{3} \mathrm{M}^{-1}\left(\mathrm{C}_{60}\right.$, estequiometría 1:1, tolueno- $\left.d_{8}\right)$. El complejo $\mathrm{C}_{60} @ 4$ se pudo estudiar mediante difracción de rayos $\mathrm{X}$, donde podía observarse que la geometría perteneciente al Buckycatcher I es la idónea para acomodar la superficie esférica del fullereno (Figura 9b). Estudios posteriores más detallados, permitieron obtener parámetros termodinámicos del proceso y un valor más preciso de la constante de asociación con el Buckminsterfullereno de $3.2 \cdot 10^{3}$ $\mathrm{M}^{-1}{ }^{84}$

\footnotetext{
${ }^{81}$ C. Mejuto, L. Escobar, G. Guisado-Barrios, P. Ballester, D. Gusev, E. Peris, Chem. Eur. J., 2017, 23, 1064410651.

${ }^{82}$ A. Sygula, R. Sygula, A. Ellern, P. W. Rabideau, Org. Lett., 2003, 5, 2595-2597.

${ }^{83}$ A. Sygula, F. R. Fronczek, R. Sygula, P. W. Rabideau, M. M. Olmstead, J. Am. Chem. Soc., 2007, 129, 38423843.

${ }^{84}$ (a) C. Muck-Lichtenfeld, S. Grimme, L. Kobryn, A. Sygula, Phys. Chem. Chem. Phys., 2010, 12, 7091-7097, (b) V. H. Le, M. Yanney, M. McGuire, A. Sygula, E. A. Lewis, J. Phys. Chem. B, 2014, 118, 11956-11964, (c) A. Sygula, M. Yanney, W. P. Henry, F. R. Fronczek, A. V. Zabula, M. A. Petrukhina, Cryst. Growth Des., 2014, $14,2633-2639$.
} 
a)

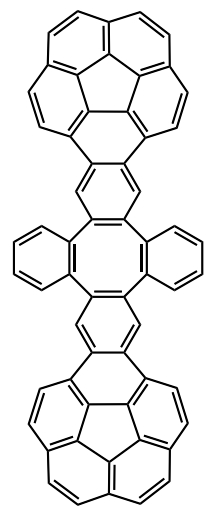

4 b)

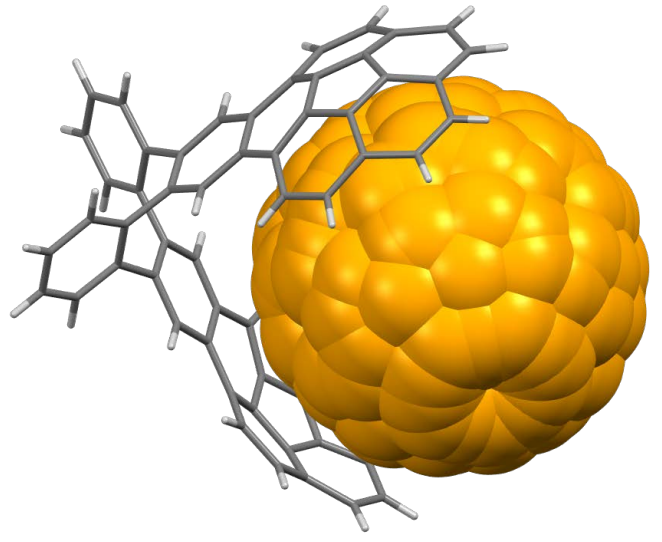

$\mathrm{C}_{60} @ 4$

Figura 9. (a) Pinza molecular Buckycatcher I y (b) el complejo de inclusión $\mathrm{C}_{60} @ 4$ obtenido por difracción de rayos X.

Tras el buen resultado inicial, el grupo de Sygula continuó desarrollando sistemas que contenían dos unidades de coranuleno. El siguiente trabajo fue el denominado como Buckycatcher II (5, Figura 10a). ${ }^{85}$ La nueva molécula se alcanzó mediante una doble cicloadición entre isocoranulenofurano y norbornadieno, obteniéndose de esta manera una nueva pinza molecular. La novedad radicaba en una estequiometria 2:1 del aducto supramolecular, que se confirmó mediante espectrometría de masas, método de las variaciones continuas (Job plot) ${ }^{86}$ así como por difracción de rayos X (Figura 10b). Las cuatro unidades de coranuleno de las dos pinzas, eran capaces de cubrir casi por completo la superficie del $\mathrm{C}_{60}$, por este motivo los autores denominaron a este receptor de fullerenos como "nanometric universal joint".

a)

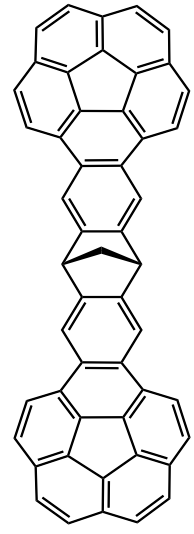

5 b)

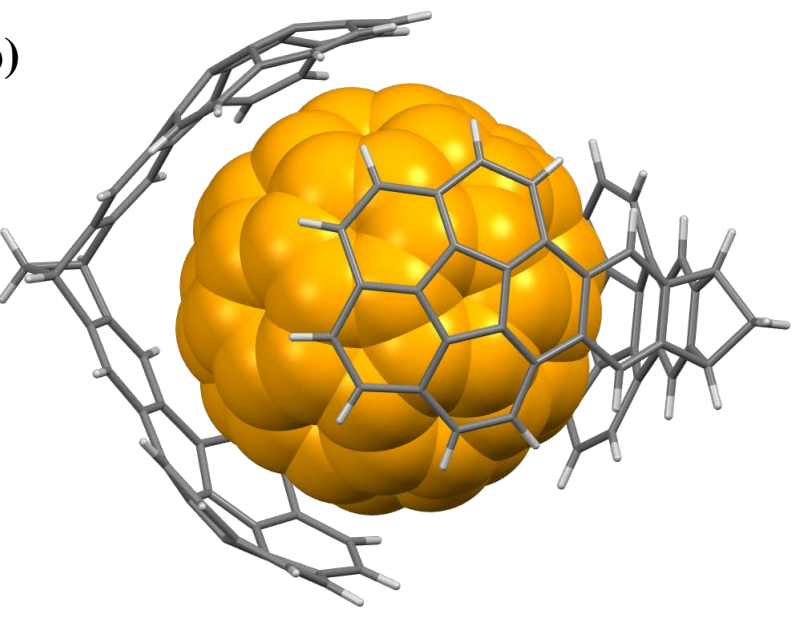

$\mathbf{C}_{60} @ \mathbf{5}_{2}$

Figura 10. (a) Pinza molecular Buckycatcher II y (b) el aducto del trímero $\mathrm{C}_{60} @ \mathbf{5}_{2}$ perteneciente a la estructura cristalina.

La asociación supramolecular de $\mathbf{5}$ con $\mathrm{C}_{60}$ se estudió por $\mathrm{RMN}$ empleando como disolvente tolueno- $d_{8}$. Se obtuvieron unos valores de $\mathrm{K}$ tan elevados $\left(\mathrm{K}_{1}=8.5 \cdot 10^{4} \mathrm{M}^{-1}\right.$ y $\mathrm{K}_{2}=$ $5.0 \cdot 10^{3} \mathrm{M}^{-1}$ ) que no pudieron ser estimados con exactitud debido a la limitada solubilidad del

\footnotetext{
85 M. Yanney, F. R. Fronczek, A. Sygula, Angew. Chem. Int. Ed., 2015, 54, 11153-11156.

${ }^{86}$ P. Job, Anal. Chim. Appl., 1928, 9, 113-203.
} 
complejo de inclusión en ese disolvente. Para una determinación más fiable de la asociación el disolvente se sustituyó por clorobenceno- $d_{5}$, alcanzando unos valores espectaculares de $\mathrm{K}_{1}=$ $1.0 \cdot 10^{4} \mathrm{M}^{-1}$ y $\mathrm{K}_{2}=1.1 \cdot 10^{3} \mathrm{M}^{-1}$. Bajo las mismas condiciones experimentales, Buckycatcher II mostraba una $\mathrm{K}$ veinte veces superior a su predecesor (Buckycatcher $\mathrm{I}$ ).

Siguiendo esta línea fructífera, Sygula y colaboradores prosiguieron la búsqueda de sistemas similares con forma de pinza molecular. ${ }^{87}$ Cabe mencionar el compuesto denominado como Buckycatcher III, que consiguió alcanzar el límite superior teórico para la estimación de las constantes de asociación supramoleculares mediante experimentos de RMN $\left(\mathrm{K} \sim 10^{5} \mathrm{M}^{-1}, \mathrm{C}_{70}\right.$, estequiometría $2: 1$, clorobenceno- $\left.d_{5}\right) .{ }^{88}$

En nuestro grupo de investigación hemos llevado a cabo estudios con pinzas moleculares con sistemas bis-coranuleno. Concretamente se han sintetizado complejos de coordinación planocuadrados de platino (II) cuyos restos acetilen-coranuleno se encontraban en posición relativa cis. Gracias a la coordinación al metal los ligandos aromáticos no planos presentaban una geometría óptima para acomodar fullerenos. ${ }^{89}$ En este trabajo se comparó la flexibilidad presente entre las diferentes pinzas sintetizadas, manifestando que el sistema más rígido (6, Figura 11a) mostraba afinidad hacia los fullerenos bajo estudio.

a)

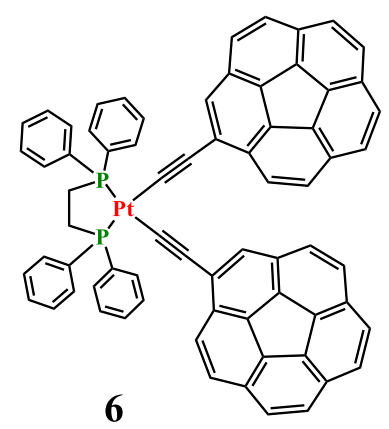

b)

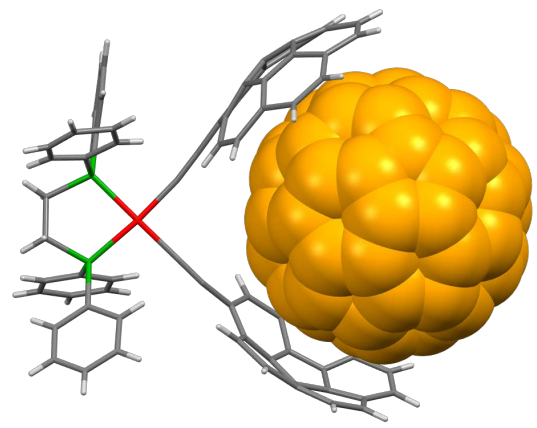

$\mathbf{C}_{60} @ 6$

Figura 11. (a) Complejo metálico 6 con brazos rígidos usado como receptor de fullerenos y (b) la estructura determinada por rayos X de $\mathrm{C}_{60} @ 6$. Átomo de platino indicado en rojo.

Así, la habilidad del complejo 6 para establecer interacciones con fullerenos se estudió por RMN. El comportamiento supramolecular encontrado para $\mathrm{C}_{60} \mathrm{y}_{70}$ fue diferente, quedando patente en sus $\mathrm{K}$, siendo de $4.6 \cdot 10^{3} \mathrm{M}^{-1}$ y $2.1 \cdot 10^{4} \mathrm{M}^{-1}$ para $\mathrm{C}_{60}$ y $\mathrm{C}_{70}$, respectivamente (tolueno$d_{8}$, estequiometría 1:1). Este ejemplo constituye el primer sistema basado en coranuleno encontrado en la bibliografía que ofrecía la capacidad de discriminación hacia $\mathrm{C}_{70}$ frente a $\mathrm{C}_{60}$. Además, pudo obtenerse un monocristal del complejo $\mathbf{6}$ interaccionando con el Buckminsterfullereno que se estudió por difracción de rayos X (Figura 11b). Los cálculos computacionales DFT realizados mostraban que la interacción por parte del metal en el evento de asociación era despreciable, sólo afectando por tanto a la disposición geométrica de los sustituyentes aromáticos no planos.

\footnotetext{
${ }^{87}$ K. G. U. R. Kumarasinghe, F. R. Fronczek, H. U. Valle, A. Sygula, Org. Lett., 2016, 18, 3054-3057.

${ }^{88}$ P. L. Abeyratne Kuragama, F. R. Fronczek, A. Sygula, Org. Lett., 2015, 17, 5292-5295.

${ }^{89}$ C. M. Álvarez, L. A. García-Escudero, R. García-Rodríguez, J. M. Martín-Álvarez, D. Miguel, V. M. Rayón, Dalton Trans., 2014, 43, 15693-15696.
} 
En nuestro grupo de investigación se ha desarrollado la primera pinza molecular conmutable basada en coranuleno que presenta afinidad hacia fullerenos. ${ }^{90}$ Gracias a las cualidades de fotoisomerización reversibles por irradiación con luz UV del grupo azobenceno, es posible alternar entre los isómeros configuracionales 7E/7Z (Esquema 3). De este modo el isómero lineal 7E, que carece de la habilidad para formar aductos supramoleculares con fullerenos, puede convertirse en el isómero $7 Z$ por irradiación con luz a $380 \mathrm{~nm}$ presentando así una topología adecuada en forma de pinza para interaccionar con fullerenos. Puesto que el isómero $\mathrm{Z}$ es menos estable, éste puede evolucionar de forma espontánea o con ayuda térmica hacia su análogo E, para de este modo cerrar el ciclo de conmutación. Las constantes estimadas mediante RMN para el derivado $7 \mathrm{Z}$ fueron del orden de $10^{3} \mathrm{M}^{-1}$ para ambos fullerenos, $\mathrm{C}_{60}$ y $_{70}$ (tolueno- $d_{8}$, estequiometría 1:1).

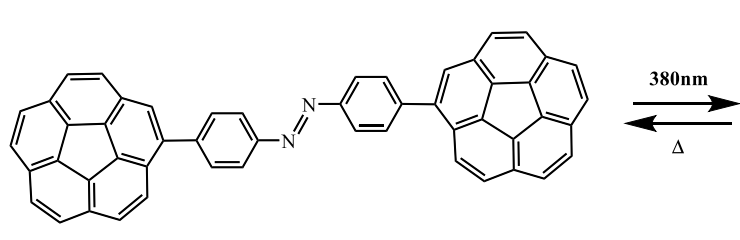

$7 \mathbf{E}$

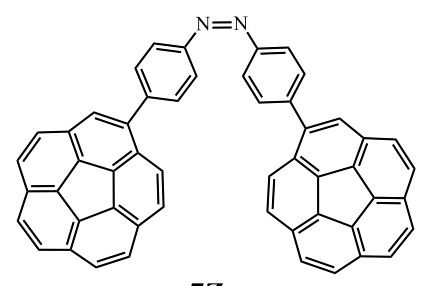

$7 Z$

Esquema 3. Ejemplo de fotoisomerización reversible para la formación de la pinza molecular 7Z.

Chen et al. en 2017 ha contribuido con un ejemplo reciente de un sistema bis-coranuleno (8, Figura 12). ${ }^{91}$ Tomando como base un soporte de tetrahidro[5] heliceno los autores consiguieron una pinza molecular que mostraba una sorprendente selectividad de complejación de $\mathrm{C}_{70}$ sobre $\mathrm{C}_{60}$, con una relación de constantes de asociación $\mathrm{K}_{\mathrm{C} 70} / \mathrm{K}_{\mathrm{C} 60}$ de 230/1.
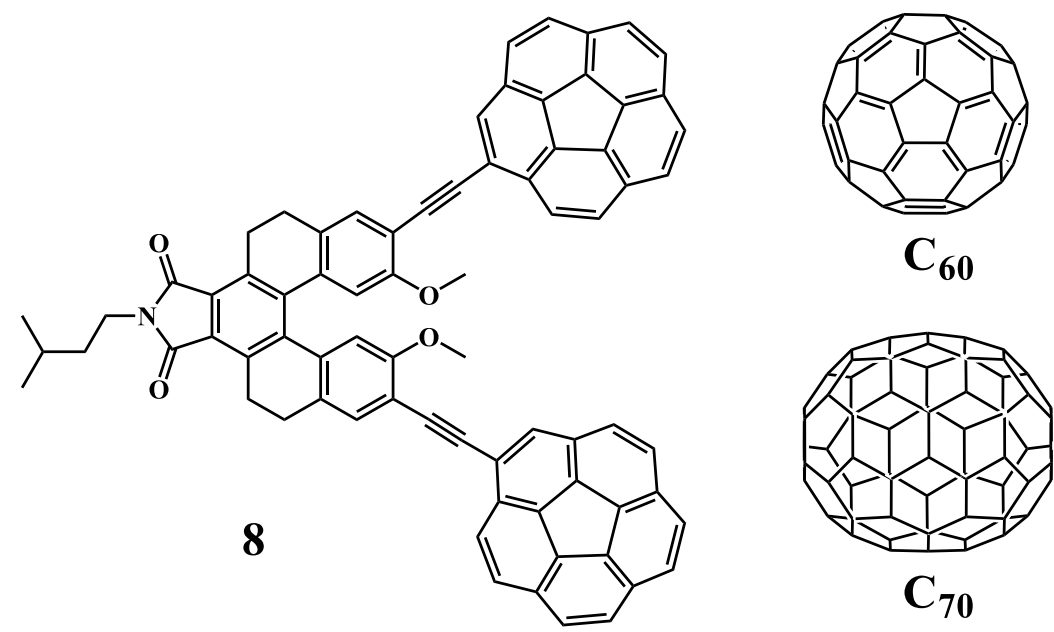

Figura 12. Estructura basada en un derivado de [5]heliceno que ha demostrado una asombrosa selectividad hacia $\mathrm{C}_{70}$.

90 H. Barbero, S. Ferrero, L. Álvarez-Miguel, P. Gómez-lglesias, D. Miguel, C. M. Álvarez, Chem. Commun., 2016, 52, 12964-12967.

91 D.-C. Yang, M. Li, C.-F. Chen, Chem. Commun., 2017, 53, 9336-9339. 


\subsection{Sistemas tris-coranuleno}

A consecuencia del gran éxito alcanzado por los sistemas que contenían dos restos coranuleno, surgieron nuevos estudios con el afán de buscar mejores receptores moleculares. La idea principal es que aumentando el número de unidades de coranuleno dentro de una misma molécula podrían aumentarse las interacciones de carácter $\pi$ responsables de las interacciones supramoleculares. Sin embargo, esta tarea a priori sencilla presenta algunos problemas, ya que si la estructura que contiene los restos aromáticos no es la adecuada puede generar la existencia de posibles efectos estéricos. Con el objetivo de evitar dicha limitación práctica, se diseñaron sistemas moleculares que permitían una gran libertad de movimiento de las unidades de coranuleno, para de esta manera buscar la mejor acomodación posible para encapsular fullerenos.

Sólo existen dos trabajos publicados que contienen sistemas tris-coranuleno, todos ellos basados en sistemas flexibles proporcionados por grupos metileno, desarrollados tanto por Sygula $(\mathbf{9} \text {, Figura 13a })^{92}$ como por nuestro grupo de investigación $\left(\mathbf{1 0}\right.$ y 11, Figura $13 \mathrm{~b}$ y c).$^{93}$

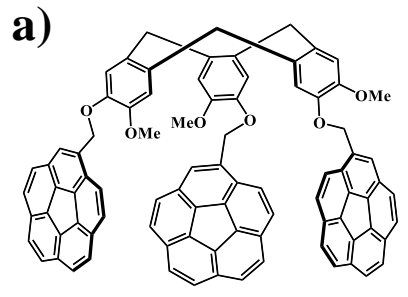

b)

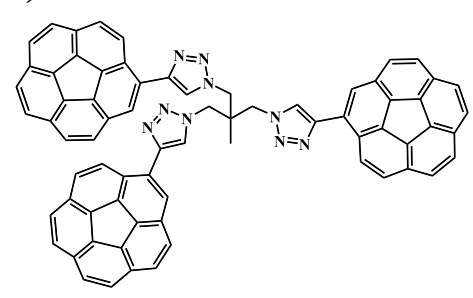

10 c)

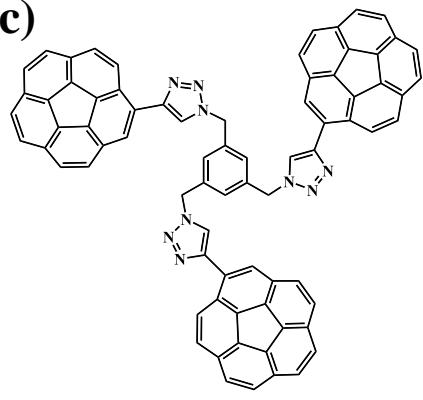

11

Figura 13. Los únicos ejemplos encontrados en la actualidad que contienen tres unidades de coranuleno.

Los estudios supramoleculares por RMN muestran un comportamiento muy similar para las tres moléculas de la Figura 13 , con $\mathrm{K}$ del orden de $10^{3} \mathrm{M}^{-1}$ para $\mathrm{C}_{60}$ (tolueno- $d_{8}$, estequiometría 1:1). Los cálculos computacionales realizados revelaron que el gran número de conformaciones de la molécula 9 permitían una interacción estable por apilamiento $\pi$ entre los grupos coranuleno. Este resultado ha quedado patente en los valores de las constantes de asociación, que son más bajas de lo esperado debido a procesos entrópicos y de solvatación. Por otra parte, la estructura optimizada del compuesto 10, sólo exhibe la interacción con dos unidades de coranuleno con la superficie del Buckminsterfullereno. La tercera unidad se encuentra orientada en posición perpendicular al fullereno lo que sugiere una interacción de carácter $\mathrm{CH}-\pi$ menos efectiva.

\subsection{Sistemas tetrakis-coranuleno}

Los únicos dos ejemplos pertenecientes en este apartado se deben a nuestro grupo de investigación. En el primer caso, un núcleo de porfirina adecuadamente sustituida con cuatro restos coranulénicos proporciona la geometría adecuada que posibilita la interacción con fullerenos (12, Figura 14a). ${ }^{94}$ Además, el sistema porfirina es capaz de proporcionar una contribución extra a la interacción supramolecular por sus conocidas cualidades para la formación de interacciones supramoleculares con fullerenos (véase Apartado 2.5.3). Sin embargo, la

\footnotetext{
92 M. Yanney, A. Sygula, Tetrahedron Lett., 2013, 54, 2604-2607.

${ }^{93}$ C. M. Álvarez, G. Aullón, H. Barbero, L. A. García-Escudero, C. Martínez-Pérez, J. M. Martín-Álvarez, D. Miguel, Org. Lett., 2015, 17, 2578-2581.

${ }^{94}$ C. M. Álvarez, H. Barbero, S. Ferrero, D. Miguel, J. Org. Chem., 2016, 81, 6081-6086.
} 
porfirina 12 meso-tetrasustituida en posición meta, se ve afectada de un efecto de atropisomerismo. Este hecho genera una mezcla de cuatro confórmeros que dan lugar a espectros de ${ }^{1} \mathrm{H}$-RMN bastante complejos y a una disminución en las constantes de asociación supramoleculares. La mejor constante de asociación obtenida fue para el isómero $\alpha_{4}$ metalado ( $\mathrm{Zn}$ ) con un valor de $2.2 \cdot 10^{4} \mathrm{M}^{-1}$ (tolueno- $d_{8}$, estequiometría $1: 1$ ).

En el segundo caso, en colaboración con el grupo de investigación de Torroba, un derivado de perilenodiimida sustituido en posiciones orto con cuatro unidades aromáticas no planas se escogió como receptor de fullerenos (13, Figura 14b). ${ }^{95}$ Pese a la complejidad presente en el espectro de ${ }^{1} \mathrm{H}-\mathrm{RMN}$, pudo llevarse a cabo una valoración por esta técnica espectroscópica en tolueno- $d_{8}$ usando $\mathrm{C}_{60}$ y $\mathrm{C}_{70}$. Se encontró una estequiometría del tipo 1:2 para ambos fullerenos y mostrando una afinidad mayor hacia $\mathrm{C}_{60}\left(\mathrm{~K}_{1}=4.7 \cdot 10^{3} \mathrm{M}^{-1}\right.$ y $\left.\mathrm{K}_{2}=2.8 \cdot 10^{3} \mathrm{M}^{-1}\right)$ frente a $\mathrm{C}_{70}\left(\mathrm{~K}_{1}=\right.$ $1.5 \cdot 10^{3} \mathrm{M}^{-1}$ y K$\left._{2}=2.2 \cdot 10^{2} \mathrm{M}^{-1}\right)$.

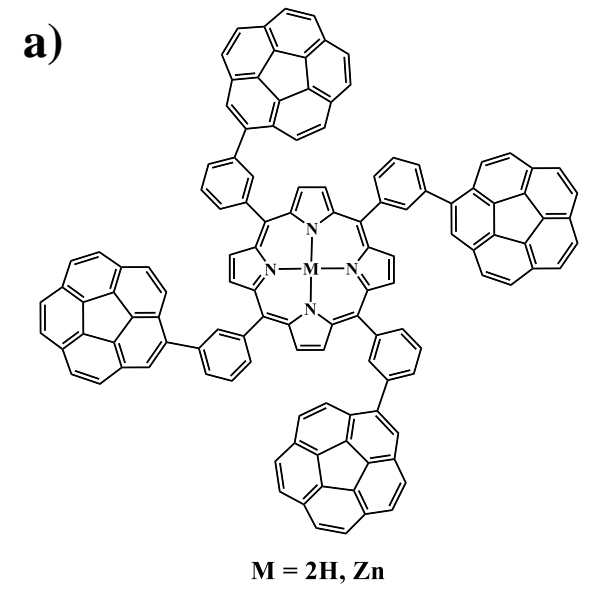

12 b)

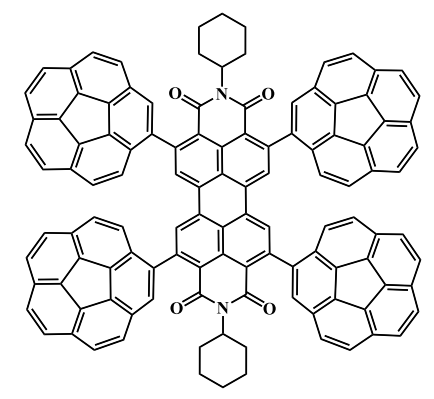

13

Figura 14. Distintas arquitecturas moleculares funcionalizadas con cuatro unidades de coranuleno.

\subsection{Polímeros basados en coranuleno}

En este último apartado, cabe citar los trabajos con diferentes tipos de polímeros basados en coranuleno realizados por Stuparu. En el primer ejemplo, un polímero en forma de estrella generado por un núcleo aromático de coranuleno es capaz de interaccionar con $\mathrm{C}_{60}$. La asociación supramolecular se evaluó de forma cualitativa mediante RMN de ${ }^{13} \mathrm{C}\left\{{ }^{1} \mathrm{H}\right\}$ en cloroformo deuterado. ${ }^{96}$ En el segundo caso, un copolímero de bloque anfifílico que contiene restos de coranuleno y $\mathrm{PEG}$, demostró excelentes propiedades para encapsular $\mathrm{C}_{60}$ en agua, siendo el primer ejemplo de una dispersión homogénea de este fullereno en agua. ${ }^{97}$

\footnotetext{
95 V. García-Calvo, J. V. Cuevas, H. Barbero, S. Ferrero, C. M. Álvarez, J. A. González, B. Díaz de Greñu, J. García-Calvo, T. Torroba, Org. Lett., 2019, 21, 5803-5807.

${ }_{96}$ M. C. Stuparu, J. Polym. Sci., Part A: Polym. Chem., 2012, 50, 2641-2649.

${ }_{97}$ M. C. Stuparu, Angew. Chem. Int. Ed., 2013, 52, 7786-7790.
} 


\subsection{SISTEMAS AROMÁTICOS BASADOS EN PORFIRINAS}

Las porfirinas son un grupo macrocíclico orgánico basado en azaanulenos aromáticos de 18 electrones $\pi$ conjugados, formados por pirroles conectadas entre sí por puentes de carbono tipo metino. El nombre de "porfirina" deriva del griego $\pi о \rho \varphi v ́ \rho \alpha$ (porfýra) cuyo significado es púrpura en castellano, debido al color tan intenso y característico que presentan estos compuestos. Son una clase de cromóforos pertenecientes a la extensa familia porfirinoide que están constituidos por las diferentes uniones posibles entre las entidades pirrólicas. Los sistemas porfirinoides incluyen estructuras muy diversas del tipo: clorinas, corroles, bacterioclorinas, subporfirinas, $\mathrm{N}-$ confundido porfirinas y porfirinas expandidas, entre otras. ${ }^{98}$

A finales del siglo XIX y principios del siglo XX, Nencki aisló la primera porfirina pura obtenida directamente de la hemina, que es una variante de la hemoglobina. ${ }^{99}$ La estructura de este macrociclo fue propuesta en un principio por Küster en $1912^{100}$ y confirmada a posteriori por los trabajos sintéticos de Fisher, ${ }^{101}$ pese a que inicialmente rechazó dicha estructura aludiendo a que un anillo de tales dimensiones no sería estable. Más adelante, el mismo Hans Fisher fue galardonado con el premio Nobel de Química en 1930 por sus investigaciones en este campo.

Las porfirinas son consideradas como los "pigmentos de la vida", ${ }^{102}$ por su extrema importancia dentro de los productos naturales, ya que estos macrociclos están presentes en sistemas biológicos que realizan funciones tan vitales como el transporte y almacenamiento de oxígeno en hemoglobinas y mioglobinas; ${ }^{103}$ o la transferencia de energía y electrones en citocromos y clorofilas. ${ }^{104}$ Otro ejemplo importante, es el perteneciente a la vitamina $\mathrm{B}_{12} \mathrm{O}$ cianocobalamina, que contiene un anillo porfirinoide derivado de corrina, esencial en la formación de eritrocitos y al mantenimiento del sistema nervioso central (Figura 15). ${ }^{105}$

Además, estas estructuras macrocíclicas han sido muy utilizados en diferentes campos de investigación por sus diversas aplicaciones como sensores químicos, cristales líquidos, células solares, medicina y catálisis, ${ }^{35 c, 106}$ entre otras. En nuestro caso, tienen un interés especial debido a dos motivos principales. Por una parte, nos servirán como el "esqueleto" básico sobre el cual se van a construir diversas arquitecturas moleculares. Por otra parte, las porfirinas muestran una

\footnotetext{
98 (a) S. Saito, A. Osuka, Angew. Chem. Int. Ed., 2011, 50, 4342-4373, (b) M. Toganoh, H. Furuta, Chem. Commun., 2012, 48, 937-954, (c) C. G. Claessens, D. González-Rodríguez, M. S. Rodríguez-Morgade, A. Medina, T. Torres, Chem. Rev., 2014, 114, 2192-2277, (d) B. Szyszko, L. Latos-Grażyński, Chem. Soc. Rev., 2015, 44, 3588-3616, (e) B. Szyszko, M. J. Białek, E. Pacholska-Dudziak, L. Latos-Grażyński, Chem. Rev., 2017, 117, 2839-2909.

99 (a) M. Nencki, N. Sieber, Arch. Explt. Path. Pharmakol., 1884, 18, 401, (b) M. Nencki, J. Z. Zaleski, Z. Physiol. Chem., 1901, 34, 997.

100 W. Küster, Z. Physiol. Chem., 1912, 82, 463-483.

101 (a) H. Fischer, J. Klarer, Liebigs Ann. Chem., 1926, 440, 181-201, (b) H. Fischer, K. Zeile, Liebigs Ann. Chem., 1929, 468, 98-116.

102 (a) A. R. Battersby, C. J. R. Fookes, G. W. J. Matcham, E. McDonald, Nature, 1980, 285, 17-21, (b) A. R. Battersby, Nat. Prod. Rep., 2000, 17, 507-526.

${ }^{103}$ C. J. Reedy, B. R. Gibney, Chem. Rev., 2004, 104, 617-650.

104 (a) I. G. Denisov, T. M. Makris, S. G. Sligar, I. Schlichting, Chem. Rev., 2005, 105, 2253-2278, (b) O. M. Senge, A. A. Ryan, A. K. Letchford, A. S. MacGowan, T. Mielke, Symmetry, 2014, 6, 781-843.

105 (a) H. W. Baik, R. M. Russell, Annu. Rev. Nutr., 1999, 19, 357-377, (b) M. J. Koury, P. Ponka, Annu. Rev. Nutr., 2004, 24, 105-131.

${ }^{106}$ (a) K. M. Kadish, K. M. Smith, R. Guilard, Handbook of Porphyrin Science: with Applications to Chemistry, Physics, Materials Science, Engineering, Biology and Medicine, World Scientific Publishing Company, Singapore, 2010, (b) H. Dong, H. Zhu, Q. Meng, X. Gong, W. Hu, Chem. Soc. Rev., 2012, 41, 1754-1808, (c) L.-L. Li, E. W.-G. Diau, Chem. Soc. Rev., 2013, 42, 291-304, (d) S. H. A. M. Leenders, R. Gramage-Doria, B. de Bruin, J. N. H. Reek, Chem. Soc. Rev., 2015, 44, 433-448, (e) Y. Ding, W.-H. Zhu, Y. Xie, Chem. Rev., 2017, $117,2203-2256$.
} 
excelente habilidad para establecer interacciones supramoleculares con fullerenos, tema que es comentado en el Apartado 2.5.3

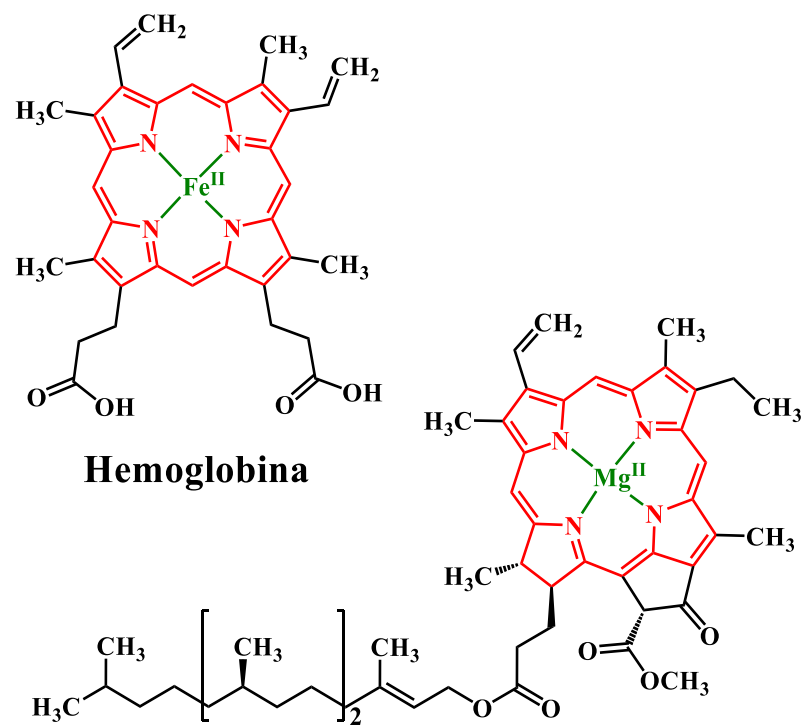

Clorofila A

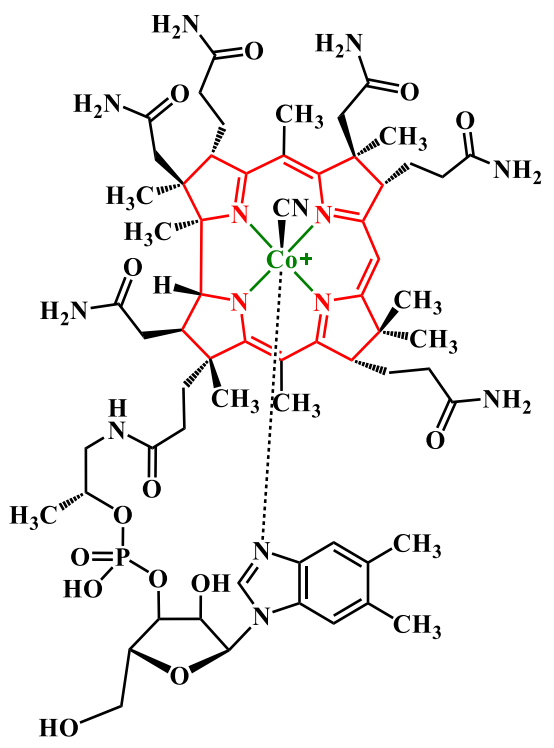

Cianocobalamina

Figura 15. Distintas moléculas encontradas en la naturaleza que están constituidas por un anillo de porfirina o derivado.

\subsubsection{Geometría y propiedades}

El esqueleto básico de porfirina está formado por cuatro unidades de pirrol interconectados entre sí por ambos carbonos alfa $(\alpha)$ mediante puentes metino (meso carbonos). Asimismo, pueden presentar sustitución en las posiciones beta del pirrol $(\beta)$ o en los meso carbonos que enlazan las unidades pirrólicas (Figura 16). ${ }^{107}$ Debido a la existencia de dos grupos NH deprotonables en el interior del anillo de porfirina, ésta es susceptible de actuar como un ligando quelato e introducir un metal en la cavidad resultante. ${ }^{108}$ Además, las porfirinas pueden protonarse a través de los nitrógenos internos formando especies catiónicas. ${ }^{109}$ Por su naturaleza aromática, los 18 electrones $\pi$ conjugados cumplen la regla de Hückel de aromaticidad $(4 n+2)$ y el núcleo de porfirina presenta una geometría plana (Figura 16). Aunque factores tales como la coordinación con metales, efectos estéricos de los sustituyentes en beta o meso, alquilación de los nitrógenos pirrólicos o protonación de los mismos, pueden distorsionar la estructura planar del macrociclo. Todos estos factores afectan a las propiedades fotofísicas, redox, catalíticas o biológicas de las porfirinas. ${ }^{110}$

107 G. P. Moss, Eur. J. Biochem., 1988, 178, 277-328.

${ }^{108}$ C. M. Lemon, P. J. Brothers, B. Boitrel, Dalton Trans., 2011, 40, 6591-6609.

109 M. J. Webb, N. Bampos, Chem. Sci., 2012, 3, 2351-2366.

${ }^{110}$ (a) K. M. Barkigia, M. D. Berber, J. Fajer, C. J. Medforth, M. W. Renner, K. M. Smith, J. Am. Chem. Soc., 1990, 112, 8851-8857, (b) K. M. Kadish, F. D'Souza, A. Villard, M. Autret, E. Van Caemelbecke, P. Bianco, A. Antonini, P. Tagliatesta, Inorg. Chem., 1994, 33, 5169-5170, (c) J. A. Shelnutt, X.-Z. Song, J.-G. Ma, S.-L. Jia, W. Jentzen, C. J. Medforth, C. J. Medforth, Chem. Soc. Rev., 1998, 27, 31-42, (d) R. E. Haddad, S. Gazeau, J. Pécaut, J.-C. Marchon, C. J. Medforth, J. A. Shelnutt, J. Am. Chem. Soc., 2003, 125, 1253-1268, (e) M. O. Senge, S. A. MacGowan, J. M. O'Brien, Chem. Commun., 2015, 51, 17031-17063, (f) M. Roucan, M. Kielmann, S. J. Connon, S. S. R. Bernhard, M. O. Senge, Chem. Commun., 2018, 54, 26-29. 


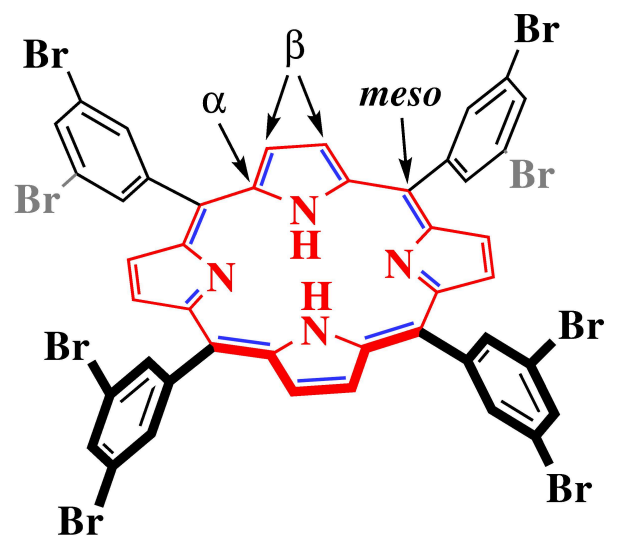

Figura 16. Disposición tridimensional de una porfirina desarrollada en esta memoria, indicando, además, las distintas posiciones relevantes del anillo aromático. Los dobles enlaces pertenecientes a los 18 electrones $\pi$ conjugados se encuentran indicados en la figura de color azul.

El alto grado de conjugación aromático ${ }^{111}$ proporciona una elevada estabilidad al sistema macrocíclico, generando adicionalmente una serie de características importantes que se reflejan en sus propiedades espectroscópicas. La corriente de anillo generada en el proceso de deslocalización electrónica origina efectos anisotrópicos, provocando cambios reseñables en las señales pertenecientes en los espectros de ${ }^{1} \mathrm{H}$ de $\mathrm{RMN}$. Así, los protones más externos pertenecientes al anillo ( $\beta$ y meso), sufren un efecto de desapantallamiento que se traduce en desplazamientos químicos a un campo bajo $(\delta \sim 8$ y $11 \mathrm{ppm})$. Los protones internos $\mathrm{NH}$ del anillo, experimentan un apantallamiento a valores de campo muy alto, que dan lugar a señales características $\left(\delta \sim-2\right.$ y -4 ppm). ${ }^{112}$ Dicha conjugación también es responsable de las bandas de absorción muy intensas en la región UV-Vis, siendo este el motivo por el cual estos compuestos son muy coloreados en disolución. Las porfirinas muestran espectros de absorción muy característicos, mostrando una banda muy intensa en la región del ultravioleta cercano, denominada banda B o Soret $(390-425 \mathrm{~nm})$, dependiendo si la porfirina presenta $\beta$ o meso sustitución; así como de cuatro bandas, a mayores longitudes de onda, en la región del visible (480 - $650 \mathrm{~nm}$ ), pero de mucha menor intensidad, llamadas bandas Q. Éstas últimas bandas son muy sensibles a los procesos de coordinación de porfirinas con metales (metaloporfirinas), ya que su número se reduce a dos bandas tras la formación del complejo metálico. Por último, todas las bandas asociadas a transiciones $\pi-\pi^{*}$ implicados en estos procesos de absorción, pueden explicarse de forma satisfactoria por el modelo de cuatro orbitales de Martin Gouterman. ${ }^{113}$

Otro aspecto que puede ser estudiado mediante experimentos de RMN a temperatura variable, es el efecto tautomérico de los protones interiores anclados a los nitrógenos. ${ }^{114} \mathrm{Tal}$ proceso dinámico es el responsable del ensanchamiento de las resonancias en las posiciones alfa

111 (a) M. Bröring, Angew. Chem. Int. Ed., 2011, 50, 2436-2438, (b) J. I. Wu, I. Fernández, P. v. R. Schleyer, J. Am. Chem. Soc., 2013, 135, 315-321.

112 (a) E. D. Becker, R. B. Bradley, J. Chem. Phys., 1959, 31, 1413-1414, (b) J. Ellis, A. H. Jackson, G. W. Kenner, J. Lee, Tetrahedron Lett., 1960, 1, 23-27, (c) E. D. Becker, R. B. Bradley, C. J. Watson, J. Am. Chem. Soc., 1961, 83, 3743-3748.

113 (a) M. Gouterman, J. Chem. Phys., 1959, 30, 1139-1161, (b) M. Gouterman, J. Mol. Spectrosc., 1961, 6, 138-163, (c) M. Gouterman, G. H. Wagnière, L. C. Snyder, J. Mol. Spectrosc., 1963, 11, 108-127.

${ }^{114}$ (a) C. B. Storm, Y. Teklu, J. Am. Chem. Soc., 1972, 94, 1745-1747, (b) R. J. Abraham, G. E. Hawkes, K. M. Smith, Tetrahedron Lett., 1974, 15, 1483-1486. 
y beta observada en la espectroscopía de $\mathrm{RMN} \mathrm{de}{ }^{13} \mathrm{C}$, promoviendo en algunos casos la completa desaparición de esas señales. ${ }^{115}$

\subsubsection{Métodos de síntesis de porfirinas}

La síntesis de porfirinas depende del grado de sustitución que presenten en las posiciones meso. De este modo, una porfirina simétrica puede obtenerse partiendo de un aldehído y pirrol apropiados. Dicha síntesis involucra ocho reacciones de sustitución electrófila aromática $\left(\mathrm{S}_{\mathrm{E}} \mathrm{Ar}\right)$ catalizada en medio ácido, en el que un electrófilo remplaza a un hidrógeno en el anillo aromático de la posición $\alpha$ del pirrol. Tras la posterior ciclación intramolecular final se forma un macrociclo no aromático denominado porfirogeno, que tras un último paso de oxidación genera como resultado la porfirina (Esquema 4). Debido al gran número de subproductos que pueden llegar a formarse, tales como derivados poliméricos de pirrol, los rendimientos globales no son muy elevados, oscilando entre un $6 \%$ y un $40 \%$.

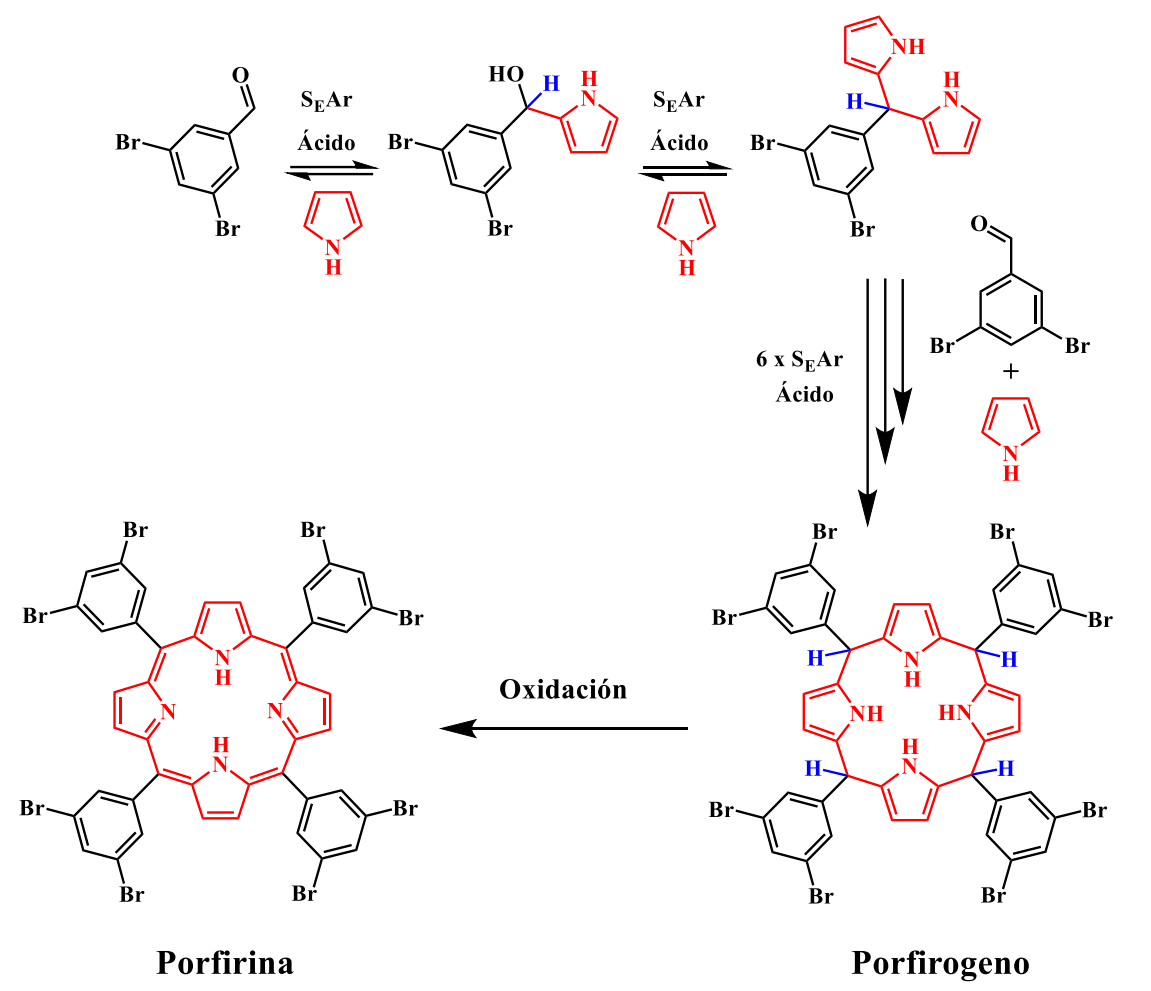

Esquema 4. Mecanismo de formación de una porfirina meso-sustituida simétrica sintetizada en este trabajo.

La primera meso-tetrafenilporfirina sintetizada fue obtenida por Rothemund haciendo reaccionar pirrol y benzaldehído en un tubo sellado con piridina. Los rendimientos obtenidos fueron bastante bajos $(4-5 \%)$ debido a las condiciones tan drásticas de temperatura y tiempo empleados $\left(150^{\circ} \mathrm{C}, 24 \mathrm{~h}\right) .{ }^{116}$ Las investigaciones posteriores se centraron en obtener rendimientos más elevados empleando condiciones de reacción más suaves. De esta manera, el grupo de Adler y Longo, modificando el método anterior, lograron alcanzar unos rendimientos entorno al 16 $20 \%$. Para ello hicieron reaccionar pirrol y benzaldehído bajo condiciones aerobias en ácido

115 R. J. Abraham, H. Pearson, K. M. Smith, J. Am. Chem. Soc., 1976, 98, 1604-1606.

116 (a) P. Rothemund, J. Am. Chem. Soc., 1935, 57, 2010-2011, (b) P. Rothemund, J. Am. Chem. Soc., 1936, $58,625-627$. 
propiónico a reflujo $\left(140^{\circ} \mathrm{C}, 30 \mathrm{~min}\right) .{ }^{117}$ En la mitad de la década de los años 80 , Lindsey et al. empleó ácidos de Lewis $\left(\mathrm{BF}_{3} \cdot \mathrm{Et}_{2} \mathrm{O}\right)$ en cantidades catalíticas para la síntesis de tetraarilporfirinas en condiciones de equilibrio termodinámico. Posteriormente, sobre el mismo medio de reacción, se utilizó 2,3-dicloro-5,6-diciano-1,4-benzoquinona (DDQ) para la oxidación del macrociclo de porfirogeno para finalmente generar la porfirina meso-sustituida correspondiente. Los rendimientos obtenidos por el método de Lindsey se encuentran entre un $30-40 \%,{ }^{118}$ mejorando los de sus predecesores. En la actualidad, las síntesis de porfirinas simétricas están basadas en algunas modificaciones de los últimos métodos comentados en este párrafo. ${ }^{119}$

Para la obtención de porfirinas asimétricas, por ejemplo, las denominadas como ABCD por mostrar un patrón de sustitución diferente en cada posición meso, se requieren de estrategias sintéticas más elaboradas y los rendimientos no suelen ser muy elevados. ${ }^{120}$

Recientemente, la síntesis química asistida por microondas ha sido muy utilizada en el campo de la Química Orgánica, debido a las ventajas derivadas de este método: reducción significativa en los tiempos de reacción, disminución de productos no deseados y de los volúmenes de disolventes empleados. ${ }^{121}$ Por todas estas virtudes mencionadas, la síntesis por radiación con microondas también ha sido aplicada para la obtención de porfirinas de diferentes grados de complejidad, ${ }^{122}$ siendo el método sintético empleado para la obtención de las porfirinas simétricas meso-sustituidas de esta memoria.

\subsubsection{Interacciones supramoleculares entre fullerenos y porfirinas}

La primera evidencia que reflejaba la existencia de la atracción entre la superficie $\pi$ plana del anillo de porfirina y la superficie $\pi$ curvada del fullereno se encontró en estado sólido. Los datos cristalográficos obtenidos mostraron distancias de contacto presentes en los complejos de cocristalización porfirina-fullereno $(2.7-3.0 \AA)$, por debajo de los radios de van der Waals (contacto átomo-átomo de carbono del fullereno a los átomos de $\mathrm{N}$ de la porfirina). ${ }^{123}$

Las interacciones supramoleculares involucradas entre la porfirina y $\mathrm{C}_{60}$ son del tipo electrostático, van der Waals o transferencia de carga (donador-aceptor). ${ }^{124}$ Estas interacciones son de carácter muy débil o casi nula en disolución para una única molécula de porfirina y

117 (a) A. D. Adler, F. R. Longo, W. Shergalis, J. Am. Chem. Soc., 1964, 86, 3145-3149, (b) A. D. Adler, F. R. Longo, J. D. Finarelli, J. Goldmacher, J. Assour, L. Korsakoff, J. Org. Chem., 1967, 32, 476-476.

118 (a) J. S. Lindsey, H. C. Hsu, I. C. Schreiman, Tetrahedron Lett., 1986, 27, 4969-4970, (b) J. S. Lindsey, I. C. Schreiman, H. C. Hsu, P. C. Kearney, A. M. Marguerettaz, J. Org. Chem., 1987, 52, 827-836.

${ }^{119}$ (a) A. M. d. A. R. Gonsalves, J. M. T. B. Varejão, M. M. Pereira, J. Heterocycl. Chem., 1991, 28, 635-640, (b) K. M. Smith, New J. Chem., 2016, 40, 5644-5649.

120 M. O. Senge, Chem. Commun., 2011, 47, 1943-1960.

${ }^{121}$ (a) P. Lidström, J. Tierney, B. Wathey, J. Westman, Tetrahedron, 2001, 57, 9225-9283, (b) C. O. Kappe, Angew. Chem. Int. Ed., 2004, 43, 6250-6284, (c) N. Sharma, U. K. Sharma, E. V. Van der Eycken, in Green Techniques for Organic Synthesis and Medicinal Chemistry, eds. W. Zhang and B. W. Cue, Wiley, New York, 2018, ch. 17, pp. 441-468.

122 (a) S. M. S. Chauhan, B. B. Sahoo, K. A. Srinivas, Synth. Commun., 2001, 31, 33-37, (b) B. F. O. Nascimento, M. Pineiro, A. M. d. A. Rocha Gonsalves, M. Ramos Silva, A. Matos Beja, J. A. Paixão, J. Porphyrins Phthalocyanines, 2007, 11, 77-84, (c) R. De Paula, M. A. F. Faustino, D. C. G. A. Pinto, M. G. P. M. S. Neves, J. A. S. Cavaleiro, J. Heterocycl. Chem., 2008, 45, 453-459, (d) M. Pineiro, Curr. Org. Synth., 2014, 11, 89-109.

${ }^{123}$ (a) Y. Sun, T. Drovetskaya, R. D. Bolskar, R. Bau, P. D. W. Boyd, C. A. Reed, J. Org. Chem., 1997, 62, 36423649, (b) P. D. W. Boyd, M. C. Hodgson, C. E. F. Rickard, A. G. Oliver, L. Chaker, P. J. Brothers, R. D. Bolskar, F. S. Tham, C. A. Reed, J. Am. Chem. Soc., 1999, 121, 10487-10495.

${ }^{124}$ (a) D. Sun, F. S. Tham, C. A. Reed, L. Chaker, P. D. W. Boyd, J. Am. Chem. Soc., 2002, 124, 6604-6612, (b) Y.-B. Wang, Z. Lin, J. Am. Chem. Soc., 2003, 125, 6072-6073, (c) P. D. W. Boyd, C. A. Reed, Acc. Chem. Res., 2005, 38, 235-242. 
fullereno, ${ }^{123 b, 124 a, c}$ posiblemente por no presentar una complementariedad de tamaño y forma adecuadas entre las especies comprometidas. Pese a que estas interacciones no se observan en disolución, si se encuentran patentes en estado sólido, como ha sido comentado con anterioridad, encontrándose un gran número de publicaciones al respecto. ${ }^{125}$ Sin embargo, existen algunos raros ejemplos que demuestran cómo una simple unidad de porfirina puede llegar a establecer aductos supramoleculares con fullerenos en disolución. Para que esto suceda el núcleo $\pi$ plano debe de adoptar una geometría parcialmente curvada, alejándose de la planaridad característica de las porfirinas. ${ }^{126}$

En lo que respecta a estructuras no monoméricas, constituidas por más de una unidad de porfirina, el primer dímero que demostró la habilidad para establecer aductos de inclusión efectivos con $C_{60}$ en disolución, fue descrito por Aida, Saigo y colaboradores en 1999. ${ }^{127}$ A partir de este punto se han utilizado sistemas que contenían bis-, tris- o multi unidades de porfirinas. Por ejemplo, disposiciones en forma de pinza, caja, jaula o anular que han demostrado una tremenda efectividad para formar complejos muy estables con fullerenos, reflejándose en los excelentes valores encontradas para las constantes de asociación. ${ }^{128}$ En estos casos, el carácter del espaciador que enlaza los diferentes motivos de porfirina y la naturaleza del metal coordinado en el anillo, ${ }^{129}$ son dos de los factores que afectan de forma decisiva a las propiedades de reconocimiento supramolecular hacia fullerenos.

Finalmente, cabe resaltar que las interacciones existentes entre las construcciones porfirinafullereno ha sido ampliamente estudiadas por sus enormes e interesantes aplicaciones en fotovoltaica orgánica y fotosíntesis artificial. ${ }^{28 c, 130}$

En esta memoria en los Artículos I, II y III hemos desarrollado sistemas moleculares que contienen un núcleo de porfirina como componente principal de unión entre los diferentes restos aromáticos planos (pireno) y no planos (coranuleno) con el fin de estudiar las interacciones supramoleculares con fullerenos resultantes.

${ }^{125}$ (a) M. M. Olmstead, D. A. Costa, K. Maitra, B. C. Noll, S. L. Phillips, P. M. Van Calcar, A. L. Balch, J. Am. Chem. Soc., 1999, 121, 7090-7097, (b) T. Ishii, N. Aizawa, M. Yamashita, H. Matsuzaka, T. Kodama, K. Kikuchi, I. Ikemoto, Y. Iwasa, J. Chem. Soc., Dalton Trans., 2000, 4407-4412, (c) P. Bhyrappa, K. Karunanithi, Inorg. Chem., 2010, 49, 8389-8400, (d) P. Bhyrappa, U. K. Sarangi, B. Varghese, Eur. J. Inorg. Chem., 2014, 2014, 5646-5650, (e) M. Roy, M. M. Olmstead, A. L. Balch, Cryst. Growth Des., 2019, 19, 6743-6751.

${ }^{126}$ (a) Y. Saegusa, T. Ishizuka, T. Kojima, S. Mori, M. Kawano, T. Kojima, Chem. Eur. J., 2015, 21, 5302-5306, (b) M. Yamada, G. Murakami, S. Kobayashi, Y. Maeda, Tetrahedron Lett., 2017, 58, 4514-4518.

${ }^{127}$ K. Tashiro, T. Aida, J.-Y. Zheng, K. Kinbara, K. Saigo, S. Sakamoto, K. Yamaguchi, J. Am. Chem. Soc., 1999, 121, 9477-9478.

128 (a) H. Uno, M. Furukawa, A. Fujimoto, H. Uoyama, H. Watanabe, T. Okujima, H. Yamada, S. Mori, M. Kuramoto, T. Iwamura, N. Hatae, F. Tani, N. Komatsu, J. Porphyrins Phthalocyanines, 2011, 15, 951-963, (b) C. García-Simón, M. Costas, X. Ribas, Chem. Soc. Rev., 2016, 45, 40-62, (c) L. Moreira, J. Calbo, J. Aragó, B. M. Illescas, I. Nierengarten, B. Delavaux-Nicot, E. Ortí, N. Martín, J.-F. Nierengarten, J. Am. Chem. Soc., 2016, 138, 15359-15367, (d) N. Fukui, T. Kim, D. Kim, A. Osuka, J. Am. Chem. Soc., 2017, 139, 9075-9088, (e) S. Xue, D. Kuzuhara, N. Aratani, H. Yamada, Org. Lett., 2019, 21, 2069-2072, (f) S. Mori, N. Kawamoto, H. Uno, ChemPlusChem, 2019, 84, 686-693.

129 (a) K. Tashiro, T. Aida, Chem. Soc. Rev., 2007, 36, 189-197, (b) D. V. Konarev, S. S. Khasanov, R. N. Lyubovskaya, Coord. Chem. Rev., 2014, 262, 16-36, (c) L. Moreira, J. Calbo, B. M. Illescas, J. Aragó, I. Nierengarten, B. Delavaux-Nicot, E. Ortí, N. Martín, J.-F. Nierengarten, Angew. Chem. Int. Ed., 2015, 54, 1255-1260, (d) P. Mondal, S. P. Rath, Coord. Chem. Rev., 2020, 405, 213117.

${ }^{130}$ (a) D. M. Guldi, Chem. Soc. Rev., 2002, 31, 22-36, (b) H. Imahori, S. Fukuzumi, Adv. Funct. Mater., 2004, 14, 525-536, (c) H. Imahori, Org. Biomol. Chem., 2004, 2, 1425-1433, (d) D. Gust, T. A. Moore, A. L. Moore, Acc. Chem. Res., 2009, 42, 1890-1898, (e) F. D'Souza, O. Ito, Chem. Commun., 2009, 4913-4928, (f) J.-F. Nierengarten, Eur. J. Inorg. Chem., 2019, 2019, 4865-4878. 
3. OBJETIVOS 


\section{OBJETIVOS}

Siguiendo los trabajos precedentes dentro del grupo de investigación se han establecido unos objetivos generales que, a lo largo del trabajo experimental desarrollado durante esta tesis, han posibilitado la generación de otros objetivos con carácter más específico.

\subsection{OBJETIVOS GENERALES}

Desarrollar una metodología sintética con el propósito de funcionalizar hidrocarburos policíclicos aromático planos y no planos, centrados en pireno y coranuleno, para lograr derivados moleculares que, haciendo uso de interacciones supramoleculares, sean susceptibles de actuar como eficientes receptores de fullerenos.

Desarrollar una metodología sintética para la obtención de porfirinas simétricas arilsustituidas en posiciones meso con el objeto de actuar como armazón para el anclaje de derivados poliaromáticas planos y no planos.

\subsection{OBJETIVOS ESPECÍFICOS}

Desarrollar construcciones moleculares basadas en porfirinas para establecer complejos de inclusión con fullerenos. Además, también se estudiará la coordinación de metales dentro del núcleo de porfirina para producir metaloporfirinas y se evaluará las interacciones supramoleculares con fullerenos.

Utilizar el uso de reacciones de acoplamiento carbono-carbono arílico catalizada con paladio para la funcionalización de porfirinas meso sustituidas con múltiples restos poliaromáticos planos y no planos.

Preparar arquitecturas que presenten múltiples centros de unión supramolecular (multivalencia) y estudiar los posibles efectos alostéricos.

Estudiar los efectos sinérgicos que podrían producirse entre los diferentes restos poliaromáticos planos y no planos con el macrociclo de porfirina. 


\section{METODOLOGÍA EMPLEADA}




\section{METODOLOGÍA EMPLEADA}

Este apartado resume los procedimientos llevados a cabo durante la realización del trabajo experimental y se ha dividido en las siguientes categorías.

\subsection{METODOLOGIA SINTÉTICA}

El conjunto de reacciones mencionadas en esta memoria se ha realizado empleando técnicas convencionales de un laboratorio de investigación sintética. Cuando fue necesario el uso de atmósferas en ausencia de oxígeno y agua, se utilizaron técnicas de Schlenk usando nitrógeno como gas inerte.

Los disolventes se adquirieron de fuentes comerciales y un número limitado ellos (DCM, $\mathrm{CHCl}_{3}$, n-hexano y AcOEt) se destilaron antes de su uso. Otros disolventes (DCM, 1,4 - dioxano y tolueno) se secaron siguiendo los procedimientos convencionales cuando era necesario la ausencia de humedad en la reacción. ${ }^{131}$ Todos los reactivos fueron suministrados por casas comerciales y usados sin previa purificación, a excepción del pirrol que fue destilado y el NBS que se recristalizó antes de su uso. El catalizador de paladio utilizado $\left[\mathrm{PdCl}_{2}(\mathrm{dppf})\right]$ se obtuvo según métodos descritos en la bibliografía. ${ }^{132}$

La mayoría de las reacciones de síntesis descritas en esta memoria se llevaron a cabo asistidas por radiación con microondas. Se empleó un reactor Anton Paar Monowave 300 usando viales acondicionados para tal fin de $10 \mathrm{~mL}$ ó $30 \mathrm{~mL}$ en condiciones de alta temperatura (120 $200{ }^{\circ} \mathrm{C}$ ) y presión $(3-10$ bar). El reactor de microondas carece del equipamiento para generar atmósferas inertes. Para superar esta limitación, previo a la radiación, el vial con los reactivos correspondientes se colocó en un matraz redondo de dos bocas conectado a línea Schlenk para generar un sistema bajo nitrógeno.

\subsubsection{Métodos de funcionalización}

La metodología sintética para la obtención de los derivados poliaromáticos planos y no planos de esta memoria reside en la conocida reacción de Suzuki-Miyaura. ${ }^{133}$ Esta reacción de acoplamiento cruzado catalizada con paladio permite la formación de enlaces carbono-carbono de tipo arílico entre las especies poliaromáticas planas y no planas con las estructuras moleculares de porfirina seleccionadas. La elección de este método está basada en una serie de ventajas que presenta en comparación con otras reacciones catalizados con metales de transición, como son: condiciones de reacción suaves, naturaleza menos tóxica de reactivos, disponibilidad de ácidos borónicos comerciales, tolerancia sobre un amplio rango de grupos funcionales y derivados de boro estables al aire y al agua. ${ }^{134}$

Para llevar a cabo esta reacción de acoplamiento C-C es necesario partir de derivados que contengan, por una parte, un halogenuro de arilo y por otra, un derivado de boro; ya sea en forma de ácido o protegido con grupo éster. Por consiguiente, las estructuras de porfirina y los

\footnotetext{
${ }^{131}$ (a) W. L. F. Armarego, C. L. L. Chai, Purification of Laboratory Chemicals, 6th, Butterworth-Heinemann, London, 2009, (b) D. B. G. Williams, M. Lawton, J. Org. Chem., 2010, 75, 8351-8354.

132 (a) G. K. Anderson, M. Lin, A. Sen, E. Gretz, in Inorg. Synth., ed. R. J. Angelici, John Wiley \& Sons, New York, 1990, vol. 28, pp. 60-63, (b) C. Nataro, S. M. Fosbenner, J. Chem. Educ., 2009, 86, 1412-1415.

133 (a) N. Miyaura, A. Suzuki, Chem. Rev., 1995, 95, 2457-2483, (b) S. Kotha, K. Lahiri, D. Kashinath, Tetrahedron, 2002, 58, 9633-9695, (c) S. E. Hooshmand, B. Heidari, R. Sedghi, R. S. Varma, Green Chem., 2019, 21, 381-405.
}

${ }^{134}$ A. J. J. Lennox, G. C. Lloyd-Jones, Chem. Soc. Rev., 2014, 43, 412-443. 
precursores aromáticos planos y no planos se seleccionaron con vistas a presentar esos grupos funcionales.

\subsubsection{Síntesis de precursores planos y no planos}

El pireno prístino no se ha utilizado en esta memoria debido a que el mono derivado bromado y el ácido borónico correspondientes (1-bromopireno y ácido 1-pirenoborónico) son compuestos comerciales. Sin embargo, dicho ácido comercial se protegió usando pinacol para obtener el éster borónico de pireno respectivo (1-pinacol pirenoboronato).

El compuesto de coranuleno se preparó siguiendo la síntesis actual descrita por Siegel en $2012 .{ }^{68}$ La síntesis de 1-bromocoranuleno y 1-pinacol coranulenoboronato se ha mejorado con respecto a las previamente descritas en la bibliografía. Los detalles de la síntesis están presentes en la parte experimental de los artículos.

\subsubsection{Métodos de purificación}

\subsubsection{Cromatografía en columna preparativa}

La cromatografía en columna preparativa fue la técnica de separación utilizada en la mayoría de los casos, empleándose gel de sílice (tamaño de partícula 40 - $63 \mu \mathrm{m} ; 230$ - 400 mesh) como fase estacionaria. El análisis de las mezclas de compuestos procedentes de crudos de reacción, así como las fracciones cromatográficas fueron examindas utilizando cromatografía en capa fina (TLC) con alúmina neutra o gel de sílice 60 con indicador fluorescente F254 soportado en placas de aluminio de $0.20 \mathrm{~mm}$ espesor. Para su visualización fue necesaria una lámpara UV (254 nm y $365 \mathrm{~nm}$ ) y reveladas cuando fue necesario con una disolución ácida de p-anisaldehído en EtOH seguida de una ligera calefacción.

\subsubsection{HPLC}

La separación de mezclas de fullerenos, concretamente $\mathrm{C}_{60}$ y $\mathrm{C}_{70}$, se realizó mediante HPLC por el servicio de Cromatografía del Laboratorio de Técnicas Instrumentales (LTI) de la Universidad de Valladolid. Se utilizó un cromatógrafo Agilent 1200 Series equipado con una columna C18 $(4.6 \mathrm{~mm} \times 250 \mathrm{~mm})$ y con un detector de UV-Vis $(333 \mathrm{~nm})$. La fase móvil empleada fue una mezcla de tolueno/metanol/acetonitrilo (60:20:20) conteniendo un $0.1 \%$ de ácido trifluoroacético a $30^{\circ} \mathrm{C}$. 


\subsection{CARACTERIZACIÓN DE COMPUETOS}

La identificación, pureza y determinación estructural de los compuestos descritos en esta memoria se llevó a cabo utilizando las siguientes técnicas instrumentales.

\subsubsection{Espectroscopía de Resonancia Magnética Nuclear de líquidos de alta resolución}

Los espectros de RMN de líquidos de alta resolución se adquirieron a una temperatura regulada de $25^{\circ} \mathrm{C}$ en espectrómetros Agilent $400 \mathrm{MR}(400 \mathrm{MHz}, 2$ canales), Agilent $500 \mathrm{DD} 2$ (500 MHz, 3 canales) con una sonda OneNMR y Agilent 500 DD2 (500 MHz, 3 canales) con sonda fría. Todos los espectrómetros se encuentran ubicados en las instalaciones del Laboratorio de Técnicas Instrumentales (LTI) de la Universidad de Valladolid. Los disolventes deuterados empleados se suministraron por fuentes comerciales y fueron usados sin tratamiento previo, a excepción del cloroformo- $d$ que se filtró sobre alúmina básica para eliminar trazas acidez. Se utilizaron tubos de vidrio de calidad para RMN de $18 \mathrm{~cm}$ de longitud y $5 \mathrm{~mm}$ de diámetro.

Los desplazamientos químicos $(\delta)$ se muestran en partes por millón $(\mathrm{ppm})$ y referenciados a TMS para ${ }^{1} \mathrm{H}$ y ${ }^{13} \mathrm{C}$ usando la señal residual del disolvente no deuterado como referencia interna. Para mantener la homogeneidad del campo magnético durante los experimentos se monitorizó la señal de deuterio mediante el sistema lock presente en el equipo. Las constantes de acoplamiento $(J)$ interprotónicas en el espectro de ${ }^{1} \mathrm{H}-\mathrm{RMN}$ están expresadas en hercios $(\mathrm{Hz})$ y la multiplicidad de las señales está indicada según la nomenclatura estándar: $\mathrm{s}=$ singlete, $\mathrm{d}=$ doblete, $\mathrm{t}=$ triplete, $\mathrm{m}=$ multiplete, $\mathrm{br}=$ señal ancha .

La asignación de las resonancias se realizó combinando los espectros monodimensionales $\left({ }^{1} \mathrm{H}\right.$ y ${ }^{13} \mathrm{C}\left\{{ }^{1} \mathrm{H}\right\}$ ), bidimensionales homonucleares $\left({ }^{1} \mathrm{H}-{ }^{1} \mathrm{H}\right.$ : COSY, DQFCOSY y ROESY) y heteronucleares $\left({ }^{1} \mathrm{H}^{-13} \mathrm{C}\right.$ : HSQC y HMBC) ${ }^{135} \mathrm{En}$ los casos donde la detección directa de ${ }^{13} \mathrm{C}$ fue difícil debido a la baja solubilidad del compuesto, los desplazamientos químicos de ${ }^{13} \mathrm{C}$ se detectaron de forma indirecta mediante los experimentos 2D heteronucleares. En estos casos los carbonos aparecerán reflejados con la denominación C (in). De forma complementaria, en la parte experimental de cada artículo se aporta la asignación completa y detallada de cada núcleo en los espectros de ${ }^{1} \mathrm{H}$ y ${ }^{13} \mathrm{C}\left\{{ }^{1} \mathrm{H}\right\}$.

Todos experimentos 2D se realizaron usando gradientes de campo pulsado (PFG) ${ }^{136}$ para la selección de rutas de coherencia de espines nucleares. Los experimentos $2 \mathrm{D}$ heteronucleares HSQC y HMBC fueron usados en su versión CRISIS2,${ }^{137}$ empleando pulsos BIP $^{138}$ en el canal de alta y baja frecuencia. En algunos casos, debido al carácter aromático de los compuestos descritos esta memoria, para la completa asignación de las señales, fue necesaria una gran resolución digital en la dimensión indirecta de carbono. Para ello se utilizaron secuencias con pulsos selectivos (band selective HSQC y band selective $\mathrm{HMBC})^{139}$ y empleando pulsos adiabáticos ${ }^{140}$ en el canal de ${ }^{13} \mathrm{C}$ para los pulsos de $180^{\circ}$.

\footnotetext{
135 T. D. W. Claridge, High-Resolution NMR Techniques in Organic Chemistry, 3rd ed., Elsevier, Boston, 2016.

136 T. Parella, Magn. Reson. Chem., 1998, 36, 467-495.

137 (a) R. D. Boyer, R. Johnson, K. Krishnamurthy, J. Magn. Reson., 2003, 165, 253-259, (b) R. Crouch, R. D. Boyer, R. Johnson, K. Krishnamurthy, Magn. Reson. Chem., 2004, 42, 301-307, (c) H. Hu, K. Krishnamurthy, Magn. Reson. Chem., 2008, 46, 683-689.

138 M. A. Smith, H. Hu, A. J. Shaka, J. Magn. Reson., 2001, 151, 269-283.

${ }^{139}$ C. Gaillet, C. Lequart, P. Debeire, J.-M. Nuzillard, J. Magn. Reson., 1999, 139, 454-459.

140 Ë. Kupce, R. Freeman, J. Magn. Reson. Ser. A, 1995, 117, 246-256.
} 
Para poder llevar a cabo una integración cuantitativa en las mezclas de fullerenos $\left(\mathrm{C}_{60} \mathrm{y}\right.$ $\mathrm{C}_{70}$ ) en los espectros de ${ }^{13} \mathrm{C}\left\{{ }^{1} \mathrm{H}\right\}$-RMN en tolueno- $d_{8}$ se utilizaron las siguientes condiciones de adquisicón: ${ }^{21 \mathrm{~b}, 141}$ pulso de $45^{\circ}, 1.048 \mathrm{~s}$ de tiempo de adquisición y $4 \mathrm{~s}$ de tiempo de relajación entre pulsos.

Todos los espectros fueron procesados y analizados mediante los programas MestreNova 12.0, VnmrJ3.2 y la versión libre VnmrJ4.2A (Agilent Technologies).

\subsubsection{Espectroscopía de Absorción UV-Visible}

Los espectros de absorción molecular UV-Vis en disolución se registraron a temperatura ambiente en un espectrofotómetro Shimadzu UV-1603 usando como fuentes de radiación lámparas de deuterio y wolframio. El espectro de barrido realizado comprende desde $800 \mathrm{~nm}$ hasta $200 \mathrm{~nm}$ con una velocidad de muestreo de $0.5 \mathrm{~nm}$ por paso. La adquisición y análisis se llevaron a cabo con el programa UVProbe 2.43 y el tratamiento posterior de datos con Microsoft Office Excel 365. La concentración empleada en las medidas fue lo suficientemente baja para garantizar el cumplimiento de la ley de Lambert-Bouguer-Beer. ${ }^{142}$ Los disolventes utilizados fueron de calidad espectrofotométrica y las celdas de muestra de cuarzo con un camino óptico de $1 \mathrm{~cm}$. Cuando fue necesaria la comparativa entre espectros, estos se normalizaron a la banda de mayor intensidad. Los coeficientes de absorción molar $(\varepsilon)$ y las longitudes de onda $(\lambda)$ están expresados en unidades de $\mathrm{M}^{-1} \cdot \mathrm{cm}^{-1} \mathrm{y} \mathrm{nm}$, respectivamente.

\subsubsection{Espectrometría de Masas}

Los análisis de masas de alta y baja resolución se realizaron por el servicio de Espectrometría de Masas del Laboratorio de Técnicas Instrumentales (LTI) de la Universidad de Valladolid. En todos los casos para la detección de la masa exacta (HRMS) de los compuestos se utilizó un MALDI-TOF (MALDI-TOF Bruker Autoflex Speed) empleándose las siguientes condiciones: láser de $\mathrm{N}_{2}$ (longitud de onda de $337 \mathrm{~nm}$, con pulsos de $100 \mu \mathrm{J}$ de energía y $1 \mathrm{~ns}$ de duración), voltaje de aceleración de $19 \mathrm{kV}$, en función de la muestra. Como matrices se usaron DCTB o dithranol.

141 (a) H. Ajie, M. M. Alvarez, S. J. Anz, R. D. Beck, F. Diederich, K. Fostiropoulos, D. R. Huffman, W. Kraetschmer, Y. Rubin, et al., J. Phys. Chem., 1990, 94, 8630-8633, (b) F. Diederich, R. L. Whetten, Acc. Chem. Res., 1992, 25, 119-126.

${ }^{142}$ A. Beer, Annalen der Physik, 1852, 162, 78-88. 


\subsection{MÉTODOS COMPUTACIONALES}

Todos los cálculos teóricos recogidos en los Artículos II y III han sido realizados por el Dr. Héctor Barbero San Juan, utilizando un equipo Intel Xeon E5-2680 v2 de 10 núcleos localizados en el Centro de Proceso de Datos (CPD) del Parque Científico de la Universidad de Valladolid. El programa de cálculo empleado ha sido GAUSSIAN-16 ${ }^{143}$ y los resultados visualizados en MERCURY 4.2.0. ${ }^{144}$

El compuesto bajo estudio perteneciente al Artículo II fue primeramente sometido a una búsqueda conformacional basada en mecánica molecular. Para ello se usó un sistema no periódico con tolueno como disolvente implícito y se llevó a cabo un conjunto de simulaciones dinámicas a $500 \mathrm{~K}, 1000 \mathrm{~K}$ y $2000 \mathrm{~K}$ utilizando el modelo de dinámica de Langevin y el campo de fuerzas generalizado de Amber (GAFF) con el paquete informático Amber. ${ }^{145}$ Posteriormente, los resultados fueron sometidos a análisis de grupos (clustering) y el más poblado se escogió para optimizar su geometría aplicando los métodos DFT presentes en el paquete informático de GAUSSIAN-16, usando el funcional de Grimme B97D3, que incluye la corrección de dispersión empírica de Becke-Johnson, ${ }^{146}$ y el conjunto de funciones base 6-31G(d,p) del grupo de Pople y colaboradores. ${ }^{147}$ Para el estudio de los aductos supramoleculares con fullerenos, la táctica empleada consistió en llevar a cabo varias optimizaciones con el método semi-empírico PM6 ${ }^{148}$ partiendo de una estructura que posee el fullereno sobre el núcleo de porfirina y los sustituyentes coranuleno en las orientaciones adecuadas. El mínimo más estable, con significado químico, fue sujeto de nuevo a un cálculo DFT para la optimización posterior de su geometría usando el protocolo previamente mencionado. Todos los mínimos encontrados fueron confirmados por análisis vibracionales poseyendo cero frecuencias imaginarias en todos los casos. Los cálculos de mecánica cuántica fueron realizados en fase gas. La aplicación de un modelo de disolvente implícito habría mejorado el modelo teórico, pero a su vez el tiempo de cálculo para alcanzar la

${ }^{143}$ M. J. Frisch, G. W. Trucks, H. B. Schlegel, G. E. Scuseria, M. A. Robb, J. R. Cheeseman, G. Scalmani, V. Barone, G. A. Petersson, H. Nakatsuji, X. Li, M. Caricato, A. V. Marenich, J. Bloino, B. G. Janesko, R. Gomperts, B. Mennucci, H. P. Hratchian, J. V. Ortiz, A. F. Izmaylov, J. L. Sonnenberg, Williams, F. Ding, F. Lipparini, F. Egidi, J. Goings, B. Peng, A. Petrone, T. Henderson, D. Ranasinghe, V. G. Zakrzewski, J. Gao, N. Rega, G. Zheng, W. Liang, M. Hada, M. Ehara, K. Toyota, R. Fukuda, J. Hasegawa, M. Ishida, T. Nakajima, Y. Honda, O. Kitao, H. Nakai, T. Vreven, K. Throssell, J. A. Montgomery Jr., J. E. Peralta, F. Ogliaro, M. J. Bearpark, J. J. Heyd, E. N. Brothers, K. N. Kudin, V. N. Staroverov, T. A. Keith, R. Kobayashi, J. Normand, K. Raghavachari, A. P. Rendell, J. C. Burant, S. S. Iyengar, J. Tomasi, M. Cossi, J. M. Millam, M. Klene, C. Adamo, R. Cammi, J. W. Ochterski, R. L. Martin, K. Morokuma, O. Farkas, J. B. Foresman, D. J. Fox, Gaussian 16 Rev. C.01, Wallingford, CT, 2016.

${ }^{144}$ C. F. Macrae, I. Sovago, S. J. Cottrell, P. T. A. Galek, P. McCabe, E. Pidcock, M. Platings, G. P. Shields, J. S. Stevens, M. Towler, P. A. Wood, J. Appl. Cryst., 2020, 53.

145 (a) D.A. Case, I.Y. Ben-Shalom, S.R. Brozell, D.S. Cerutti, T.E. Cheatham, III, V.W.D. Cruzeiro, T.A. Darden, R.E. Duke, D. Ghoreishi, M.K. Gilson, H. Gohlke, A.W. Goetz, D. Greene, R Harris, N. Homeyer, S. Izadi, A. Kovalenko, T. Kurtzman, T.S. Lee, S. LeGrand, P. Li, C. Lin, J. Liu, T. Luchko, R. Luo, D.J. Mermelstein, K.M. Merz, Y. Miao, G. Monard, C. Nguyen, H. Nguyen, I. Omelyan, A. Onufriev, F. Pan, R. Qi, D.R. Roe, A. Roitberg, C. Sagui, S. Schott-Verdugo, J. Shen, C.L. Simmerling, J. Smith, R. Salomon-Ferrer, J. Swails, R.C. Walker, J. Wang, H. Wei, R.M. Wolf, X. Wu, L. Xiao, D.M. York and P.A. Kollman (2018), AMBER 2018, University of California, San Francisco, (b) D. A. Case, T. E. Cheatham III, T. Darden, H. Gohlke, R. Luo, K. M. Merz Jr, A. Onufriev, C. Simmerling, B. Wang, R. J. Woods, J. Comput. Chem., 2005, 26, 1668-1688, (c) R. Salomon-Ferrer, D. A. Case, R. C. Walker, Wiley Interdiscip. Rev.:Comput. Mol. Sci., 2013, 3, 198-210. ${ }^{146}$ (a) S. Grimme, J. Comput. Chem., 2006, 27, 1787-1799, (b) S. Grimme, S. Ehrlich, L. Goerigk, J. Comput. Chem., 2011, 32, 1456-1465.

147 (a) R. Ditchfield, W. J. Hehre, J. A. Pople, J. Chem. Phys., 1971, 54, 724-728, (b) W. J. Hehre, R. Ditchfield, J. A. Pople, J. Chem. Phys., 1972, 56, 2257-2261, (c) M. M. Francl, W. J. Pietro, W. J. Hehre, J. S. Binkley, M. S. Gordon, D. J. DeFrees, J. A. Pople, J. Chem. Phys., 1982, 77, 3654-3665.

148 J. J. P. Stewart, J. Mol. Model., 2007, 13, 1173-1213. 
convergencia habría sido mucho mayor. Puesto que todas las moléculas son neutras y el disolvente es poco polar (tolueno), podemos asumir que la energía de estabilización proporcionada por la solvatación no modifica los resultados publicados en el Artículo II de forma significativa.

Las geometrías optimizadas de las porfirinas correspondientes al Artículo III y los aductos supramoleculares del mismo fueron obtenidos mediante métodos DFT (GAUSSIAN-16) con el funcional B97D3, que contiene la corrección de dispersión empírica de Becke-Johnson y proporcionada por Grimme y colaboradores. ${ }^{46}$ Se eligió el conjunto de valencia divida del grupo de Pople 6-31G(d,p) como funciones base. ${ }^{147}$ Los efectos del disolvente fueron corregidos usando el modelo continuo polarizable $(\mathrm{PCM})$ con tolueno $(\varepsilon=2.3741)$ como disolvente. ${ }^{149}$ La estrategia llevada a cabo para obtener los complejos de inclusión consistió en emplear la estructura optimizada de la porfirina anfitrión y colocar manualmente las correspondientes moléculas de fullereno entre los dos brazos de coranuleno, rotando los enlaces sencillos $\mathrm{C}-\mathrm{C}$ al mismo tiempo para que ambos fragmentos de PAH coincidan con la superficie de fullereno. Para la situación que involucraba $\mathrm{C}_{70}$, se optimizaron diversas orientaciones del fullereno y sólo la situación más estable se consideró. Todos los mínimos encontrados fueron confirmados por análisis vibracional poseyendo cero frecuencias imaginarias en todos los casos. Las energías electrónicas de deformación $\left(\mathrm{E}_{\mathrm{def}}\right)$ se estimaron restando la energía electrónica de la geometría optimizada del Host $(\mathrm{H})$ de la energía electrónica de la estructura optimizada del aducto Host-Guest (HG) de acuerdo con la Ecuación 1. Para el supuesto caso de complejo de inclusión $\mathrm{HG}_{2}$, la resta se llevó a cabo a partir de la estructura del Host que se muestra en los complejos parentales 1:1 (HG) según la Ecuación 2.

$$
\begin{array}{ll}
E_{\text {def }}=E_{H G}(H)-E_{H}(H) & \text { Ecuación 1 } \\
E_{\text {def }}=E_{H G_{2}}(H)-E_{H G}(H) & \text { Ecuación 2 }
\end{array}
$$

Los subíndices denotan la geometría usada y las letras entre paréntesis corresponden con la entidad molecular de Host estudiada (porfirina en todos los casos).

Las energías electrónicas de interacción ( $\mathrm{E}_{\text {int }}$ ) en los Artículos II y III se calcularon sobre las geometrías optimizadas utilizando un conjunto de bases más extendidas $6-31+\mathrm{G}(\mathrm{d}, \mathrm{p})$ incluyendo funciones difusas ${ }^{150}$ y teniendo en cuenta el error de superposición de bases (BSSE) con el esquema de contrapeso del funcional Boys-Bernardi ${ }^{151}$ de la siguiente manera:

$$
E_{\text {int }}(H G)=E_{H G}^{H G}(H G)-E_{H G}^{H G}(H)-E_{H G}^{H G}(G) \quad \text { Ecuación } 3
$$

Los subíndices designan la geometría usada (complejos de inclusión en todos los casos) y los superíndices son el conjunto de bases (del aducto supramolecular en todos los casos); H y G corresponden a las entidades Host y Guest, respectivamente, y HG al aducto supramolecular.

El análisis de las interacciones no covalentes en los Artículos II y III se obtuvieron mediante la localización de los puntos críticos donde el gradiente de densidad reducido disminuye a valores bajos de densidad electrónica de acuerdo con el esquema de Yang y colaboradores

${ }^{149}$ G. Scalmani, M. J. Frisch, J. Chem. Phys., 2010, 132, 114110.

${ }^{150}$ M. J. Frisch, J. A. Pople, J. S. Binkley, J. Chem. Phys., 1984, 80, 3265-3269.

151 (a) S. F. Boys, F. Bernardi, Mol. Phys., 1970, 19, 553-566, (b) S. Simon, M. Duran, J. J. Dannenberg, J. Chem. Phys., 1996, 105, 11024-11031, (c) T. Van Mourik, A. K. Wilson, K. A. Peterson, D. E. Woon, T. H. Dunning, in Adv. Quantum Chem., eds. J. R. Sabin, M. C. Zerner, E. Brändas, S. Wilson, J. Maruani, Y. G. Smeyers, P. J. Grout and R. McWeeny, Academic Press, 1998, vol. 31, pp. 105-135, (d) K. N. Kirschner, J. B. Sorensen, J. P. Bowen, J. Chem. Educ., 2007, 84, 1225-1229. 
provisto en el paquete informático NCIPlot. ${ }^{152}$ Los cálculos se realizaron con densidades promoleculares y los gradientes de isosuperficie se muestran con isovalores de 0.3 u.a y coloreados según el valor del signo $\lambda_{2}$ (segundo autovalor de la matriz Hessiana de dicha densidad electrónica). Para facilitar la comprensión de las gráficas, las interacciones no covalentes están representadas de acuerdo con el esquema rojo-verde-azul, donde el azul significa interacción atractiva fuerte, el verde interacción atractiva débil y el rojo interacción repulsiva. Las gráficas fueron visualizadas en Chimera ${ }^{153}$ con la ayuda del plugin Tangram NCIPlotGUI creado por el grupo de Insilichem. ${ }^{154}$

\subsection{EVALUACIÓN DE LAS PROPIEDADES DE LOS COMPUESTOS}

Los compuestos finales desarrollados durante esta tesis doctoral presentan una serie de propiedades características que han sido evaluadas mediante el uso de las siguientes metodologías.

\subsubsection{Determinación de constantes de asociación}

Se utilizó el método de dilución aplicando la técnica de RMN para estimar las constantes de asociación supramoleculares de los compuestos finales con los fullerenos bajo estudio $\left(\mathrm{C}_{60} \mathrm{y}\right.$ $\mathrm{C}_{70}$ ).

Se preparó una disolución de cada porfirina problema (anfitrión - Host) de concentración $10^{-4} \mathrm{M}$ o $10^{-5} \mathrm{M}$ disuelta en tolueno deuterado, y un volumen conocido de $500 \mu \mathrm{L}$ transferido al tubo de RMN. La valoración se realizó añadiendo sucesivas alícuotas de una disolución de fullereno (huésped - Guest) en tolueno deuterado de concentración $10^{-3} \mathrm{M}$ o $10^{-4} \mathrm{M}$ cubriendo un intervalo amplio de equivalentes. ${ }^{155}$ Este método es conocido como valoración (titration). Se adquirió un espectro de ${ }^{1} \mathrm{H}-\mathrm{RMN}$ a temperatura ambiente por cada adición. Los cambios en desplazamientos químicos observados $(\Delta \delta)$ para las resonancias elegidas se representaron en función de la fracción molar del fullereno. Las curvas obtenidas, conocidas como isotermas de unión (binding isotherm), se ajustaron por un método no lineal según el tipo de equilibrio que presenten en disolución (véase más abajo). ${ }^{156}$ Cabe mencionar en este punto, que en todos los casos encontrados en esta memoria nos encontramos ante un equilibrio de intercambio rápido en la escala de tiempos de RMN. Esto se traduce en que las resonancias observadas $(\delta)$ son el promedio ponderado de las especies anfitrión libre y anfitrión presente en el complejo.

152 (a) E. R. Johnson, S. Keinan, P. Mori-Sánchez, J. Contreras-García, A. J. Cohen, W. Yang, J. Am. Chem. Soc., 2010, 132, 6498-6506, (b) J. Contreras-García, E. R. Johnson, S. Keinan, R. Chaudret, J.-P. Piquemal, D. N. Beratan, W. Yang, J. Chem. Theory Comput., 2011, 7, 625-632.

153 E. F. Pettersen, T. D. Goddard, C. C. Huang, G. S. Couch, D. M. Greenblatt, E. C. Meng, T. E. Ferrin, J. Comput. Chem., 2004, 25, 1605-1612.

${ }^{154}$ Rodríguez-Guerra Pedregal, J. Development and Application of a Computational Platform for Complex Molecular Design, Universitat Autònoma de Barcelona, 2018. ISBN 9788449082382. https://ddd.uab.cat/record/9788449201498. (https://github.com/insilichem/tangram_nciplot).

155 La elección y justificación de la concentración de Host (anfitrión) y Guest (huésped) en cada caso está detallado en la parte experimental de cada artículo.

156 (a) L. Fielding, Tetrahedron, 2000, 56, 6151-6170, (b) P. Thordarson, Chem. Soc. Rev., 2011, 40, 13051323, (c) P. Thordarson, in Supramolecular Chemistry: From Molecules to Nanomaterials, eds. P. A. Gale and J. W. Steed, John Wiley \& Sons, Chichester, UK, 2012, vol. 2, pp. 239-274, (d) D. Brynn Hibbert, P. Thordarson, Chem. Commun., 2016, 52, 12792-12805. 


\section{Equilibrio 1:1}

El sistema correspondiente al equilibrio 1:1 es el más sencillo y puede definirse con la siguiente ecuación química:

$$
\mathrm{H}+\mathrm{G} \rightleftharpoons \mathrm{HG} \quad \mathrm{K}=\frac{[\mathrm{HG}]}{[\mathrm{H}][\mathrm{G}]} \quad \text { Ecuación } 4
$$

La medida de la constante de asociación (K) requiere del conocimiento de las concentraciones libres en disolución de [H], [G] y [HG], siendo estas las concentraciones de Host (anfitrión), Guest (huésped) y aducto de inclusión Host-Guest (anfitrión-huésped), respectivamente. Desafortunadamente, estas concentraciones no se pueden medir directamente con lo que se evalúa una propiedad física del sistema. En nuestro caso utilizamos la técnica de $\mathrm{RMN}$, siendo el desplazamiento químico $(\delta)$ la propiedad física que se monitoriza en función de la cantidad de Guest añadido. Este proceso, como ya hemos comentado, se denomina valoración.

Los cambios en desplazamientos químicos observados por RMN $(\Delta \delta)$ son proporcionales a la concentración de la especie [HG] (siempre y cuando el Guest sea una especie "silenciosa", como es nuestro caso al realizar espectros de ${ }^{1} \mathrm{H}-\mathrm{RMN}$ en el estudio con fullerenos):

$$
\Delta \delta=\delta_{\Delta \mathrm{HG}}\left(\frac{[\mathrm{HG}]}{[\mathrm{H}]_{0}}\right) \quad \text { Ecuación } 5
$$

Haciendo uso de la Ecuación 4, aplicando el balance de materia y ordenando términos, obtenemos una ecuación cuadrática en función de la concentración de la especie [HG], cuya solución real es:

$$
[\mathrm{HG}]=\frac{1}{2}\left(\left[\mathrm{G}_{0}\right]+\left[\mathrm{H}_{0}\right]+\frac{1}{\mathrm{~K}}\right)-\sqrt{\left(\left[\mathrm{G}_{0}\right]+\left[\mathrm{H}_{0}\right]+\frac{1}{\mathrm{~K}}\right)^{2}+4\left[\mathrm{G}_{0}\right]\left[\mathrm{H}_{0}\right]} \quad \text { Ecuación } 6
$$

Donde:

$[\mathrm{H}]_{0}$ es la concentración inicial de la especie Host

$[\mathrm{G}]_{0}$ es la concentración inicial de la especie Guest

$\delta_{\Delta \mathrm{HG}}$ es la diferencia de $\delta$ entre las especies $\mathrm{HG}\left(\delta_{\mathrm{HG}}\right)$ y $\mathrm{H}$ libre $\left(\delta_{\mathrm{H}}\right): \delta_{\Delta \mathrm{HG}}=\delta_{\mathrm{HG}}-\delta_{\mathrm{H}}$

En este punto es posible describir los cambios producidos experimentalmente durante el experimento de valoración expuesto en la Ecuación 5 con ayuda de la concentración [HG] presente en la Ecuación 6 . De forma práctica, para obtener las dos variables desconocidas $\left(\delta_{\Delta \mathrm{HG}}\right.$ y K) se lleva a cabo una regresión no lineal de los datos obtenidos en función de dos parámetros conocidos $\left([\mathrm{H}]_{0}\right.$ y $\left.[\mathrm{G}]_{0}\right)$.

\section{Equilibrio 1:2}

El sistema perteneciente al equilibro 1:2 implica que una molécula Host es capaz de acomodar dos moléculas Guest de forma secuencial, dando lugar a dos constantes de asociación $\left(\mathrm{K}_{1}\right.$ y $\left.\mathrm{K}_{2}\right)$, una para cada etapa de complejación, tal y como muestran las siguientes ecuaciones químicas:

$$
\begin{array}{lll}
\mathrm{H}+\mathrm{G} \rightleftharpoons \mathrm{HG} & \mathrm{K}_{1}=\frac{[\mathrm{HG}]}{[\mathrm{H}][\mathrm{G}]} & \text { Ecuación 7 } \\
\mathrm{HG}+\mathrm{G} \rightleftharpoons \mathrm{HG}_{2} & \mathrm{~K}_{2}=\frac{\left[\mathrm{HG}_{2}\right]}{[\mathrm{H}][\mathrm{HG}]} & \text { Ecuación 8 }
\end{array}
$$


Como en el caso anterior, no podemos conocer las concentraciones de todas las especies en disolución, con lo que procedemos de forma análoga a medir el cambio de una propiedad física durante el transcurso de la valoración. En este caso los cambios en desplazamientos químicos observados por RMN $(\Delta \delta)$ son proporcionales a la concentración de la especie [G] de la siguiente manera (siempre y cuando el Guest sea una especie "silenciosa", como es nuestro caso):

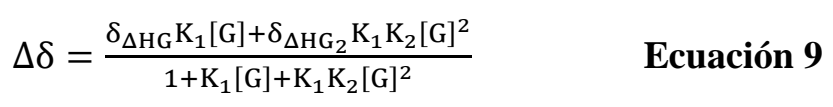

Donde [G] es la concentración libre de Guest, y es calculada usando la siguiente ecuación cúbica:

$$
[G]^{3}(A)+[G]^{2}(B)+[G](C)-\left[G_{0}\right]=0 \quad \text { Ecuación } 10
$$

Con:

$$
\begin{gathered}
\mathrm{A}=\left(\mathrm{K}_{1} \mathrm{~K}_{2}\right) \\
\mathrm{B}=\left\{\mathrm{K}_{1}\left(2 \mathrm{~K}_{2}[\mathrm{H}]_{0}-\mathrm{K}_{2}[\mathrm{G}]_{0}+1\right)\right\} \\
\mathrm{C}=\left\{\mathrm{K}_{1}\left([\mathrm{H}]_{0}-[\mathrm{G}]_{0}\right)+1\right\}
\end{gathered}
$$

Donde las nuevas variables son:

$\mathrm{K}_{1}$ es la constante de equilibrio en el primer proceso supramolecular

$\mathrm{K}_{2}$ es la constante de equilibrio en el segundo proceso supramolecular

$\delta_{\Delta \mathrm{HG} 2}$ es la diferencia de $\delta$ entre las especies $\mathrm{HG}_{2}\left(\delta_{\mathrm{HG} 2}\right)$ y $\mathrm{H}$ libre $\left(\delta_{\mathrm{H}}\right): \delta_{\Delta \mathrm{HG} 2}=\delta_{\mathrm{HG} 2}-\delta_{\mathrm{H}}$

Sin entrar en excesivos detalles y de forma similar al equilibrio anterior, los parámetros desconocidos en este sistema son calculados mediante una regresión no lineal de los datos obtenidos.

En cada caso, $\delta_{\Delta \mathrm{HG}}$ y $\mathrm{K}$ para el equilibrio $1: 1$ y $\delta_{\Delta \mathrm{HG}}, \delta_{\Delta \mathrm{HG} 2}, \mathrm{~K}_{1}$ y $\mathrm{K}_{2}$ para el equilibrio 1:2 se obtuvieron usando el algoritmo de ajuste de curvas no lineales desarrollada por el profesor Pall Thordarson (Universidad de Nueva Gales del Sur, Sídney, Australia), disponible en la dirección web http://supramolecular.org (accesible desde 2016). Todos los ajustes de datos de la presente tesis doctoral pueden consultarse de forma libre y gratuita, encontrándose los correspondientes links de acceso en la información suplementaria de cada artículo.

\subsubsection{Estequiometría de los aductos supramoleculares: Modelos de unión}

Un método muy popular para la obtención de la estequiometría de complejos metalligando es el método de las variaciones continuas o Job plot ${ }^{86}$ Este método ha demostrado ser adecuado para el análisis de la formación de complejos metal-ligando, sin embargo, puede proporcionar resultados engañosos en ciertas ocasiones si se aplica en el campo de la Química Supramolecular.

De forma general, el método de las variaciones continuas solo funciona de forma correcta cuando hay solo un tipo de complejo presente (por ejemplo 1:1). Sin embargo, cuando hay más de un complejo existente en disolución, el método puede proporcionar resultados falsos. Además, simulaciones realizadas por el grupo de Janusz Jurczak ${ }^{157}$ han demostrado que para sistemas con concentraciones muy diluidos de Host el método de Job plot siempre muestran un perfil indicativo

${ }^{157}$ F. Ulatowski, K. Dąbrowa, T. Bałakier, J. Jurczak, J. Org. Chem., 2016, 81, 1746-1756. 
de estequiometría 1:1, pese a la existencia real de dos constantes. Por todo ello, el método de Job plot no es utilizado en esta memoria.

Para la determinación de la estequiometría presente en el proceso supramolecular recurrimos al método recientemente descrito por el profesor Pall Thordarson. ${ }^{156 \mathrm{~d}}$ A continuación introduciremos y comentaremos los diferentes modelos de unión existentes. Dichos modelos guardan una estrecha relación con la estequiometría del sistema, así el equilibrio 1:2 puede describirse a partir de cuatro modelos de unión distintos. Cada uno de ellos impone o aplica unas condiciones que lo distinguen de los demás.

\section{Modelo 1:1}

Este es el modelo clásico perteneciente al equilibrio 1:1 y ha sido explicado en el Apartado anterior 4.4.1.

\section{Modelo Completo 1:2 (Full 1:2)}

Este método implica que los dos lugares de unión no son idénticos para el Host y permite efectos alostéricos. La cooperatividad está representada con el parámetro $\alpha$ y guarda la siguiente relación con las constantes de equilibrio $\mathrm{K}_{1}$ y $\mathrm{K}_{2}$ :

$$
\alpha=\frac{4 K_{2}}{K_{1}} \quad \text { Ecuación } 11
$$

En función del valor de $\alpha$ tenemos:

$\alpha>1$ cooperatividad o alosterismo positivo

$\alpha<1$ cooperatividad o alosterismo negativo

$\alpha=1$ no hay cooperatividad

Este efecto de cooperatividad refleja la influencia mutua presente entre los sitios de unión. Por tanto, si $\alpha>1$ se sugiere que la ocupación del primer centro receptor facilita la interacción por el segundo centro de unión para formar el complejo final 1:2.

Es el modelo más restrictivo, ya que no realiza ninguna suposición acerca de la correlación entre las constantes $\mathrm{K}_{1}$ y $\mathrm{K}_{2}$ ni de los desplazamientos químicos de las especies $\delta_{\Delta \mathrm{HG} 2}$ y $\delta_{\Delta \mathrm{HG}}$.

\section{Modelo Aditivo 1:2 (Additive 1:2)}

Este modelo supone que los desplazamientos químicos observados son simplemente aditivos, es decir, el desplazamiento causado por el segundo centro de unión es exactamente el mismo que el del primero, con lo que tenemos $\delta_{\Delta \mathrm{HG} 2}=2 \delta_{\Delta \mathrm{HG}}$. No presupone valores acerca de la correlación entre las constantes $\mathrm{K}_{1}$ y $\mathrm{K}_{2}$.

\section{Modelo No cooperativo 1:2 (Non-cooperative 1:2)}

Este modelo implica que los centros de unión son idénticamente iguales e independientes unos de otros, no existiendo cambios en las propiedades de unión de la posición vacante tras la ocupación del primer centro. Por lo tanto, asume que $K_{1}=4 K_{2}$. No presupone valores para los desplazamientos químicos del primer y segundo evento de unión. En este caso el valor de $\alpha$ es igual a 1 . 


\section{Modelo Estadístico 1:2 (Statistical 1:2)}

Este modelo supone que los dos centros de unión se comportan como dos Host independientes, asumiendo las aproximaciones hechas por los otros dos modelos anteriores, es decir, $\delta_{\Delta \mathrm{HG} 2}=2 \delta_{\Delta \mathrm{HG}}$ y $\mathrm{K}_{1}=4 \mathrm{~K}_{2}$.

Un resumen comparativo con la finalidad de clarificar los diferentes modelos 1:2 se muestra en la Tabla 1.

\begin{tabular}{|c|c|c|}
\hline \multirow{2}{*}{ Modelo de unión } & \multicolumn{2}{|c|}{ Relación entre: } \\
\cline { 2 - 3 } & $\mathrm{K}_{1} \mathrm{y} \mathrm{K}_{2}$ & $\delta_{\Delta \mathrm{HG} 2} \mathrm{y} \delta_{\Delta \mathrm{HG}}$ \\
\hline Full $1: 2$ & $\mathrm{~K}_{1} \neq 4 \mathrm{~K}_{2}$ & $\delta_{\Delta \mathrm{HG} 2} \neq 2 \delta_{\Delta \mathrm{HG}}$ \\
Additive $1: 2$ & $\mathrm{~K}_{1} \neq 4 \mathrm{~K}_{2}$ & $\delta_{\Delta \mathrm{HG} 2}=2 \delta_{\Delta \mathrm{HG}}$ \\
Non-cooperative $1: 2$ & $\mathrm{~K}_{1}=4 \mathrm{~K}_{2}$ & $\delta_{\Delta \mathrm{HG} 2} \neq 2 \delta_{\Delta \mathrm{HG}}$ \\
Satistical $1: 2$ & $\mathrm{~K}_{1}=4 \mathrm{~K}_{2}$ & $\delta_{\Delta \mathrm{HG} 2}=2 \delta_{\Delta \mathrm{HG}}$ \\
\hline
\end{tabular}

Tabla 1: Relaciones entre las constantes y desplazamientos químicos que sirven para describir el equilibrio 1:2 para los cuatro modelos de unión.

El método más eficaz para determinar la estequiometría del aducto supramolecular es ajustar los datos experimentales a los diferentes modelos y comparar la calidad del ajuste de los resultados obtenidos, con el fin de evaluar cual sería el modelo más adecuado para explicar el sistema supramolecular.

La covarianza del ajuste ( $\left.\operatorname{cov}_{\text {fit }}\right)$ es uno de los indicadores que se utiliza para la elección de un modelo. Se calcula dividiendo la covarianza de los residuales del ajuste por la covarianza de los datos experimentales. Para comparar entre modelos diferentes se divide la $\operatorname{cov}_{\text {fit }}$ del modelo 1:1 por la $\operatorname{cov}_{\text {fit }}$ de cada uno de los modelos 1:2 (más complejos). Si el resultado obtenido en esta comparativa (Factor $\operatorname{cov}_{\mathrm{fit}}$ ) ofrece un valor mínimo o igual que tres, entonces el modelo más complejo es capaz de explicar mejor el sistema (Ecuación 12).

$$
\text { Factor } \operatorname{cov}_{\mathrm{fit}}=\frac{\operatorname{cov}_{\mathrm{fit}}(1: 1)}{\operatorname{cov}_{\mathrm{fit}}(1: 2)} \geq 3 \quad \text { Ecuación } 12
$$

Si al realizar la comparativa entre modelos, ningún modelo complejo es capaz de cumplir con la Ecuación 12, entonces el más simple de los modelos es el más adecuado para explicar el sistema, pero tampoco inhabilita la existencia de los anteriores.

En el caso de que dos modelos 1:2 satisfagan la relación anterior (Ecuación 12), aplicaremos un test de significancia $\mathrm{P}$ a la suma de los cuadrados de los residuales (SSR) de cada modelo.

Durante el proceso de cálculo de las constantes de asociación (Apartado 4.4.1), también se han obtenido los valores de las covarianzas de los ajustes $\left(\operatorname{cov}_{\text {fit }}\right)$. La comparativa entre los diferentes modelos de unión se encuentra comentada en la parte experimental de cada artículo y se llevó a cabo usando la hoja de cálculo de Microsoft Office Excel 365. 


\section{DISCUSIÓN DE RESULTADOS}




\section{DISCUSIÓN DE RESULTADOS}

En este apartado procederemos a discutir los resultados obtenidos durante el desarrollo de la presente tesis doctoral que ha dado lugar a tres publicaciones científicas. Los tres trabajos están fundamentados en una serie de porfirinas funcionalizadas con diferentes sustituyentes policíclicos aromáticos planos y no planos, donde se estudia cómo afecta el número y orientación espacial de los sustituyentes en las interacciones supramoleculares con fullerenos.

\subsection{PORFIRINAS MESO-OCTAARILSUSTITUIDAS SIMÉTRICAS CON LIGANDOS POLIAROMÁTICOS PLANOS}

\subsubsection{Artículo I: Dual-Tweezer Behavior of an Octapodal Pyrene Porphyrin-Based System as a Host for Fullerenes}

Este primer trabajo está relacionado con porfirinas simétricas meso-sustituidas con restos PAH planos. En estudios previos en nuestro grupo de investigación, ${ }^{94}$ obtuvimos una mesotetraarilporfirina con ligandos pireno en posiciones meta mediante una cuádruple reacción de Suzuki. Sin embargo, el espectro de ${ }^{1} \mathrm{H}-\mathrm{RMN}$ mostraba la existencia de una mezcla de cuatro atropisómeros en proporción relativa a una distribución estadística, siendo además no separables debido a su rápida isomerización (Figura 17a). Pese a tal limitación, se estudió la habilidad de la mezcla en su conjunto para interaccionar con $\mathrm{C}_{60}$. Se demostró que el isómero $\boldsymbol{\alpha}_{\mathbf{4}}-\mathbf{2 H}-\mathbf{P T P y r}$ presentaba las mayores constantes de asociación $\left(\mathrm{K} \sim 10^{3} \mathrm{M}^{-1}\right.$, estequiometria 1:1, tolueno- $\left.d_{8}\right)$.

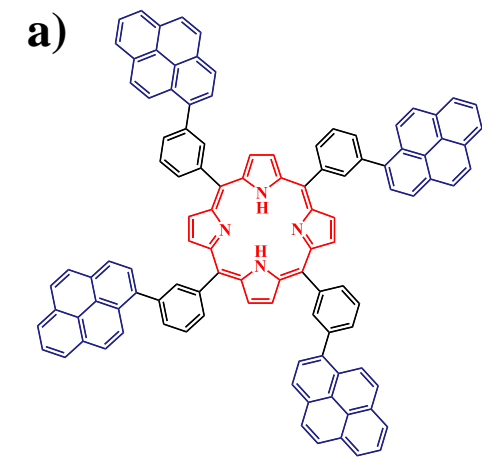

2H-PTPyr

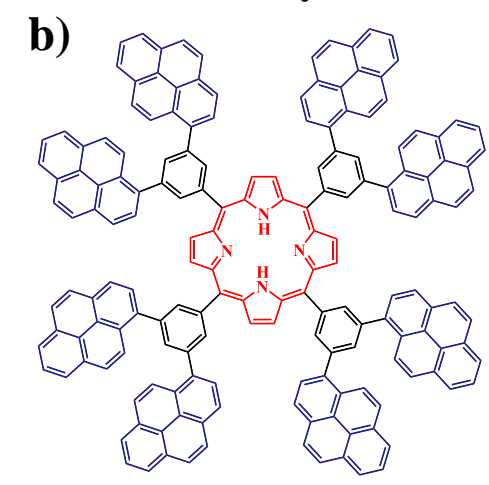

2HPOP

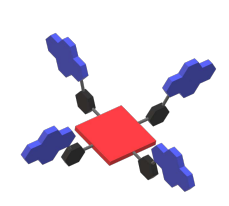

$\alpha_{4}$

$1 / 8$

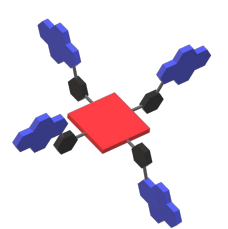

$\alpha_{3} \beta$

$4 / 8$

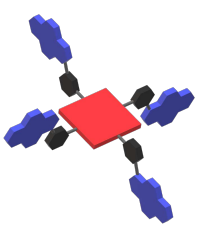

$\alpha_{2} \beta_{2}$

$2 / 8$

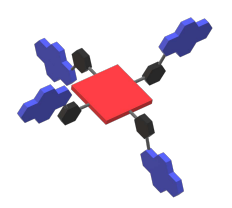

$\alpha \beta \alpha \beta$

$1 / 8$

Mezcla de atropisómeros

Difícil análisis supramolecular y valores bajos de K

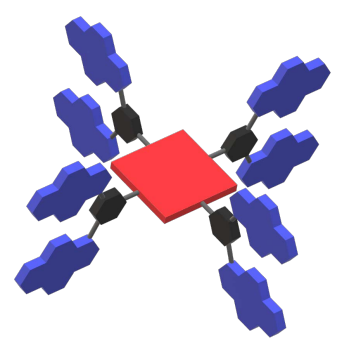

Figura 17. (a) Estudio previo de porfirinas meta aril-sustituidas con ligandos pireno. ${ }^{94}$ También se representa la orientación espacial y distribución estadística de los atropisómeros. (b) Trabajo realizado en esta memoria de una porfirina funcionalizada con ocho unidades de pireno. 
En el presente trabajo, introducimos dos unidades de pireno en las posiciones meta del grupo arilo, para obtener de este modo una porfirina meso-octasustituida simétrica (Figura 17b). El propósito es evitar la formación de la mezcla de atropisómeros, ya que proporciona espectros de ${ }^{1} \mathrm{H}$-RMN bastante complejos de interpretar que dificultan enormemente el análisis supramolecular con fullerenos. Asimismo, esta mezcla de isómeros disminuye la interacción con el $\mathrm{C}_{60}$ provocando que las constantes de asociación $(\mathrm{K})$ obtenidas muestren valores bajos. Por otra parte, el objetivo es aumentar los posibles efectos sinérgicos presentes entre el núcleo de porfirina y las unidades aromáticas planas de pireno. Además, la disposición geométrica de la molécula con cuatro brazos de pireno arriba y otros cuatro abajo con respecto al núcleo plano de porfirina, denominada como "double picket fence" (doble cerca o valla), introduce la posibilidad al sistema de actuar como una pinza sencilla o doble, con vistas a una posible interacción supramolecular de tipo 1:2 (Figura 18).

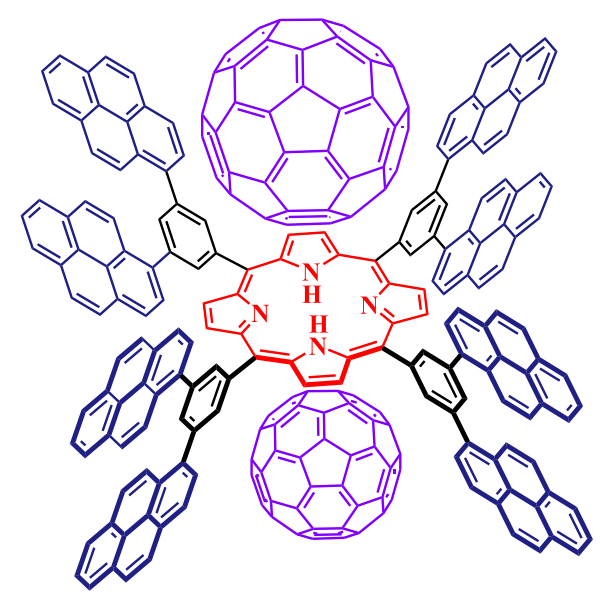

Figura 18. Representación esquemática idealizada de la porfirina mostrando una disposición espacial de tipo "double picket fence" para una posible interacción supramolecular de tipo 1:2.

Para la obtención de la porfirina objetivo 2HPOP y su versión análoga metalada ZnPOP, planteamos diversas rutas sintéticas (Esquema 5). Los primeros intentos involucran las reacciones entre las porfirinas completamente sustituidas en meta con ocho grupos boronato ZnPOB y 2HPOB con el compuesto comercial 1-bromopireno, proporcionando un rendimiento extremadamente bajo (entre el 1 - 5\%) tras la reacción de Suzuki (Esquema 5, Rutas 1 y 2). No obstante, este resultado puede mejorarse intercambiando los grupos boronato de las porfirinas de partida por sustituyentes tipo bromo. De este modo, partiendo de $\mathbf{Z n P O B r}$ (Esquema 5, Ruta 3) logramos obtener el compuesto ZnPOP con un rendimiento del 15\%, sustancialmente mejor que los encontrados en las rutas anteriores. Otra mejora sintética que se implementó fue cambiar la porfirina de partida por el análogo octabromado no metaladao 2HPOBr. La síntesis del núcleo principal de porfirina bromada $2 \mathrm{HPOBr}$ se puede obtener fácilmente a partir de pirrol y 3,5dibromobenzaldehído con la ayuda de radiación microondas. Con este nuevo método sintético se han mejorado los rendimientos, disminuido los tiempos de reacción y facilitado el aislamiento de la porfirina con respecto a los métodos clásicos. 


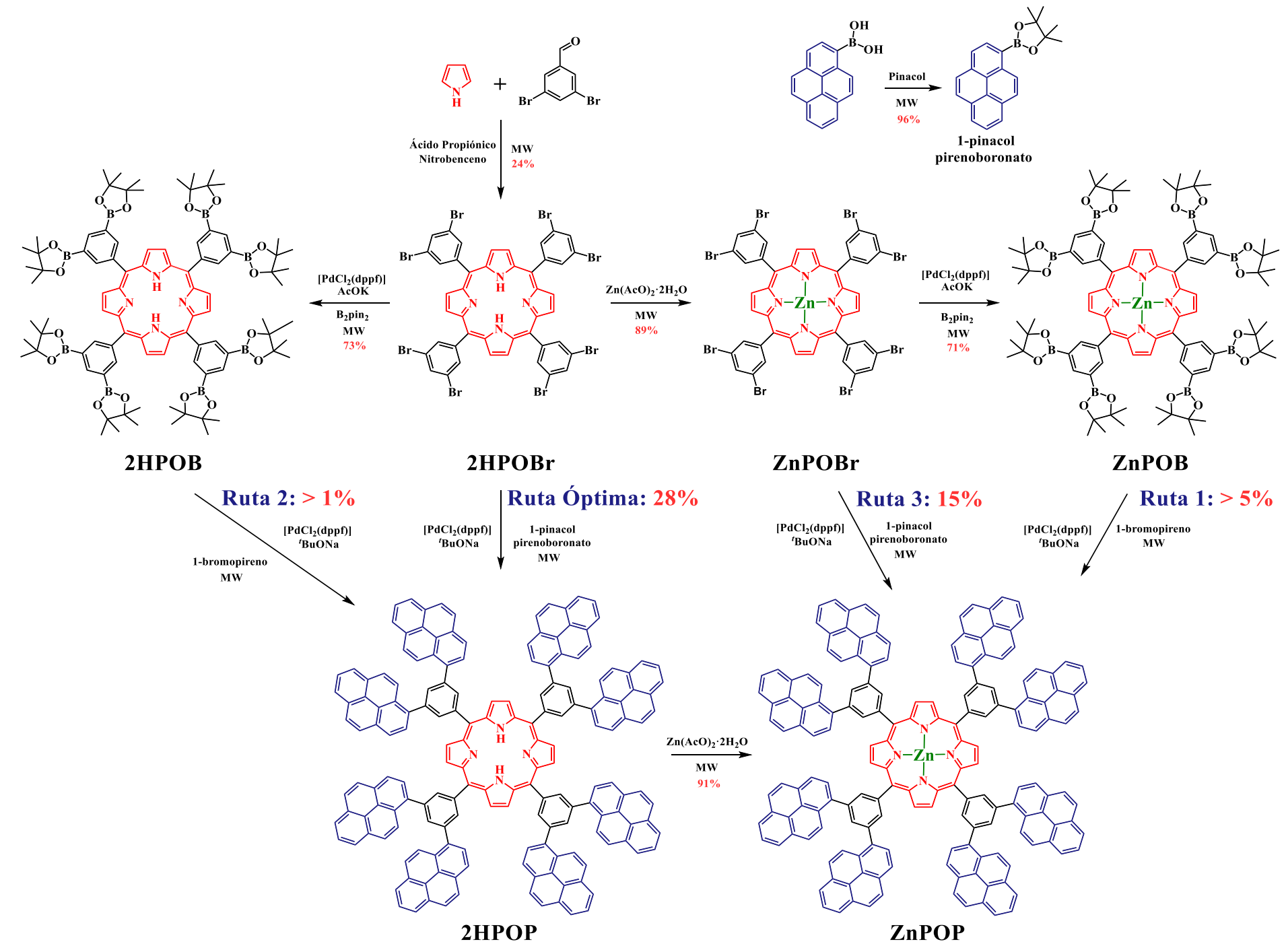

Esquema 5. Todas las rutas de síntesis exploradas para la obtención de las porfirinas objetivo de este primer trabajo. 
De esta forma, tomando como punto de partida $2 \mathrm{HPOBr}$ conseguimos el compuesto objetivo 2HPOP a través una óctuple reacción de Suzuki asistida por radiación microondas con un rendimiento muy aceptable del 28\% (Esquema 5, Ruta Óptima). Cabe resaltar que este rendimiento global implica un rendimiento individual para cada reacción de acoplamiento cruzado del $85 \%$. El uso del reactor de microondas es fundamental para el éxito de la reacción, puesto que disminuye el número de productos secundarios no deseados. Finalmente, la metalación de $2 \mathbf{H P O P}$ con $\mathrm{Zn}(\mathrm{AcO})_{2} \cdot 2 \mathrm{H}_{2} \mathrm{O}$ proporciona $\mathbf{Z n P O P}$ de una manera sencilla y prácticamente cuantitativa (91\%) (Esquema 5). De esta forma tenemos una nueva plataforma molecular para la interacción con fullerenos y que permitirá estudiar el impacto causado por la introducción del metal en el evento supramolecular. Es bien conocido que la coordinación de metales puede repercutir en la geometría del anillo de porfirina ${ }^{108,110 \mathrm{e}}$ y proporcionar algún tipo de interacción no covalente adicional que afecte a la interacción con fullerenos. ${ }^{123 b, 128 c, 129 a, c}$

Los espectros de ${ }^{1} \mathrm{H}-\mathrm{RMN}$ de las octa-pirenoporfirinas simétricas 2HPOP y ZnPOP muestran la equivalencia de las ocho unidades de pireno indicando una simetría $\mathrm{D}_{4 \mathrm{~h}}$ en disolución (Figura 19). Es reseñable señalar la presencia de los protones internos $\mathrm{NH}\left(\mathrm{H}_{1}\right)$ de $\mathbf{2 H P O P}$ a un característico desplazamiento químico de $\delta=-2.50 \mathrm{ppm}$. Así como los protones pertenecientes a los beta pirroles $\left(\mathrm{H}_{2}\right)$ que aparecen a un $\delta=9.46 \mathrm{ppm}$. El resto de las resonancias de la molécula aparecen a desplazamientos químicos habituales para compuestos aromáticos. Como era de esperar, la metaloporfirina ZnPOP muestra la ausencia de los protones internos NH del núcleo de porfirina en el espectro de ${ }^{1} \mathrm{H}-\mathrm{RMN}$ (Figura 19b). Cabe resaltar el diferente comportamiento entre las especies 2HPOP y $\mathbf{Z n P O P}$ observado en $\mathrm{CDCl}_{3}$. Mientras que el espectro de ${ }^{1} \mathrm{H}-\mathrm{RMN}$ de 2HPOP presenta señales agudas en el intervalo de concentraciones estudiado $\left(10^{-4}\right.$ hasta $10^{-6}$ M), en el espectro de ZnPOP las señales son relativamente anchas en disolución. Sin embargo, para disoluciones más diluidas $\left(10^{-5} \mathrm{M}\right)$ las señales se afinan de forma significativa. Este comportamiento es indicativo de la existencia de un proceso intermolecular en el compuesto ZnPOP en $\mathrm{CDCl}_{3}$. En cambio, al utilizar tolueno- $d_{8}$ como disolvente no se observa tal dependencia de la concentración para ninguno de los compuestos. Esto puede atribuirse a que los disolventes aromáticos son capaces de afectar las interacciones intermoleculares de apilamiento tipo $\pi .{ }^{123 b}$ Estos experimentos sugieren la existencia de un cierto grado de apilamiento debido a interacciones $\pi$ entre porfirinas en $\mathbf{Z n P O P}$ en $\mathrm{CDCl}_{3}$. 
a)

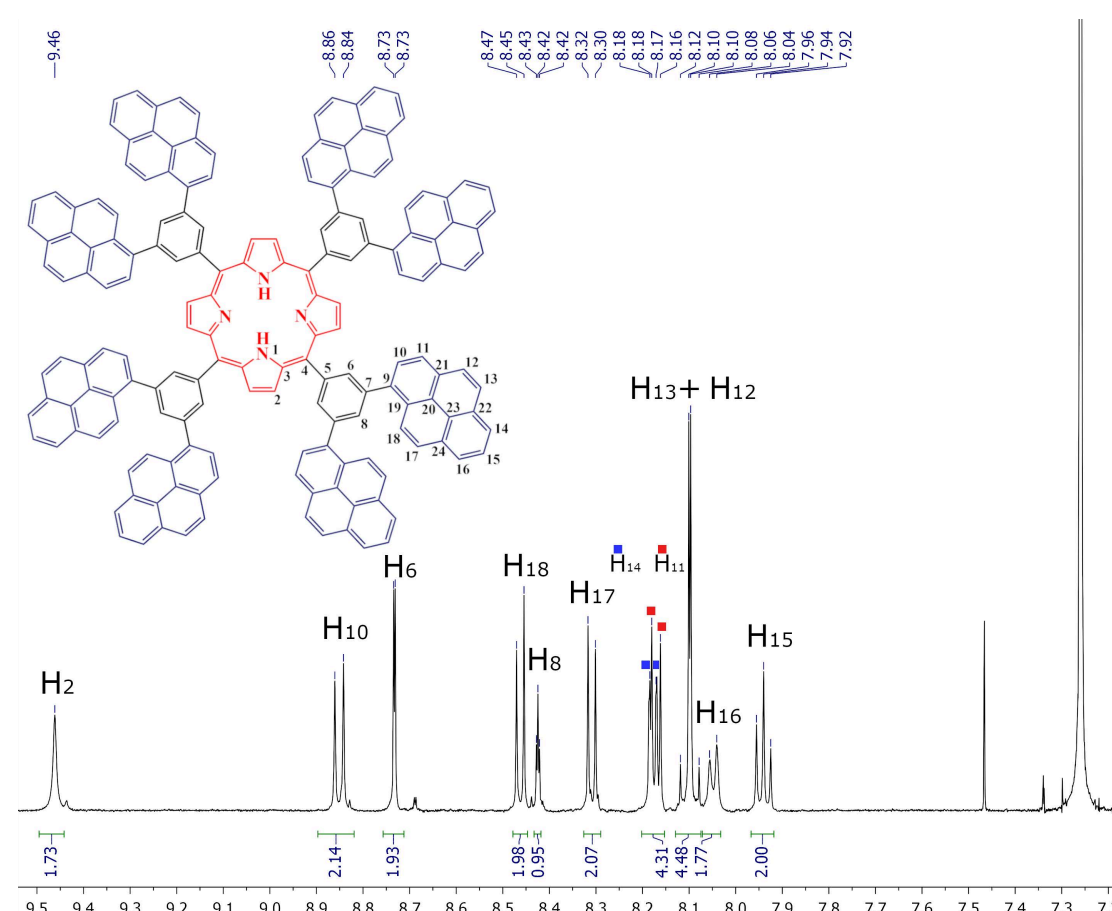

b)

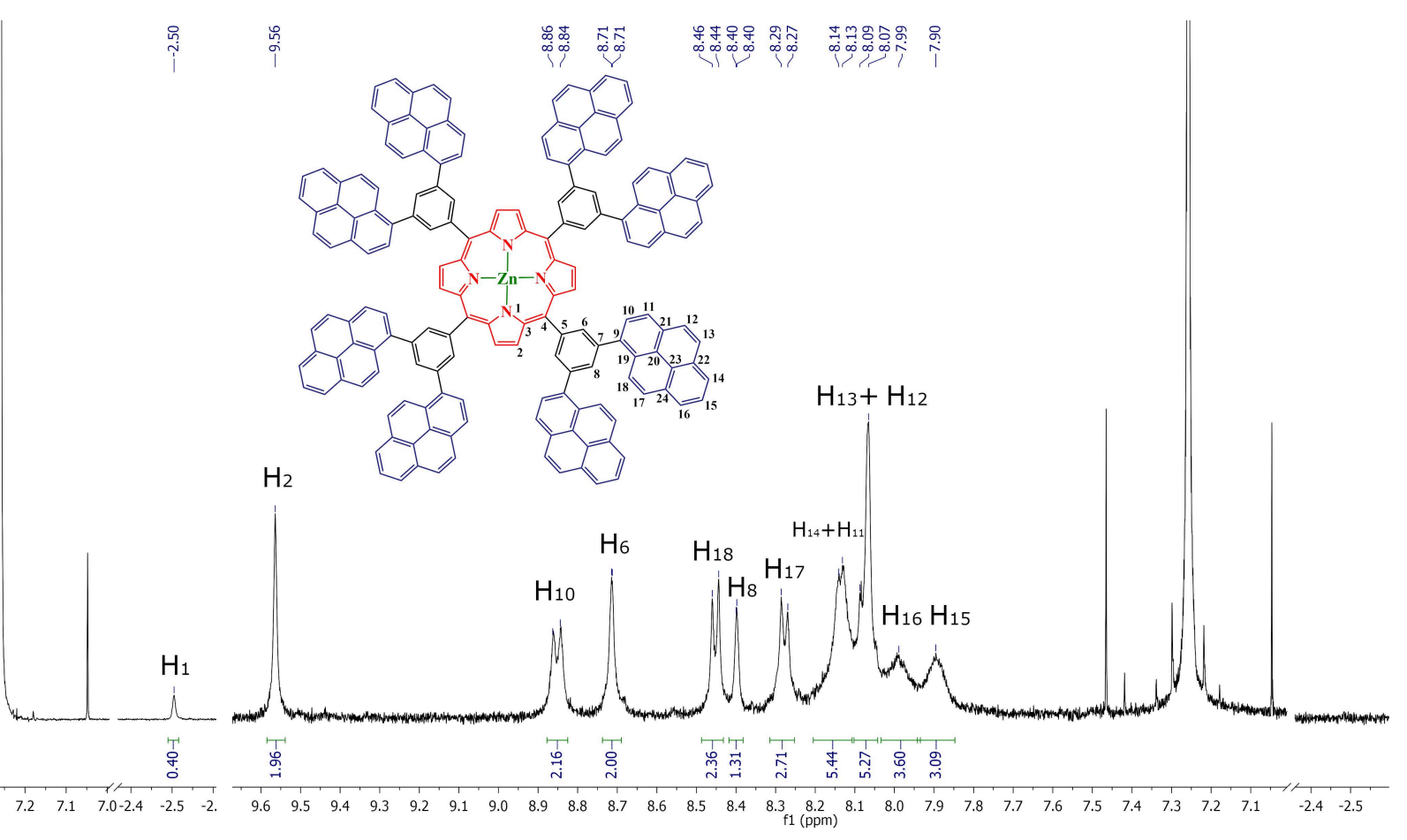

Figura 19. Espectros de ${ }^{1} \mathrm{H}-\mathrm{RMN}\left(500 \mathrm{MHz}, \mathrm{CDCl}_{3}\right.$ ) de los compuestos (a) 2HPOP y (b) ZnPOP. 
En el espectro de absorción UV-Vis en tolueno de las octa-pirenoporfirinas (Figura 20) se observa que la intensa banda Soret manifiesta un ligero desplazamiento hacia el rojo para ZnPOP (432 nm) comparado con 2HPOP (428 nm). Este pequeño pero apreciable cambio de longitudes de onda puede estar relacionado con un posible alejamiento de la planaridad del núcleo de porfirina, tal y como se describe en la bibliografía. ${ }^{110 c, d, e, ~} 158$ En el espectro también se pueden observar las bandas Q de menor intensidad en el intervalo 500-670 nm, cuyo número se observa reducido tras el proceso de metalación del núcleo macrocíclico.

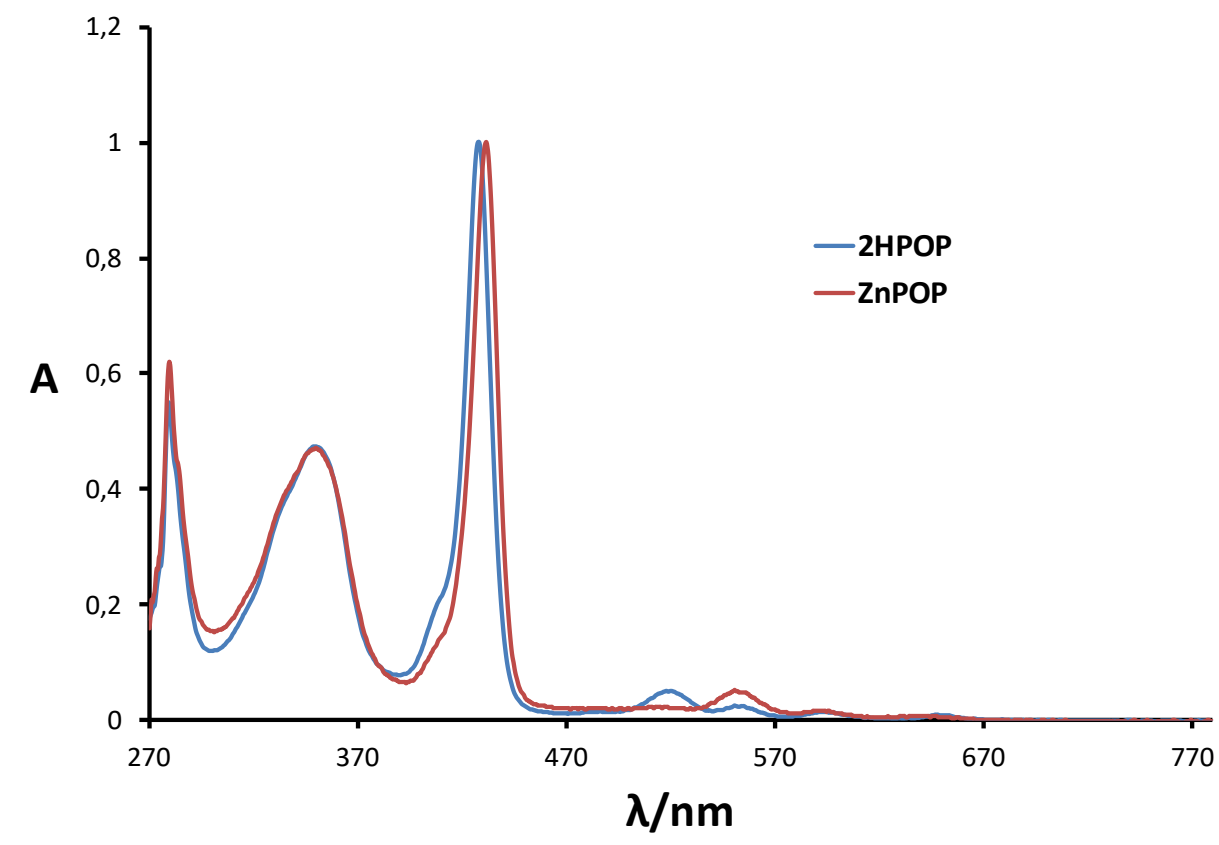

Figura 20. Espectro normalizado de absorción UV-Vis en tolueno de las porfirinas 2HPOP y ZnPOP.

Nos resultó interesante estudiar si las porfirinas 2HPOP y ZnPOP son capaces de actuar como pinza sencilla o doble frente a $\mathrm{C}_{60}$ y $\mathrm{C}_{70}$, es decir, si son capaces de aceptar uno o dos fullerenos debido a la presencia de dos potenciales centros de unión (Figura 18).

Inicialmente realizamos las valoraciones con concentraciones $10^{-4} \mathrm{M}$ de las porfirinas anfitriones (Host) 2HPOP y ZnPOP frente a $\mathrm{C}_{60}$ (Guest). Sin embargo, esa concentración no pudo utilizarse en ninguno de los dos sistemas porfirina para el estudio con $\mathrm{C}_{70}$, debido a la precipitación de los aductos de inclusión supramolecular durante el transcurso de la valoración. Este problema pudo solventarse utilizando una concentración para ambos Host de $10^{-5} \mathrm{M}$ para los experimentos de valoración con $\mathrm{C}_{70}$. La formación de ese precipitado sugiere que existe una afinidad mucho mayor por $\mathrm{C}_{70}$ que por $\mathrm{C}_{60}$ en ambos sistemas de porfirinas.

Comenzamos nuestros estudios con ZnPOP y llevamos a cabo las valoraciones con $\mathrm{C}_{60} \mathrm{y}$ $\mathrm{C}_{70}$ por ${ }^{1} \mathrm{H}-\mathrm{RMN}$ en tolueno- $d_{8}$. En ambos experimentos, se puede confirmar la formación del aducto supramolecular en disolución por los cambios observados en los desplazamientos químicos de los protones $\mathrm{H}_{8}$ y $\mathrm{H}_{18}$ durante la adición de los fullerenos (Figura 21a y b).

158 M. O. Senge, Chem. Commun., 2006, 243-256. 
a)

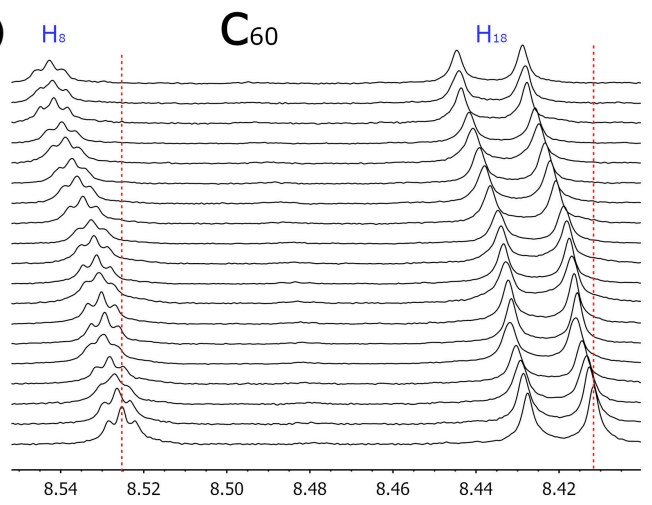

c)

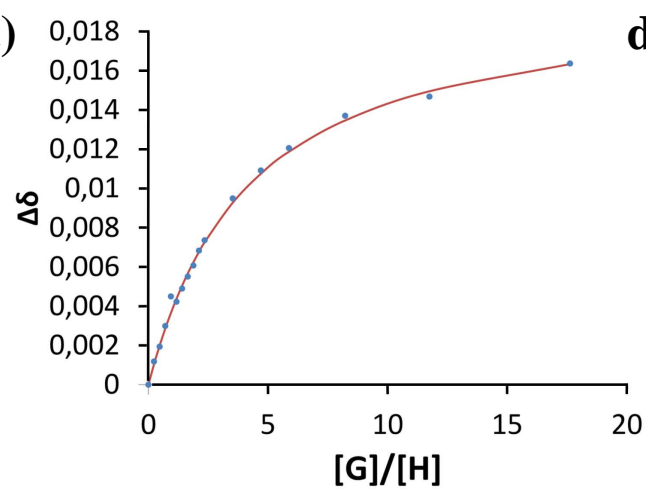

b)

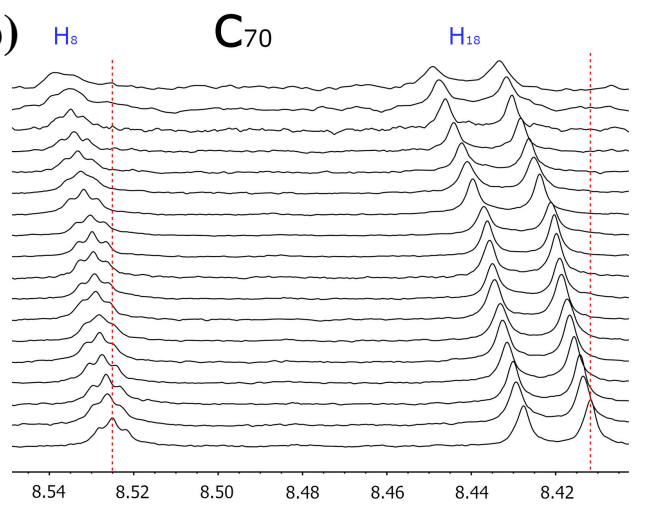

d)

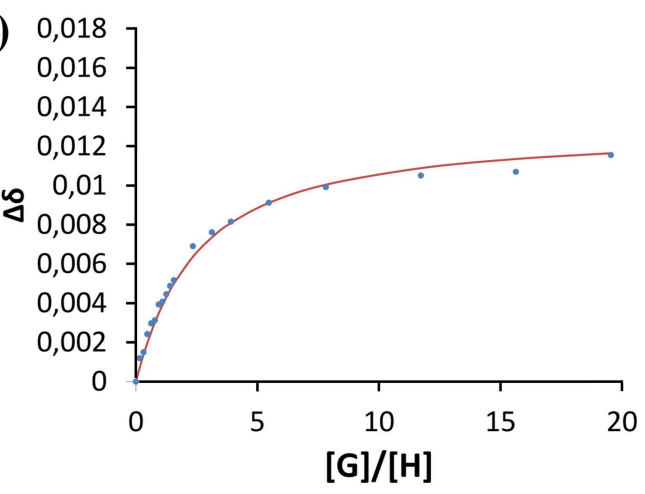

Figura 21. (a y b) Espectros de ${ }^{1} \mathrm{H}-\mathrm{RMN}\left(500 \mathrm{MHz}\right.$, tolueno- $\left.d_{8}\right)$ mostrando el cambio en el desplazamiento químico de $\mathrm{H}_{8}$ y $\mathrm{H}_{18}$ para $\mathbf{Z n P O P}$ tras la adición de alícuotas de $\mathrm{C}_{60}$ (a) o $\mathrm{C}_{70}$ (b). (c y d) Gráficas correspondientes a los cambios en los desplazamientos químicos frente la fracción molar del fullereno $[\mathrm{G}] /[\mathrm{H}]$, donde $[\mathrm{G}]$ (Guest) corresponde al $\mathrm{C}_{60}$ (c) o $\mathrm{C}_{70}(\mathrm{~d})$ y $[\mathrm{H}]$ (Host) es $\mathbf{Z n P O P}$. La línea roja pertenece al ajuste no lineal de $\Delta \delta\left(\mathrm{H}_{8}\right)$ para una isoterma de unión de un modelo 1:1. Nota: $[\mathrm{H}]_{0}=10^{-4} \mathrm{M}$ para $\mathrm{C}_{60} \mathrm{y}[\mathrm{H}]_{0}=10^{-5} \mathrm{M}$ para $\mathrm{C}_{70}$.

Las isotermas de unión (binding isotherm) resultantes de los experimentos de valoración con $\mathrm{C}_{60}$ y $\mathrm{C}_{70}$ se pueden ajustar, en ambos casos, a un modelo 1:1 (Figura 21c y d). No encontramos evidencias en ningún caso para un posible ajuste perteneciente a un modelo 1:2. Las gráficas de la Figura 21 muestran claramente una saturación más rápida para $\mathrm{C}_{70}$, que alcanza el límite de desplazamiento químico máximo $\Delta \delta_{\max }$ mucho antes que $\mathrm{C}_{60}$. Esto refleja una mayor constante de asociación $\mathrm{K}$ para el sistema $\mathbf{Z n P O P}$ y $\mathrm{C}_{70}$. Las constantes obtenidas para $\mathbf{Z n P O P}$

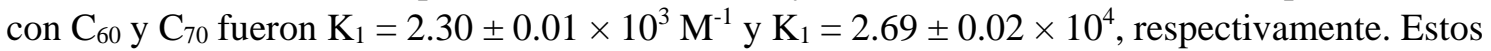
valores ponen de manifiesto que $\mathbf{Z n P O P}$ posee una alta selectividad hacia $\mathrm{C}_{70}$, como demuestran las constantes de asociación que son de un orden de magnitud mayor que para $\mathrm{C}_{60}$.

Por el contrario, la valoración de 2HPOP con $\mathrm{C}_{70}$ no muestra el típico perfil de isoterma de unión encontrado para su homólogo ZnPOP. En su lugar observamos un comportamiento mucho más complicado perteneciente a un sistema no 1:1. ${ }^{156 c}$ Este comportamiento más complejo se visualizó a diferentes concentraciones de $\operatorname{Host}\left([\mathrm{H}]_{0}\right)$. La Figura $22 \mathrm{~b}$ muestra el cambio de $\Delta \delta$ frente a la fracción molar de fullereno $\left(\mathrm{C}_{70}\right)$. Dicha gráfica muestra claramente dos puntos de inflexión a $[\mathrm{G}] /[\mathrm{H}]=1$ y $[\mathrm{G}] /[\mathrm{H}]=2$. Las isotermas de unión para estos casos pueden ajustarse a un modelo Non-cooperative 1:2 con valores de constantes de $\mathrm{K}_{1}=1.40 \pm 0.05 \times 10^{4} \mathrm{M}^{-1} \mathrm{y} \mathrm{K}_{2}=$ $3.50 \pm 0.13 \times 10^{3} \mathrm{M}^{-1}$. 

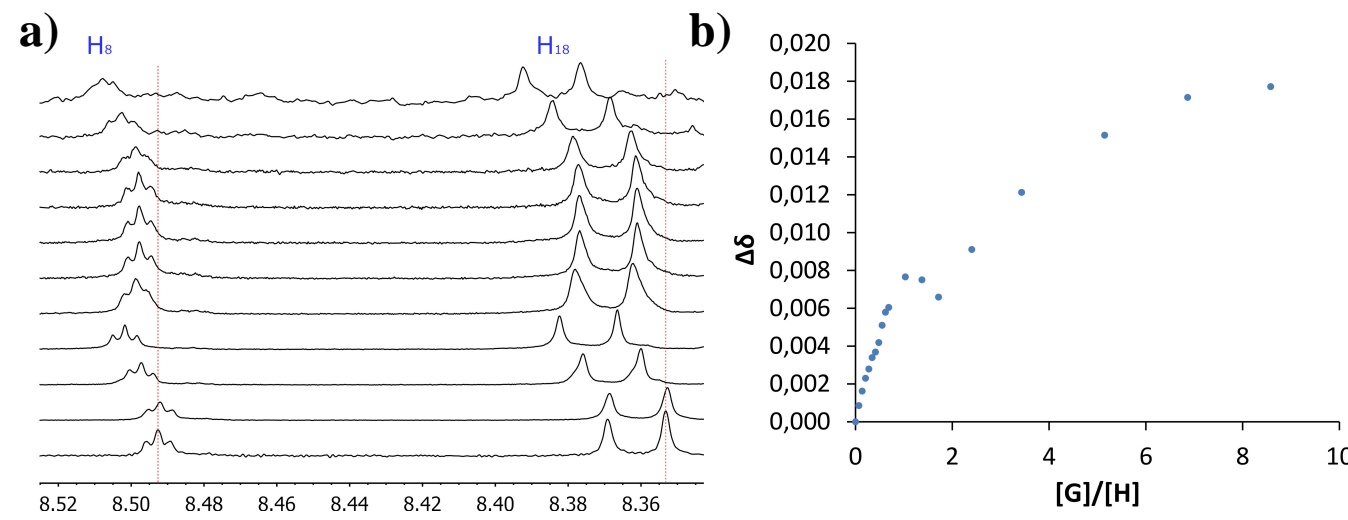

Figura 22. (a) Espectros apilados de ${ }^{1} \mathrm{H}-\mathrm{RMN}$ (500 MHz, tolueno- $d_{8}$ ) mostrando la variación en el desplazamiento químico de $\mathrm{H}_{8}$ y $\mathrm{H}_{18}$ de $2 \mathbf{H P O P}\left([\mathrm{H}]_{0}=10^{-4} \mathrm{M}\right)$, tras añadir alícuotas de $\mathrm{C}_{70}$. (b) Gráfica correspondiente a los cambios en el desplazamiento químico de $\mathrm{H}_{8}$ frente a $[\mathrm{G}] /[\mathrm{H}]$, done $\mathrm{G}$ es $\mathrm{C}_{70}$ y $\mathrm{H}$ es 2HPOP, mostrando el comportamiento complejo de la isoterma de unión $\left([\mathrm{H}]_{0}=10^{-5} \mathrm{M}\right)$. Nota: la línea roja discontinua en (a) es una guía de referencia para el ojo.

Este comportamiento de doble pinza de 2HPOP también se encontró para la interacción con $\mathrm{C}_{60}$. Sin embargo, la isoterma de unión no muestra un comportamiento tan complejo como en el caso anterior con $\mathrm{C}_{70}$. En su lugar se obtiene una curva asintótica. Consideramos los diferentes modelos de unión (1:1, Full 1:2, Additive 1:2, Non-cooperative 1:2 y Statistical 1:2) para el sistema 2HPOP y $\mathrm{C}_{60}$. Un análisis de las covarianzas (Factor $\operatorname{cov}_{\text {fit }}$ ) muestra que los modelos Full 1:2 y Non-cooperative 1:2 son capaces de describir mejor el sistema supramolecular que el modelo simple 1:1 (Tabla 2). (En este punto hay que recordar Ecuación 12, Apartado 4.4.2). Finalmente, tras llevar a cabo un test de significancia P, el modelo Non-cooperative 1:2 representa el mejor ajuste para los datos experimentales. El valor obtenido para las constantes de asociación son $\mathrm{K}_{1}=1.49 \pm 0.01 \times 10^{3} \mathrm{M}^{-1}$ y $\mathrm{K}_{2}=3.71 \pm 0.02 \times 10^{2} \mathrm{M}^{-1}$. Un resumen global de los datos se muestra en la Tabla 2.

\begin{tabular}{|c|c|c|c|c|c|c|c|c|c|c|c|}
\hline $\begin{array}{l}\text { Modelo de } \\
\text { unión }\end{array}$ & $\begin{array}{c}\mathbf{K}_{1} \\
\left(\mathbf{M}^{-1}\right)\end{array}$ & $\begin{array}{c}\mathbf{K}_{2} \\
\left(\mathbf{M}^{1}\right)\end{array}$ & $\begin{array}{c}\text { SSR } \\
\left(10^{-5}\right)\end{array}$ & $\begin{array}{l}\operatorname{cov}_{\text {fit }} \\
\left(1^{-4}\right)\end{array}$ & $\begin{array}{c}\text { Factor } \\
\text { cov fit }^{\text {fit }}\end{array}$ & $\alpha$ & $\begin{array}{c}\text { Puntos } \\
\text { ajustados }\end{array}$ & $\begin{array}{l}\text { Parám. } \\
\text { ajustados }\end{array}$ & $\begin{array}{l}\text { Grados } \\
\text { libertad }\end{array}$ & $\begin{array}{c}\text { Factor } \\
\text { F }\end{array}$ & $\underset{\text { (test significancia) }}{\mathbf{P}}$ \\
\hline $1: 1$ & 2560 & ------ & 9.94 & 7.32 & 1.00 & ------ & 88 & 5 & 83 & ------- & ------- \\
\hline Full 1:2 & 1353 & 26 & 3.05 & 2.31 & 3.17 & 0.076 & 88 & 10 & 78 & ------- & ------- \\
\hline $\begin{array}{c}\text { Additive } \\
1: 2\end{array}$ & 1289 & -179 & 7.08 & 5.07 & 1.44 & -0.56 & 88 & 6 & 82 & ------- & -------- \\
\hline $\begin{array}{c}\text { Non-cooperative } \\
1: 2 \\
\end{array}$ & 1485 & 371 & 3.06 & 2.32 & 3.16 & 1 & 88 & 9 & 79 & 0.336 & 1.00 \\
\hline $\begin{array}{c}\text { Statistical } \\
1: 2\end{array}$ & 6970 & 1743 & 7.79 & 5.63 & 1.30 & 1 & 88 & 5 & 83 & ------- & ------ \\
\hline
\end{tabular}

Tabla 2. Comparación de los diferentes modelos de unión de los datos obtenidos de la valoración por $\mathrm{RMN}$ de $\mathbf{2 H P O P}$ con $\mathrm{C}_{60}$.

Por lo tanto, la interacción supramolecular entre 2HPOP y los fullerenos estudiados $\mathrm{C}_{60} \mathrm{y}$ $\mathrm{C}_{70}$ puede describirse mediante modelos Non-cooperative 1:2. Esto quiere decir que la acepción del primer fullereno por parte de la porfirina no provoca cambios significativos en las propiedades de unión de la posición vacante del sistema. Dicho de otro modo, la información del primer evento supramolecular no se transmite al segundo centro receptor. 
Estos resultados indican que la selección entre el comportamiento de pinza doble o sencilla puede controlarse simplemente por coordinación de Zn (II) en el anillo de porfirina. Esto ilustra como las pequeñas modificaciones en el esqueleto de porfirina, como por ejemplo al coordinar un metal, pueden conducir a cambios drásticos en el comportamiento supramolecular (Figura 23).

a)

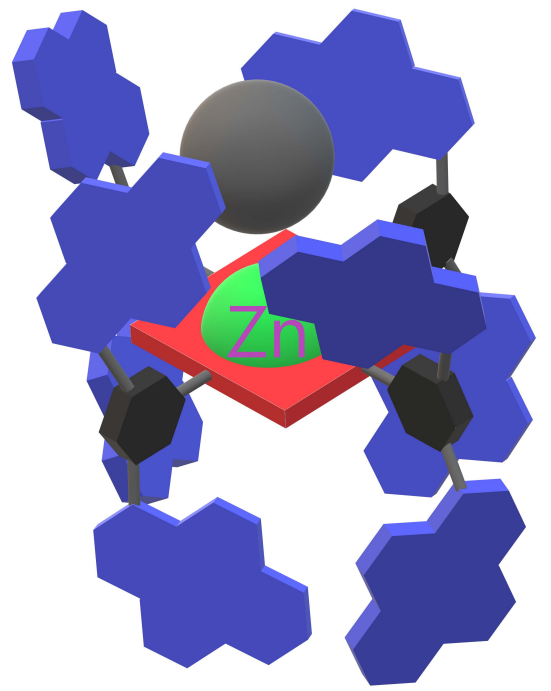

b)

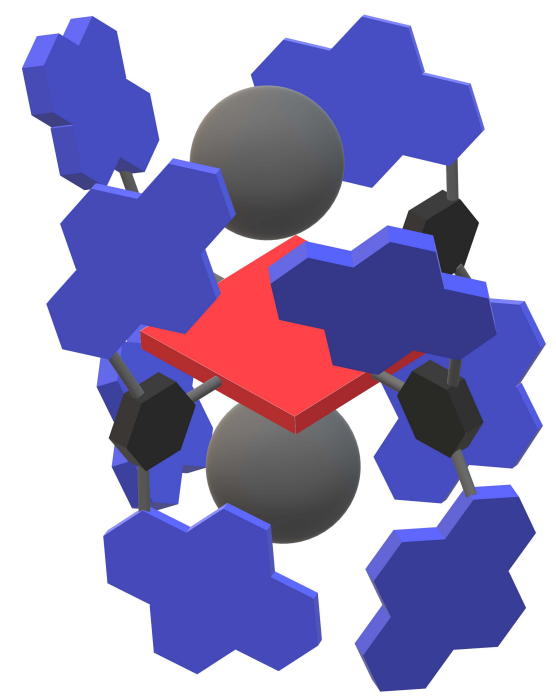

Figura 23. Representación esquemática idealizada mostrando el comportamiento de pinza sencilla para (a) ZnPOP y pinza doble para (b) 2HPOP con $\mathrm{C}_{60}$.

Además, el cambio de comportamiento de pinza sencilla en ZnPOP a doble en 2HPOP se produce con retención de la gran selectividad mostrada para $\mathrm{C}_{70}$ sobre $\mathrm{C}_{60}$ (Tabla 3).

\begin{tabular}{|c|c|c|}
\hline & $\mathbf{C}_{\mathbf{6 0}}$ & $\mathbf{C}_{\mathbf{7 0}}$ \\
\hline ZnPOP & $\mathrm{K}_{1}=2.30 \pm 0.01 \times 10^{3}$ & $\mathrm{~K}_{1}=2.69 \pm 0.02 \times 10^{4}$ \\
\hline \multirow{2}{*}{ 2HPOP } & $\mathrm{K}_{1}=1.49 \pm 0.01 \times 10^{3}$ & $\mathrm{~K}_{1}=1.40 \pm 0.05 \times 10^{4}$ \\
& $\mathrm{~K}_{2}=3.71 \pm 0.02 \times 10^{2}$ & $\mathrm{~K}_{2}=3.50 \pm 0.13 \times 10^{3}$ \\
\hline
\end{tabular}

Tabla 3. Resumen de las constantes de asociación $\mathrm{K}\left(\mathrm{M}^{-1}\right)$ de $2 \mathrm{HPOP}$ y $\mathbf{Z n P O P}$ para $\mathrm{C}_{60}$ $\left([\mathrm{H}]_{0}=10^{-4} \mathrm{M}\right)$ y $\mathrm{C}_{70}\left([\mathrm{H}]_{0}=10^{-5} \mathrm{M}\right)$ obtenidas por ${ }^{1} \mathrm{H}-\mathrm{RMN}\left(500 \mathrm{MHz}\right.$, tolueno- $d_{8}, 298$ $\mathrm{K})$.

Es digno de mención que las constantes encontradas para ambos fullerenos son similares a las basadas en sistemas PAH no planos del tipo coranuleno. Por ejemplo, la pinza con dos unidades de coranuleno Buckycatcher I (Apartado 2.4.1.4.2, Figura 9) de Sygula ${ }^{83,84}$ y el complejo platino con dos restos de coranuleno preparado en nuestro grupo de investigación (Apartado 2.4.1.4.2, Figura 11), ${ }^{89}$ muestran valores de constantes del mismo orden de magnitud que las porfirinas simétricas 2HPOP y ZnPOP con restos PAH planos. En estos sistemas octapirenoporfirinas se han eliminado la mezcla de atropisómeros, aumentando las constantes de asociación y la posibilidad de modificar la estequiometría de los aductos supramoleculares a placer. 
A la vista de la selectividad observada para $\mathrm{C}_{70}$ (Tabla 3) nos planteamos la posibilidad de usar estos sistemas para separar o enriquecer mezclas de fullerenos $\mathrm{C}_{60} / \mathrm{C}_{70}$ secuestrando selectivamente $\mathrm{C}_{70}$ de la disolución. Para ello, se pesó una mezcla equimolar de $\mathrm{C}_{60}$ y $\mathrm{C}_{70}$ y se disolvió en tolueno- $d_{8}$. Esta disolución se repartió en dos partes para realizar los experimentos de RMN por un lado y HPLC y UV-Vis por otro. Realizamos un espectro cuantitativo de ${ }^{13} \mathrm{C}\left\{{ }^{1} \mathrm{H}\right\}$ RMN a la mezcla equimolar $\mathrm{C}_{60} / \mathrm{C}_{70}$ (Figura 24a). ${ }^{21 \mathrm{~b}, 141 \mathrm{a}, \mathrm{b}}$ La adición de 1 equivalente de $\mathbf{2 H P O P}$ condujo a la formación del complejo de inclusión como un precipitado negro que se pudo separar del sobrenadante por decantación. El espectro cuantitativo de ${ }^{13} \mathrm{C}\left\{{ }^{1} \mathrm{H}\right\}$-RMN de esta disolución separada mostró una proporción $\mathrm{C}_{70} / \mathrm{C}_{60}$ de 1:2.7 (Figura 24b) que también se verificó por UVVis y HPLC. ${ }^{141 a, 159}$ Este resultado demuestra de una forma sencilla que simplemente añadiendo 1 equivalente de 2HPOP la muestra se enriquece en $\mathrm{C}_{60}$. Este nivel de enriquecimiento aumenta con la adición 2HPOP. Así, la adición de 0.7 equivalentes sobre una mezcla equimolar de fullerenos genera una proporción de 1:2.0 de $\mathrm{C}_{60}$ en disolución. Cuando empleamos 1.6 equivalentes de 2HPOP el nivel de enriquecimiento alcanza proporciones $\mathrm{C}_{70} / \mathrm{C}_{60}$ de 1:4.6, con una pérdida del $42 \%$ de $\mathrm{C}_{60}$ como coprecipitado.

a) Equimolar: $\mathrm{C}_{60} / \mathrm{C}_{70}$

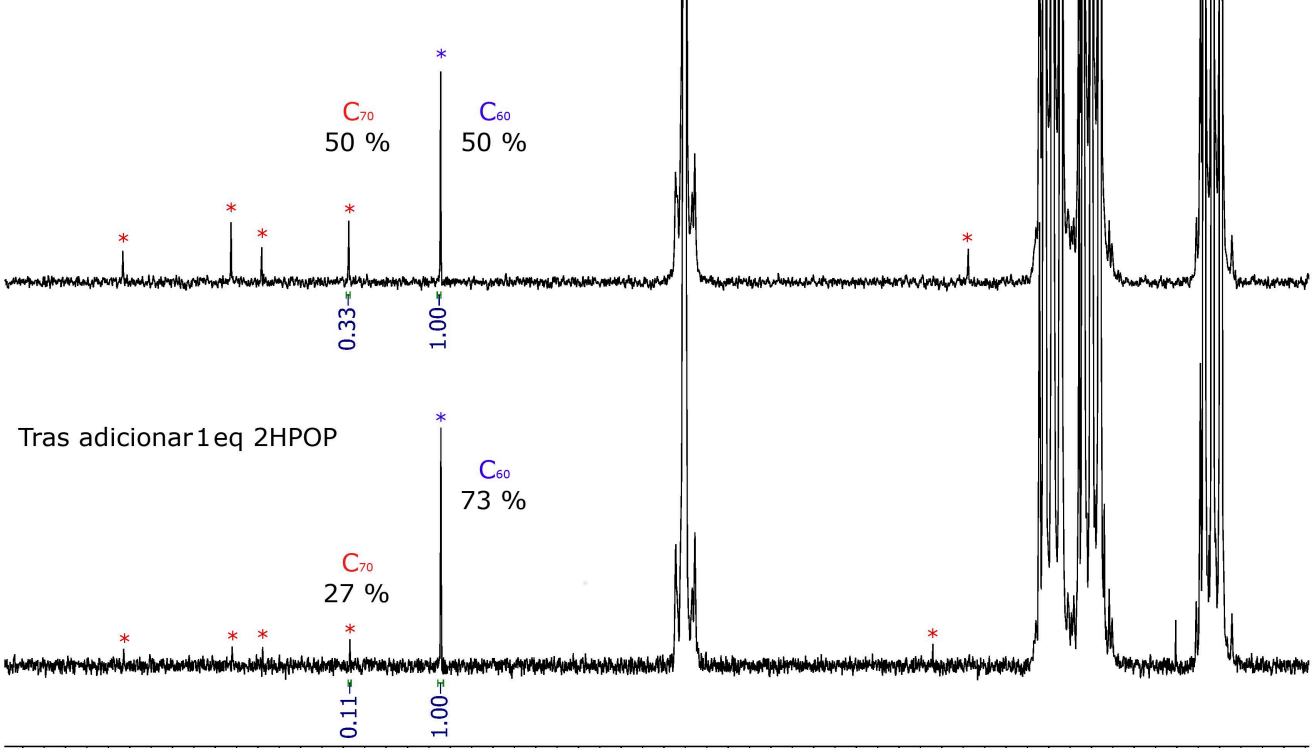

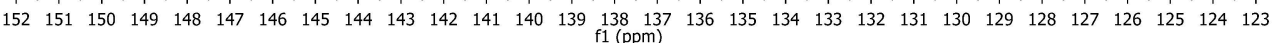

Figura 24. Espectros cuantitativos de ${ }^{13} \mathrm{C}\left\{{ }^{1} \mathrm{H}\right\}$-RMN (126 MHz, tolueno- $d_{8}$ ) de una disolución equimolar $\mathrm{C}_{60} / \mathrm{C}_{70}$ (a) antes de adicionar 2HPOP y (b) después de la adición de 1 equivalente de 2HPOP. La intensidad de las señales pertenecientes al $\mathrm{C}_{70}$ se reduce como resultado de la formación del aducto de inclusión con la porfirina. Nota: las 5 resonancias para el $\mathrm{C}_{70}$ están indicadas con asteriscos rojos y la única señal para el $\mathrm{C}_{60}$ en asterisco púrpura. La proporción de $\mathrm{C}_{60} / \mathrm{C}_{70}$ se obtuvo por integración de las señales considerando su proporción relativa de núcleos.

159 J. P. Hare, H. W. Kroto, R. Taylor, Chem. Phys. Lett., 2013, 589, 57-60. 
Tras estos buenos resultados, centramos nuestra atención hacia el uso de ZnPOP para el enriquecimiento de fullerenos. Siguiendo la misma metodología preparamos la mezcla equimolar de $\mathrm{C}_{60} / \mathrm{C}_{70}$ (Figura 25a) y tras añadir 0.5 equivalentes de ZnPOP encontramos mediante ${ }^{13} \mathrm{C}\left\{{ }^{1} \mathrm{H}\right\}$ RMN cuantitativo que la proporción de fullerenos era casi similar a la de partida, con un ligero exceso en disolución para el Buckminsterfullereno $\left(\mathrm{C}_{60}\right)$ (Figura $25 \mathrm{~b}$ ). Sobre ese mismo tubo se añadieron otros 0.5 equivalentes de $\mathbf{Z n P O P}$, proporcionado en este caso un espectro de ${ }^{13} \mathrm{C}\left\{{ }^{1} \mathrm{H}\right\}$ RMN cuantitativo donde sólo la señal perteneciente al $\mathrm{C}_{60}$ es visible (Figura 25c).

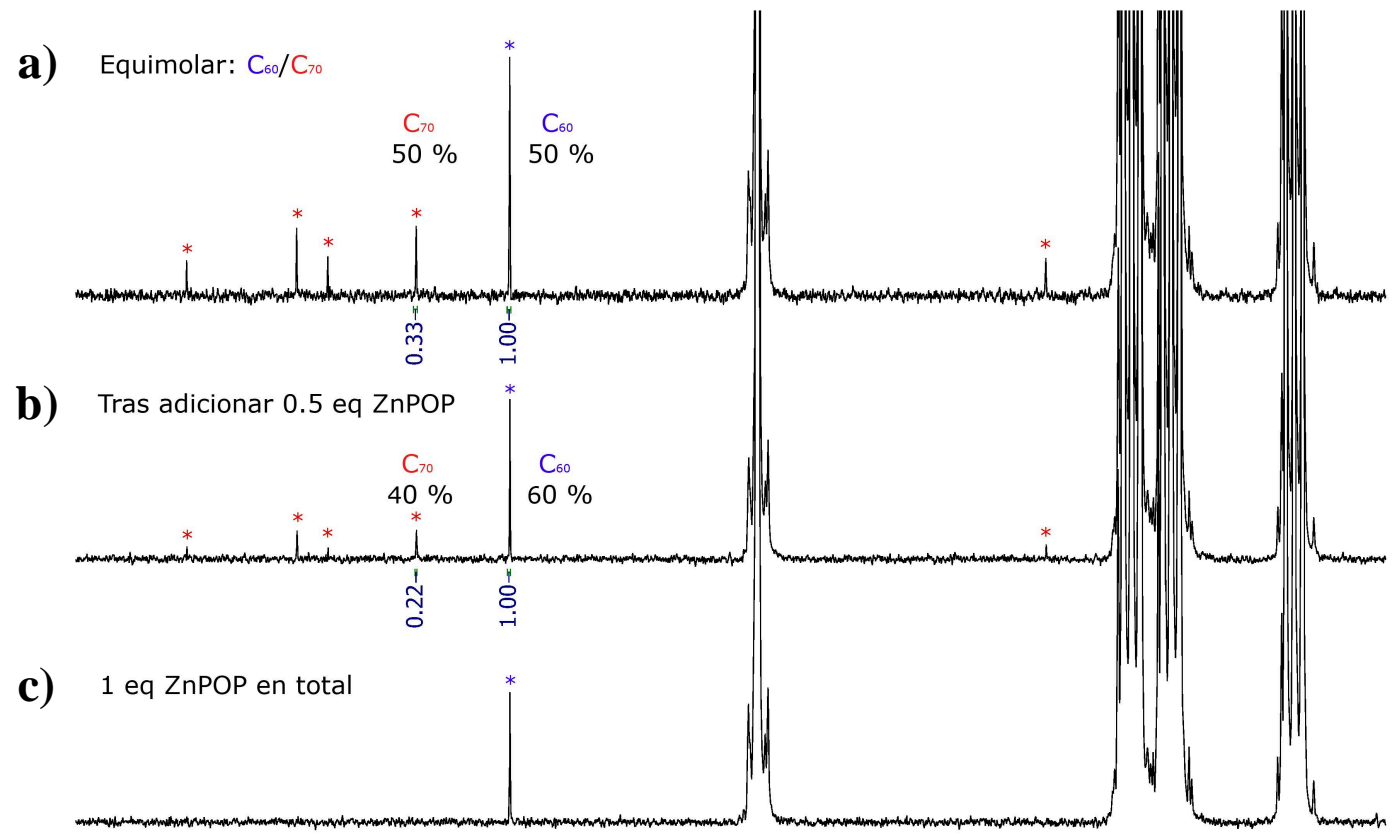

$\begin{array}{llllllllllllllllllllllllllllll}152 & 151 & 150 & 149 & 148 & 147 & 146 & 145 & 144 & 143 & 142 & 141 & 140 & 139 & 138 & 137 & 136 & 135 & 134 & 133 & 132 & 131 & 130 & 129 & 128 & 127 & 126 & 125 & 124 & 123\end{array}$

Figura 25. Espectros cuantitativos de ${ }^{13} \mathrm{C}\left\{{ }^{1} \mathrm{H}\right\}$-RMN (126 MHz, tolueno- $d_{8}$ ) de una disolución equimolar $\mathrm{C}_{60} / \mathrm{C}_{70}$ (a) antes de adicionar $\mathbf{Z n P O P , ~ ( b ) ~ t r a s ~ a n ̃ a d i r ~} 0.5$ equivalentes de ZnPOP y (c) tras adicionar un total de 1 equivalente de ZnPOP. Nótese cómo las señales pertenecientes al $\mathrm{C}_{70}$ se reducen como resultado de la formación del aducto de inclusión con la porfirina, llegando incluso a desaparecer por completo en el último experimento.

Estos experimentos muestran que en mezclas equimolares de $\mathrm{C}_{60} / \mathrm{C}_{70}$, es posible obtener disoluciones enriquecidas en $\mathrm{C}_{60}$ en proporciones de 1:8.1 (Tabla 4) empleando el sistema ZnPOP (1 equivalente). La pérdida obtenida por coprecipitación en este caso sólo es del 13\% con respecto al valor inicial de $\mathrm{C}_{60}$, mejorando los resultados obtenidos para el análogo sin metalar 2HPOP, para los cuales la perdida es del $42 \%$. 


\begin{tabular}{|c|c|ccc|}
\hline & Fullereno & RMN & UV-Vis & HPLC \\
\hline \multirow{2}{*}{ Equimolar } & $\mathbf{C}_{60}$ & $50 \%$ & $48 \%(0.87 \mathrm{mM})$ & $49 \%(0.68 \mathrm{mM})$ \\
& $\mathbf{C}_{70}$ & $50 \%$ & $52 \%(0.92 \mathrm{mM})$ & $51 \%(0.71 \mathrm{mM})$ \\
\hline \multirow{2}{*}{0.5 eq ZnPOP } & $\mathbf{C}_{60}$ & $60 \%$ & - & - \\
& $\mathbf{C}_{70}$ & $40 \%$ & - & - \\
\hline \multirow{2}{*}{1 eq ZnPOP } & $\mathbf{C}_{60}$ & Única señal detectada & $87 \%(0,72 \mathrm{mM})$ & $89 \%(0,59 \mathrm{mM})$ \\
& $\mathbf{C}_{70}$ & - & $13 \%(0,11 \mathrm{mM})$ & $11 \%(0,07 \mathrm{mM})$ \\
\hline
\end{tabular}

Tabla 4. Resumen de porcentajes y concentraciones encontrados en la mezcla de fullerenos con ZnPOP.

En ese punto, hay que matizar que la molécula ZnPOP se comporta como una pinza sencilla, mientras que para el caso de 2HPOP, la pérdida de $\mathrm{C}_{60}$ como coprecipitado podría deberse a su comportamiento de pinza doble. Aunque estos resultados aún están lejos de ser excelentes en comparación con jaulas moleculares basadas en porfirinas específicamente diseñadas, ${ }^{160}$ muestran la utilidad de estas octa-pirenoporfirinas para enriquecer mezclas de fullerenos de una manera sencilla y práctica.

Como conclusiones, en este primer trabajo mediante una síntesis en dos etapas se ha obtenido un sistema de porfirina funcionalizado con ocho unidades de pireno que muestra una alta afinidad hacia $\mathrm{C}_{60} \mathrm{y}_{70}$. La clave del éxito radica en la incorporación en todas las posiciones meta de ocho restos pireno para obtener una porfirina meso-tetraarilsustituida, que proporciona un gran efecto sinérgico entre el núcleo de porfirina y las unidades PAH planas. Estas porfirinas de tipo "double picket fence" pueden actuar como pinzas dobles o sencillas. La coordinación de $\mathrm{Zn}^{+2}$ en el macrociclo de porfirina permite cambiar este comportamiento supramolecular frente a fullerenos. Por lo tanto, la selección del sistema como pinza doble (2HPOP) o pinza sencilla (ZnPOP) puede lograrse simplemente por la coordinación de $\mathrm{Zn}^{+2}$ a la porfirina. Además, estos compuestos pueden discriminar entre $\mathrm{C}_{70} \mathrm{y}_{60}$, y se ha demostrado su uso para el enriquecimiento de mezclas de fullerenos. Estos sistemas de porfirinas constituyen el primer ejemplo de discriminación entre $\mathrm{C}_{60}$ y $\mathrm{C}_{70}$ basados en una pinza molecular de pireno. Este tipo de discriminación generalmente se observa en sistemas que contienen PAH no planos de tipo coranuleno, que muestran una mejor complementariedad de forma, o en el caso de la utilización de jaulas moleculares complejas diseñadas específicamente.

${ }^{160}$ (a) C. Zhang, Q. Wang, H. Long, W. Zhang, J. Am. Chem. Soc., 2011, 133, 20995-21001, (b) Y. Shi, K. Cai, H. Xiao, Z. Liu, J. Zhou, D. Shen, Y. Qiu, Q.-H. Guo, C. Stern, M. R. Wasielewski, F. Diederich, W. A. Goddard, J. F. Stoddart, J. Am. Chem. Soc., 2018, 140, 13835-13842. 


\title{
5.2. PORFIRINAS MESO-OCTAARILSUSTITUIDAS SIMÉTRICAS CON LIGANDOS POLIAROMÁTICOS NO PLANOS
}

\author{
5.2.1. Artículo II: Octapodal Corannulene Porphyrin-Based Assemblies: Allosteric \\ Behavior in Fullerene Hosting
}

Tras los interesantes resultados obtenidos con ligandos PAH planos descritos en el Apartado 5.1, donde la presencia de ocho unidades de pireno en posiciones meta diera lugar a altas constantes de asociación hacia fullerenos, así como selectividad de $\mathrm{C}_{70}$ sobre $\mathrm{C}_{60}$, nos motivó a explorar un sistema basado en coranuleno. El coranuleno debido a su geometría curvada se encuentra mejor posicionado para producir interacciones supramoleculares con la superficie esférica del Buckminsterfullereno (Apartado 2.4.1.3). En el presente trabajo, y siguiendo un esquema sintético similar al descrito en el Apartado 5.1, se introducen unidades de coranuleno en las dos posiciones meta del grupo arilo, para de esta manera obtener una porfirina mesooctaarilsustituida simétrica (Figura 26a).

a)

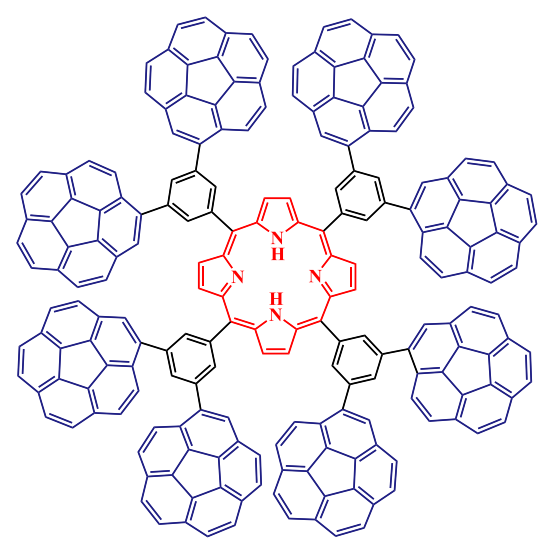

b)

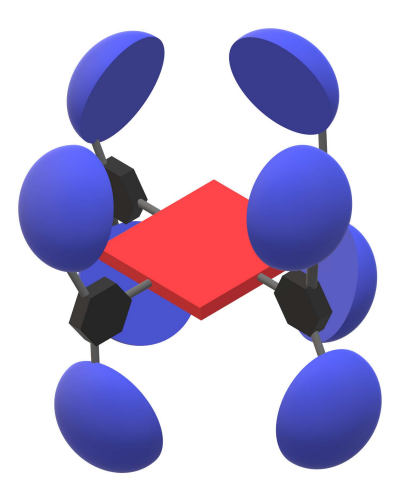

Figura 26. (a) Porfirina meso-octaarilsustituida simétrica con restos coranuleno desarrollada en el presente trabajo. (b) Representación esquemática de la porfirina mostrando la disposición espacial de los brazos aromáticos no planos idealmente dispuestos para interaccionar con fullerenos.

La disposición de los sustituyentes en estos sistemas porfirina octasustituidos permite evitar la formación de atropisomerismo, facilitando no sólo el análisis supramolecular con fullerenos sino también la obtención de mayores constantes de asociación al encontrarse los sustituyentes preorganizados para interaccionar con fullerenos. Además, esperamos incrementar los efectos sinérgicos presentes entre el núcleo de la porfirina y las unidades aromáticas no planas. Otro aspecto interesante es evaluar como la interacción del primer fullereno puede afectar a la interacción del segundo, es decir, la presencia o no de alosterismo y la capacidad del sistema para actuar como pinza sencilla o doble (Figura 26b).

Para obtener el compuesto coranulénico mostrado en la Figura 26 empleamos una síntesis convergente. Nuestro punto de partida es una porfirina adecuadamente funcionalizada para incorporar ocho sustituyentes aromáticos no planos. Elegimos la octa-bromoporfirina metasustituida 2H-POctaBr como precursor ideal de porfirina sobre el cual elaborar el marco más complejo deseado. Este compuesto presenta ocho átomos de bromo en la posición meta de la tetraaril meso-porfirina y permite realizar una múltiple reacción de Suzuki usando el apropiado éster borónico de coranuleno (Bpin-Cor) (Esquema 6). 


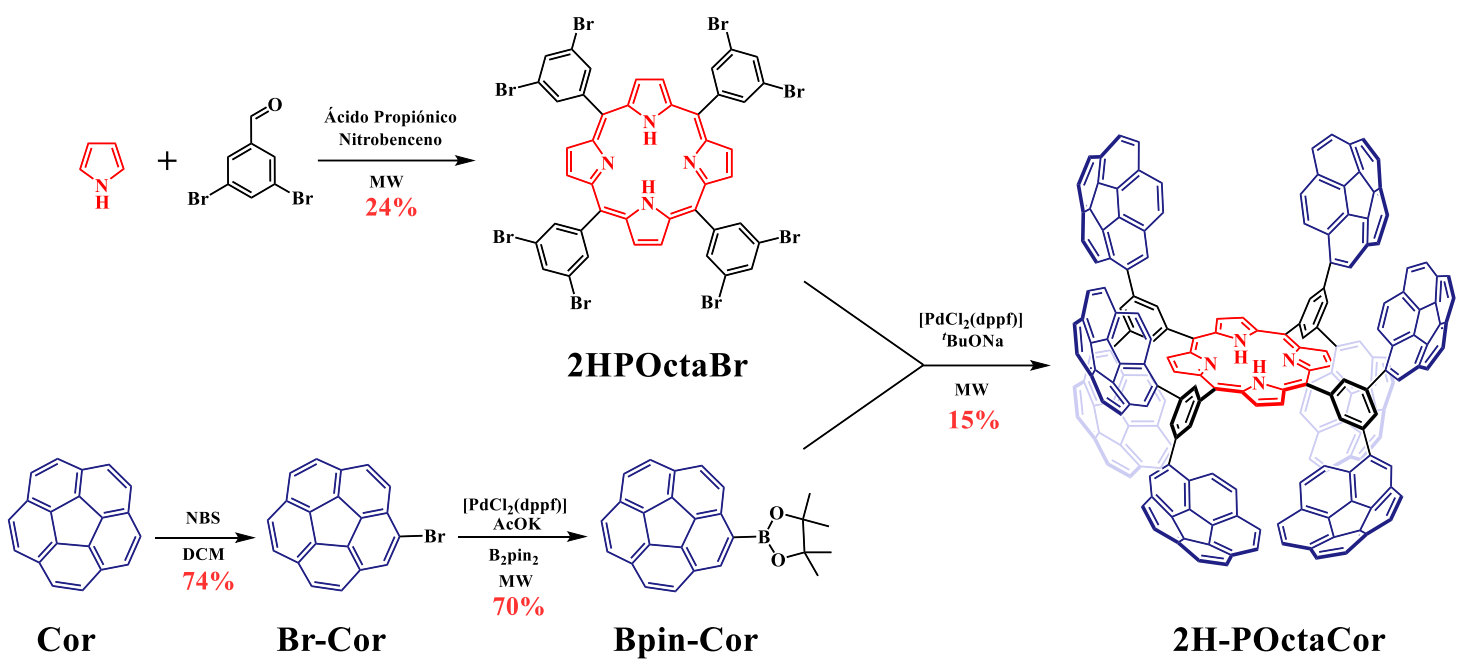

Esquema 6. Ruta sintética para la obtención del compuesto 2H-POctaCor.

La utilización de 1-pinacol coranulenoboronato (Bpin-Cor) es clave para la introducción de ocho unidades de coranuleno dentro del sistema porfirina por medio de la reacción de Suzuki. La borilación de coranuleno (Cor) a través de la reacción de Miyaura permite obtener Bpin-Cor a partir de 1-bromocoranuleno (Br-Cor). Esta reacción está asistida por radiación de microondas (Esquema 6). Este método mejora de forma significativa el tiempo de reacción en comparación con el método tradicional de síntesis de $24 \mathrm{~h}$ a reflujo frente a $80 \mathrm{~min}$ por MW. ${ }^{70 \mathrm{c}}$ Posteriormente, realizamos una óctuple reacción de Suzuki entre 2H-POctaBr y Bpin-Cor empleando radiación de microondas (Esquema 6). De esta forma, el compuesto 2H-POctaCor se pudo aislar con un rendimiento total del 15\% tras optimización. De hecho, cambiando las posiciones de los grupos funcionales involucrados en la reacción, es decir haciendo reaccionar Br-Cor y 2 HPOB o ZnPOB, conduce a rendimientos decepcionantes del 1 - 5\%. Además, en este caso se obtiene un gran número de productos de reacción incompletos (porfirinas que contienen menos de ocho unidades de coranuleno) y otras impurezas que impiden obtener 2H-POctaCor de forma pura. En claro contraste, la ruta optimizada mostrada en el Esquema 6 permite obtener 2H-POctaCor con un rendimiento del 15\%, que es muy satisfactorio si se tiene en cuenta que involucra ocho reacciones de acoplamiento $\mathrm{C}-\mathrm{C}$ catalizado por paladio. Cabe mencionar, que este sistema contiene el mayor número de restos coranuleno anclados a una única molécula hasta la fecha. Hay que resaltar que el uso de MW es muy beneficioso en algunos pasos sintéticos que involucran múltiples reacciones de acoplamiento C-C en las que la rápida formación de subproductos podría dificultar la obtención del producto deseado final. ${ }^{121}$

A pesar de la poca solubilidad de la porfirina octapodal de coranuleno 2H-POctaCor, ésta pudo caracterizarse por métodos espectroscópicos. El espectro de absorción UV-Vis exhibe la típica banda intensa Soret a $426 \mathrm{~nm}$ junto a otras bandas Q menos intensas a mayores longitudes de onda. Por otro lado, el espectro de ${ }^{1} \mathrm{H}-\mathrm{RMN}$ de la octa-coranulenoporfirina simétrica $\mathbf{2 H}$ POctaCor en cloroformo- $d$ es bastante sencillo debido a la alta simetría del compuesto (Figura 27). Los protones de los dos grupos $\mathrm{NH}\left(\mathrm{H}_{1}\right)$ aparecen a un característico desplazamiento químico de campo alto $(\delta=-2.50 \mathrm{ppm})$. Sólo una señal de beta pirrol $\left(\mathrm{H}_{2}\right)$ está presente a campo bajo $(\delta=$ $9.31 \mathrm{ppm}$ ). Estos datos, junto con la equivalencia de las ocho unidades de coranuleno, indican una simetría efectiva $\mathrm{D}_{4 \mathrm{~h}}$ en disolución. La mayoría de las señales aromáticas pertenecientes al coranuleno aparecen en un intervalo de desplazamientos químicos muy pequeño, imposibilitando una asignación completa de todos los núcleos protónicos. 


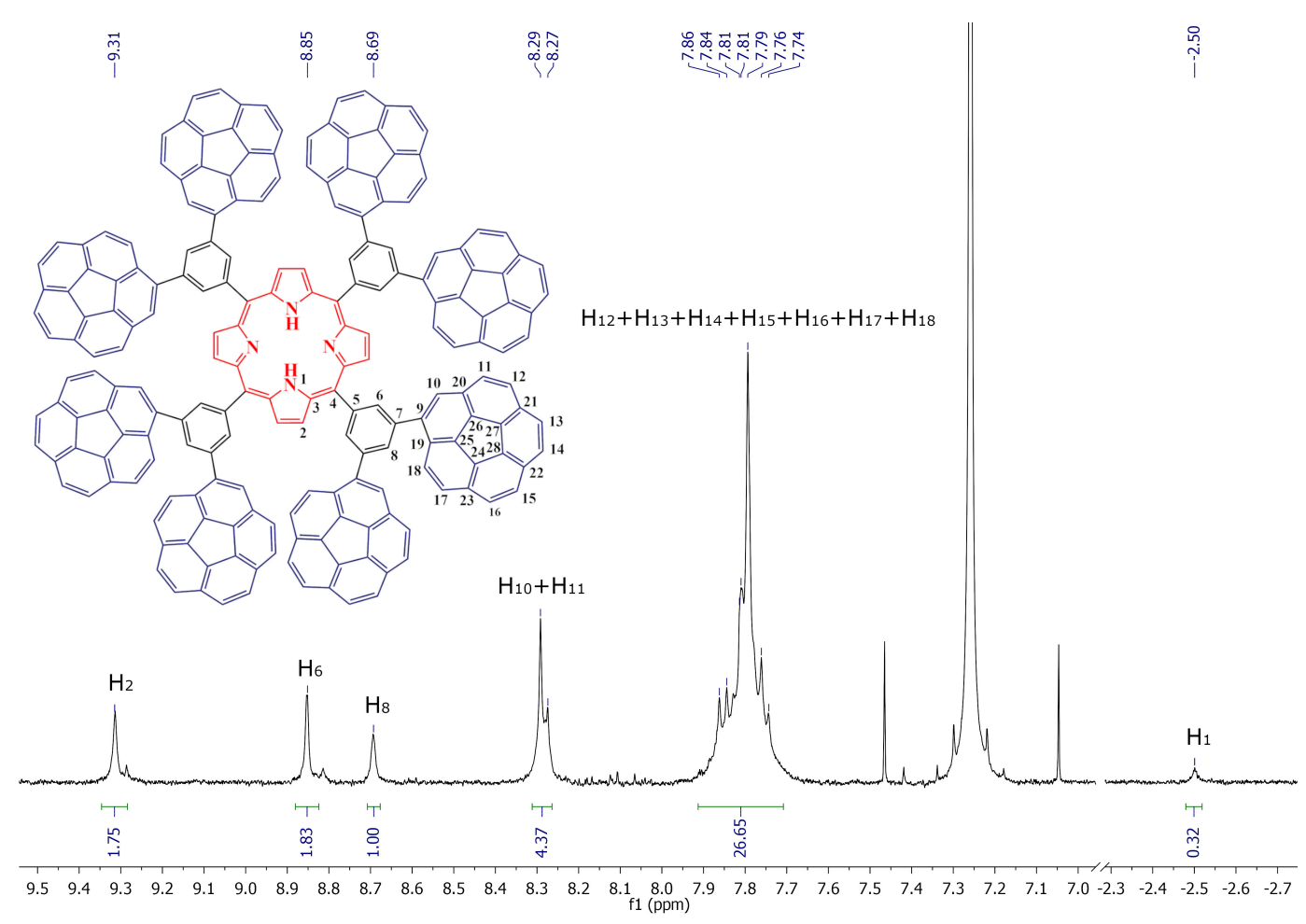

Figura 27. Espectro de ${ }^{1} \mathrm{H}-\mathrm{RMN}\left(500 \mathrm{MHz}, \mathrm{CDCl}_{3}\right)$ de la porfirina 2H-POctaCor.

Finalmente, la confirmación de esta octa-coranulenoporfirina se llevó a cabo por espectrometría de masas de alta resolución (HRMS). La Figura 28 muestra el pico esperado para el ion molecular protonado $\mathrm{C}_{204} \mathrm{H}_{94} \mathrm{~N}_{4}[\mathrm{M}+\mathrm{H}]^{+}$a $\mathrm{m} / z 2601.7586$ (calculado 2601.7619, $3.3 \mathrm{ppm}$ de error).

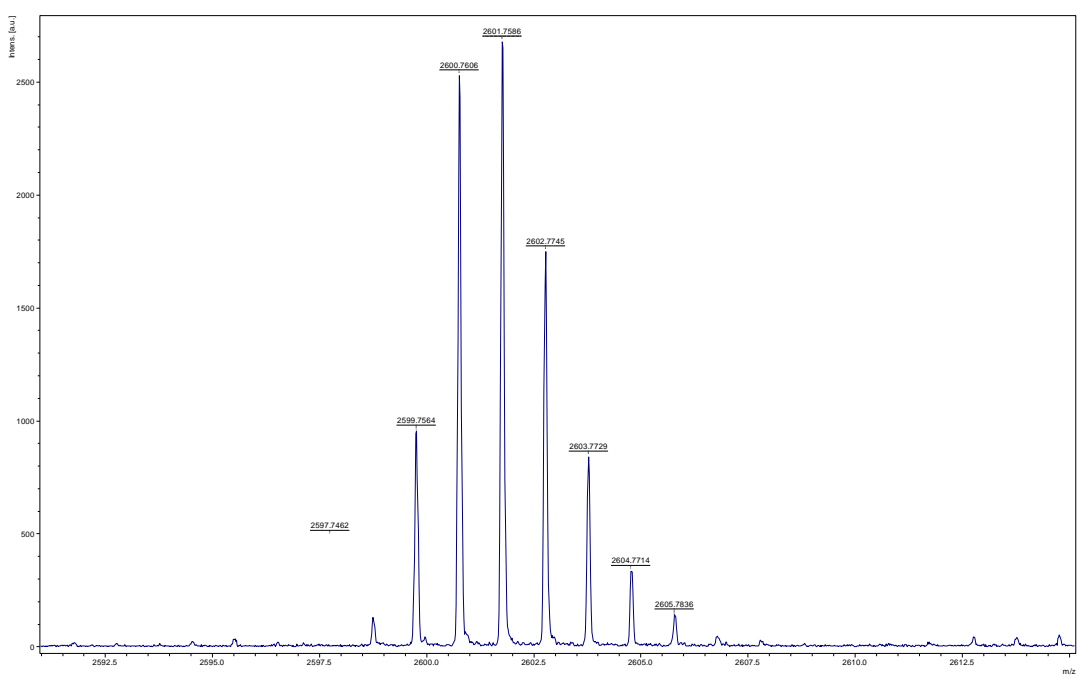

Figura 28. HRMS (MALDI-TOF) en dithranol del compuesto 2H-POctaCor $[\mathrm{M}+\mathrm{H}]^{+}$.

Como puede apreciarse en el espectro de ${ }^{1} \mathrm{H}-\mathrm{RMN}$ de la Figura 29, las señales son relativamente anchas y no sufren cambios significativos con la dilución. Aunque es probable que exista cierto grado de apilamiento $\pi$ intermolecular, esta observación sugiere la presencia de interacciones intramoleculares de tipo $\pi{ }^{72 b, d, 84 a, c, 92,161}$

${ }^{161}$ B. Topolinski, B. M. Schmidt, M. Kathan, S. I. Troyanov, D. Lentz, Chem. Commun., 2012, 48, 6298-6300. 


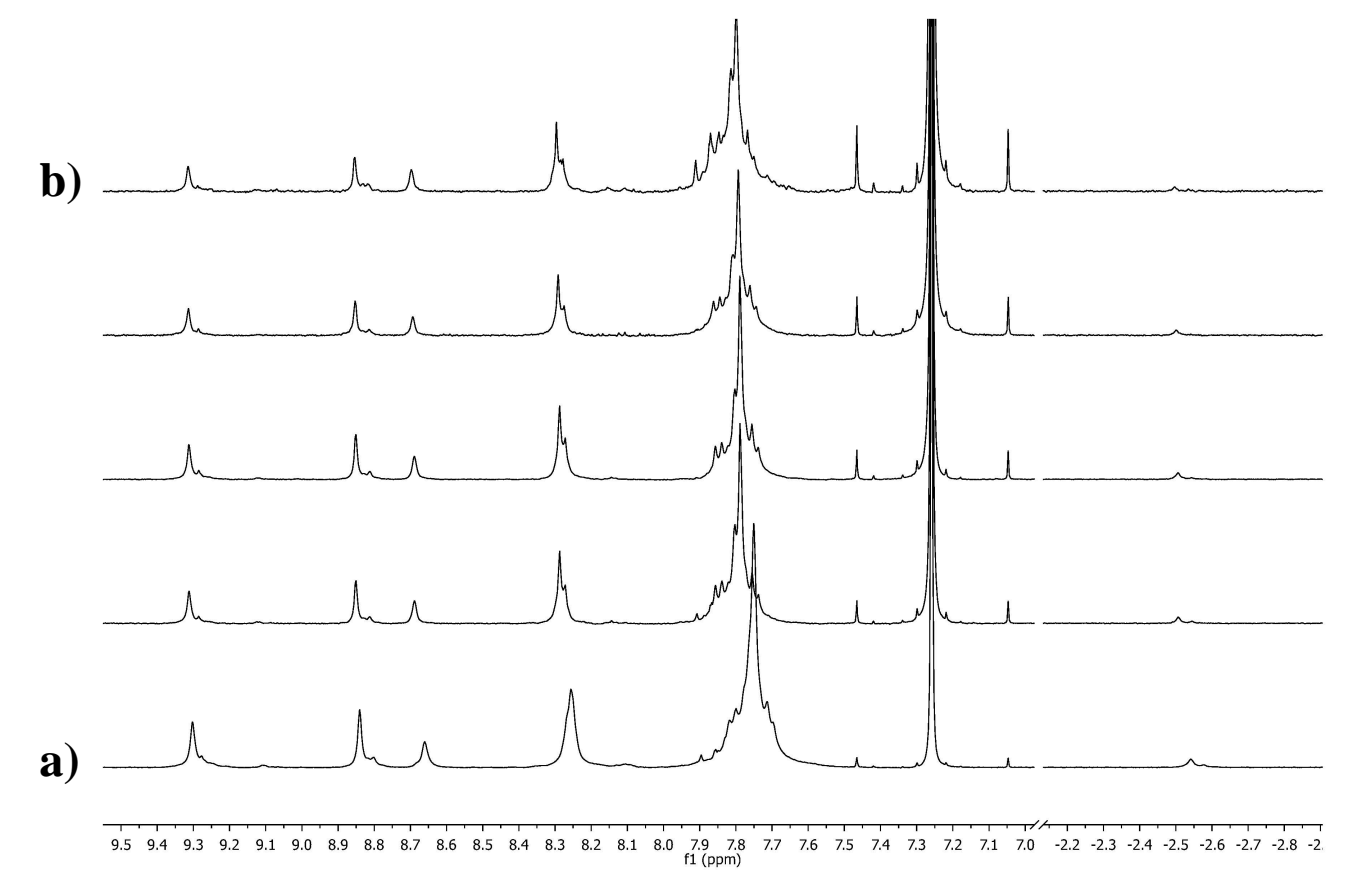

Figura 29. Espectros de ${ }^{1} \mathrm{H}-\mathrm{RMN}\left(500 \mathrm{MHz}, \mathrm{CDCl}_{3}\right)$ de 2H-POctaCor tras añadir alícuotas de $\mathrm{CDCl}_{3}$. Inicial: $10^{-4} \mathrm{M}(\mathrm{a})$. Final: $10^{-5} \mathrm{M}(\mathrm{b})$.

Para explorar más la posibilidad de la existencia de interacciones intramoleculares de tipo $\pi$, el compuesto 2H-POctaCor se optimizó primero mediante una búsqueda conformacional por mecánica molecular. Posteriormente se llevó a cabo una completa optimización DFT de los mejores candidatos encontrados usando un nivel de teoría de B97D3/6-31G(d,p). ${ }^{146,}{ }^{147}$ Llama la atención, que el mínimo de energía más bajo corresponde a un confórmero cuyo núcleo de porfirina se ha distorsionado de forma sustancial, dando como resultado una geometría en forma de silla de montar (Figura 30). Esta situación se origina por las interacciones de apilamiento cóncavo - convexo entre pares de unidades de coranuleno. La posible formación de confórmeros como resultado de estas interacciones intramoleculares probablemente contribuyan al ensanchamiento de las señales observado en el espectro de RMN de ${ }^{1} \mathrm{H}$ (Figura 29).
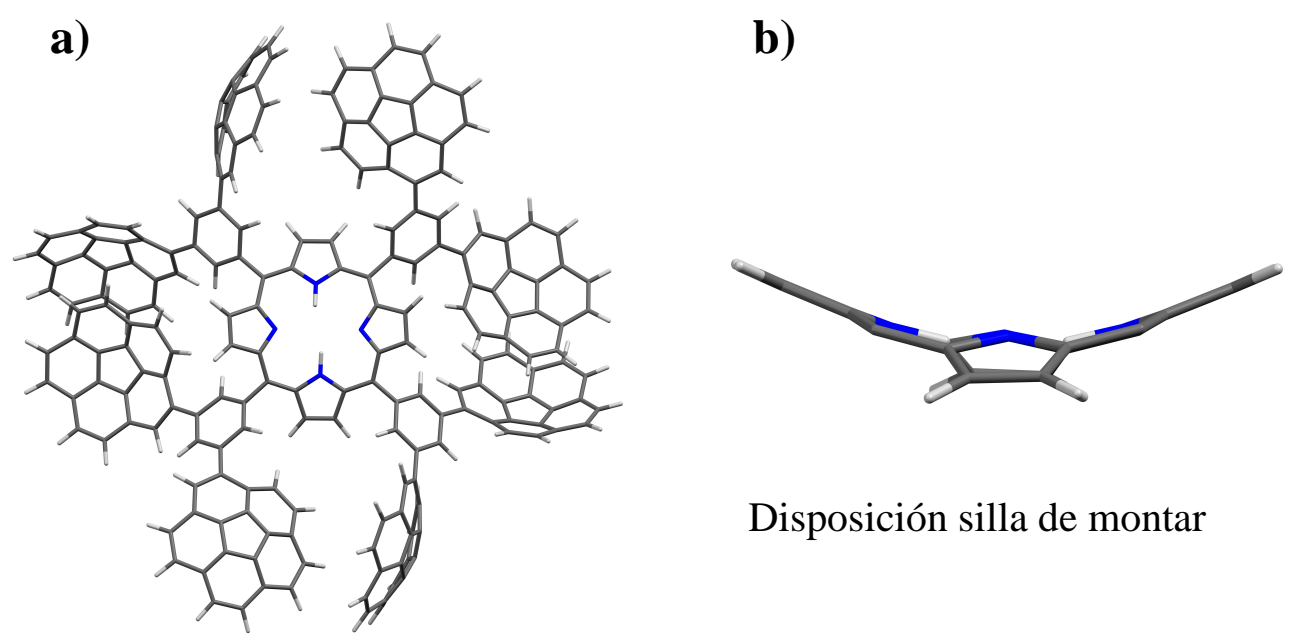

Disposición silla de montar

Figura 30. (a) Vista superior del mínimo de energía más bajo de la estructura optimizada del compuesto 2H-POctaCor. (b) Vista lateral del anillo de porfirina donde se muestra la disposición de silla de montar. 
La Figura 30a muestra que se establecen interacciones de carácter $\pi-\pi$ entre pares de unidades de coranuleno. Sin embargo, estas interacciones podrían producir penalizaciones energéticas a la hora de alojar fullerenos. Esto se debe a que todas las interacciones de coranuleno tienen que superarse antes de llevar a cabo la interacción con fullerenos. Por último, gracias a los cálculos DFT, observamos que la porfirina adopta una disposición $4+4$, por arriba y por abajo del plano de la porfirina distorsionada, en una disposición espacial de tipo "double picket fence". Esta orientación espacial de los restos coranuleno podría conducir a la unión de dos fullerenos, es decir a un comportamiento de doble pinza de 2 H-POctaCor.

Con el objetivo de investigar estos posibles inconvenientes y estudiar el comportamiento supramolecular de $\mathbf{2 H}$-POctaCor, realizamos experimentos de valoración con $\mathrm{C}_{60}$ y $\mathrm{C}_{70}$ por ${ }^{1} \mathrm{H}$ RMN en tolueno- $d_{8}$. Una faceta importante que nos gustaría explorar es si la octacoranulenoporfirina podría actuar como receptor de dos fullerenos. Debido a la baja solubilidad de 2H-POctaCor en tolueno- $d_{8}$, seleccionamos una concentración inicial de Host $[\mathrm{H}]_{0}=10^{-5} \mathrm{M}$. Tras la adición de 0.17 eq de $\mathrm{C}_{60}$ observamos un desplazamiento en las señales de ${ }^{1} \mathrm{H}-\mathrm{RMN}$, indicando que el evento supramolecular entre 2H-POctaCor y el Buckminsterfullereno se está produciendo. Además del cambio en el desplazamiento químico observamos un ensanchamiento de las señales (Figura 31a). Este suceso se atribuye a un régimen de intercambio intermedio en la escala de tiempos de RMN entre el Guest libre y enlazado. ${ }^{162}$ Hacia el final de la valoración (en presencia de un exceso de $\mathrm{C}_{60}$ ) las señales vuelven a ser agudas, debido a que el equilibrio está completamente desplazado hacia la formación del complejo de inclusión $\mathrm{C}_{60} @ \mathbf{2 H}$-POctaCor. A pesar de este ensanchamiento, la señal perteneciente al beta pirrol $\left(\mathrm{H}_{2}\right)$, que se mantiene relativamente aguda y definida durante todo el proceso, pudo seguirse fácilmente durante el transcurso de la valoración (Figura 31a). Un comportamiento similar sucede durante la valoración del sistema $2 \mathrm{H}$-POctaCor y $\mathrm{C}_{70}$ (Figura $31 \mathrm{~b}$ ). Tras la adición de alícuotas de $\mathrm{C}_{70}$, observamos un desplazamiento en las señales de protón indicativo de la formación del evento Host-Guest en disolución. En este caso, percibimos un ensanchamiento muy acusado de las resonancias. Pese a ello, la señal correspondiente al beta pirrol $\left(\mathrm{H}_{2}\right)$ pudo seguirse apropiadamente durante la valoración y su desplazamiento es indicativo del proceso de asociación supramolecular (Figura $31 b)$.

En ambos estudios con fullerenos, los datos de las isotermas de unión (binding isotherm) obtenidas pueden ajustarse a un modelo 1:1 (Figura 31c y d). La constante de asociación para $\mathrm{C}_{70}\left(\mathrm{~K}_{1}=2.13 \pm 0.10 \times 10^{5} \mathrm{M}^{-1}\right)$ es un orden de magnitud superior que para el $\mathrm{C}_{60}\left(\mathrm{~K}_{1}=2.71 \pm\right.$ $0.08 \times 10^{4} \mathrm{M}^{-1}$ ). Este resultado muestra que nuestro sistema supramolecular exhibe un cierto grado de selectividad hacia $\mathrm{C}_{70}$. Además, las interacciones intramoleculares entre las unidades coranulénicas en 2H-POctaCor (Figura 30a) aparentemente no disminuyen su capacidad para alojar fullerenos. Este hecho contrasta con los sistemas tris-coranuleno (véase Aparatado 2.4.1.4.3), donde las interacciones intramoleculares entre las unidades de coranuleno son las responsables de las bajas afinidades hacia el Buckminsterfullereno observadas.

162 (a) M. Pons, O. Millet, Prog. Nucl. Magn. Reson. Spectrosc., 2001, 38, 267-324, (b) A. D. Bain, Prog. Nucl. Magn. Reson. Spectrosc., 2003, 43, 63-103, (c) I. R. Kleckner, M. P. Foster, Biochim. Biophys. ActaProteins Proteomics, 2011, 1814, 942-968. 

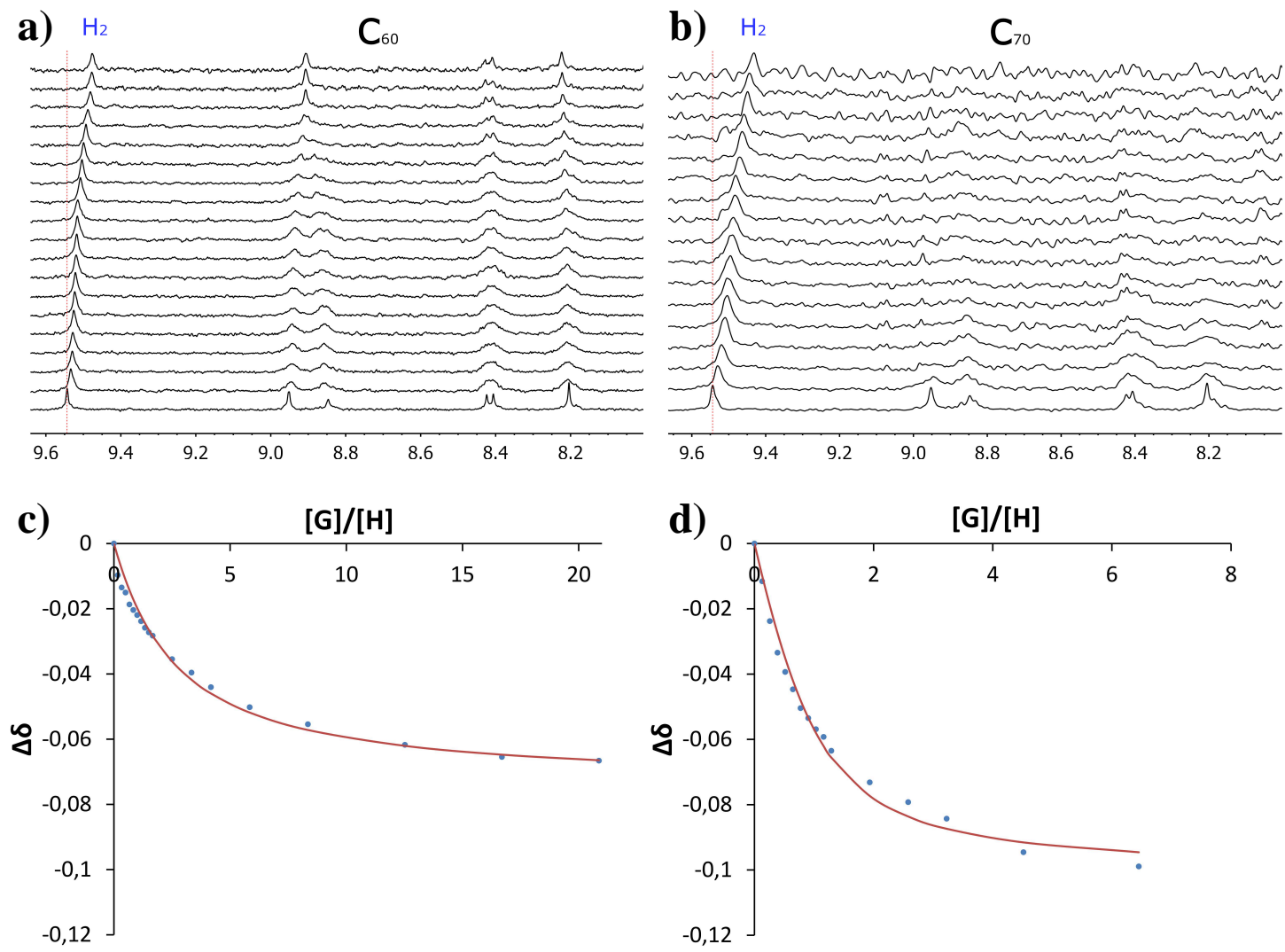

Figura 31. (a y b) Espectros de ${ }^{1} \mathrm{H}-\mathrm{RMN}\left(500 \mathrm{MHz}\right.$, tolueno- $\left.d_{8}\right)$ mostrando el cambio en desplazamiento químico de $\mathrm{H}_{2}$ de $\mathbf{2 H}$-POctaCor tras la adición de alícuotas de (a) $\mathrm{C}_{60} \mathrm{O}$ (b) $\mathrm{C}_{70}$. (c y d) Gráficas correspondientes a los cambios en desplazamientos químicos frente la fracción molar del fullereno [G]/[H], donde [G] (Guest) corresponde al (c) $\mathrm{C}_{60}$ o (d) $\mathrm{C}_{70}$ y [H] (Host) es 2H-POctaCor. La línea roja pertenece al ajuste no lineal de $\Delta \delta\left(\mathrm{H}_{2}\right)$ para una isoterma de unión de un modelo 1:1.

Los efectos alostéricos son un aspecto clave para entender los procesos de reconocimiento molecular en la Química Supramolecular. Estos efectos alostéricos pueden presentar valores positivos o negativos (inhibitorios) y juegan un papel crucial en sistemas bioquímicos complejos. Así, cuando el efecto es positivo indica que la interacción del primer centro receptor incrementa la afinidad aceptora por el segundo centro vacante. Por otro lado, cuando el efecto es negativo produce efectos contrarios, llegando en algunos casos a inhibir de forma completa la interacción supramolecular por el segundo centro receptor. Un conocido ejemplo de proceso inhibitorio afecta a la enzima aspartato-transcarbamilasa que sufre un cambio estructural resultando en una conformación inactiva. ${ }^{163}$ Otro caso muy conocido, en este caso de alosterismo positivo, es la coordinación de la primera molécula de oxígeno por parte del grupo hemo en el sistema hemoglobina-oxígeno. Dicha coordinación induce cambios conformacionales que resultan en una mayor afinidad por la coordinación de la segunda molécula de $\mathrm{O}_{2}$ al otro centro receptor remanente (véase Apartado 2.1). ${ }^{12}$

Es importante resaltar que nuestro sistema octapodal no muestra evidencias de un modelo de asociación 1:2, a pesar de su obvio potencial para actuar como una doble pinza al presentar dos posibles centros receptores por arriba y por abajo del plano de porfirina (Figura 26b). La asociación del primer fullereno por parte de $\mathbf{2 H}$-POctaCor parece inhibir la interacción de una segunda unidad de fullereno. Por todo esto consideramos que este sistema coranulénico octapodal

163 (a) M. N. Blackburn, H. K. Schachman, Biochemistry, 1977, 16, 5084-5091, (b) J. A. Endrizzi, P. T. Beernink, T. Alber, H. K. Schachman, Proc. Natl. Acad. Sci., 2000, 97, 5077-5082. 
es un candidato perfecto para el estudio de posibles efectos alostéricos en el proceso de interacción con fullerenos. Con el objetivo de profundizar en la comprensión de este fenómeno, realizamos cálculos DFT para arrojar luz sobre el mecanismo por el cual se observa una estequiometria 1:1 en lugar de 1:2 en los experimentos en disolución realizados por RMN. Otro aspecto interesante que nos gustaría evaluar es si todas las unidades de coranuleno están involucradas en el proceso de reconociendo molecular. La estructura del complejo de inclusión $\mathrm{C}_{60} @ \mathbf{2 H}$-POctaCor obtenido por cálculos DFT se muestra en la Figura 32.

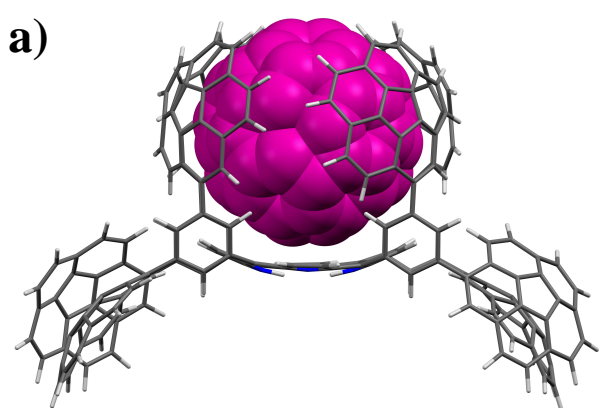

c)

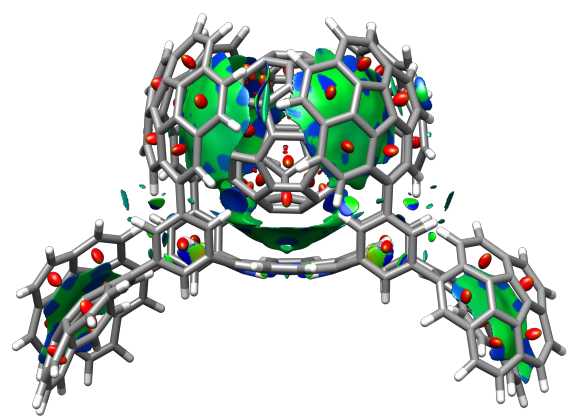

b)

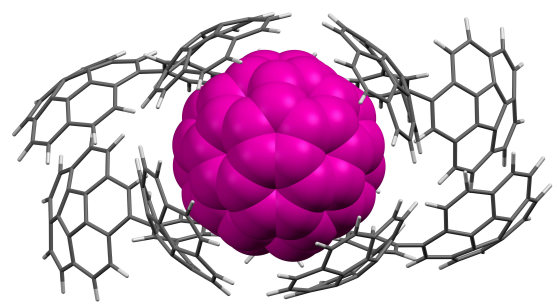

d)

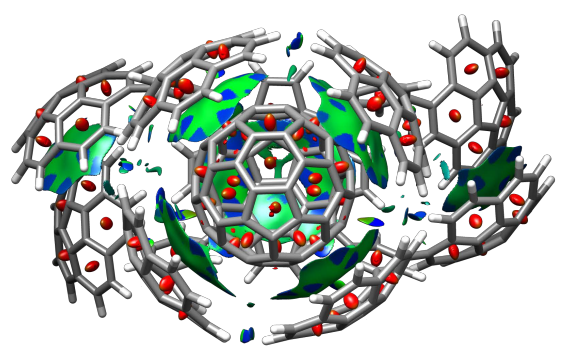

Figura 32. (a y b) Estructuras optimizadas DFT de $\mathrm{C}_{60} @$ 2H-POctaCor. (a) Vista lateral y (b) superior de la estructura optimizada. (c y d) Mismas perspectivas que las anteriores mostrando los gráficos de las interacciones no covalentes (NCIPlot) de la estructura optimizada $\mathrm{C}_{60} @ 2 \mathrm{H}-$ POctaCor.

Como puede observarse en la Figura 32a, el núcleo de porfirina posee un cierto grado de flexibilidad que permite a las cuatro unidades de coranuleno de la misma cara del anillo de porfirina orientarse para generar una interacción óptima con la superficie externa del fullereno. Asimismo, para poder maximizar estas interacciones, los hidrógenos en posiciones orto de los sustituyentes fenileno tienden a apuntar hacia el $\mathrm{C}_{60}$. Por otro lado, el núcleo de porfirina participa de forma activa en el proceso de interacción supramolecular, ya que la distancia entre el núcleo y el fullereno se encuentra dentro del intervalo de contacto de dispersión atractiva (2.869 ̊). Estas fuertes interacciones para envolver efectivamente la superficie del $\mathrm{C}_{60}$ conducen a la compresión de los brazos de coranuleno de la cara activa de la porfirina (Figura 32a). Las interacciones supramoleculares entre el Host y el $\mathrm{C}_{60}$ se observan más fácilmente sobre la base de los puntos críticos. ${ }^{152}$ La Figura 32c y d muestra cuatro interacciones atractivas procedentes de los brazos de coranuleno junto con una interacción adicional procedente del núcleo de porfirina, todas ellas dispuestas en forma de cuenco entre el fullereno y la molécula 2H-POctaCor. La excelente complementariedad entre el $\mathrm{C}_{60}$ y la porfirina queda reflejada en las isosuperficies que cubren la superficie del fullereno casi en su totalidad. También pueden observarse interacciones entre las otras unidades de coranuleno del otro lado de la molécula que están interaccionando entre sí. Estas contribuciones adicionales intramoleculares contribuyen a la estabilización global del aducto supramolecular. 
Estos datos muestran que la interacción con fullereno para dar lugar al aducto $\mathrm{C}_{60} @ \mathbf{2 H}$ POctaCor $\left(\mathrm{K}_{1}\right.$ del equilibrio 1:1) deforma la geometría inicial de $\mathbf{2 H}$-POctaCor. Tal y como se puede apreciar en Figura 32a, al comprimirse la cara activa de la porfirina alrededor del $\mathrm{C}_{60}$ se produce la expansión de las cuatro unidades de coranuleno de la otra cara. Esta deformación conduce a una mala preorganización del Host provocando que las cuatro unidades de coranuleno de la cara inactiva ahora se encuentren demasiado lejos para la interacción con una segunda unidad fullereno.

A la vista de estos resultados, decidimos también estudiar la interacción con una segunda molécula de $\mathrm{C}_{60}$. Para ello, la estructura del complejo $\left(\mathrm{C}_{60}\right)_{2} @ \mathbf{2 H}-\mathbf{P O c t a C o r}$ se optimizó mediante cálculos DFT (Figura 33).

a)

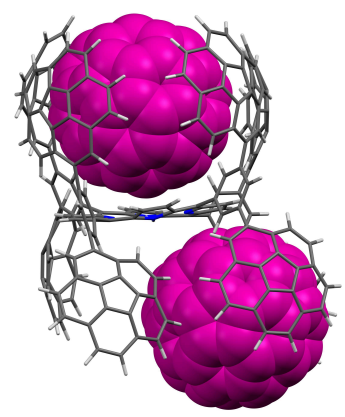

b)

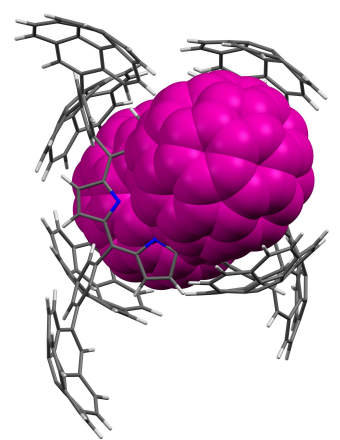

c)

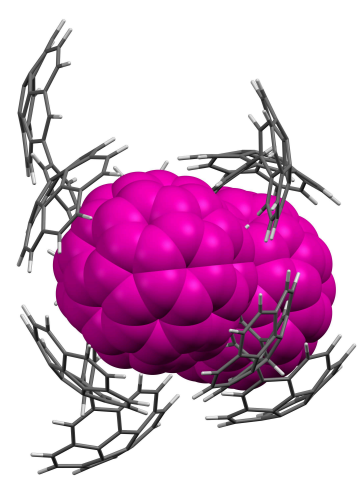

Figura 33. (a) Vista lateral, (b) inferior y (c) superior de la estructura optimizada $\left(\mathrm{C}_{60}\right)_{2} @ 2 \mathrm{H}-\mathrm{POctaCor}$.

La asociación de la primera molécula de fullereno con la porfirina dificulta una asociación eficiente con la segunda molécula que se acerca por la otra cara. El Host sufre una reorganización estructural que resulta en una conformación sub-óptima para poder acomodar la segunda unidad de fullereno. La interacción entre el primer $\mathrm{C}_{60} \mathrm{y}$ el núcleo de porfirina se reduce de forma considerable para cubrir parcialmente la superficie del segundo $\mathrm{C}_{60}$. Por tanto, el alojamiento del primer fullereno en el aducto $\mathrm{C}_{60} @ \mathbf{2 H}$-POctaCor conduce a un alosterismo negativo (inhibitorio), dificultando o evitando la asociación por parte del segundo Buckminsterfullereno. Este efecto puede atribuirse al cambio conformacional del segundo centro receptor tras la interacción del primer fullereno.

Es bien conocido que la coordinación de metales puede conducir a cambios en la geometría del anillo macrocíclico de porfirina. Para estudiar si es posible evitar el cambio conformacional inhibitorio de este sistema tras la interacción con el primer $\mathrm{C}_{60}$, coordinamos $\mathrm{Zn}^{2+}$ en la porfirina. Como resultado de la coordinación del metal, esperamos que la metaloporfirina Zn-POctaCor, muestre un menor grado de flexibilidad del núcleo macrocíclico en comparación con la porfirina de partida 2H-POctaCor.

La metalación de la octa-coranulenoporfirina 2H-POctaCor puede realizarse de forma sencilla por reacción con $\mathrm{Zn}(\mathrm{AcO})_{2} \cdot 2 \mathrm{H}_{2} \mathrm{O}$ utilizado un método asistido por radiación de microondas $\left(120{ }^{\circ} \mathrm{C}, 90 \mathrm{~min}\right.$, tolueno/ $\left.\mathrm{CHCl}_{3}\right)$. Este método permite la obtención de $\mathbf{Z n}$ POctaCor, tras una etapa final de purificación, con un rendimiento excelente cuantitativo (86\%) (Esquema 7). 


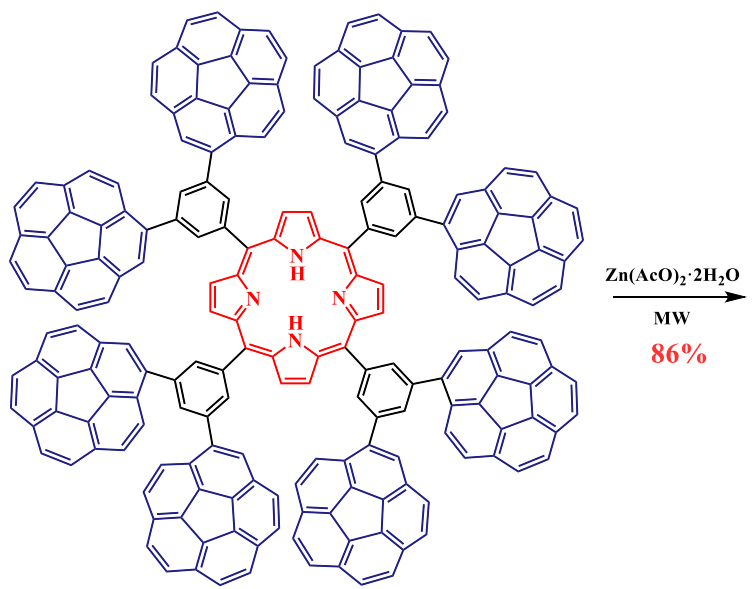

2H-POctaCor

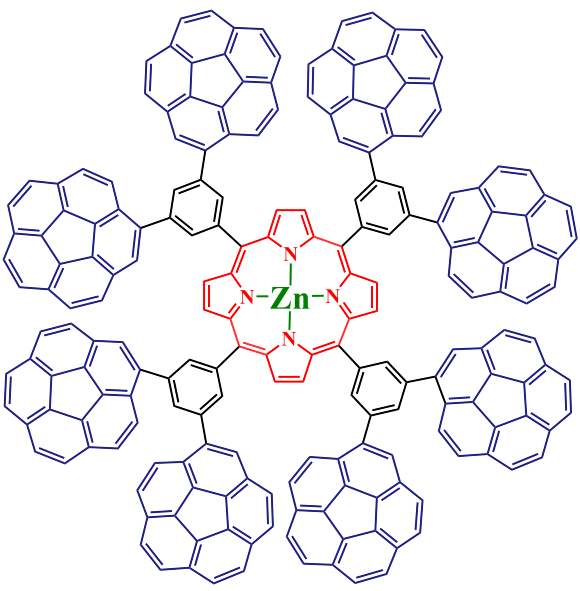

Zn-POctaCor

Esquema 7. Síntesis de la metaloporfirina Zn-POctaCor.

El espectro de ${ }^{1} \mathrm{H}-\mathrm{RMN}$ de la octa-coranulenoporfirina simétrica metalada de coranuleno Zn-POctaCor (Figura 34) muestra la desaparición de los protones internos pertenecientes al grupo NH de la porfirina. También, observamos una única señal correspondiente al beta pirrol $\left(\mathrm{H}_{2}\right)$, indicativo de una simetría $\mathrm{D}_{4 \mathrm{~h}}$, a un desplazamiento químico de $\delta=9.41 \mathrm{ppm}$. Como en el caso de 2H-POctaCor, las señales aromáticas resuenan en un intervalo de desplazamiento químico muy pequeño, impidiendo la asignación completa de todos los protones.

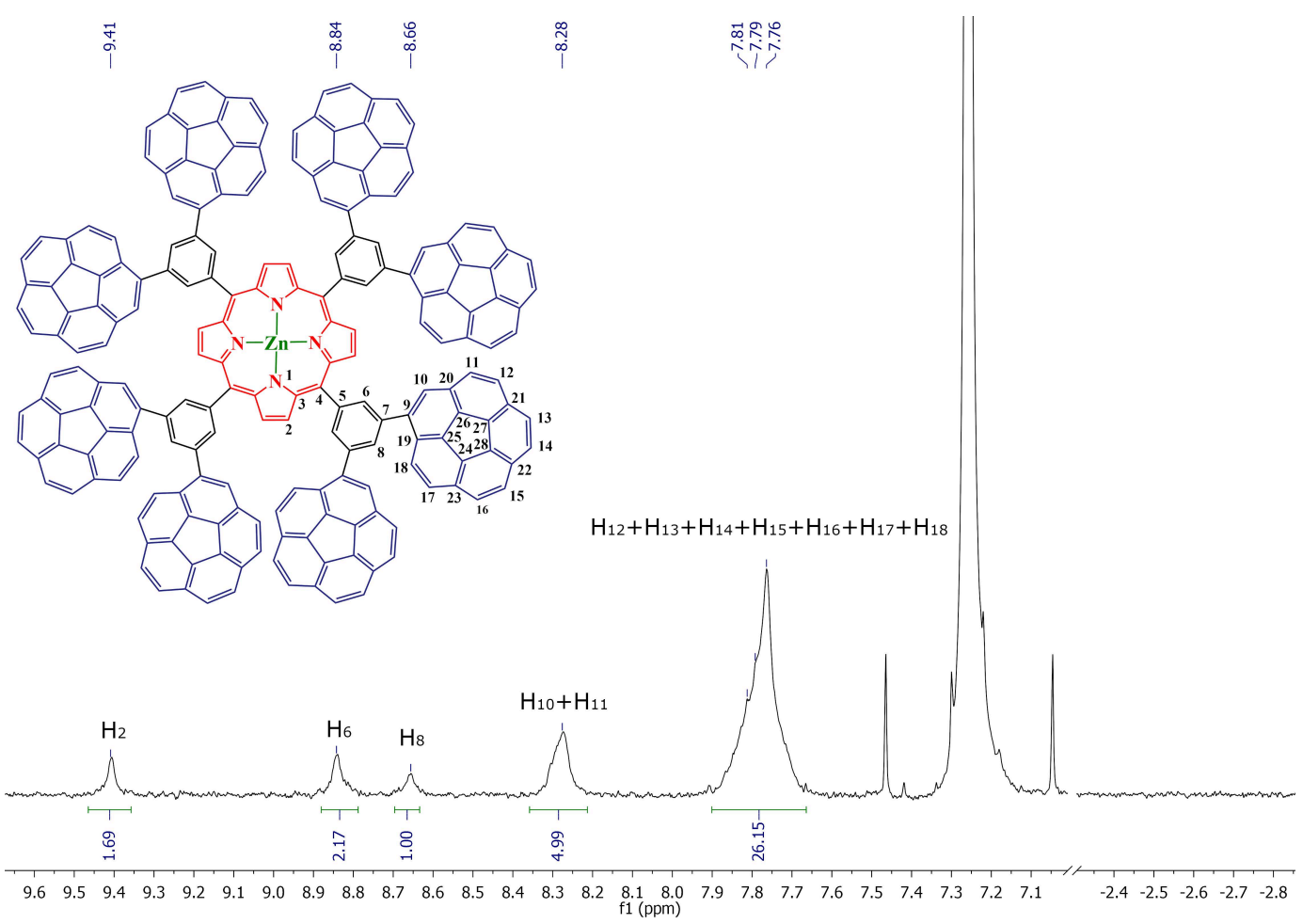

Figura 34. Espectro de ${ }^{1} \mathrm{H}-\mathrm{RMN}\left(500 \mathrm{MHz}, \mathrm{CDCl}_{3}\right)$ de la porfirina Zn-POctaCor. 
El espectro de absorción UV-Vis en tolueno de las porfirinas octapodales 2H-POctaCor y Zn-POctaCor (Figura 35) muestran las características banda Soret y bandas Q. La intensa banda Soret refleja un pequeño desplazamiento hacia el rojo para Zn-POctaCor (431 nm) comparando con 2H-POctaCor $(426 \mathrm{~nm})$. Esto sugiere que la coordinación del metal podría distorsionar ligeramente el núcleo plano de porfirina. ${ }^{110 c, d, e, ~} 158$

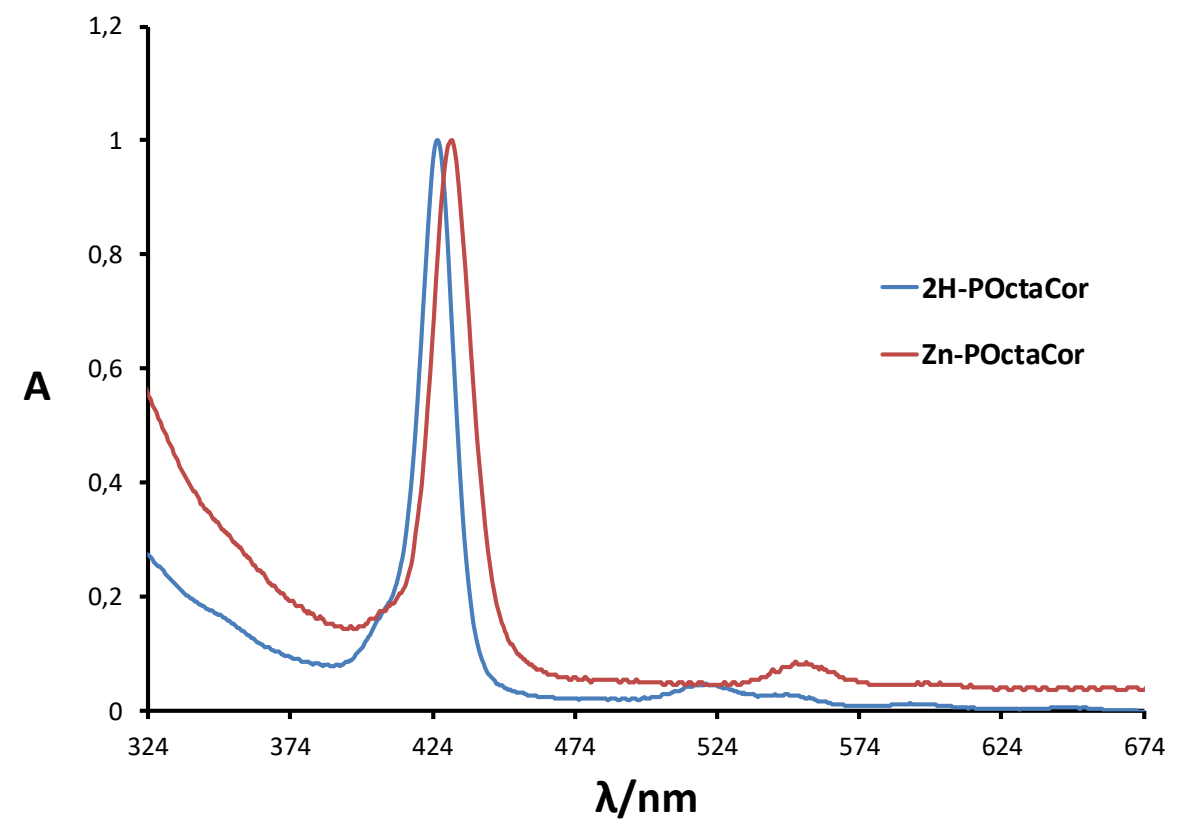

Figura 35. Espectro normalizado de absorción UV-Vis en tolueno de las porfirinas $\mathbf{2 H}$ POctaCor y Zn-POctaCor.

La valoración por ${ }^{1} \mathrm{H}-\mathrm{RMN}$ en tolueno- $d_{8}$ de Zn-POctaCor con $\mathrm{C}_{60}$ y $\mathrm{C}_{70}$ dio lugar a un desplazamiento de las señales junto a un gran ensanchamiento de las mismas. La anchura de las resonancias dificulta el estudio supramolecular del sistema. Pese a ello, el comportamiento del sistema pudo ajustarse a un modelo 1:1 para ambos fullerenos. Las constantes de asociación, $\mathrm{K}_{1}$ $=2.19 \pm 0.05 \times 10^{4} \mathrm{M}^{-1}$ y $\mathrm{K}_{1}=1.16 \pm 0.40 \times 10^{5} \mathrm{M}^{-1}$ para $\mathrm{C}_{60} \mathrm{y} \mathrm{C}_{70}$ respectivamente, indican selectividad para $\mathrm{C}_{70}$ sobre $\mathrm{C}_{60}$, como en el caso de la porfirina sin metalar $\mathbf{2 H}$-POctaCor, aunque en este caso son ligeramente inferiores (Tabla 5).

\begin{tabular}{|c|c|c|}
\hline & $\mathbf{C}_{\mathbf{6 0}}$ & $\mathbf{C}_{\mathbf{7 0}}$ \\
\hline 2H-POctaCor & $2.71 \pm 0.08 \times 10^{4}$ & $2.13 \pm 0.10 \times 10^{5}$ \\
\hline Zn-POctaCor & $2.19 \pm 0.05 \times 10^{4}$ & $1.16 \pm 0.40 \times 10^{5}$ \\
\hline
\end{tabular}

Tabla 5. Resumen de las constantes de asociación $\mathrm{K}_{1}\left(\mathrm{M}^{-1}\right)$ para $\mathbf{2 H - P O c t a C o r}$ y $\mathbf{Z n -}$ POctaCor para los diferentes fullerenos obtenidas mediante ${ }^{1} \mathrm{H}-\mathrm{RMN}(500 \mathrm{MHz}$, tolueno$d_{8}, 298 \mathrm{~K}$ ) ajustados a un modelo 1:1.

Nuestros resultados sugieren que la flexibilidad del sistema disminuye tras la coordinación de $\mathrm{Zn}^{2+}$ y esto da lugar a unas constantes de asociación ligeramente menores. Sin embargo, esta disminución en la flexibilidad del sistema no impide por completo la expansión de la otra cara de la porfirina tras la coordinación del primer fullereno, desfavoreciendo la asociación del segundo fullereno, dando lugar a la formación del aducto 1:1 observado experimentalmente. Por tanto, el sistema Zn-POctaCor también presenta un alosterismo negativo. 
A modo de conclusión, en este trabajo se ha obtenido en pocos pasos sintéticos una porfirina meso-octapodal simétrica con sustituyentes coranuleno y su análogo metalado con $\mathrm{Zn}(\mathrm{II})$. Estas nuevas plataformas supramoleculares contienen el mayor número de unidades de coranuleno presentes hasta la fecha para una única molécula. Estos compuestos muestran grandes constantes de asociación para los fullerenos estudiados $\mathrm{C}_{60}$ y $\mathrm{C}_{70}$ y presentan selectividad para $\mathrm{C}_{70}$ sobre $\mathrm{C}_{60}$, como se desprende de la mayor afinidad para este último. A pesar de la presencia de dos centros receptores potenciales, el sistema se comporta como una pinza sencilla, formando aductos de inclusión con fullerenos 1:1, en lugar de una pinza doble. Los cálculos DFT realizados indican que las cuatro unidades de coranuleno y el núcleo de la porfirina participan en el proceso de reconocimiento molecular. La gran afinidad mostrada por la primera unidad de $\mathrm{C}_{60}$ desencadena un cambio conformacional en la molécula Host que se transmite al segundo centro receptor. El núcleo de porfirina y la aproximación de las cuatro unidades de coranuleno de la cara activa comprimen el primer centro receptor a expensas de expandir las unidades restantes de coranuleno del segundo centro vacante. De esta manera se perjudica la acepción de una segunda unidad de fullereno, generando un efecto alostérico negativo o inhibitorio dado que se desactiva la segunda cavidad aceptora. Los efectos alostéricos observados en esta nueva porfirina "double picket fence" podrían utilizarse para acomodar otros Guest de mayor tamaño (como por ejemplo fullerenos de alto orden: $\mathrm{C}_{76}, \mathrm{C}_{78}, \mathrm{C}_{84}, \mathrm{C}_{90}$, etc) en el segundo centro de unión expandido. 


\subsection{PORFIRINAS MESO-TETRAARILSUSTITUIDAS SIMÉTRICAS CON LIGANDOS POLIAROMÁTICOS PLANOS Y NO PLANOS}

\subsubsection{Artículo III: Porphyrin-based systems containing polyaromatic fragments: decoupling the synergistic effects in aromatic-porphyrin-fullerene systems}

En este tercer trabajo se evalúan las implicaciones que conlleva eliminar los efectos de cooperatividad o sinérgicos con el núcleo de porfirina durante el transcurso de las interacciones supramoleculares. En los trabajos presentados en los Apartados 5.1 y 5.2, se observó un efecto sinérgico entre en el anillo de porfirina y los PAH planos y no planos que aumentaba las interacciones supramoleculares en esos sistemas (Figura 36).

a)

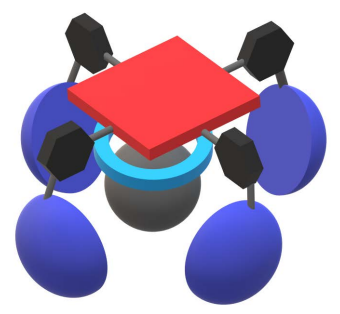

Mezcla de atropisómeros

$\alpha_{4}-2 H-P T C o r$ b)

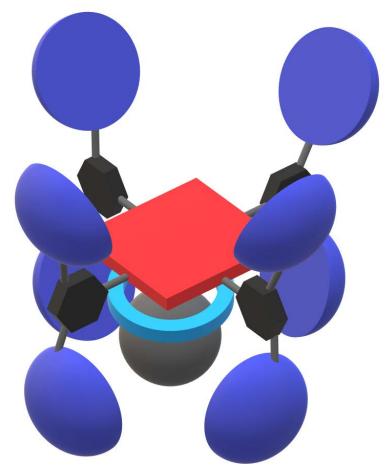

2H-POctaCor c)

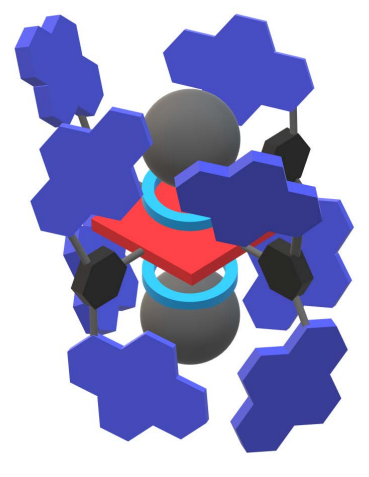

2HPOP

Figura 36. (a) Sistema porfirina desarrollado con ligandos PAH no planos dentro del grupo de investigación ${ }^{94}$ y (b y c) obtenidas durante la presente tesis doctoral mostrando el comportamiento como pinza sencilla o doble. Todas las plataformas moleculares son de tipo "picket fence". El círculo azul representa una idealización de la interacción entre el núcleo de porfirina (Host) con las diferentes unidades de fullereno $\left(\mathrm{C}_{60}\right.$, Guest $)$ en cada caso.

El enfoque en el presente trabajo es eliminar la contribución del núcleo de porfirina en el proceso de reconocimiento de fullerenos para poder estudiar sólo las interacciones supramoleculares aportadas por las unidades PAH. La disposición en para del grupo arilo de las meso-tetraarilporfirinas se escogió como las más adecuada, ya que permite alejar los fragmentos de pireno y coranuleno del núcleo de porfirina. Como puede apreciarse en la Figura 37, esta disposición espacial de las unidades PAH distante del núcleo porfirínico debería de impedir los posibles efectos cooperativos entre ambas partes. Hay que resaltar que el diseño de este sistema permite obtener una porfirina distinta a las de tipo "picket fence" que hemos mencionado a lo largo de todo este trabajo (compárese por ejemplo la Figura 36b y c con la Figura 37) y que podemos denominar como pinza doble "clásica".

Para poder obtener las apropiadas porfirinas meso-tetraarilsustituidas simétricas nos apoyaremos en la metodología desarrollada en el Apartado 4.1.1 de esta tesis doctoral, haciendo uso de la reacción de Suzuki. 
a)

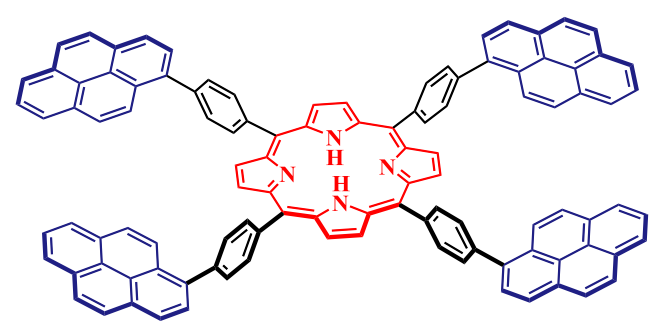

2H-PTetraPyr

c)

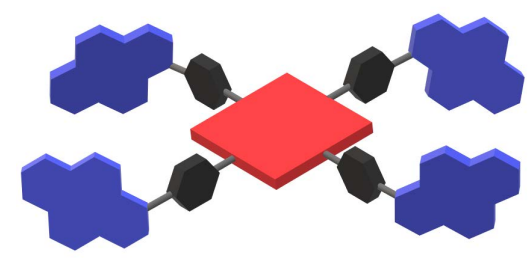

b)

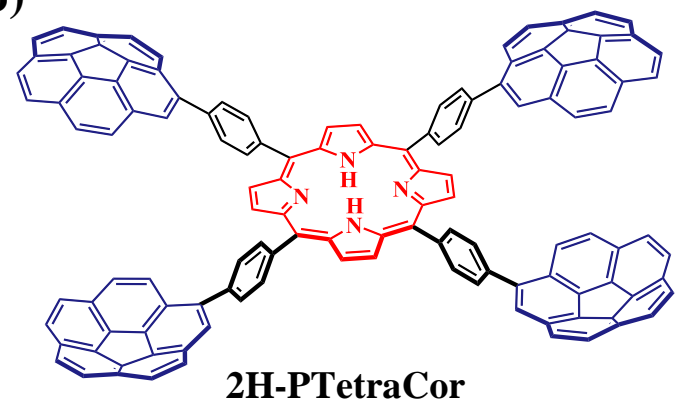

d)

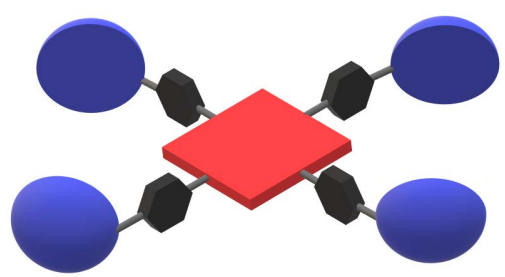

Figura 37. (a y b) Porfirinas meso-tetraarilsustituidas simétricas con unidades de pireno y coranuleno obtenidas en el presente trabajo. (c y d) Representación idealizada tridimensional de las porfirinas en forma de pinzas dobles "clásicas".

La preparación de las porfirinas objetivo 2H-PTetraPyr y 2H-PTetraCor (Figura 37), requieren de una porfirina apropiada para la introducción de las cuatro unidades PAH (pireno y coranuleno) en las posiciones para del precursor meso-tetraarilporfirina. Comenzamos nuestros estudios buscando una ruta sintética adecuada para obtener la porfirina que contiene las cuatro unidades de pireno (2H-PTetraPyr). El compuesto plano de pireno es más accesible, tanto económicamente como sintéticamente, que el aromático no plano de coranuleno. Por este motivo elegimos el pireno como resto aromático de partida para optimizar la obtención de esta nueva familia de porfirinas para-tetraarilsustituidas. Además, el compuesto 2H-PTetraPyr es un sistema susceptible de actuar como receptor de fullerenos.

Es necesaria una porfirina que presente grupos funcionales adecuados en para que permita la construcción de sistemas más complejos a través de la reacción de Suzuki. Se evaluaron dos rutas alternativas basadas en la presencia de grupos bromo o éster borónico en las posiciones para del arilo de las meso-tetraarilporfirinas. La primera ruta (Esquema 8, Ruta A,) involucra la preparación de una porfirina tetra-boronato 2H-PTetraBpin que se hace reaccionar con 1-bromopireno. La segunda ruta (Esquema 8, Ruta B) emplea como producto de partida una porfirina tetra-bromada $\mathbf{2 H}$-PTetraBr que se hace reaccionar con 1-pinacol pirenoboronato. La síntesis de ambos precursores de porfirina se realizó a partir de reactivos comerciales empleando un reactor de radiación de microondas. De esta manera, 2H-PTetraBpin y 2H-PTetraBr precipitan en la mezcla de reacción (nitrobenceno y ácido propiónico) y se obtienen con un 18 y $36 \%$ de rendimiento, respectivamente. ${ }^{164}$

164 (a) S. Wan, F. Gándara, A. Asano, H. Furukawa, A. Saeki, S. K. Dey, L. Liao, M. W. Ambrogio, Y. Y. Botros, X. Duan, S. Seki, J. F. Stoddart, O. M. Yaghi, Chem. Mater., 2011, 23, 4094-4097, (b) X. Liu, Y. Xu, Z. Guo, A. Nagai, D. Jiang, Chem. Commun., 2013, 49, 3233-3235. 

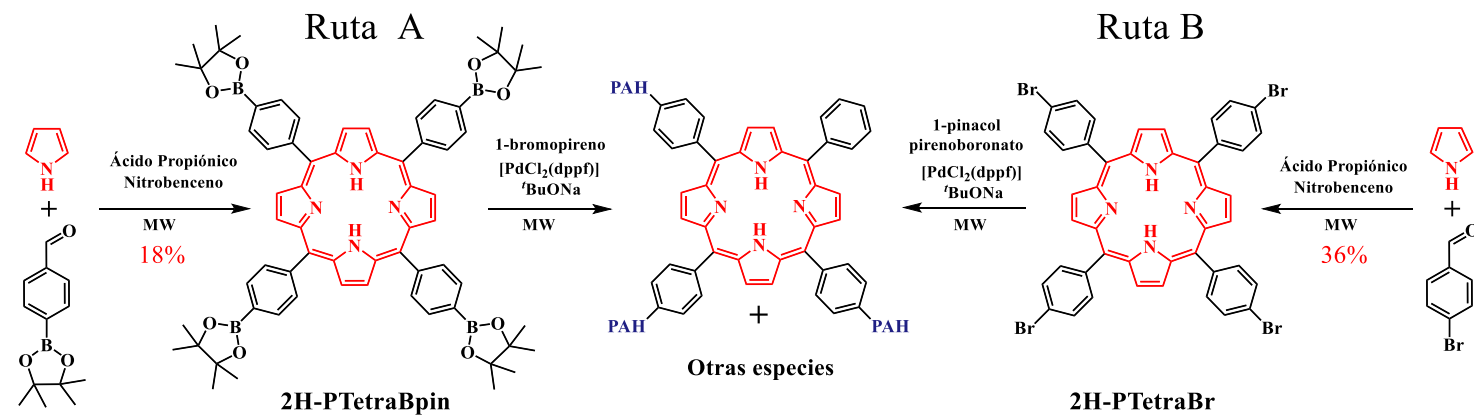

Esquema 8. Rutas sintéticas inicialmente estudiadas para la obtención de 2H-PTetraPyr.

Los intentos iniciales de introducir cuatro unidades de pireno usando como base las porfirinas de partida 2 H-PTetraBpin y 2 H-PTetraBr, proporciona una mezcla compleja de distintas especies de difícil análisis y separación. Entre los subproductos obtenidos se encuentran productos de homoacoplamiento entre unidades de pireno y porfirinas que contenían menos de cuatro unidades de pireno. Con el propósito de mejorar la síntesis intentamos una ruta alternativa utilizando metaloporfirinas. Estos compuestos mejoraron drásticamente la introducción de los restos de pireno dentro del sistema porfirina. Así, la metalación de las porfirinas 2H-PTetraBpin y 2H-PTetraBr con $\mathrm{Zn}(\mathrm{OAc})_{2} \cdot 2 \mathrm{H}_{2} \mathrm{O}$ proporciona Zn-PTetraBpin y Zn-PTetraBr, respectivamente, con rendimientos cercanos al 90\% (Esquema 9).

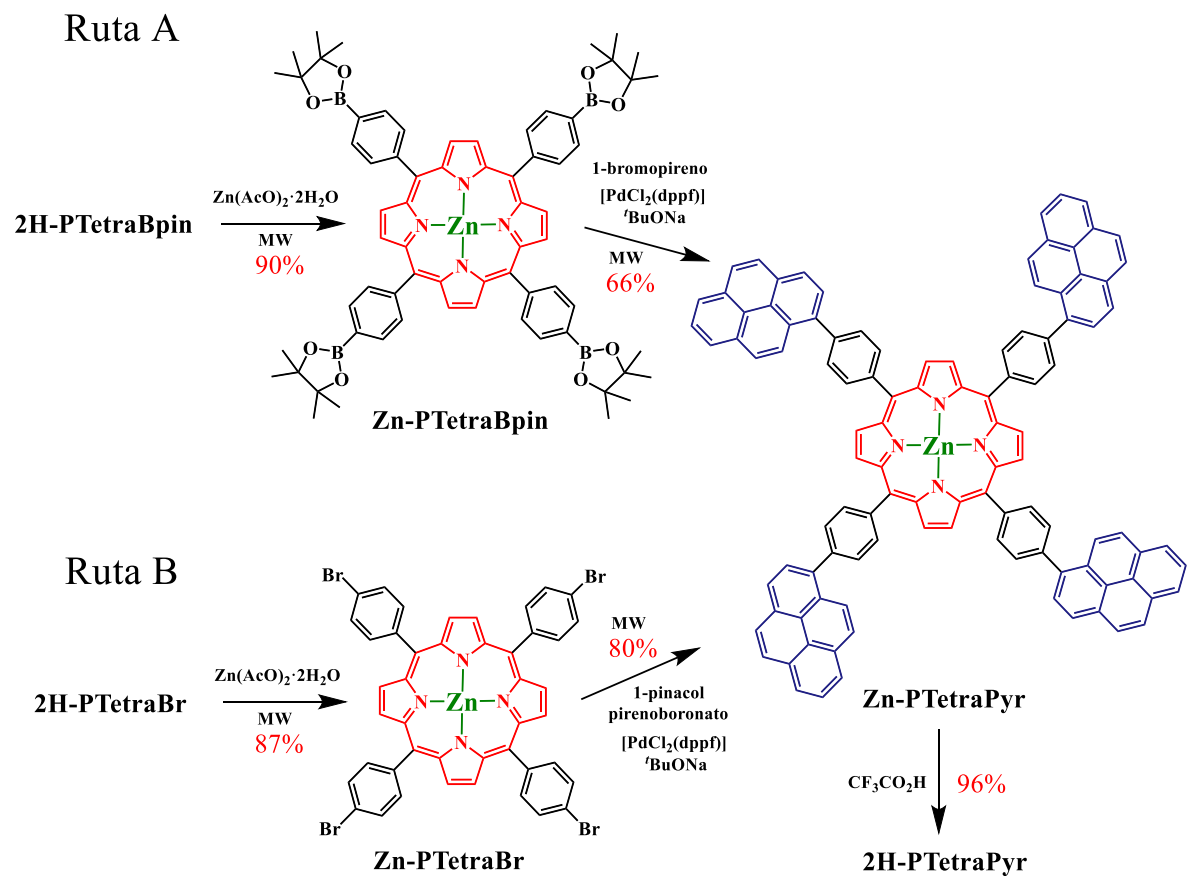

Esquema 9. Rutas sintéticas estudiadas para la obtención de 2H-PTetraPyr y ZnPTetraPyr.

De esta forma, realizando la reacción de Suzuki en la metaloporfirina tetra-bromada $\mathbf{Z n -}$ PTetraBr obtenemos la porfirina meso-tetraarilsustituida simétrica de pireno Zn-PTetraPyr con un rendimiento del 80\% (Esquema 9, Ruta B). Este compuesto final también puede obtenerse, aunque con un menor rendimiento (66\%), partiendo de Zn-PTetraBpin (Esquema 9, Ruta A). Posteriormente, 2H-PTetraPyr es fácilmente accesible con un rendimiento casi cuantitativo por tratamiento con ácido trifluororoacético (Esquema 9). Estos dos sistemas Zn-PTetraPyr y 2H- 
PTetraPyr de porfirinas con restos de pireno son candidatos para estudiar su comportamiento supramolecular frente a fullerenos.

Teniendo un esquema optimizado para la obtención de 2H-PTetraPyr, el siguiente paso es la síntesis de una porfirina con cuatro unidades de coranuleno en las posiciones en para al grupo arilo del núcleo de porfirina. Para ello se utilizaron Bpin-Cor y Zn-PTetraBr como precursores sintéticos (Esquema 10).
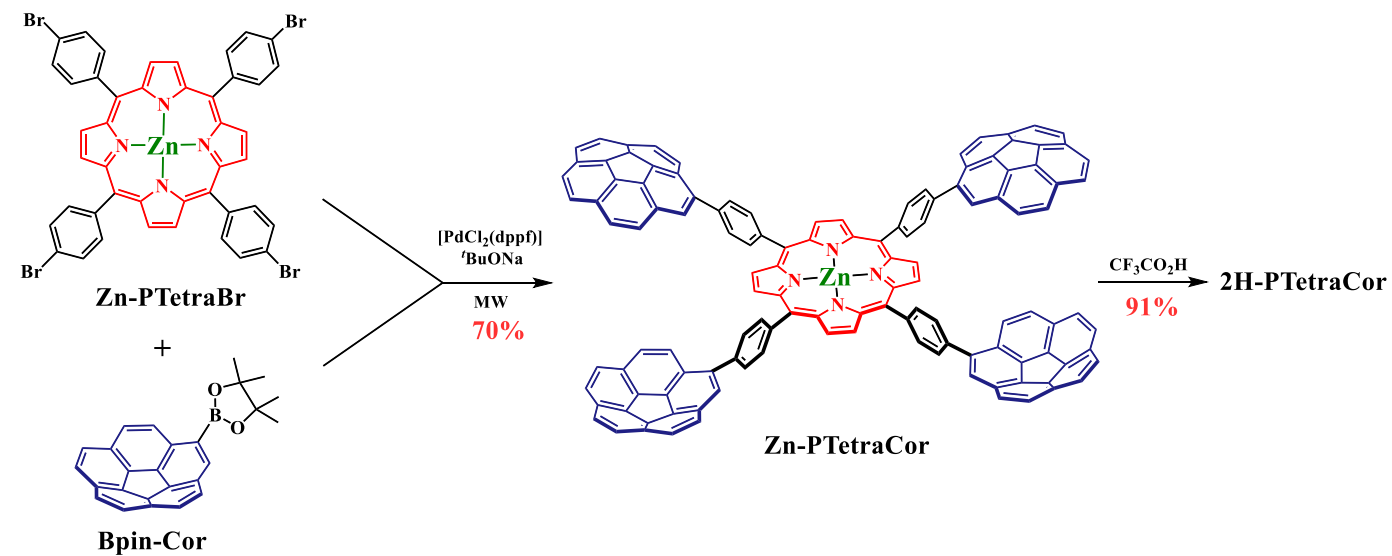

Esquema 10. Ruta sintética optimizada para el sistema tetracoranuleno porfirina $\mathbf{2 H}$ PTetraCor y Zn-PTetraCor.

Siguiendo este esquema, a través de una cuádruple reacción de Suzuki se puede obtener Zn-PTetraCor con un rendimiento del 70\%. ${ }^{165}$ Este rendimiento es bastante aceptable teniendo en cuenta las múltiples reacciones de acoplamiento cruzado con ligandos de coranuleno que tienen lugar y que, como se observa a lo largo de esta memoria, los rendimientos obtenidos por reacciones de Suzuki para derivados de coranuleno son en general bastante inferiores a la de sus análogos de pireno. Por ejemplo, compárese con el 15\% de rendimiento obtenido en la reacción de Suzuki óctuple para obtener 2H-POctaCor (Apartado 5.2, Esquema 6). La correspondiente desmetalación de Zn-PTetraCor proporciona el análogo 2H-PTetraCor, otro sistema potencial para interaccionar con fullerenos.

La confirmación de estos nuevos sistemas de tetra-coranuleno y tetra-pireno se llevó a cabo por espectrometría de masas de alta resolución (HRMS). Por ejemplo, para 2H-PTetraCor (Figura 38a) y Zn-PTetraCor (Figura 38b) se observan los picos del ion molecular $[\mathrm{M}]^{+}$a $\mathrm{m} / \mathrm{z}$ $1606.4994\left(\mathrm{C}_{124} \mathrm{H}_{62} \mathrm{~N}_{4}\right.$, calculado $1606.4969,2.5 \mathrm{ppm}$ de error $)$ y $1668.4085\left(\mathrm{C}_{124} \mathrm{H}_{60} \mathrm{~N}_{4} \mathrm{Zn}\right.$, calculado 1668.4104, $-1.9 \mathrm{ppm}$ de error), respectivamente. Los espectros de ${ }^{1} \mathrm{H}-\mathrm{RMN}$ en $\mathrm{CDCl}_{3}$ muestran la equivalencia en disolución de las cuatro unidades PAH planas y no planas y la presencia de un único beta pirrol $\left(\mathrm{H}_{2}\right)$ como cabría esperar de una simetría $\mathrm{D}_{4 \mathrm{~h}}$. Así, la porfirina 2H-PTetraPyr muestra una señal ancha característica a un desplazamiento químico de campo alto de $\delta=-2.48 \mathrm{ppm}$ que indica la presencia de los dos grupos $\mathrm{NH}\left(\mathrm{H}_{1}\right)$. En el caso del sistema 2H-PTetraCor estos grupos $\mathrm{NH}$ aparecen a un desplazamiento químico de $\delta=-2.52 \mathrm{ppm}$ (Figura 40a). Cabe mencionar, que tanto 2H-PTetraCor como Zn-PTetraCor muestran señales de resonancias agudas en todo el intervalo de concentraciones estudiado (Figura 40). Esto contrasta con el comportamiento de 2H-POctaCor estudiado en el Apartado 5.2 (Figura 27), que mostraba un ensanchamiento apreciable de las señales debido a las interacciones $\pi-\pi$ intramoleculares entre los pares de unidades de coranuleno. Este resultado sugiere, por tanto, que dichas interacciones intramoleculares no están presentes en 2H-PTetraCor y Zn-PTetraCor.

165 Zn-PTetraCor también puede prepararse usando como productos de partida Zn-PTetraBpin y Br-Cor (Esquema 9, similar Ruta A). En este caso el rendimiento es del 56\%. 

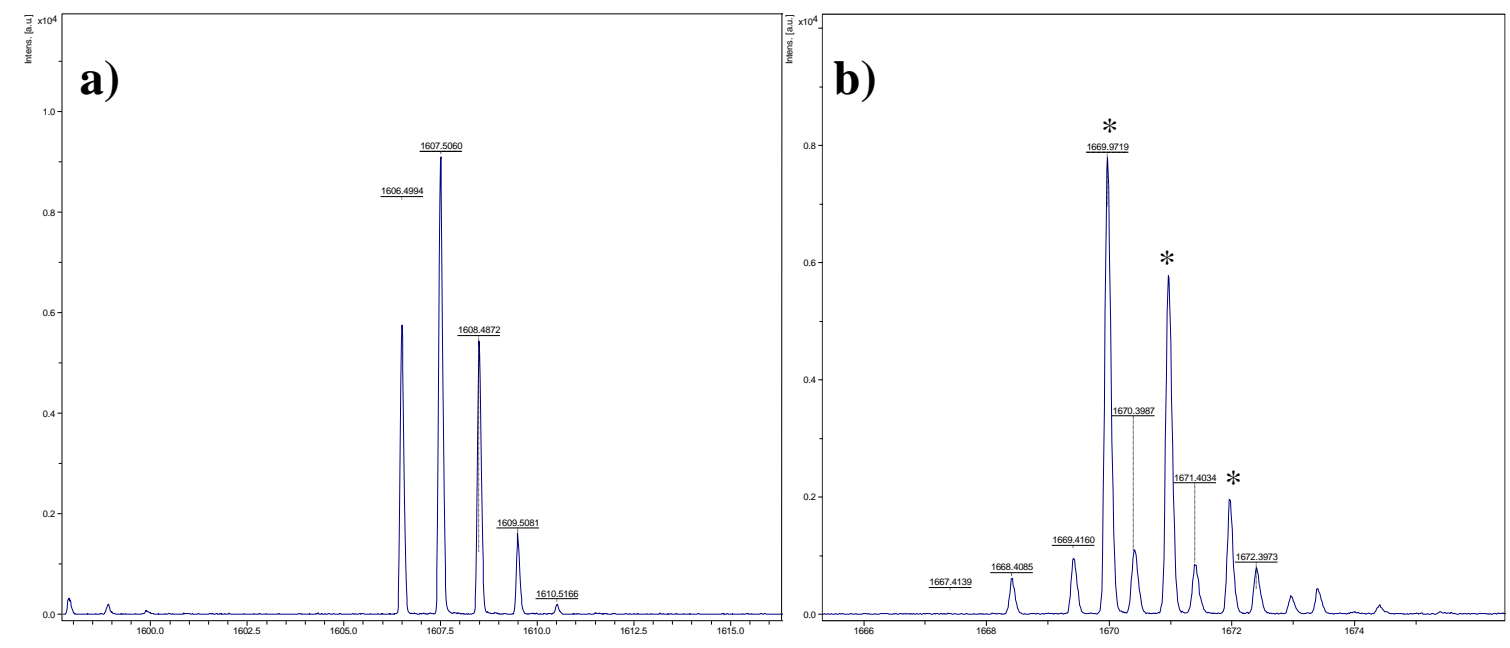

Figura 38. HRMS (MALDI-TOF) en DCTB de los compuestos (a) 2H-PTetraCor y (b) Zn-PTetraCor $[\mathrm{M}]^{+}$. Los asteriscos indican la matriz utilizada de PEG.

La porfirina meso-teatrasustituida 2H-PTetraCor también se estudió mediante cálculos DFT y la Figura 39 muestra el confórmero más estable. En la estructura optimizada, los cuatro restos tetraarílicos están aproximadamente perpendiculares al núcleo plano del anillo de porfirina, lo que está de acuerdo con la disposición encontrada en estructuras de rayos X en sistemas similares de tetraaril porfirinas con sustitución en posiciones para. ${ }^{166}$ Además, se puede concluir a partir de los cálculos DFT que no hay interacciones de tipo $\pi-\pi$ intramoleculares entre las unidades de coranuleno. Este resultado es diferente al observado para el sistema 2H-POctaCor del Apartado 5.2 (Figura 30a), donde las unidades de coranuleno establecían interacciones intramoleculares.

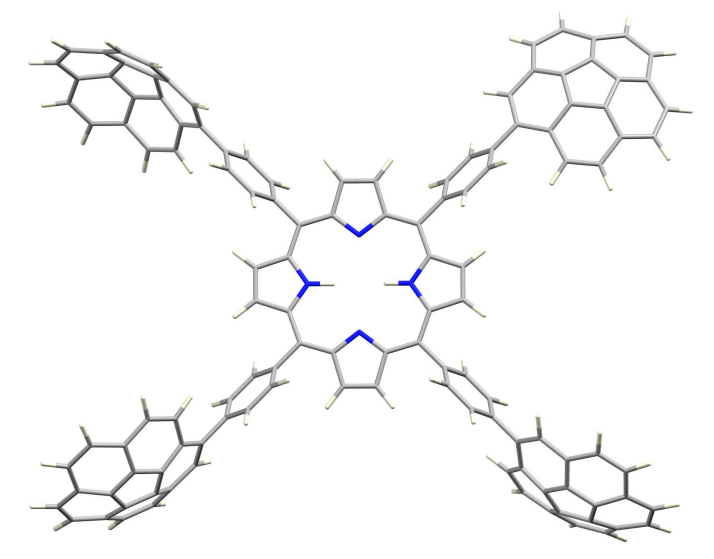

Figura 39. Estructura optimizada del compuesto 2H-PTetraCor. El ángulo $\alpha$ es cercano a $90^{\circ}\left(\alpha=90.85^{\circ}\right)$. Dicho ángulo $\alpha$ es definido como el ángulo formado por el derivado de coranuleno meso-sustituido con el centroide de la porfirina como vértice (para más detalles véase Figura 42).

166 (a) H.-B. Acta Crystallographica Section CZhao, L. Chen, B.-Y. Wang, J.-X. Liao, Y.-J. Xu, Acta Cryst. C, 2013, 69, 651-653, (b) N. Sheng, S. Zong, W. Cao, J. Jiang, Z. Wang, Y. Cui, ACS Appl. Mater. Interfaces, 2015, 7, 19718-19725, (c) P. Kuś, J. Kusz, M. Książek, J. Chem. Crystallogr., 2020, 50, 21-27. En estas estructuras de rayos $X$, en sistemas para sustituidos, el valor de alfa es próximo a $90^{\circ}\left(91.62^{\circ}-88.46^{\circ}\right)$ como el observado en la estructura optimizada 2 H-PTetraCor. 
a)

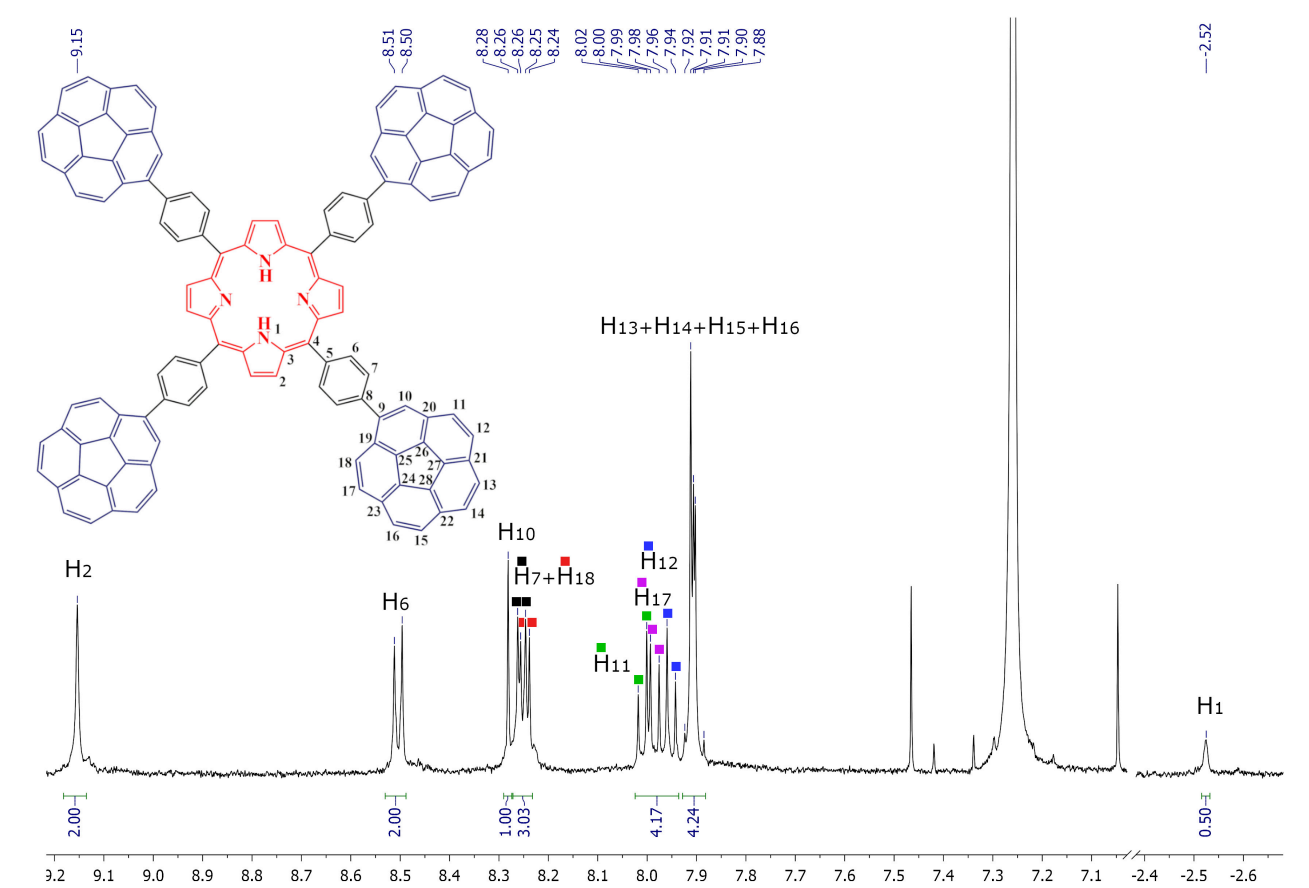

b)

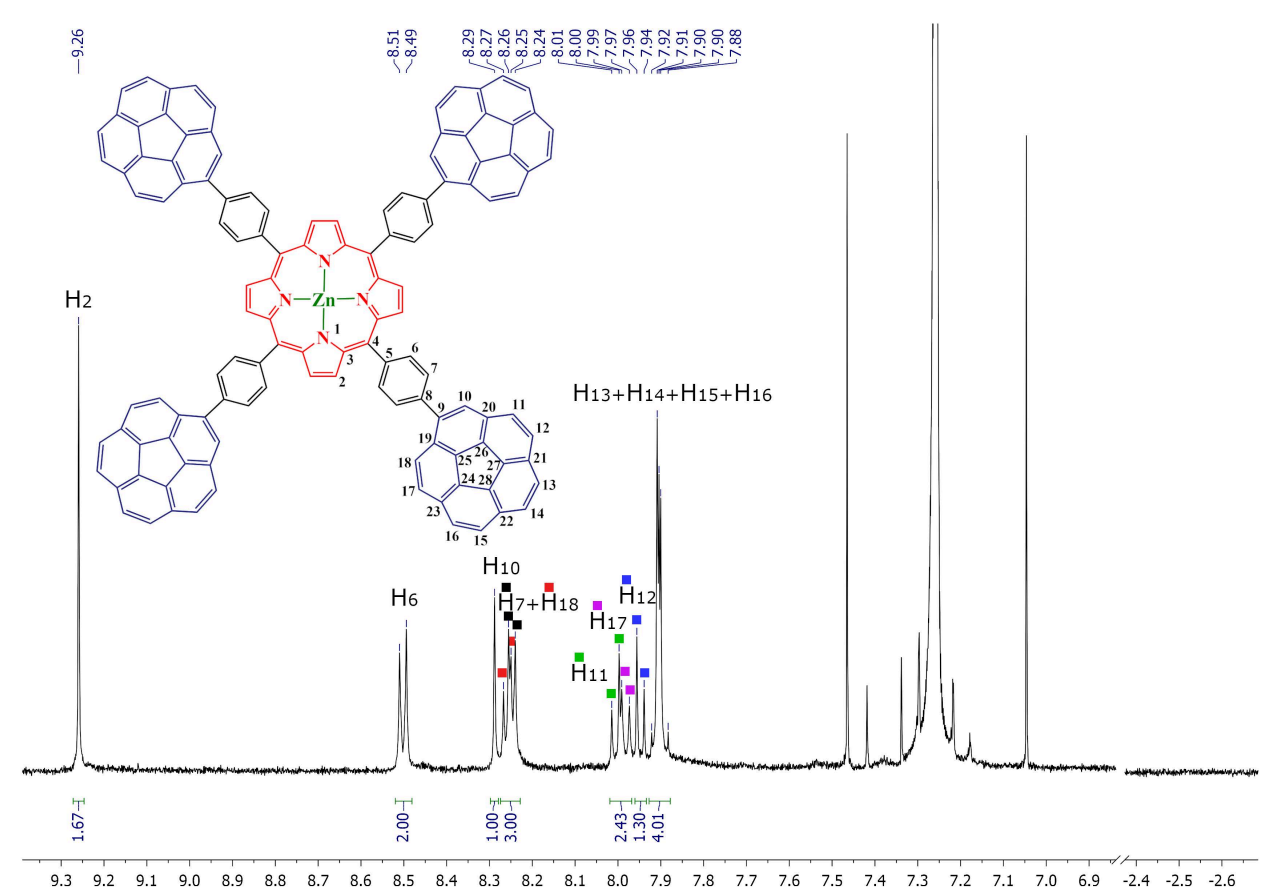

Figura 40. Espectros de ${ }^{1} \mathrm{H}-\mathrm{RMN}\left(500 \mathrm{MHz}, \mathrm{CDCl}_{3}\right.$ ) de las porfirinas (a) 2H-PTetraCor y (b) Zn-PTetraCor. 
En el caso de 2H-PTetraCor, tal y como se aprecia en la Figura 39, las dos unidades de coranuleno a cada lado de la porfirina están preorganizadas para la interacción con fullerenos $\left(\mathrm{C}_{60}\right.$ y $\mathrm{C}_{70}$ ) y los dos sitios potenciales de unión adoptan una conformación aproximadamente cóncavaconvexa. El hueco formado por los dos restos de coranuleno es lo suficientemente grande (16 $\AA$ ) para acomodar una molécula de $\mathrm{C}_{60}$, sugiriendo que sólo es necesaria una pequeña deformación del sistema para maximizar la interacción con el fullereno. Asimismo, la estructura optimizada muestra, como era de esperar, que el núcleo de porfirina se encuentra localizado lejos de las unidades de los restos coranuleno y por lo tanto es esperable que no participe de forma sinérgica en el proceso de reconocimiento supramolecular con fullerenos junto a las dos pinzas. De hecho, este nuevo sistema podría comportarse como una pinza molecular clásica ("classic molecular tweezer"), en el que la porfirina actúa como una simple unidad conectora (Figura 37b y d). Esta disposición espacial contrasta con los sistemas "picket fence" con meta-sustitución discutidos en los Apartados 5.1 y 5.2, en los que la porfirina participa de forma activa en el proceso de interacción supramolecular dando lugar por ello a grandes constantes de asociación.

Con el fin de evaluar el efecto del desacoplamiento del núcleo de la porfirina durante el evento supramolecular, estudiamos si los nuevos sistemas de porfirina para-tetrasustituidos basados en pireno o coranuleno pueden servir como receptor de fullerenos. Los compuestos con restos de pireno $\mathbf{2 H}$-PTetraPyr y Zn-PTetraPyr no muestran evidencia alguna de interacción por ${ }^{1} \mathrm{H}-\mathrm{RMN}$ en tolueno- $d_{8}$ con ninguno de los fullerenos estudiados $\left(\mathrm{C}_{60} \mathrm{y} \mathrm{C}_{70}\right)$. Tras adicionar un exceso de cualquiera de los fullerenos (10 equivalentes) no se observan cambios en los desplazamientos químicos de ${ }^{1} \mathrm{H}-\mathrm{RMN}$ en disolución (tolueno- $d_{8}$ ). Este hecho contrasta con las porfirinas sustituidas con restos pireno en meta $^{94}$ y sustituidas en todas las posiciones meta (Apartado 5.1), que mostraron la formación de complejos de inclusión con fullerenos. Sin embargo, este resultado no es especialmente inesperado, ya que es bien conocido que la disposición plana de los restos PAH no permite una interacción supramolecular efectiva con la superficie esférica del $\mathrm{C}_{60}$ debido a su mala complementariedad de forma. Las altas afinidades encontradas para fullerenos en los anteriores sistemas se atribuye parcialmente a los efectos cooperativos o sinérgicos del núcleo de porfirina con las unidades PAH planas. Por tanto, la ausencia de asociación con $\mathrm{C}_{60}$ y $\mathrm{C}_{70}$ observada en los sistemas para sustituidos sugiere que el núcleo de la porfirina no está involucrado en el proceso de reconocimiento supramolecular.

En cambio, los sistemas 2H-PTetraCor y Zn-PTetraCor, que contienen restos de coranuleno mostraron cambios en los desplazamientos químicos observados por ${ }^{1} \mathrm{H}-\mathrm{RMN}$ (tolueno- $\left.d_{8}\right)$ tras la adición de $\mathrm{C}_{60} \mathrm{o} \mathrm{C}_{70}$. Este efecto es indicativo de una interacción supramolecular con fullerenos, que en este caso está favorecida por la presencia de las unidades de coranuleno en lugar de pireno. Como ya hemos comentado, los PAH no planos por su geometría curvada interaccionan de una mejor manera con la superficie esférica del Buckminsterfullereno $\left(\mathrm{C}_{60}\right)$, ya que pueden realizar interacciones complementarías de tipo $\pi-\pi$ cóncavas - convexas. Posteriormente, realizamos para las especies 2H-PTetraCor y ZnPTetraCor un completo estudio supramolecular mediante valoraciones por ${ }^{1} \mathrm{H}-\mathrm{RMN}$ en tolueno- $d_{8}$. En ambos sistemas, la adición de alícuotas de $\mathrm{C}_{60}$ muestra cambios apreciables en los desplazamientos químicos y es posible seguir varias señales durante el transcurso de la valoración (Figura 41). 
a)

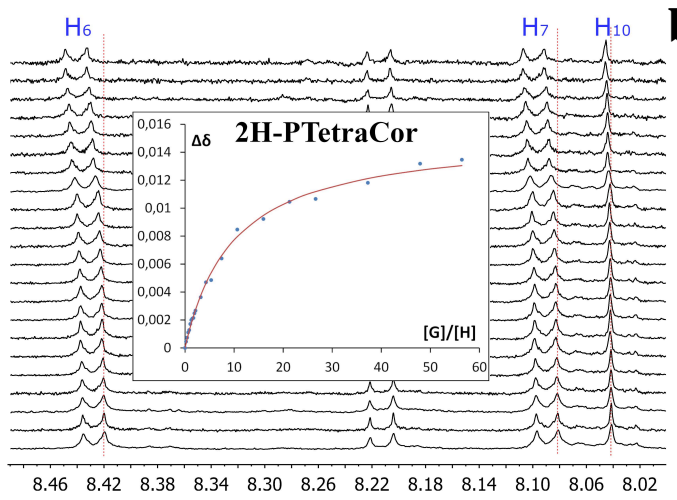

b)

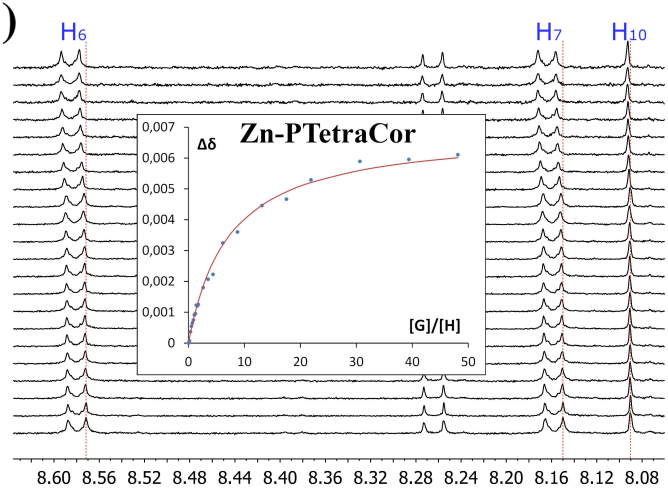

Figura 41. Espectros de ${ }^{1} \mathrm{H}-\mathrm{RMN}\left(500 \mathrm{MHz}\right.$, tolueno- $\left.d_{8}\right)$ mostrando el cambio en desplazamientos químicos de $\mathrm{H}_{6}, \mathrm{H}_{7}$ y $\mathrm{H}_{10}$ de (a) 2H-PTetraCor y (b) Zn-PTetraCor tras la adición de alícuotas de $\mathrm{C}_{60}$. Recuadro: Gráficas correspondientes a los cambios en desplazamientos químicos frente a la fracción molar del fullereno $[\mathrm{G}] /[\mathrm{H}]$, donde $[\mathrm{G}]$ (Guest) corresponde al $\mathrm{C}_{60} \mathrm{y}[\mathrm{H}]$ (Host) es 2H-PTetraCor o Zn-PTetraCor. La línea roja pertenece al ajuste no lineal de $\Delta \delta\left(\mathrm{H}_{6}\right)$ para una isoterma de unión de un modelo 1:1.

Las isotermas de unión (binding isotherm) obtenidas en la valoración para ambos fullerenos se pueden ajustar a un modelo 1:1 (Figura 41). Las constantes de asociación obtenidas para 2HPTetraCor y Zn-PTetraCor frente a $\mathrm{C}_{60}$ muestran unos valores de $\mathrm{K}_{1}=8.73 \pm 0.05 \times 10^{1}$ y $\mathrm{K}_{1}$ $=2.73 \pm 0.02 \times 10^{2}$. Del mismo modo, se realizaron las valoraciones con $\mathrm{C}_{70} \mathrm{y}$ en la Tabla 6 se recogen las constantes estimadas para ambos fullerenos al realizar un ajuste a un modelo 1:1.

\begin{tabular}{|c|c|c|}
\hline & $\mathbf{C}_{\mathbf{6 0}}$ & $\mathbf{C}_{\mathbf{7 0}}$ \\
\hline 2H-PTetraCor & $8.73 \pm 0.05 \times 10^{1}$ & $5.24 \pm 0.02 \times 10^{1}$ \\
\hline Zn-PTetraCor & $2.73 \pm 0.02 \times 10^{2}$ & $2.16 \pm 0.01 \times 10^{2}$ \\
\hline
\end{tabular}

Tabla 6. Resumen de las constantes de asociación $\mathrm{K}_{1}\left(\mathrm{M}^{-1}\right)$ de $2 \mathrm{H}-\mathbf{P T e t r a C o r}$ y $\mathbf{Z n -}$ PTetraCor para los diferentes fullerenos obtenidas mediante ${ }^{1} \mathrm{H}-\mathrm{RMN}(500 \mathrm{MHz}$, tolueno- $d_{8}, 298 \mathrm{~K}$ ) ajustados a un modelo 1:1.

Ambas porfirinas 2H-PTetraCor y Zn-PTetraCor mostraron interacción con $\mathrm{C}_{70}$, aunque el valor de las constantes de asociación es muy similar a las obtenidas para $\mathrm{C}_{60} \mathrm{y}$ relativamente bajas en todos los casos. Estos resultados indican que los sistemas para sustituidos no muestran discriminación entre fullerenos. Cabe resaltar, que las constantes estimadas son bastante más pequeñas que las obtenidas para $\boldsymbol{\alpha}_{4}$-2H-PTCor (Figura 36a) ${ }^{94}$ o 2H-POctaCor (Apartado 5.1), en donde el núcleo de porfirina participa de forma activa en el proceso reconocimiento supramolecular. Realizando un análisis comparativo (Tabla 7), estos datos muestran valores aproximadamente dos órdenes de magnitud más pequeños para la interacción con $\mathrm{C}_{60}, \mathbf{2 H}$ PTetraCor frente a $\mathbf{2 H}$-PTCor (promedio de la mezcla de atropisómeros) y $\mathbf{2 H}$-POctaCor (Apartado 5.2). Esta diferencia es incluso mayor para la asociación con $\mathrm{C}_{70}$, 2H-PTetraCor (5.24 $\left.\pm 0.02 \times 10^{1}\right)$ frente a $\mathbf{2 H}-$ POctaCor $\left(2.13 \pm 0.10 \times 10^{5}\right)$. 


\begin{tabular}{|c|c|c|}
\hline & $\mathbf{C}_{\mathbf{6 0}}$ & $\mathbf{C}_{\mathbf{7 0}}$ \\
\hline 2H-PTCor & $5.4 \pm 0.2 \times 10^{3(\mathrm{a})}$ & (b) $^{(\mathrm{b})}$ \\
\hline 2H-POctaCor & $2.71 \pm 0.08 \times 10^{4}$ & $2.13 \pm 0.10 \times 10^{5}$ \\
\hline 2H-PTetraCor & $8.73 \pm 0.05 \times 10^{1}$ & $5.24 \pm 0.02 \times 10^{1}$ \\
\hline
\end{tabular}

Tabla 7. Resumen comparativo de las constantes de asociación $\mathrm{K}_{1}\left(\mathrm{M}^{-1}\right)$ de 2H-PTCor, ${ }^{94}$ 2H-POctaCor y 2H-PTetraCor para los diferentes fullerenos obtenidas mediante ${ }^{1} \mathrm{H}$ RMN (500 MHz, tolueno- $d_{8}, 298 \mathrm{~K}$ ) ajustados a un modelo 1:1. (a) Promedio de la mezcla de atropisómeros, (b) No se realizó ningún estudio con ese fullereno.

Podemos extraer tres conclusiones importantes de estos estudios:

a) Las constantes de asociación para 2H-PTetraCor y Zn-PTetraCor son relativamente similares a pesar de que la coordinación de metales puede afectar a la conformación plana del anillo de porfirina ${ }^{110 c, d, e, 158}$ (Tabla 6). Además, y lo que es más importante, estas constantes de asociación son relativamente pequeñas en comparación con los otros sistemas porfirinas que presentan sustituciones con unidades de coranuleno en meta $^{94}$ y sustituidas en todas las posiciones meta (Apartado 5.2). Estos resultados sugieren que el núcleo de porfirina tiene poca o prácticamente ninguna participación en el proceso de reconocimiento molecular.

b) Con relación al punto anterior, la ausencia de discriminación entre $\mathrm{C}_{70}$ y $\mathrm{C}_{60}$ en estos sistemas PTetraCor también podría atribuirse, al menos en parte, a la falta de participación del núcleo macrocíclico de porfirina en el evento supramolecular.

c) Aunque existen dos posibles centros de unión en estos derivados de tetra-coranuleno (Figura 39), los datos experimentales obtenidos de la valoración por RMN indican una asociación 1:1 y no muestran evidencias para la existencia de aductos 1:2. Por lo tanto, los sistemas $\mathbf{2 H}$ PTetraCor y Zn-PTetraCor se comportan, al menos aparentemente, como una pinza sencilla (single-tweezer) frente a interacciones supramoleculares con fullerenos.

Con vistas a obtener un mayor grado de detalle del proceso de reconocimiento molecular se realizaron cálculos DFT. Las geometrías optimizadas de $\mathrm{C}_{60} @ \mathbf{2 H}-\mathbf{P T e t r a C o r}$ y $\mathrm{C}_{70} @ \mathbf{2 H}$ PTetraCor se representan en la Figura 42. Las distancias promedio calculadas en ambas estructuras entre la superficie cóncava interior de los fragmentos de coranuleno y la superficie convexa exterior de la superficie del fullereno se encuentran dentro del intervalo habitual para generar interacciones de dispersión favorables $(\leq 3.5 \AA){ }^{84 a, 167}$ Las energías de interacción calculadas son de $43.75 \mathrm{kcal} \cdot \mathrm{mol}^{-1}$ y $44.25 \mathrm{kcal} \cdot \mathrm{mol}^{-1}$, para $\mathrm{C}_{60}$ y $\mathrm{C}_{70}$, respectivamente. Esta pequeña diferencia energética entre ambos sistemas $\left(0.50 \mathrm{kcal} \cdot \mathrm{mol}^{-1}\right)$ indica que $\mathbf{2 H}$-PTetraCor interacciona casi de manera idéntica con ambos fullerenos. Este resultado está de acuerdo con la falta de selectividad observada experimentalmente por RMN entre las constantes de asociación para $\mathrm{C}_{60} \mathrm{y}_{70}$ (Tabla 6). Durante la formación de los aductos de inclusión, los dos brazos de coranuleno del mismo lado de la molécula se reorganizan ligeramente a través de una rotación del enlace $\mathrm{C}-\mathrm{C}\left(\mathrm{C}_{8}-\mathrm{C}_{9}\right.$, véase numeración Figura 40$)$ para poder alinearse con la superficie convexa externa de fullereno. Además, las unidades de coranuleno deben aproximarse lo suficientemente cerca del anfitrión para establecer interacciones atractivas. La pinza esperada en el caso de caso de la interacción con $\mathrm{C}_{70}$ muestra una abertura mayor debido a la excentricidad de este fullereno (Figura 42c). Sin embargo, es necesaria una pequeña deformación del sistema para acomodar cualquiera de los dos fullerenos.

167 (a) P. A. Denis, RSC Adv., 2013, 3, 25296-25305, (b) D. Josa, J. Rodríguez-Otero, E. M. Cabaleiro-Lago, L. A. Santos, T. C. Ramalho, J. Phys. Chem. A, 2014, 118, 9521-9528. 
a)

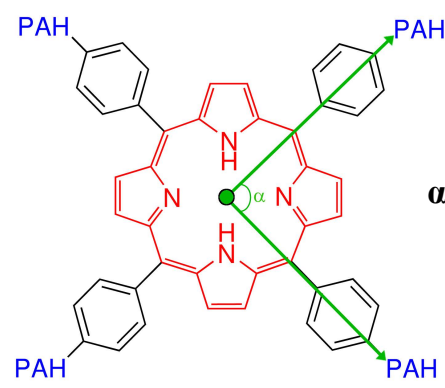

b)

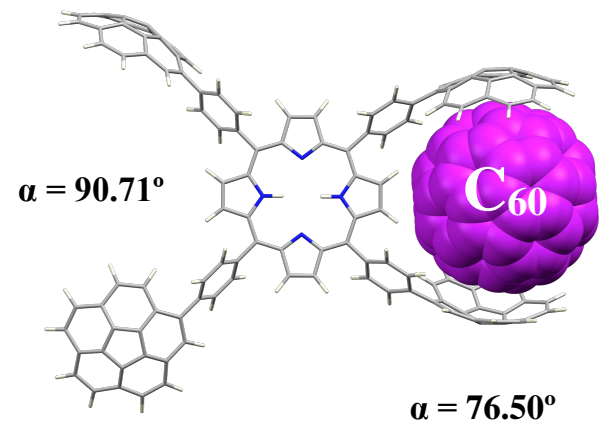

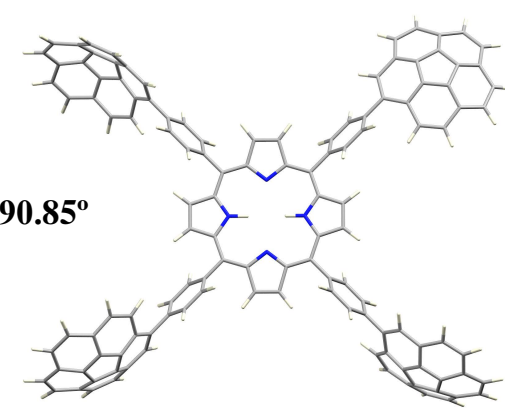

c)

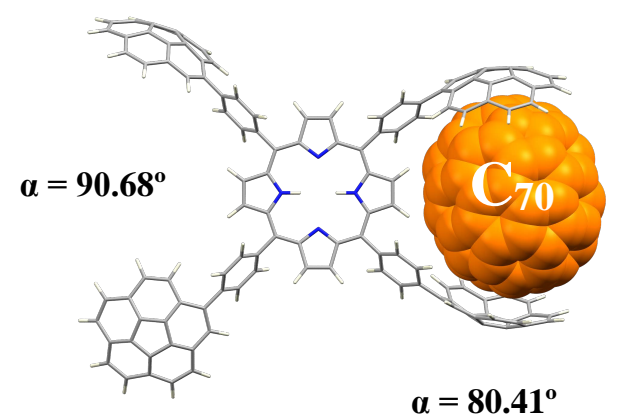

Figura 42. (a) Representación del ángulo $\alpha$ entre los dos meso sustituyentes en la estructura optimizada, donde el punto verde se corresponde con el centroide del núcleo de porfirina y ejerce como vértice. Estructuras optimizadas de (b) $\mathrm{C}_{60} @ \mathbf{2 H}-\mathbf{P T e t r a C o r}$ y (c) $\mathrm{C}_{70} @ 2 \mathrm{H}-\mathrm{PT}$ traCor. Los fullerenos están representados en estilo spacefill y coloreados en violeta y naranja para $\mathrm{C}_{60}$ y $_{70}$, respectivamente.

Así, en 2H-PTetraCor el ángulo $\alpha$ formado por los meso sustituyentes de coranuleno con el centroide de la porfirina como vértice se desvía del valor original de $90.85^{\circ}$ (Figura 42a). ${ }^{166}$ Esto es debido a que cuando se produce la interacción con los fullerenos, las dos unidades de coranuleno se desplazan una hacia la otra para alcanzar la forma de pinza óptima, y como consecuencia el ángulo $\alpha$ disminuye ligeramente $\left(76.50^{\circ}\right.$ para $\mathrm{C}_{60} @ \mathbf{2 H}-\mathbf{P T e t r a C o r}$ (Figura $42 \mathrm{~b}$ ) y 80.41 ${ }^{\circ}$ para $\mathrm{C}_{70} @ \mathbf{2 H}-\mathbf{P T e t r a C o r}$ (Figura 42c)), mientras que el segundo centro de unión presenta valores de $\alpha$ cercanos a los originales de $90^{\circ}\left(90.71^{\circ}\right.$ y $90.68^{\circ}$ para $\mathrm{C}_{60}$ y $\mathrm{C}_{70}$, respectivamente). Por tanto, el primer evento de unión, es decir, la pequeña compresión de una pinza al interaccionar con el fullereno, no se transmite conformacionalmente al segundo centro receptor de la molécula. La energía de deformación, esto es, la energía requerida para que el Host adopte una conformación adecuada para la unión del fullereno, es bastante accesible. El valor estimado es de tan sólo $5.55 \mathrm{kcal} \cdot \mathrm{mol}^{-1}$ y $3.78 \mathrm{kcal} \cdot \mathrm{mol}^{-1}$ para los complejos $\mathrm{C}_{60} @ \mathbf{2 H}-\mathbf{P T e t r a C o r}$ y $\mathrm{C}_{70} @ \mathbf{2 H}-\mathbf{P T e t r a C o r}$, respectivamente.

También se estudió el efecto de la interacción con una segunda unidad de fullereno y se optimizaron los aductos $\left(\mathrm{C}_{60}\right)_{2} @ \mathbf{2 H}-\mathbf{P T e t r a C o r}$ y $\left(\mathrm{C}_{70}\right)_{2} @ \mathbf{2 H}$-PTetraCor, con el fin de estimar las energías de deformación para el segundo evento de unión. Los valores calculados, son de 9.04 $\mathrm{kcal} \cdot \mathrm{mol}^{-1}$ y $7.41 \mathrm{kcal} \cdot \mathrm{mol}^{-1}$, respectivamente. Tan sólo un poco superiores a los obtenidos para la asociación de una sola unidad de $\mathrm{C}_{60} \mathrm{o}$ de $\mathrm{C}_{70}$. Dicho de otro modo, la asociación del primer fullereno no afecta sustancialmente al segundo centro receptor y, por tanto, pueden considerare como dos centros de unión aproximadamente independientes. El pequeño aumento en la energía de deformación para el segundo evento, junto con las modestas constantes de asociación (Tabla 6), podrían ayudar a racionalizar el modelo 1:1 observado experimentalmente por las valoraciones de RMN, a pesar de que los dos centros receptores actúan de forma aproximadamente 
independiente. ${ }^{168}$ Este valor moderado de las constantes de asociación dificulta la determinación exacta de la estequiometria del sistema y, por tanto, no se puede establecer de manera inequívoca. Es decir, los datos podrían ser también consistentes con una interacción de tipo 1:2 en donde ambos centros receptores actúan de forma independiente con poca o ninguna participación del núcleo de porfirina durante el proceso de interacción supramolecular. Por tanto, la asociación 1:1 observada se puede describir como "aparente". En este sentido, aunque es conocido que metaloporfirinas que contienen $\mathrm{Zn}(\mathrm{II})$ pueden interaccionar con $\mathrm{C}_{60}$ o $\mathrm{C}_{70}{ }^{128 \mathrm{c}, 129 \mathrm{c}}$ no tenemos ninguna evidencia de que esta interacción este sucediendo en nuestros sistemas de porfirinas.

Los cálculos DFT muestran la falta de participación del núcleo de porfirina en la formación del aducto supramolecular. Por tanto, desacoplar la influencia del núcleo de porfirina de la pinza molecular formada por las unidades de coranuleno, conlleva implicaciones supramoleculares importantes dentro del sistema de porfirina para tetraarilsustituida. Por una parte, el núcleo de porfirina actúa como una simple unidad conectora y no está involucrada en el proceso de reconocimiento supramolecular. Como resultado, se obtiene una menor energía de interacción por la pérdida de cooperación entre el núcleo de porfirina y los fragmentos PAH planos y no planos. Este hecho se refleja por las bajas constantes de asociación observadas experimentalmente. Por otro lado, un efecto derivado de lo anterior es que la porfirina no transmite la información del primer evento de unión supramolecular al segundo centro receptor. Por ello puede considerarse que el sistema consta de dos pinzas independientes, es decir, el sistema no presenta cooperatividad o alosterismo. Esto claramente contrasta con el gran efecto inhibitorio presente en 2H-POctaCor (Apartado 5.2). En la molécula octapodal de coranuleno 2H-POctaCor la participación activa del núcleo de porfirina en la unión de $\mathrm{C}_{60} \mathrm{o}_{70}$, aunque claramente beneficiosa para lograr altas afinidades hacia ambos fullerenos, inhibió fuertemente la unión de un segundo Guest. Por último, la falta de discriminación entre ambos fullerenos en los sistemas PTetraCor probablemente sea fruto, al menos en parte, de la falta de participación del núcleo de porfirina durante el proceso interacción supramolecular.

Como resumen, en este trabajo se ha sintetizado mediante una cuádruple reacción de Suzuki un conjunto de porfirinas tetrasustituidas con ligandos PAH planos y no planos. La introducción en para de los restos de pireno y coranuleno permite disponerlos relativamente alejados del núcleo de porfirina. Tanto las valoraciones por RMN como los cálculos DFT mostraron que el núcleo de porfirina no se involucra en el proceso de reconocimiento supramolecular de fullerenos. Los sistemas basados en pireno no mostraron evidencia alguna de poder interaccionar con fullerenos. Sin embargo, los sistemas 2H-PTetraCor y Zn-PTetraCor basados en coranuleno actúan como pinzas moleculares clásicas ("classical molecular tweezer") con dos pinzas aproximadamente independientes. El hecho de que estos sistemas muestren una asociación "aparente" 1:1 se atribuye principalmente a los bajos valores de las constantes de asociación en lugar de a un efecto alostérico negativo o inhibitorio. Por tanto, la introducción de los sustituyentes PAH en la posición para del grupo arilo disminuye drásticamente la capacidad de interaccionar con fullerenos debido a este efecto de "desacoplamiento" del núcleo de porfirina. Este efecto también puede presentar algunos beneficios, como la prevención de grandes cambios estructurales que inhiben un posible segundo evento de unión. Estos resultados destacan el papel crucial que juega el diseño molecular en la construcción de sistemas supramoleculares complejos.

\footnotetext{
${ }^{168}$ En centros receptores independientes o no cooperativos el valor de $K_{2}$ es 4 veces inferior al valor de $K_{1}$, por motivos puramente estadísticos. Por tanto, dado los valores relativamente pequeños de $K_{1}$ (Tabla 6) la determinación experimental de $\mathrm{K}_{2}$, aún menor, es muy complicada.
} 
6. CONCLUSIONES 


\section{CONCLUSIONES}

De un modo análogo a como se organizó el Apartado 3 de Objetivos, esta sección muestra unas conclusiones generales que a su vez han generado otras específicas.

\subsection{CONCLUSIONES GENERALES}

Se ha desarrollado y optimizado una metodología sintética para funcionalizar organizaciones moleculares basadas en meso-porfirinas simétricas aril-sustituidas que contienen múltiples ligandos PAH planos y no planos, de tipo pireno y coranuleno. El nuevo conjunto de porfirinas se ha obtenido en pocos pasos sintéticos y con buenos rendimientos moderados, teniendo en cuenta la cantidad elevada de sustituyentes poliaromáticos introducidos en el sistema, hasta ocho en algunos casos. Estos novedosos compuestos muestran altas afinidades receptoras hacia fullerenos.

Se ha preparado un grupo de porfirinas y metaloporfirinas meso-octa o tetra-arilsustituidas simétricas con múltiples grupos PAH planos y no planos, dando como resultado arquitecturas moleculares con varios centros de unión supramolecular.

\subsection{CONCLUSIONES ESPECÍFIFICAS}

La presencia del núcleo de porfirina juega un papel fundamental en el reconocimiento supramolecular hacia fullerenos. Esto es crítico en los sistemas que contienen ligandos PAH planos de tipo pireno. Así, se obtiene que en sistemas de porfirina con sustituyentes en meta posición proporciona constantes de asociación elevadas y selectividad frente a fullerenos. Además, dichas constantes son muy altas para sistemas basados en pireno. Sin embargo, en estos sistemas que presentan ligandos PAH planos en posiciones para, no se produce interacción supramolecular observable.

Un hecho derivado de la conclusión anterior es la selectividad presente hacia $\mathrm{C}_{70}$ frente a $\mathrm{C}_{60}$ en los sistemas porfirinas meta sustituidos. Este resultado no sucede en los sistemas con ligandos en posiciones para, en donde el núcleo de porfirina no participa en el proceso de reconocimiento supramolecular.

En los sistemas meso-octaarilsustituidos con ligandos PAH planos de tipo pireno, la coordinación de $\mathrm{Zn}$ (II) por parte del anillo de porfirina provoca un cambio estructural que afecta al comportamiento supramolecular del sistema. Para ambos fullerenos estudiados, los sistemas porfirinas que actúan como una pinza doble (modelo 1:2) cambian de actuación a una pinza sencilla (modelo 1:1) tras la formación de la metaloporfirina.

En los sistemas meso-octaarilsustituidos con ligandos PAH no planos de tipo coranuleno, la constante de asociación obtenida para el primer fullereno es tan elevada que desencadena un cambio estructural en el segundo centro receptor. Como resultado se produce un efecto inhibitorio que afecta a la acepción del segundo fullereno. La coordinación del metal dentro del anillo de porfirina no es capaz de modificar estructuralmente el sistema como sucede con el uso de ligando PAH planos. Esto es debido a que la interacción supramolecular con los restos de coranuleno es mucho más fuerte que para los restos pireno. Por consiguiente, este efecto inhibitorio se observa tanto en el sistema porfirina como en la metaloporfirina, obteniéndose en ambos casos pinzas sencillas. 
En las porfirinas meso-tetraarilsustituidas, el diseño sintético en posiciones para da lugar a constantes de asociación pequeñas, ausencia de selectividad hacia fullerenos y a la formación de dos pinzas moleculares clásicas. Todo ello es consecuencia de la no interacción del núcleo de porfirina durante el proceso de interacción supramolecular. 


\subsection{CONCLUSIONS}

Following a structure similar to that in Part 3 (Objectives), this section presents some general conclusions that have given rise to other specific conclusions.

\subsubsection{GENERAL CONCLUSIONS}

A synthetic methodology has been developed for the functionalization of molecular scaffolds based on symmetric aryl-substituted meso-porphyrins bearing multiple planar (pyrene) and non-planar (corannulene) PAH ligands. This new set of porphyrins has been obtained with moderate yields via a small number of steps considering the high number of PAH moieties being introduced to the system, as many as eight in some cases. These novel compounds show high receptor affinities for fullerenes.

A series of symmetric meso-octa- and tetraaryl-substituted porphyrins and metalporphyrins bearing multiple planar and non-planar PAH ligands has been prepared, affording molecular scaffolds with multiple supramolecular binding sites.

\subsubsection{SPECIFIC CONCLUSIONS}

The presence of the porphyrin core plays a fundamental role in supramolecular fullerene recognition. This issue is critical in systems bearing planar pyrene PAH ligands. Meta-substituted porphyrin systems provide high binding constants and selectivity for fullerenes. Additionally, these binding constants are very high for pyrene-based systems. However, in the systems containing planar PAH ligands in the para positions, no observable supramolecular interactions occur.

Another finding derived from the previous conclusion is the selectivity for $\mathrm{C}_{70}$ over $\mathrm{C}_{60}$ in meta-substituted porphyrin systems. This selectivity does not occur in the para-substituted porphyrins, in which the porphyrin core is not involved in the supramolecular recognition process.

In the meso-octaaryl-substituted systems with planar pyrene ligands, the metal $\mathrm{Zn}$ (II) coordination into the porphyrin core triggers a structural change that affects the behavior of the supramolecular system. Namely, the porphyrin system switches from double- (1:2 model) to single- (1:1 model) tweezer behavior after metal-porphyrin formation for both the fullerenes studied.

In the meso-octaaryl-substituted non-planar corannulene systems, the binding constant obtained for the first fullerene event is so high that it triggers a structural change in the second binding site. As a result, the second fullerene interaction is inhibited. The metal coordination of the porphyrin core does not structurally modify the system, as occurs when planar PAH ligands are used. This is because the supramolecular interactions of corannulene are much stronger than those of pyrene. Consequently, this inhibitory effect was also observed in both the porphyrin and metal-porphyrin systems, with single-tweezers being obtained in both cases.

In the meso-tetraaryl-substituted porphyrins, the rational design in the para positions afforded low binding constants, the absence of fullerene selectivity and formation of classical molecular tweezers. All of these features are a consequence of the non-involvement of the porphyrin core in the supramolecular recognition process. 
7. ARTÍCULOS PUBLICADOS 


\section{ARTÍCULOS PUBLICADOS}

\subsection{ARTÍCULO I:}

Dual-Tweezer Behavior of an Octapodal Pyrene Porphyrin-Based System as a Host for Fullerenes

J. Org. Chem. 2019, 84, 6183 - 6190 


\title{
Dual Tweezer Behavior of an Octapodal Pyrene Porphyrin-based Sys- tem as a Host for Fullerenes
}

\author{
Sergio Ferrero, Héctor Barbero, Daniel Miguel, Raúl García-Rodríguez* and Celedonio M. Álvarez* \\ GIR MIOMeT, IU CINQUIMA/Química Inorgánica, Facultad de Ciencias, Universidad de Valladolid, E-47011, Valladolid, Spain
}

Supporting Information Placeholder

ABSTRACT: The incorporation of eight pyrene units in a single porphyrin core exhibits a great synergistic effect, resulting in high affinity towards

$\mathrm{C}_{60}$ and $\mathrm{C}_{70}$. This octapyrene porphyrin is easily accessible by a straightforward two-step synthetic approach that involves an octuple Suzuki reaction.

The new supramolecular platform can present single or double tweezer fullerene hosting behavior. The switch from double to single tweezer behav-

iour is triggered by the simple coordination of $\mathrm{Zn}^{2+}$ to the porphyrin. Both the octa-pyrene porphyrin $2 \mathbf{H P O P}$ and its zinc metalloporphyrin analogue

ZnPOP show very high affinity for $\mathrm{C}_{60}$ and $\mathrm{C}_{70}$, while simultaneously allowing the discrimination of $\mathrm{C}_{70}$ over $\mathrm{C}_{60}$ in a $\mathrm{C}_{60} / \mathrm{C}_{70}$ mixture. The use of

2HPOP and ZnPOP for the enrichment of real fullerene mixtures is also demonstrated.

\section{INTRODUCTION}

Intermolecular $\pi$ - $\pi$ interactions are one of the main driving forces responsible for controlling supramolecular chemistry in carbon nanostructures. ${ }^{1}$ In this regard, shape complementarity between the different nanostructures is known to play a major role. It is also widely accepted that good interaction with $\mathrm{C}_{60}$ or $\mathrm{C}_{70}$ requires non-planar structures, ${ }^{2}$ and in this context non-planar polycyclic aromatic hydrocarbons (PAHs), such as the unique bowl-shaped corannulene-based systems, have emerged as very important. ${ }^{3}$ On the other hand, systems based on the planar PAH pyrene are ideally suited for interaction with more extended structures such as carbon nanotubes ${ }^{4}$ and graphene. ${ }^{5}$ Not surprisingly, only a few examples of pyrene-fullerene interactions have been reported, ${ }^{6}$ most of them involving the design of complex molecular cages. ${ }^{7}$ In contrast with non-planar PAH-based approaches, ${ }^{8}$ no discrimination between $\mathrm{C}_{60}$ and $\mathrm{C}_{70}$ has been reported for pyrene-based systems. This is quite surprising, since current supramolecular approaches require more complex scaffolds based on non-planar PAHs such as corannulene moieties ${ }^{9}$ which are not easily synthetically accessible. Achieving a good balance between facile synthesis and a high affinity constant, and in particular the ability to achieve discrimination, still remains challenging. Therefore, the development of cheaper and more synthetically accessible pyrene-based systems is an attractive but difficult task.

In the search for new molecular architectures that act as hosts for fullerenes, researchers have focused on porphyrin-based systems. Although porphyrins are known to interact with fullerenes and co-crystallization adducts have been extensively reported, ${ }^{10}$ for a single core 
porphyrin, this interaction is usually too weak to be observed in solution. ${ }^{10 a}, 10 c, 11$ Therefore, in order to achieve high affinity constants, the preparation of multiporphyrinic cages is required..$^{12}$ Considerable efforts have been devoted to the tailoring of such complex systems to improve the interaction with fullerenes. Although this approach has been shown to provide some remarkably high affinities towards fullerenes, including selectivity for $\mathrm{C}_{70}$ over $\mathrm{C}_{60},{ }^{11 a}, 12-13$ their complex, multistep, and tedious syntheses prevent this approach from becoming general for fullerene interaction and discrimination. We have recently shown that easily accessible porphyrins based on a meso-susbtituted tetraaryl porphyrin core bearing different $\mathrm{PAH}$ units could be used for $\mathrm{C}_{60}$ hosting. ${ }^{14}$ The corannulene-based system, which contained four corannulene units, showed a remarkably high affinity constant $\left(\mathrm{K}_{\mathrm{a}}=2.2 \times 10^{4} \mathrm{M}^{-1}\right)$ for the $\alpha_{4}$ atropoisomer. One distinct limitation, however, was that the formation of atropisomers, whose separation was not possible, not only resulted in a complex and difficult-to-analyse mixture of species, but also diminished the interaction with $\mathrm{C}_{60}$.

Herein, we report the first example of a single core porphyrin that discriminates $\mathrm{C}_{70}$ over $\mathrm{C}_{60}$ in a fullerene mixture. The system is based on the simultaneous introduction of eight commercially available planar PAH pyrene moieties at the meta positions on a tetraaryl porphyrin system. This not only avoids the formation of atropisomers, but also results in a great synergistic effect between the porphyrin core and the pyrene units (Figure 1). This approach avoids the use of less synthetically and commercially accessible systems, such as those based on non-planar PAHs like corannulene, and also introduces the possibility for the system to act as a single or a double-tweezer structure as a host for fullerenes. This particular behaviour stems from the arrangement of four pyrene arms above and four below the porphyrin ring plane, resulting in a 'double picket fence' porphyrin.

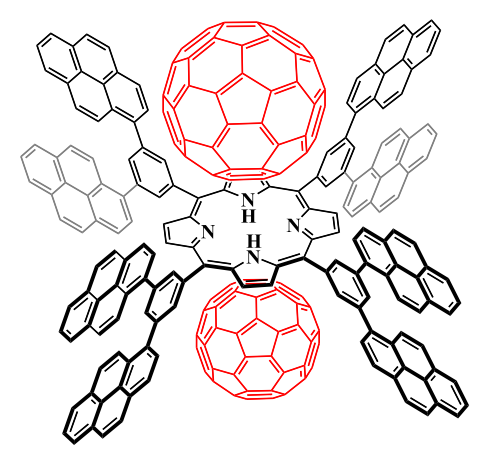

Figure 1. Schematic representation of the tetraaryl octapyrene porphyrin reported in this work and its potential behavior as a double-tweezer structure to host fullerenes.

\section{RESULTS AND DISCUSSION}

As noted in the introduction, porphyrin systems are ideal scaffolds for constructing relatively complex molecular architectures. Although one unit of pyrene is known not to affect the recognition of fullerenes, we reasoned that fullerene recognition could be achieved through the cooperative effect of several units of pyrene on a porphyrin core. We sought to introduce two pyrene moieties at the meta position of an aryl group of a symmetrically substituted meso tetraaryl porphyrin to yield an octapyrene-based system (Figure 1). In such a system, the 
formation of atropisomers is prevented and the pyrene units would be ideally placed to interact with fullerenes in a cooperative manner thanks to the particular arrangement provided by the central scaffold. This, along with the great synergistic effect between the porphyrin core and the pyrene units, would result in a simple but effective platform for fullerene hosting. In addition to this, the $4+4$ arrangement of the pyrene arms in the "up" and "down" positions with regards to the porphyrin plane could allow the system to act as a double molecular tweezer for which 1:2 supramolecular interactions could occur.

We envisaged that such a system could be easily prepared in a two-step synthesis following the so-called "divergent" approach, in which a suitable porphyrin core with functionalities that can be subsequently used as reactive points for the construction of a more complex scaffold is first prepared. Our initial attempts involving the reaction of the meta-substituted octaboronate-porphyrin compound $\mathbf{2 H P O B}$ and 1-bromopyrene resulted in an extremely low yield (less than 1\%) for the octa Suzuki reaction (see SI, route 2). However, this could be easily circumvented by employing the meta substituted octabromo-porphyrin $\mathbf{2 H P O B r}$ as the starting porphyrin core (Scheme 1 ). The synthesis of this compound was easily accomplished in 15 min by a MW-assisted method in which $\mathbf{2 H P O B r}$ cleanly precipitates from the reaction mixture (see experimental section). This approach drastically improved the yield (24\%) compared to that of the previously existing method (11\%), which required of $48 \mathrm{~h}$ of reflux in propionic acid and purification by chromatography. ${ }^{15}$ With this compound in hand, the target compound 2HPOP was obtained via a MW-assisted octuple Suzuki reaction. The use of a MW reactor is critical for the success of the reaction, as it is known to drastically decrease the amount of undesired byproducts. ${ }^{16}$ This can be easily realised from the remarkably high total yield of $28 \%$ (i.e., more than $85 \%$ per single cross-coupling reaction) and the fact that similar reactions involving a high number of Pd-catalysed C-C couplings are known to be problematic due to the rapid build-up of by-products, which can completely prevent product formation. ${ }^{17}$ Metallation of $\mathbf{2 H P O P}$ with $\mathrm{Zn}(\mathrm{OAc})_{2} 2 \mathrm{H}_{2} \mathrm{O}$ to give $\mathbf{Z n P O P}$ (Scheme 1) was straightforwardly achieved in a quantitative manner, thus providing an additional platform for fullerene hosting and also for evaluating the impact of the introduction of a metal on the supramolecular binding behaviour. It is known that metal insertion can lead to remarkable changes in the geometry of the central ring of the porphyrin ${ }^{18}$ and provide a new set of noncovalent interactions ${ }^{10 a}, 11 a, 19$, both of which may lead to a change in the hosting behaviour of the system.

Scheme 1 Optimized synthesis of 2 HPOP and $\mathbf{Z n P O P}^{a}$

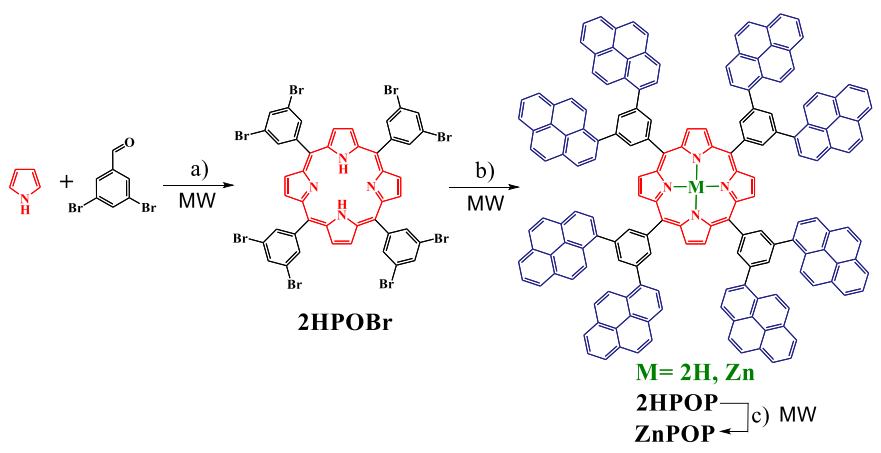


${ }^{\mathrm{a} R e a g e n t s ~ a n d ~ c o n d i t i o n s: ~(a) ~ p r o p i o n i c ~ a c i d, ~ n i t r o b e n z e n e, ~} \mathrm{MW}, 200{ }^{\circ} \mathrm{C}$; (b) Bpin-Pyrene (1), $\left[\mathrm{PdCl}_{2}(\mathrm{dppf})\right],{ }^{\mathrm{t}} \mathrm{BuONa}$, toluene, $\mathrm{MW},(\mathrm{c})$ $\mathrm{Zn}(\mathrm{OAc})_{2} \cdot 2 \mathrm{H}_{2} \mathrm{O}, \mathrm{CHCl}_{3} /$ toluene, $\mathrm{MW}, 120^{\circ} \mathrm{C}$.

All the aforementioned porphyrins were fully characterized by NMR spectroscopy, UV-Vis absorption spectroscopy and high-resolution MALDI-TOF mass spectrometry (see the experimental part and SI). The UV-Vis absorption spectra in toluene display the expected weak Q-bands in the range 500-670 $\mathrm{nm}$ and the intense Soret bands, which are red-shifted for ZnPOP (432 nm) as compared to 2 HPOP (428 $\mathrm{nm})$. This small but distinctive red-shift of the band has been suggested to be related to an increase in the non-planarity of the porphyrin. ${ }^{18 \mathrm{~d}, 20}{ }^{1} \mathrm{H}$ NMR spectra of the octapyrene porphyrins $\mathbf{2 H P O P}$ and ZnPOP show the equivalency of the eight pyrene moieties resulting from the effective $\mathrm{D}_{4 \mathrm{~h}}$ symmetry in solution (see ${ }^{1} \mathrm{H}$ and ${ }^{13} \mathrm{C}\left\{{ }^{1} \mathrm{H}\right\}$ spectra in the SI). The presence of the two inner NH protons of $\mathbf{2 H P O P}$ is observed at a characteristic upfield shift of $\delta=-2.50 \mathrm{ppm}$ as a consequence of the shielding they experience from the aromatic ring current present in the porphyrin core. This signal is absent in the metallated porphyrin ZnPOP. It is worth mentioning the different behavior observed for 2HPOP and $\mathbf{Z n P O P}$ in $\mathrm{CDCl}_{3}$. While the ${ }^{1} \mathrm{H}$ NMR spectrum of $\mathbf{2 H P O P}$ exhibits sharp resonances for the range of concentrations studied $\left(10^{-4}-10^{-6} \mathrm{M}\right)$, ZnPOP shows very broad resonances in relatively dilute solutions $\left(10^{-5} \mathrm{M}\right)$ that become sharper with the further dilution of the sample (See SI, Figs S9). This behavior is indicative of an intermolecular process. ${ }^{21}$ However, both $\mathbf{2 H P O P}$ and ZnPOP show non-concentration-dependent behavior in toluene- $\mathrm{d}_{8}$, a solvent that is known to disrupt intermolecular $\pi-\pi$ stacking interactions. ${ }^{10 a, 21 a}$ This suggests that ZnPOP, unlike its unmetallated analogue 2HPOP, may undergo a certain degree of stacking due to $\pi$ - $\pi$ interactions between porphyrins in $\mathrm{CDCl}_{3}$. The extent to which the $\mathrm{Zn}$ centre directly contributes to the formation of these $\pi$ - $\pi$ stacking interactions is unknown at this stage.

We then moved to study the supramolecular behavior of ZnPOP and $\mathbf{2 H P O P}$ as hosts for $\mathrm{C}_{60}$ and $\mathrm{C}_{70}$. We were particularly interested in studying whether these porphyrin systems could act as a single or double tweezers (i.e., whether they could accept one or two fullerenes, as shown in Fig. 1). We initially used a host concentration of $[\mathrm{H}]_{0}=10^{-4} \mathrm{M}$. Although the titrations could be carried out for $\mathrm{C}_{60}$, the titration of ZnPOP and 2HPOP with $\mathrm{C}_{70}$ was prevented by the appearance of a precipitate. This suggested a much larger affinity of both systems for $\mathrm{C}_{70}$ than for $\mathrm{C}_{60}$, for which no precipitate was observed. We therefore set the concentration of host to $[\mathrm{H}]_{0}=10^{-5} \mathrm{M}$ for the titration experiments involving $\mathrm{C}_{70}$. We started our studies with $\mathbf{Z n P O P}$, and we carried out titration experiments with $\mathrm{C}_{60}$ and $\mathrm{C}_{70}$ in toluene-d 8 . In both experiments, we followed the shift of $\mathrm{H}_{8}$ (see figure 2, S22 and S24 in the SI) during the titration. As shown in Figure 2 above, the chemical shift for $\mathrm{H}_{8}$ changes during the titration of $\mathbf{Z n P O P}$ with $\mathrm{C}_{60}$ or $\mathrm{C}_{70}$, indicating supramolecular association and host-guest formation in both cases. The non-linear binding isotherm that results from the titration experiments with $\mathrm{C}_{60}$ or $\mathrm{C}_{70}$ could be fitted, in both cases, to a 1:1 model (Fig. 2 below). No evidence for a 1:2 model in which ZnPOP accepts two fullerenes was observed. These plots clearly show a faster saturation for $\mathrm{C}_{70}$, which reaches the limiting chemical shift $\Delta \delta_{\max }$ much faster than $\mathrm{C}_{60}$, reflecting a greater binding constant value $K_{a}$ for $Z_{n P O P}$ and $C_{70}$. The calculated binding constants of $\mathbf{Z n P O P}$ for $\mathrm{C}_{60}$ and $\mathrm{C}_{70}$ are $\mathrm{K}_{1}=2.30 \pm 0.01 \times 10^{3} \mathrm{M}^{-1}$ and $\mathrm{K}_{1}=$ 
$2.69 \pm 0.02 \times 10^{4} \mathrm{M}^{-1}$, respectively. This shows that $\mathbf{Z n P O P}_{\mathbf{n}}$ has a very high selectivity, preferring $\mathrm{C}_{70}$ over $\mathrm{C}_{60}$, as demonstrated by the binding constant for $\mathrm{C}_{70}$, which is an order of magnitude larger than the one for $\mathrm{C}_{60}$.
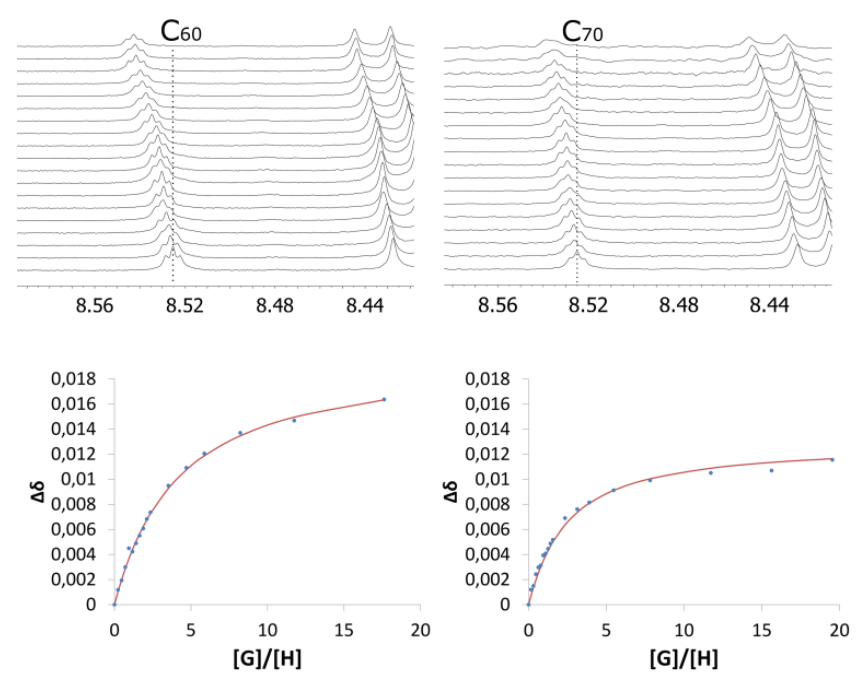

Figure 2. (Above) ${ }^{1} \mathrm{H}$ NMR spectra in toluene- $\mathrm{d}_{8}$ showing the $\mathrm{H}_{8}$ chemical shift of $\mathbf{Z n P O P}$ upon the addition of aliquots of $\mathrm{C}_{60}$ (left) or $\mathrm{C}_{70}$ (right). (Below) Plot of the changes in the chemical shift against $[\mathrm{G}] /[\mathrm{H}]$, where $\mathrm{G}$ (guest) is $\mathrm{C}_{60}$ or $\mathrm{C}_{70}$ and $\mathrm{H}$ (host) is ZnPOP. The red line corresponds to the nonlinear fitting of $\Delta \delta$ for $\mathrm{H}_{8}$ to a 1:1 binding isotherm. It can be seen that the titration with $\mathrm{C}_{70}$ reaches supramolecular saturation earlier than $\mathrm{C}_{60}$, reflecting a larger binding constant. Note: $[\mathrm{H}]_{0}=10^{-4} \mathrm{M}$ for $\mathrm{C}_{60}$ titration and $[\mathrm{H}]_{0}=10^{-5} \mathrm{M}$ for $\mathrm{C}_{70}$.

In sharp contrast, the titration of $\mathbf{2 H P O P}$ with $\mathrm{C}_{70}$ did not show the typical 1:1 binding isotherm observed for $\mathbf{Z n P O P}$. Instead, a very complex behaviour was observed, indicative of a non-1:1 system. ${ }^{22}$ This complex behaviour was observed at different initial concentrations of the host, $[\mathrm{H}]_{0}$ (see figure S28 and S30 SI). Figure 3 shows the change of $\Delta \delta$ against [Guest]/[Host]. The graph shows two inflexion points at $[\mathrm{G}] /[\mathrm{H}]=1$ and $c a \cdot[\mathrm{G}] /[\mathrm{H}]=2$. The binding isotherm could be fitted to a $1: 2$ non-cooperative model for which the values $\mathrm{K}_{1}=$ $1.40 \pm 0.05 \times 10^{4} \mathrm{M}^{-1}$ and $\mathrm{K}_{2}=3.50 \pm 0.13 \times 10^{3} \mathrm{M}^{-1}$ were obtained. ${ }^{23}$ This double tweezer behaviour of $\mathbf{2 H P O P}$ was also observed for the interaction with $\mathrm{C}_{60}$. The binding isotherm observed in this case did not show such complex behaviour, but instead an asymptotic curve.

This apparently simple behaviour could also be better explained by a $1: 2$ non-cooperative model $\left(\operatorname{cov}_{\mathrm{fit}}=3.16\right)^{23 \mathrm{~b}}$ with $\mathrm{K}_{1}=1.49 \pm 0.01 \mathrm{x} 10^{3}$ $\mathrm{M}^{-1}$ and $\mathrm{K}_{2}=3.71 \pm 0.02 \times 10^{2} \mathrm{M}^{-1}$ (see SI for details), than by a $1: 1$ model as in the case of ZnPOP.

These results show that the selection between double/single tweezer behavior might be controlled by simply coordinating $\mathrm{Zn}^{2+}$ in the porphyrin, thus illustrating how subtle changes in the porphyrin skeleton may lead to drastic changes in their supramolecular behavior. 


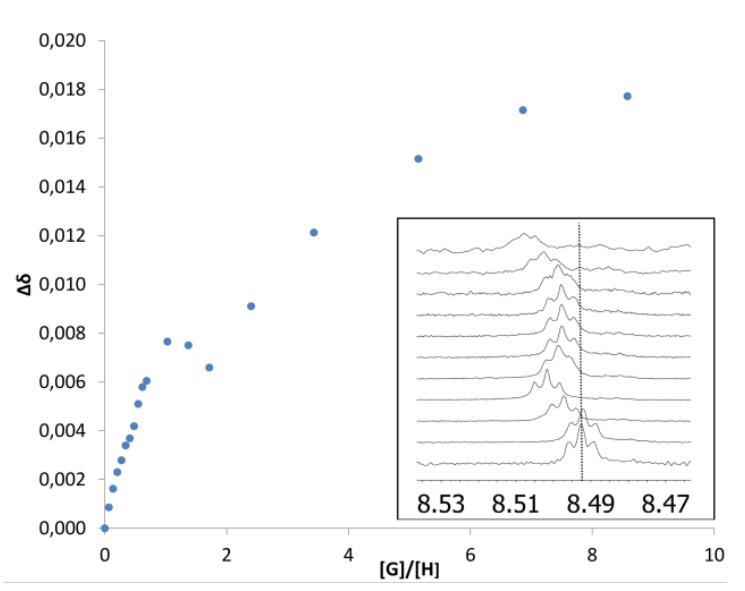

Figure 3. Plot of changes in the chemical shift of $\mathrm{H}_{8}$ against $[\mathrm{G}] /[\mathrm{H}]$, where $\mathrm{G}$ (guest) is $\mathrm{C}_{70}$ and $\mathrm{H}$ (host) is 2HPOP, showing the more complex behaviour of the binding isotherm. $[\mathrm{H}]_{0}=10^{-5} \mathrm{M}$. Inset, stacked ${ }^{1} \mathrm{H}$ NMR spectra showing the variation of the $\mathrm{H}_{8}$ chemical shift of 2HPOP, $[\mathrm{H}]_{0}=$ $10^{-4} \mathrm{M}$, upon the addition of aliquots of $\mathrm{C}_{70}$. Note: the dotted line is a guide to the eye.

Importantly, the great selectivity for $\mathrm{C}_{70}$ over $\mathrm{C}_{60}$ (one order of magnitude) is retained in the case of $\mathbf{2 H P O P}$ when switching from a single tweezer behaviour, as observed in ZnPOP, to a double tweezer one (Table 1). It is worth mentioning that the binding constants for both fullerenes are similar to those based on non-planar PAH systems bearing more complex corannulene motifs, whose bowl-shaped polycyclic aromatic hydrocarbon structure is known to provide complementarity between corannulene-fullerene surfaces. ${ }^{8 \mathrm{~b}, 24}$ This shows the great potential of our simple approach based on the two-step synthesis of a single porphyrin bearing eight pyrene units.

Table 1. Summary of Binding Constants $\mathrm{K}_{\mathrm{a}}\left(\mathrm{M}^{-1}\right)$ of $2 \mathrm{HPOP}$ and $\mathrm{ZnPOP}$ for $\mathrm{C}_{60}\left([\mathrm{H}]_{0}=10^{-4} \mathrm{M}\right)$ and $\mathrm{C}_{70}\left([\mathrm{H}]_{0}=10^{-5} \mathrm{M}\right)$ in Toluene- $\mathrm{d}_{8}$

\begin{tabular}{lll}
\hline & $\mathrm{C}_{60}$ & $\mathrm{C}_{70}$ \\
\hline ZnPOP & $\mathrm{K}_{1}=2.30 \pm 0.01 \times 10^{3}$ & $\mathrm{~K}_{1}=2.69 \pm 0.02 \times 10^{4}$ \\
\hline \multirow{2}{*}{ 2HPOP } & $\mathrm{K}_{1}=1.49 \pm 0.01 \times 10^{3}$ & $\mathrm{~K}_{1}=1.40 \pm 0.05 \times 10^{4}$ \\
& $\mathrm{~K}_{2}=3.71 \pm 0.02 \times 10^{2}$ & $\mathrm{~K}_{2}=3.50 \pm 0.13 \times 10^{3}$ \\
\hline
\end{tabular}

Having established that the switch from double to single tweezer behaviour is triggered by the simple coordination of $\mathrm{Zn}^{2+}$ to the porphyrin core, we then moved to evaluate the possibility of using these systems to separate/enrich a $\mathrm{C}_{60} / \mathrm{C}_{70}$ fullerene mixture by selectively sequestering $\mathrm{C}_{70}$ from the solution. We were motivated to explore this possibility by the large selectivity for $\mathrm{C}_{70}$ over $\mathrm{C}_{60}$ shown by $\mathbf{Z n}_{\mathbf{n}} \mathbf{P O P}$ and 2HPOP, as well as the low solubility of the adducts formed with $\mathrm{C}_{70}$, as noted above. We initially dissolved an equimolar amount of $\mathrm{C}_{60} / \mathrm{C}_{70}$ in toluene- $\mathrm{d}_{8}$ and recorded a ${ }^{13} \mathrm{C}\left\{{ }^{1} \mathrm{H}\right\}$ NMR spectrum ${ }^{25}$ (Figure 4, above). The addition of one equivalent of $2 \mathbf{H P O P}$ resulted in the formation of the fullerene-porphyrin adduct as a black precipitate after sonication of the sample, which could be easily separated from the supernatant by simply decanting the solution. The ${ }^{13} \mathrm{C}\left\{{ }^{1} \mathrm{H}\right\}$ spectrum of the decanted supernatant shows a $\mathrm{C}_{60} / \mathrm{C}_{70}$ ratio of $1: 2.7$ (Figure 4, below), which was also verified by UV-Vis and HPLC. ${ }^{25 b}{ }^{26}$ Thus, a nearly three times more enriched sample of $\mathrm{C}_{60}$ was easily obtained by simply adding one equivalent of 2HPOP. The level of enrichment of $\mathrm{C}_{60}$ in solution was found to increase steadily with the 
addition of 2 HPOP. The addition of $0.7 \mathrm{eq}$ and $1.6 \mathrm{eq}$ to $1: 1$ mixtures of $\mathrm{C}_{60} / \mathrm{C}_{70}$ resulted in enrichment levels of $1: 2.0$ and $1: 4.6$ of $\mathrm{C}_{60}$ in the solution, respectively, as analyzed by ${ }^{13} \mathrm{C}\left\{{ }^{1} \mathrm{H}\right\}$ NMR, UV-Vis and HPLC, with a loss of $42 \%$ of $\mathrm{C}_{60}$ as co-precipitate for the latter case (see SI).

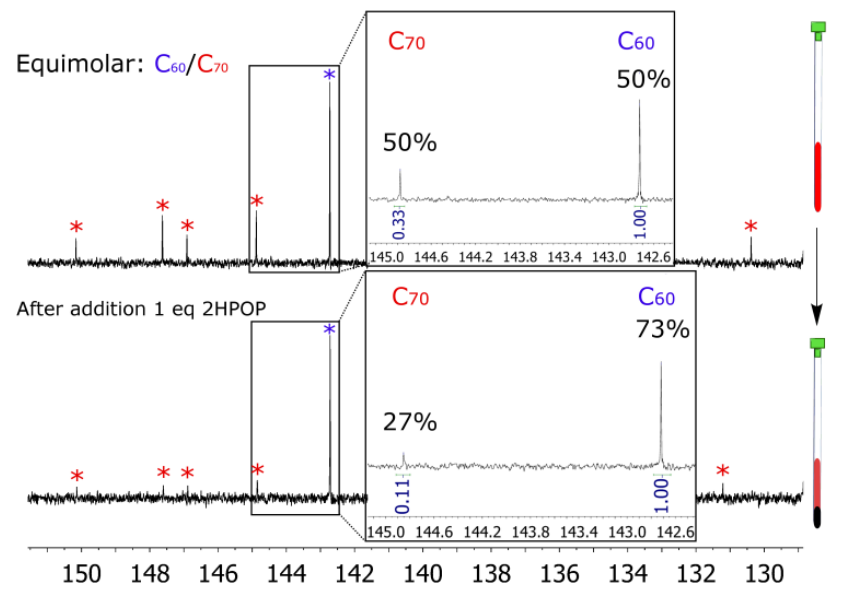

Figure 4. Quantitative ${ }^{13} \mathrm{C}\left\{{ }^{1} \mathrm{H}\right\}$ NMR spectra in toluene- $\mathrm{d}_{8}$ of an equimolar solution of $\mathrm{C}_{60} / \mathrm{C}_{70}$ before (above) and after (below) the addition of 1 equivalent of $\mathbf{2 H P O P}$. Signals of $\mathrm{C}_{70}$ are reduced as a result of its precipitation as the $\mathbf{2 H P O P}$ adduct of $\mathrm{C}_{70}$. Note: The 5 resonances for $\mathrm{C}_{70}$ are shown with red asterisks, and the one for $\mathrm{C}_{60}$ with a purple asterisk. The fullerene $\mathrm{C}_{60} / \mathrm{C}_{70}$ ratio was extracted from the integration of their signals considering their relative proportion of nuclei.

Encouraged by these good results, we turned our attention towards the use of ZnPOP for fullerene enrichment. We were intrigued to test whether we could improve the results obtained with 2 HPOP and minimise the amount of $\mathrm{C}_{60}$ loss as co-precipitate. We found that the addition of 1 equivalent of $\mathbf{Z n P O P}$ to a 1:1 mixture of $\mathrm{C}_{70} / \mathrm{C}_{60}$ in toluene resulted in a 1:8.1 enrichment of $\mathrm{C}_{60}$ in solution, while only losing $13 \%$ of the initial amount of $\mathrm{C}_{60}$ by co-precipitation, thus improving the results obtained with $\mathbf{2 H P O P}$. A distinctive difference in this case is that $\mathbf{Z n P O P}$ behaves as a single tweezer for fullerene recognition, while in the case of $\mathbf{2 H P O P}$ the loss of $\mathrm{C}_{60}$ as co-precipitate could be enhanced by its double tweezer behaviour. Nonetheless, these results show the generality of this approach to enrich fullerene mixtures in a simple and handy manner.

\section{CONCLUSIONS}

We have reported a two-step synthesis of a single porphyrin core system bearing 8 pyrene units that shows high affinity towards $\mathrm{C}_{60}$ and $\mathrm{C}_{70}$. The key to the success of our approach is the integration of 8 pyrene units in a tetraaryl meso-substituted porphyrin, which results in a great synergistic effect between the porphyrin core and the pyrene units. The resulting 'double picket fence' porphyrin can behave as either a double or single tweezer simply by the introduction of $\mathrm{Zn}^{2+}$ into the porphyrin core, which triggers the switch from double (2HPOP) to single (ZnPOP) tweezer behavior, thus allowing additional control of our supramolecular platform. In addition to this, ZnPOP and 
2HPOP can discriminate between $\mathrm{C}_{70}$ and $\mathrm{C}_{60}$, and their use for the easy enrichment of $\mathrm{C}_{60} / \mathrm{C}_{70}$ mixtures of fullerenes is demonstrated. To the best of our knowledge, this constitutes the first example of discrimination between $\mathrm{C}_{60}$ and $\mathrm{C}_{70}$ using a pyrene-based molecular tweezer. This type of discrimination has generally been the domain of non-planar PAH systems that display greater shape complementarity or of complex molecular cages, but both designs are much more synthetically costly.

\section{EXPERIMENTAL}

General Methods

All reagents were purchased from commercial sources and used without further purification. Solvents were either used as purchased or dried according to procedures described elsewhere. ${ }^{27}$ Microwave reactions were carried out using an Anton Paar Monowave 300 Reactor. Column chromatography was carried out using silica gel 60 (particle size $0.040-0.063 \mathrm{~mm} ; 230-400$ mesh) as the stationary phase, and TLC was performed on precoated silica gel plates $(0.25 \mathrm{~mm}$ thick, $60 \mathrm{~F} 254)$ and visualized under UV light and/or by immersion in anisaldehyde. NMR spectra and NMR titrations were recorded on $500 \mathrm{MHz}$ Agilent DD2 instruments equipped with a coldprobe. Fullerene ${ }^{13} \mathrm{C}\left\{{ }^{1} \mathrm{H}\right\}$ NMR experiments were recorded on $500 \mathrm{MHz}$ Agilent instruments equipped with a ONEPROBE using the following acquisition parameters: $4 \mathrm{~s}$ relaxation delay between transients, $45^{\circ}$ pulse width, and $1.048 \mathrm{~s}$ acquisition time. ${ }^{1} \mathrm{H}$ and ${ }^{13} \mathrm{C} . \mathrm{NMR}$ chemical shifts $(\delta)$ are reported in parts per million ( $\mathrm{ppm})$ and are referenced to TMS, using the solvent as an internal reference. Coupling constants $(J)$ are reported in $\mathrm{Hz}$. Standard abbreviations are used to indicate multiplicity: $\mathrm{s}=$ singlet, $\mathrm{d}=\mathrm{doublet}, \mathrm{t}=$ triplet, $\mathrm{m}=$ multiplet. ${ }^{1} \mathrm{H}$ and ${ }^{13} \mathrm{C}$ peak assignments were performed using 2D NMR methods (DQFCOSY, band selective ${ }^{1} \mathrm{H}-{ }^{1} \mathrm{H}-\mathrm{ROESY}$, band selective ${ }^{1} \mathrm{H}-{ }^{13} \mathrm{C}$ HSQC, band selective ${ }^{1} \mathrm{H}-{ }^{13} \mathrm{C}$ HMBC). Due to low solubility, some carbon signals were detected indirectly via ${ }^{1} \mathrm{H}-{ }^{13} \mathrm{C}-\mathrm{HMBC}$ experiments; in these cases, the abbreviation in is used. High resolution mass spectra were recorded at the mass spectrometry service of the Laboratory of Instrumental Techniques of the University of Valladolid. A MALDI-TOF system (MALDI-TOF), the Bruker Autoflex Speed ( $\mathrm{N}_{2}$ laser: 337 $\mathrm{nm}$, pulse energy $100 \mu \mathrm{J}, 1 \mathrm{~ns}$; acceleration voltage: $19 \mathrm{kV}$, reflector positive mode) was used. Trans-2-[3-(4-tert-butylphenyl)-2-methyl-2propenylidene]malonitrile (DCTB) and 1,8,9-anthracenetriol, 1,8-dihydroxy-9(10H)-anthracenone (dithranol) were used as matrixes. UV/Vis spectra were recorded using a Shimadzu UV-1603 with spectrophotometric grade solvents. UV/vis absorption spectral wavelengths $(\lambda)$ are reported in nanometers $(\mathrm{nm})$, and molar absorption coefficients $(\varepsilon)$ are reported in $\mathrm{M}^{-1} \mathrm{~cm}^{-1}$. High performance liquid

chromatography (HPLC) was performed at the chromatography service of the Laboratory of Instrumental Techniques of the University of Valladolid using an Agilent 1200 Series with a C18 column $(4.6 \mathrm{~mm} \times 250 \mathrm{~mm})$ with a UV/Vis (333 nm) detector. The mobile phase was toluene/methanol/acetonitrile $(60: 20: 20)$ containing $0.1 \%$ trifluoroacetic acid (TFA) at $30^{\circ} \mathrm{C}$.

\section{Pinacol pyreneboronate (1)}

1-pyreneboronic acid (100 mg, $0.406 \mathrm{mmol})$ and pinacol $(72.3 \mathrm{mg}, 0.609 \mathrm{mmol})$ were placed into a sealed vessel specifically designed for microwave irradiation. Initially, the mixture was heated inside a microwave reactor at $140{ }^{\circ} \mathrm{C}$ without stirring, allowing pinacol to melt, and 
then stirred for $15 \mathrm{~min}$. The mixture was dissolved in $20 \mathrm{ml}$ of DCM and placed into a separatory funnel with $20 \mathrm{ml}$ of warm $\mathrm{H}_{2} \mathrm{O}$. The organic phase was washed with $20 \mathrm{ml}$ of warm $\mathrm{H}_{2} \mathrm{O}$ twice, and the aqueous phase was extracted with $10 \mathrm{ml}$ of DCM. The organic layer was dried with anhydrous $\mathrm{MgSO}_{4}$, filtered and concentrated to afford $\mathbf{1}$ as a pure white solid (128 $\left.\mathrm{mg}, 96 \%\right)$. The spectroscopic data were in agreement with those reported in the literature..$^{28}$

\section{$2 \mathrm{HPOBr}$}

Pyrrole (139 $\mu \mathrm{L}, 2 \mathrm{mmol})$, 3,5-dibromobenzaldehyde ( $557 \mathrm{mg}, 2 \mathrm{mmol}$ ), propionic acid (7 mL, $87 \mathrm{mmol}$ ) and nitrobenzene (13 mL, 126 mmol) were mixed in a sealed vessel specifically designed for microwave irradiation. The mixture was stirred inside a microwave reactor at $200^{\circ} \mathrm{C}$ for $15 \mathrm{~min}$; the pressure reached up to 4 bar. The dark crude was stored in a refrigerator for 2 days and then filtered in a Büchner funnel and washed with $\mathrm{MeOH}$. The obtained solid was placed in an oven and kept under reduced pressure $\left(200^{\circ} \mathrm{C}, 3 \mathrm{~h}, 90\right.$ torr $)$ to remove residual nitrobenzene and finally give the dark purple solid $2 \mathrm{HPOBr}(150 \mathrm{mg}, 24 \%$ yield $) .{ }^{1} \mathrm{H}$ NMR $(500 \mathrm{MHz}, \mathrm{Chloroform}-d): \delta$ $8.89\left(\mathrm{~s}, 8 \mathrm{H}, \mathrm{H}_{2}\right), 8.31\left(\mathrm{~d}, J=1.8 \mathrm{~Hz}, 8 \mathrm{H}, \mathrm{H}_{6}\right), 8.15\left(\mathrm{t}, J=1.8 \mathrm{~Hz}, 4 \mathrm{H}, \mathrm{H}_{8}\right),-2.99\left(\mathrm{br}, 2 \mathrm{H}, \mathrm{H}_{1}\right) .{ }^{13} \mathrm{C}\left\{{ }^{1} \mathrm{H}\right\} \mathrm{NMR}(126 \mathrm{MHz}, \mathrm{Chloroform}-d): \delta$ $144.93\left(\mathrm{C}_{5}\right), 135.93\left(\mathrm{C}_{6}\right), 133.90\left(\mathrm{C}_{8}\right), 121.57\left(\mathrm{C}_{7}\right), 117.57\left(\mathrm{C}_{4}-\mathrm{in}\right)$. HR-MS (MALDI-TOF): m/z for $\mathrm{C}_{44} \mathrm{H}_{22} \mathrm{Br}_{8} \mathrm{~N}_{4}\left[\mathrm{M} \mathrm{H}^{+}\right]^{+}$calcd: 1246.5310. Found: 1246.5311 (0.1 ppm error). UV/vis (toluene): $\lambda 402(\varepsilon=33259), 422(\varepsilon=164714), 515(\varepsilon=8578), 545(\varepsilon=2507)$, $587(\varepsilon=2639)$

2HPOP

2HPOBr (10 mg, $0.0080 \mathrm{mmol})$, pinacol pyreneboronate (1) $(23.3 \mathrm{mg}, 0.071 \mathrm{mmol}),\left[\mathrm{PdCl}_{2}(\mathrm{dppf})\right](9.3 \mathrm{mg}, 0.0128 \mathrm{mmol})$ and ${ }^{\mathrm{t}} \mathrm{BuO}-$ $\mathrm{Na}(18.5 \mathrm{mg}, 0.192 \mathrm{mmol})$ were mixed in a sealed vessel specifically designed for microwave irradiation and put the microwave reactor inside a two-necked round-bottom flask in order to keep the system under an inert atmosphere. $1.4 \mathrm{ml}$ of dry toluene was added. The mixture was stirred inside a microwave reactor at $150^{\circ} \mathrm{C}$ for $135 \mathrm{~min}$ (the pressure reached up to 3.8 bar). After cooling, the solvent was removed under vacuum and the crude was purified by column chromatography on silica gel, using hexane/AcOEt gradient elution (3:1$2: 1-1: 1)$ and $\mathrm{CHCl}_{3}$ to finally give a purple solid 2HPOP (5.0 mg, $28 \%$ yield). ${ }^{1} \mathrm{H}$ NMR (500 MHz, Chloroform- $d$ ) $\delta: 9.46\left(\mathrm{~s}, 8 \mathrm{H}, \mathrm{H}_{2}\right)$, $8.85\left(\mathrm{~d}, J=9.3 \mathrm{~Hz}, 8 \mathrm{H}, \mathrm{H}_{10}\right), 8.73\left(\mathrm{~d}, J=1.7 \mathrm{~Hz}, 8 \mathrm{H}, \mathrm{H}_{6}\right), 8.46\left(\mathrm{~d}, J=7.9 \mathrm{~Hz}, 8 \mathrm{H}, \mathrm{H}_{18}\right), 8.42\left(\mathrm{t}, J=1.7 \mathrm{~Hz}, 4 \mathrm{H}, \mathrm{H}_{8}\right), 8.31(\mathrm{~d}, J=7.9 \mathrm{~Hz}$, $\left.8 \mathrm{H}, \mathrm{H}_{17}\right), 8.19-8.15\left(\mathrm{~m}, 16 \mathrm{H}, \mathrm{H}_{14}+\mathrm{H}_{11}\right), 8.12-8.07\left(\mathrm{~m}, 16 \mathrm{H}, \mathrm{H}_{13}+\mathrm{H}_{12}\right), 8.05\left(\mathrm{~d}, J=7.7 \mathrm{~Hz}, 8 \mathrm{H}, \mathrm{H}_{16}\right), 7.94\left(\mathrm{t}, J=7.7 \mathrm{~Hz}, 8 \mathrm{H}, \mathrm{H}_{15}\right),-2.50$ (br, $\left.2 \mathrm{H}, \mathrm{H}_{1}\right) .{ }^{13} \mathrm{C}\left\{{ }^{1} \mathrm{H}\right\} \mathrm{NMR}\left(126 \mathrm{MHz}\right.$, Chloroform-d) $\delta: 142.42\left(\mathrm{C}_{5}\right), 139.76\left(\mathrm{C}_{19}\right), 136.92\left(\mathrm{C}_{7}\right), 135.99\left(\mathrm{C}_{6}\right), 132.15\left(\mathrm{C}_{8}\right), 131.35$ $\left(\mathrm{C}_{22}\right), 130.81\left(\mathrm{C}_{24}+\mathrm{C}_{20}\right), 128.73\left(\mathrm{C}_{9}\right), 128.07\left(\mathrm{C}_{18}\right), 127.90\left(\mathrm{C}_{11}\right), 127.51\left(\mathrm{C}_{13}\right), 127.32\left(\mathrm{C}_{12}\right), 125.92\left(\mathrm{C}_{15}\right), 125.13\left(\mathrm{C}_{14}\right), 125.05\left(\mathrm{C}_{10}\right)$ $125.01\left(\mathrm{C}_{\mathrm{q}}\right), 124.90\left(\mathrm{C}_{16}\right), 124.82\left(\mathrm{C}_{17}\right), 124.80\left(\mathrm{C}_{\mathrm{q}}\right), 120.11\left(\mathrm{C}_{4}\right)$. HR-MS (MALDI-TOF): m/z for $\mathrm{C}_{172} \mathrm{H}_{94} \mathrm{~N}_{4}[\mathrm{M}+\mathrm{H}]^{+}$calcd: 2214.7473. Found: $2214.7424(-4.9$ ppm error). UV/vis (toluene): $\lambda 280(\varepsilon=275508), 350(\varepsilon=238277), 410(\varepsilon=106537), 428(\varepsilon=$ $503476), 518(\varepsilon=25202), 551(\varepsilon=12601)$.

ZnPOP 
2HPOP $(5.0 \mathrm{mg}, 0.0022 \mathrm{mmol})$ and $\mathrm{Zn}(\mathrm{AcO})_{2} \cdot 2 \mathrm{H}_{2} \mathrm{O}(7.2 \mathrm{mg}, 0.033 \mathrm{mmol})$ were mixed in a sealed vessel specifically designed for microwave irradiation and a mixture of $1.5 \mathrm{ml}$ of $\mathrm{CHCl}_{3} / 1.5 \mathrm{ml}$ of toluene was added. The mixture was stirred inside a microwave reactor at $120^{\circ} \mathrm{C}$ for $90 \mathrm{~min}$ (the pressure reached up to $4.7 \mathrm{bar}$ ). After cooling, the solvent was removed under vacuum and the solid obtained was dissolved in $10 \mathrm{ml}$ of $\mathrm{CHCl}_{3}$ and placed into a separatory funnel and washed with $5 \mathrm{ml}$ of $\mathrm{H}_{2} \mathrm{O}$. The organic layer was removed under low pressure to give a purple solid ZnPOP (4.5 mg, 91\%). ${ }^{1} \mathrm{H}$ NMR $(500 \mathrm{MHz}$, Chloroform- $d) \delta$ : $9.56\left(\mathrm{~s}, 8 \mathrm{H}, \mathrm{H}_{2}\right), 8.85$ (d, $J=9.5 \mathrm{~Hz}, 8 \mathrm{H}$, $\left.\mathrm{H}_{10}\right), 8.71\left(\mathrm{~d}, J=0.7 \mathrm{~Hz}, 8 \mathrm{H}, \mathrm{H}_{6}\right), 8.45\left(\mathrm{~d}, J=8.0 \mathrm{~Hz}, 8 \mathrm{H}, \mathrm{H}_{18}\right), 8.40\left(\mathrm{t}, J=0.7 \mathrm{~Hz}, 4 \mathrm{H}, \mathrm{H}_{8}\right), 8.28\left(\mathrm{~d}, J=8.0 \mathrm{~Hz}, 8 \mathrm{H}, \mathrm{H}_{17}\right), 8.17-8.12(\mathrm{~m}$, $\left.16 \mathrm{H}, \mathrm{H}_{14}+\mathrm{H}_{11}\right), 8.11-8.04\left(\mathrm{~m}, 16 \mathrm{H}, \mathrm{H}_{13}+\mathrm{H}_{12}\right), 7.99\left(\mathrm{br}, 8 \mathrm{H}, \mathrm{H}_{16}\right), 7.90\left(\mathrm{br}, 8 \mathrm{H}, \mathrm{H}_{15}\right) .{ }^{13} \mathrm{C}\left\{{ }^{1} \mathrm{H}\right\} \mathrm{NMR}(126 \mathrm{MHz}, \mathrm{Chloroform}-d) \delta$ : $150.26\left(\mathrm{C}_{3}\right), 143.19\left(\mathrm{C}_{5}\right), 139.47\left(\mathrm{C}_{19}\right), 137.06\left(\mathrm{C}_{7}\right), 135.97\left(\mathrm{C}_{6}\right), 132.27\left(\mathrm{C}_{2}\right), 131.79\left(\mathrm{C}_{8}\right), 131.19\left(\mathrm{C}_{22}\right), 130.67\left(\mathrm{C}_{24}+\mathrm{C}_{20}\right), 128.67$ (C9), $128.05\left(\mathrm{C}_{18}\right), 127.67\left(\mathrm{C}_{11}\right), 127.36\left(\mathrm{C}_{13}\right), 127.25\left(\mathrm{C}_{12}\right), 125.72\left(\mathrm{C}_{15}\right), 124.97\left(\mathrm{C}_{14}\right), 124.93\left(\mathrm{C}_{10}\right), 124.76\left(\mathrm{C}_{16}\right), 124.62\left(\mathrm{C}_{17}\right)$, $120.77\left(\mathrm{C}_{4}\right)$. HR-MS (MALDI-TOF): $\mathrm{m} / \mathrm{z}$ for $\mathrm{C}_{172} \mathrm{H}_{92} \mathrm{~N}_{4} \mathrm{Zn}[\mathrm{M}+\mathrm{H}]^{+}$calcd: 2277.6652 . Found: 2277.668 (1.5 ppm error). UV/vis (toluene $): \lambda 280(\varepsilon=274000), 350(\varepsilon=208000), 415(\varepsilon=81000), 432(\varepsilon=442000), 551(\varepsilon=23000)$.

\section{$\mathrm{ZnPOBr}$}

2HPOBr $(60 \mathrm{mg}, 0.048 \mathrm{mmol})$ and $\mathrm{Zn}(\mathrm{AcO})_{2} \cdot 2 \mathrm{H}_{2} \mathrm{O}(84 \mathrm{mg}, 0.382 \mathrm{mmol})$ were mixed in a sealed vessel specifically designed for microwave irradiation, and $1.5 \mathrm{ml}$ of $\mathrm{CHCl}_{3}$ was added. The mixture was stirred inside the microwave reactor at $150{ }^{\circ} \mathrm{C}$ for $150 \mathrm{~min}$; the pressure reached up to 10 bar. Subsequently, the crude was dissolved in $20 \mathrm{ml}$ of $\mathrm{CHCl}_{3}$, placed in a separatory funnel, and washed with $10 \mathrm{ml}$ of $\mathrm{H}_{2} \mathrm{O}$. The organic layer was removed under low pressure to give the purple solid ZnPOBr (56 mg, $89 \%$ yield). ${ }^{1} \mathrm{H} \mathrm{NMR}(500 \mathrm{MHz}$, Chloroform- $d): \delta 8.99\left(\mathrm{~s}, 8 \mathrm{H}, \mathrm{H}_{2}\right), 8.31\left(\mathrm{~d}, J=1.8 \mathrm{~Hz}, 8 \mathrm{H}, \mathrm{H}_{6}\right), 8.15\left(\mathrm{t}, J=1.8 \mathrm{~Hz}, 4 \mathrm{H}, \mathrm{H}_{8}\right) .{ }^{13} \mathrm{C}\left\{{ }^{1} \mathrm{H}\right\} \mathrm{NMR}(126 \mathrm{MHz}, \mathrm{Chloroform}-d): \delta$ $149.91\left(\mathrm{C}_{3}\right), 135.83\left(\mathrm{C}_{6}\right), 133.67\left(\mathrm{C}_{8}\right), 132.33\left(\mathrm{C}_{2}\right), 121.45$ (C7-in), 118.45 (C4-in). HR-MS (MALDI-TOF): m/z for $\mathrm{C}_{44} \mathrm{H}_{20} \mathrm{Br}_{8} \mathrm{~N}_{4} \mathrm{Zn}_{\mathrm{n}}$ $[\mathrm{M}+\mathrm{H}]^{+}$calcd: 1309.4344 . Found: $1309.4372(2.1 \mathrm{ppm}$ error). UV/vis (toluene): $\lambda 401(\varepsilon=24400), 424(\varepsilon=160981), 515(\varepsilon=6428)$, $550(\varepsilon=6100), 587(\varepsilon=2529)$

\section{ZnPOB}

ZnPOBr (30 mg, $0.023 \mathrm{mmol})$, bis(pinacolato)diboron (70 mg, $0.276 \mathrm{mmol}),\left[\mathrm{PdCl}_{2}(\mathrm{dppf})\right](6.7 \mathrm{mg}, 0.0092 \mathrm{mmol})$, and AcOK (54.16 $\mathrm{mg}, 0.552 \mathrm{mmol}$ ) were mixed in a sealed vessel specifically designed for microwave irradiation. The microwave Vessel was placed inside a two-necked round-bottom flask in order to keep the system under an inert atmosphere. $0.7 \mathrm{ml}$ of dry dioxane and $35 \mu$ l of pyridine were then added to the microwave vessel. The mixture was stirred inside the microwave reactor at $160^{\circ} \mathrm{C}$ for 150 min; the pressure reached 3 bar. Subsequently, the solvent was removed under vacuum and the obtained solid was dissolved in $20 \mathrm{ml}$ of $\mathrm{CHCl}_{3}$, placed in a separatory funnel, and washed with $10 \mathrm{ml}$ of $\mathrm{H}_{2} \mathrm{O}$. The solvent was evaporated from the deep red organic layer, and the obtained solid was transferred to a centrifugation vial and underwent five wash-centrifuge cycles with hexane to finally afford the purple solid ZnPOB (27 mg, $71 \%$ yield). ${ }^{1} \mathrm{H}$ NMR $(500 \mathrm{MHz}$, Chloroform- $d): \delta 8.85\left(\mathrm{~s}, 8 \mathrm{H}, \mathrm{H}_{2}\right), 8.73\left(\mathrm{~d}, J=1.2 \mathrm{~Hz}, 8 \mathrm{H}, \mathrm{H}_{6}\right), 8.64\left(\mathrm{t}, J=1.2 \mathrm{~Hz}, 4 \mathrm{H}, \mathrm{H}_{8}\right), 1.36(\mathrm{~s}, 96 \mathrm{H}$, $\left.\mathrm{H}_{10}\right) .{ }^{13} \mathrm{C}\left\{{ }^{1} \mathrm{H}\right\} \operatorname{NMR}\left(126 \mathrm{MHz}\right.$, Chloroform-d) $\delta: 150.23\left(\mathrm{C}_{3}\right), 142.75\left(\mathrm{C}_{6}\right), 141.74\left(\mathrm{C}_{5}\right), 140.02\left(\mathrm{C}_{8}\right), 131.97\left(\mathrm{C}_{2}\right), 126.23\left(\mathrm{C}_{7}\right), 120.91$ 
$\left(\mathrm{C}_{4}\right), 83.81\left(\mathrm{C}_{9}\right), 24.94\left(\mathrm{C}_{10}\right)$. HR-MS (MALDI-TOF): $\mathrm{m} / \mathrm{z}$ for $\mathrm{C}_{92} \mathrm{H}_{116} \mathrm{~B}_{8} \mathrm{~N}_{4} \mathrm{O}_{16} \mathrm{Zn}[\mathrm{M}+\mathrm{H}]^{+}$calcd: 1683.8502 . Found: 1683.8619 (11.7 ppm error). UV/vis (toluene): $\lambda 405(\varepsilon=22741), 426(\varepsilon=186524), 550(\varepsilon=12414)$.

$2 \mathrm{HPOB}$

2HPOBr (20 mg, $0.016 \mathrm{mmol})$, bis(pinacolato)diboron (48.75 mg, $0.192 \mathrm{mmol}),\left[\mathrm{PdCl}_{2}(\mathrm{dppf})\right](4.68 \mathrm{mg}, 0.0064 \mathrm{mmol})$, and AcOK ( $36.9 \mathrm{mg}, 0.384 \mathrm{mmol}$ ) were mixed into a sealed vessel specifically designed for microwave irradiation. The microwave vessel was placed inside a two-necked round-bottom flask in order to keep the system under an inert atmosphere. $0.5 \mathrm{ml}$ of dry dioxane was then added to the microwave vessel. The mixture was stirred inside the microwave reactor at $160^{\circ} \mathrm{C}$ for $150 \mathrm{~min}$ and reached a pressure of $3 \mathrm{bar}$. Subsequently, the solvent was removed under vacuum and the obtained solid was dissolved in $15 \mathrm{ml}$ of $\mathrm{CHCl}_{3}$, placed in a separatory funnel, and washed with $8 \mathrm{ml}$ of $\mathrm{H}_{2} \mathrm{O}$. The solvent of the deep red organic layer was evaporated. The obtained solid was transferred to a centrifugation vial and underwent five washing-centrifugation cycles with hexane ( 5 times) to finally afford the purple solid $\mathbf{2 H P O B ~ ( 1 9 ~ m g , ~} 73 \%$ yield). ${ }^{1} \mathrm{H}$ NMR $\left(500 \mathrm{MHz}\right.$, Chloroform-d): $\delta 8.76\left(\mathrm{~s}, 8 \mathrm{H}, \mathrm{H}_{2}\right), 8.71\left(\mathrm{~d}, J=1.2 \mathrm{~Hz}, 8 \mathrm{H}, \mathrm{H}_{6}\right), 8.65\left(\mathrm{t}, J=1.2 \mathrm{~Hz}, 4 \mathrm{H}, \mathrm{H}_{8}\right), 1.36\left(\mathrm{~s}, 96 \mathrm{H}, \mathrm{H}_{10}\right),-2.79$ (br, $\left.2 \mathrm{H}, \mathrm{H}_{1}\right) .{ }^{13} \mathrm{C}\left\{{ }^{1} \mathrm{H}\right\} \operatorname{NMR}(126 \mathrm{MHz}$, Chloroform- $d): \delta 142.80\left(\mathrm{C}_{6}\right), 141.05\left(\mathrm{C}_{5}\right), 140.28\left(\mathrm{C}_{8}\right), 131.28\left(\mathrm{C}_{2}\right), 126.45\left(\mathrm{C}_{7}\right), 119.99\left(\mathrm{C}_{4}\right)$, 83.87 (C9), $24.93\left(\mathrm{C}_{10}\right)$. HR-MS (MALDI-TOF): $\mathrm{m} / \mathrm{z}$ for $\mathrm{C}_{92} \mathrm{H}_{118} \mathrm{~B}_{8} \mathrm{~N}_{4} \mathrm{O}_{16}[\mathrm{M}+\mathrm{H}]^{+}$calcd 1622.9443. Found: $1622.9426(-1.7 \mathrm{ppm}$ error). UV/vis (toluene): $\lambda 407(\varepsilon=59125), 422(\varepsilon=298419), 515(\varepsilon=12104), 548(\varepsilon=3957)$.

\section{ASSOCIATED CONTENT}

\section{Supporting Information}

The Supporting Information is available free of charge on the ACS Publications website. Methods and details, synthetic procedures and spectra of compounds are provided in PDF format.

\section{AUTHOR INFORMATION}

\section{Corresponding Author}

Celedonio M. Álvarez: GIR MIOMeT, IU CINQUIMA/Química Inorgánica, Facultad de Ciencias, Universidad de Valladolid, E47011, Valladolid, Spain.

E-mail: celedonio.alvarez@uva.es

Raul Garcia-Rodriguez GIR MIOMeT, IU CINQUIMA/Química Inorgánica, Facultad de Ciencias, Universidad de Valladolid, E47011, Valladolid, Spain.

E-mail: raul.garcia.rodriguez@uva.es.

\section{Notes}

The authors declare no competing financial interests. 


\section{ACKNOWLEDGMENT}

This research was supported by the Spanish Ministerio de Economía y Competitividad (MINECO) (project number CTQ 2013-41067-P). R.G.-R. acknowledges the Spanish MINECO - AEI and the European Union (ESF) for a Ramon y Cajal contract (RYC-2015-19035). H. B. acknowledges the Alfonso Martín Escudero Foundation for a postdoctoral fellowship.

\section{REFERENCES}

(1) Pérez, E. M.; Martín, N. Chem. Soc. Rev. 2015, 44, 6425-6433.

(2) Pérez, E. M.; Martín, N. Chem. Soc. Rev. 2008, 37, 1512-1519.

(3) (a) Scott, L. T.; Hashemi, M. M.; Bratcher, M. S. J. Am. Chem. Soc. 1992, 114, 1920-1921; (b) Wu, Y.-T.; Siegel, J. S. Chem. Rev. 2006, 106, $4843-$ 4867; (c) Li, X.; Kang, F.; Inagaki, M. Small 2016, 12, 3206-3223; (d) Saito, M.; Shinokubo, H.; Sakurai, H. Materials Chemistry Frontiers 2018, 2 , 635-661; (e) Nestoros, E.; Stuparu, M. C. Chem. Commun. 2018, 54, 6503-6519.

(4) (a) Ehli, C.; Rahman, G. M. A.; Jux, N.; Balbinot, D.; Guldi, D. M.; Paolucci, F.; Marcaccio, M.; Paolucci, D.; Melle-Franco, M.; Zerbetto, F.; Campidelli, S.; Prato, M. J. Am. Chem. Soc. 2006, 128, 11222-11231; (b) Zhao, Y.-L.; Hu, L.; Grüner, G.; Stoddart, J. F. J. Am. Chem. Soc. 2008, 130, 16996-17003; (c) Zhao, Y.-L.; Stoddart, J. F. Acc. Chem. Res. 2009, 42, 1161-1171; (d) Bilalis, P.; Katsigiannopoulos, D.; Avgeropoulos, A.; Sakellariou, G. RSC Advances 2014, 4, 2911-2934; (e) de Juan, A.; López-Moreno, A.; Calbo, J.; Ortí, E.; Pérez, E. M. Chem. Sci. 2015, 6, 7008-7014; (f) López-Moreno, A.; Pérez, E. M. Chem. Commun. 2015, 51, 5421-5424; (g) Calbo, J.; López-Moreno, A.; de Juan, A.; Comer, J.; Ortí, E.; Pérez , E. M. Chemistry - A European Journal 2017, 23, 12909-12916.

(5) (a) Zhang, M.; Parajuli, R. R.; Mastrogiovanni, D.; Dai, B.; Lo, P.; Cheung, W.; Brukh, R.; Chiu, P. L.; Zhou, T.; Liu, Z.; Garfunkel, E.; He, H. Small 2010, 6, 1100-1107; (b) Mann, J. A.; Rodríguez-López, J.; Abruña, H. D.; Dichtel, W. R. J. Am. Chem. Soc. 2011, 133, 17614-17617; (c) Ciesielski, A.; Samori, P. Chem. Soc. Rev. 2014, 43, 381-398; (d) KC, C. B.; Lim, G. N.; D'Souza, F. Angew. Chem. Int. Ed. 2015, 54, 5088-5092; (e) Ciesielski, A.; Samorì, P. Adv. Mater. 2016, 28, 6030-6051; (f) Bottari, G.; Herranz, M. Á.; Wibmer, L.; Volland, M.; Rodríguez-Pérez, L.; Guldi, D. M.; Hirsch, A.; Martín, N.; D'Souza, F.; Torres, T. Chem. Soc. Rev. 2017, 46, 4464-4500; (g) Garrido, M.; Calbo, J.; Rodríguez-Pérez, L.; Aragó, J.; Ortí, E.; Herranz, M. A.; Martín, N. Chem. Commun. 2017, 53, 12402-12405.

(6) Mulla, K.; Shaik, H.; Thompson, D. W.; Zhao, Y. Org. Lett. 2013, 15, 4532-4535.

(7) (a) Ronson, T. K.; League, A. B.; Gagliardi, L.; Cramer, C. J.; Nitschke, J. R. J. Am. Chem. Soc. 2014, 136, 15615-15624; (b) Ronson, T. K.; Meng, W.; Nitschke, J. R. J. Am. Chem. Soc. 2017, 139, 9698-9707.

(8) (a) Álvarez, C. M.; García-Escudero, L. A.; García-Rodríguez, R.; Martín-Álvarez, J. M.; Miguel, D.; Rayón, V. M. Dalton Transactions 2014, 43, 15693-15696; (b) Abeyratne Kuragama, P. L.; Fronczek, F. R.; Sygula, A. Org. Lett. 2015, 17, 5292-5295; (c) Yang, D.-C.; Li, M.; Chen, C.-F. Chem. Commun. 2017, 53, 9336-9339.

(9) (a) Sygula, A.; Fronczek, F. R.; Sygula, R.; Rabideau, P. W.; Olmstead, M. M. J. Am. Chem. Soc. 2007, 129, 3842-3843; (b) Stuparu, M. C. Angew. Chem. Int. Ed. 2013, 52, 7786-7790; (c) Yanney, M.; Fronczek, F. R.; Sygula, A. Angew. Chem. Int. Ed. 2015, 54, 11153-11156; (d) Kumarasinghe, K. 
G. U. R.; Fronczek, F. R.; Valle, H. U.; Sygula, A. Org. Lett. 2016, 18, 3054-3057; (e) Barbero, H.; Ferrero, S.; Álvarez-Miguel, L.; Gómez-Iglesias, P.; Miguel, D.; Álvarez, C. M. Chem. Commun. 2016, 52, 12964-12967.

(10) (a) Boyd, P. D. W.; Hodgson, M. C.; Rickard, C. E. F.; Oliver, A. G.; Chaker, L.; Brothers, P. J.; Bolskar, R. D.; Tham, F. S.; Reed, C. A. J. Am. Chem. Soc. 1999, 121, 10487-10495; (b) Olmstead, M. M.; Costa, D. A.; Maitra, K.; Noll, B. C.; Phillips, S. L.; Van Calcar, P. M.; Balch, A. L. J. Am. Chem. Soc. 1999, 121, 7090-7097; (c) Boyd, P. D. W.; Reed, C. A. Acc. Chem. Res. 2005, 38, 235-242; (d) Bhyrappa, P.; Karunanithi, K. Inorg. Chem. 2010, 49, 8389-8400; $\quad$ (e) Bhyrappa, P.; Sarangi, U. K.; Varghese, B. Eur. J. Inorg. Chem. 2014, 2014, 5646-5650.

(11) (a) Tashiro, K.; Aida, T. Chem. Soc. Rev. 2007, 36, 189-197; (b) Bromby, A. D.; Hogan, D. T.; Sutherland, T. C. New J. Chem. 2017, 41, 48024805 .

(12) Durot, S.; Taesch, J.; Heitz, V. Chem. Rev. 2014, 114, 8542-8578.

(13) (a) Canevet, D.; Pérez, E. M.; Martín, N. Angew. Chem. Int. Ed. 2011, 50, 9248-9259; (b) Jurow, M.; Farley, C.; Pabon, C.; Hageman, B.; Dolor, A.; Drain, C. M. Chem. Commun. 2012, 48, 4731-4733; (c) García-Simón, C.; Garcia-Borràs, M.; Gómez, L.; Parella, T.; Osuna, S.; Juanhuix, J.; Imaz, I.; Maspoch, D.; Costas, M.; Ribas, X. Nature Communications 2014, 5, 5557; (d) Fang, X.; Zhu, Y.-Z.; Zheng, J.-Y. J. Org. Chem. 2014, 79, 11841191; (e) García-Simón, C.; Costas, M.; Ribas, X. Chem. Soc. Rev. 2016, 45, 40-62.

(14) Álvarez, C. M.; Barbero, H.; Ferrero, S.; Miguel, D. J. Org. Chem. 2016, 81, 6081-6086.

(15) (a) Kimura, M.; Shiba, T.; Muto, T.; Hanabusa, K.; Shirai, H. Macromolecules 1999, 32, 8237-8239; (b) Kimura, M.; Shiba, T.; Yamazaki, M.; Hanabusa, K.; Shirai, H.; Kobayashi, N. J. Am. Chem. Soc. 2001, 123, 5636-5642.

(16) Kappe, C. O. Angew. Chem. Int. Ed. 2004, 43, 6250-6284.

(17) Yao, D.; Zhang, X.; Mongin, O.; Paul, F.; Paul-Roth, C. O. Chemistry A European Journal 2016, 22, 5583-5597.

(18) (a) Lemon, C. M.; Brothers, P. J.; Boitrel, B. Dalton Transactions 2011, 40, 6591-6609; (b) Kadish, K. M.; Smith, K. M.; Guilard, R. Handbook of Porphyrin Science (Volumes 21- 25); World Scientific Publishing Company, 2012; Vol. Volumes 21 - 25; (c) Valicsek, Z.; Horváth, O. Microchem. J. 2013, 107, 47-62; (d) Senge, M. O.; MacGowan, S. A.; O'Brien, J. M. Chem. Commun. 2015, 51, 17031-17063.

(19) (a) Jian-Yu, Z.; Kentaro, T.; Yusuke, H.; Kazushi, K.; Kazuhiko, S.; Takuzo, A.; Shigeru, S.; Kentaro, Y. Angew. Chem. Int. Ed. 2001, 40, 18571861; (b) Sun, D.; Tham, F. S.; Reed, C. A.; Chaker, L.; Boyd, P. D. W. J. Am. Chem. Soc. 2002, 124, 6604-6612; (c) Wang, Y.-B.; Lin, Z. J. Am. Chem. Soc. 2003, 125, 6072-6073; (d) Ayako, O.; Kentaro, T.; Kentaro, Y.; Takahiro, T.; Takeshi, A.; Takuzo, A. Angew. Chem. Int. Ed. 2006, 45, 35423546; (e) Yanagisawa, M.; Tashiro, K.; Yamasaki, M.; Aida, T. J. Am. Chem. Soc. 2007, 129, 11912-11913.

(20) (a) A. Shelnutt, J.; Song, X.-Z.; Ma, J.-G.; Jia, S.-L.; Jentzen, W.; J. Medforth, C.; J. Medforth, C. Chem. Soc. Rev. 1998, 27, 31-42; (b) Haddad, R. E.; Gazeau, S.; Pécaut, J.; Marchon, J.-C.; Medforth, C. J.; Shelnutt, J. A. J. Am. Chem. Soc. 2003, 125, 1253-1268; (c) Senge, M. O. Chem. Commun. 2006, 0, 243-256.

(21) (a) Hunter, C. A.; Sanders, J. K. M. J. Am. Chem. Soc. 1990, 112, 5525-5534; (b) Saegusa, Y.; Ishizuka, T.; Kojima, T.; Mori, S.; Kawano, M.; Kojima, T. Chemistry A European Journal 2015, 21, 5302-5306. 
(22) Thordarson, P. In Supramolecular Chemistry: From Molecules to Nanomaterials; Gale, P. A., Steed, J. W., Eds.; John Wiley \& Sons: Chichester, UK, 2012; Vol. 2, p 239-274.

(23) (a) Thordarson, P. Chem. Soc. Rev. 2011, 40, 1305-1323; (b) Brynn Hibbert, D.; Thordarson, P. Chem. Commun. 2016, 52, 12792-12805.

(24) (a) Yanney, M.; Sygula, A. Tetrahedron Lett. 2013, 54, 2604-2607; (b) Álvarez, C. M.; Aullón, G.; Barbero, H.; García-Escudero, L. A.; Martínez-Pérez, C.; Martín-Álvarez, J. M.; Miguel, D. Org. Lett. 2015, 17, 2578-2581.

(25) (a) Taylor, R.; Hare, J. P.; Abdul-Sada, A. a. K.; Kroto, H. W. J. Chem. Soc., Chem. Commun. 1990, 0, 1423-1425; (b) Ajie, H.; Alvarez, M. M.; Anz, S. J.; Beck, R. D.; Diederich, F.; Fostiropoulos, K.; Huffman, D. R.; Kraetschmer, W.; Rubin, Y.; et al. The Journal of Physical Chemistry 1990, 94 , 8630-8633; (c) Diederich, F.; Whetten, R. L.Acc. Chem. Res. 1992, 25, 119-126.

(26) Hare, J. P.; Kroto, H. W.; Taylor, R. Chem. Phys. Lett. 2013, 589, 57-60.

(27) (a) Armarego, W. L. F.; Chai, C. L. L. Purification of Laboratory Chemicals, 6th; Butterworth-Heinemann: London, 2009. (b) Williams, D. B. G.; Lawton, M. Drying of Organic Solvents: Quantitative Evaluation of the Efficiency of Several Desiccants. J. Org. Chem. 2010, 75, 8351-8354.

(28) Matthias, B.; Wilfried, W.; Martin, J.; Wolfgang, R.; Claudia, M.; Irene, B.; Hans, H.; A. Dieter, S. Eur. J. Org. Chem. 2001, $2001,3819-3829$. 
Table of Contents artwork

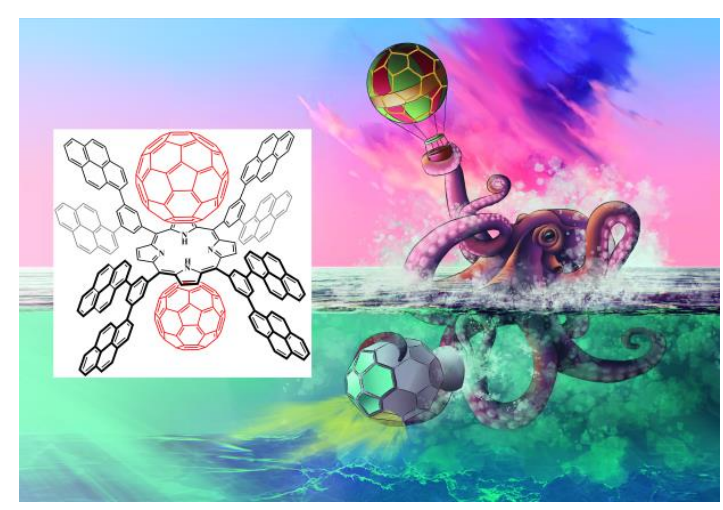





\subsection{ARTÍCULO II:}

Octapodal Corannulene Porphyrin-Based Assemblies: Allosteric Behavior in Fullerene Hosting

J. Org. Chem. 2020, 85, 4918 - 4926 


\title{
Octapodal corannulene porphyrin-based assemblies: allosteric behav- ior in fullerene hosting
}

\author{
Sergio Ferrero, Héctor Barbero, Daniel Miguel, Raúl García-Rodríguez* and Celedonio M. Álvarez* \\ GIR MIOMeT, IU CINQUIMA/Química Inorgánica, Facultad de Ciencias, Universidad de Valladolid, E-47011 Valladolid, Spain
}

\begin{abstract}
An octapodal corannulene-based supramolecular system has been prepared by introducing eight corannulene moieties in a porphyrin scaffold. Despite the potential of this double picket fence porphyrin for double-tweezer behavior, NMR titrations show exclusive formation of $1: 1$ adducts. The system exhibits very strong affinity for $\mathrm{C}_{60}$ and $\mathrm{C}_{70}\left(\mathrm{~K}_{1}=(2.71 \pm 0.08) \times 10^{4}\right.$ and $(2.13 \pm 0.1) \times 10^{5} \mathrm{M}^{-1}$, respectively $)$, presenting selectivity for the latter. DFT calculations indicate that in addition to the four corannulene units, the relatively flexible porphyrin tether actively participates in the recognition process, resulting in a strong synergistic effect. This leads to a very strong interaction with $\mathrm{C}_{60}$, which in turn also induces a large structural change on the other face (second potential binding site), leading to a negative allosteric effect. We also introduced $\mathrm{Zn}^{2+}$ in the porphyrin core in an attempt to modulate its flexibility. The resulting metalloporphyrin also displayed single-tweezer behavior, albeit with slightly smaller binding constants for $\mathrm{C}_{60}$ and $\mathrm{C}_{70}$, suggesting that the effect of the coordination of fullerene to one face of our supramolecular platform was still transmitted to the other face, leading to the deactivation of the second potential binding site.
\end{abstract}

\section{INTRODUCTION}

Since its establishment, supramolecular chemistry ${ }^{1}$ has been used to design and develop new entities with a wide range of applications in various areas of science. Inspired by nature, an interesting topic in supramolecular chemistry is the development of artificial receptors that echo the allosteric control of more complex biological systems. ${ }^{2}$ The term allosterism describes structural changes that occur upon the coordination of a substrate to a binding site (allosteric site) of the host. ${ }^{3}$ The information associated with the first event is transmitted to a different binding site by a change in the conformation, which can lead to activation (positive cooperation) or deactivation (negative cooperation or inhibition) of the binding site. This represents a very useful tool to control the coordination of different sites, and not surprisingly, has attracted a great deal of attention in the supramolecular chemistry community. ${ }^{4}$

Additionally, carbon nanostructures, particularly fullerenes, have found a variety of applications in supramolecular chemistry due to their unique structures and electronic properties. ${ }^{5}$ Great efforts have been made to construct supramolecular assemblies that host fullerenes through weak intermolecular forces ${ }^{6}$ to develop high-performance devices, in particular, photoelectrochemical devices and solar cells.

Size and shape complementarity are crucial to achieving efficient supramolecular host-guest binding. In this regard, bowl-shaped aromatic hydrocarbons or buckybowls ${ }^{7}$ are attracting increasing attention and finding new applications in materials science. ${ }^{8}$ Corannulene, ${ }^{9}$ the 
most-interesting buckybowl, has unique properties not seen in planar $\pi$-conjugated compounds arising from its nonplanarity, which enables it to form supramolecular assemblies with fullerenes through non-covalent interactions. Its net dipolar moment, ${ }^{10}$ together with its exceptional concave-convex complementary for $\pi-\pi$ stacking, ${ }^{11}$ allows it to strongly interact with fullerenes via the well-known "ball in socket" interactions. Not surprisingly, corannulene has proven to be a very useful motif for the design of various materials and a very attractive building block in the construction of organic electronic devices, including solar cells and non-linear optical materials. ${ }^{8 \mathrm{~b}, 12}$ In particular, it has played a central role in the design of efficient receptors for fullerenes. The use of corannulene as a building block, however, has been limited by its tedious synthesis, which requires a large number of steps. Considerable efforts have been devoted to improve current synthetic methods as well as to its derivatization with suitable functional groups to enable its use in producing more complex architectures. Although a single pristine corannulene unit cannot bind fullerene strongly enough for the corannulene-fullerene inclusion complex to be observed in solution, ${ }^{13}$ the careful design of molecules incorporating two corannulene units has proven to be a very useful strategy to improve corannulene-fullerene interactions.

Researchers have long focused on improving the strength and selectivity of fullerene receptors. The historical evolution of multicorannulene 'pincer' systems is shown in Figure 1, which shows selected examples. ${ }^{14}$ The first and most obvious such pincer systems were based on two corannulene units, and have had a great impact on supramolecular-fullerene interactions. In particular, Sygula's buckycatcher I (Figure 1, A) ${ }^{14 a, 14 c}$ represented a breakthrough as the first example of the formation of a stable inclusion complex with fullerene, and presented association constants of $2.78 \times 10^{3} \mathrm{M}^{-1}\left(\mathrm{C}_{60}\right)$ and $3.03 \times 10^{3} \mathrm{M}^{-1}\left(\mathrm{C}_{70}\right)$ in toluene at $298 \mathrm{~K}$. Sygula subsequently engineered the tether between the two corannulene moieties to improve the preorganization of the host and the fullerene guest, expanding the buckycatcher family (buckycatchers II and III, not depicted in the figure) ${ }^{14 e, 14 f, 14 \mathrm{~h}}$ and improving the $\mathrm{C}_{60}$ binding constant by an order of magnitude. We developed a platinum-based system with two corannulene moieties, which was the first system capable of discriminating $\mathrm{C}_{60}$ over $\mathrm{C}_{70}$ (B); ${ }^{14 \mathrm{~d}}$ subsequently, Chen et al. achieved outstanding discrimination $\left(\mathrm{K}_{\mathrm{C} 70} / \mathrm{K}_{\mathrm{C} 60}=230: 1\right)$ using the two corannulene moiety system $\mathbf{C}^{141}$. In contrast, systems bearing tris-corannulene clips, such as $\mathbf{D}^{14 \mathrm{~b}}$ and $\mathbf{E},{ }^{14 \mathrm{~g}, 14 \mathrm{j}}$ have not had the same success as systems bearing two corannulene units due to their lower ability to associate fullerenes. The lower binding constants observed for these tripodal systems seems to stem from their much greater flexibility, which favors self-interaction and consequently notably reduces their interaction with fullerenes. These examples highlight the importance of the preorganization and morphology of the supramolecular platform in fullerene association, which can be as important as the number of corannulene units attached. Therefore, to increase host-guest surface contact, careful design of fullerene receptors is required in addition to increasing the number of corannulene units. 


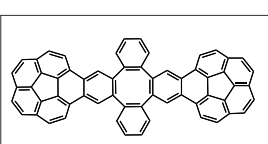

A, Sygula 2007

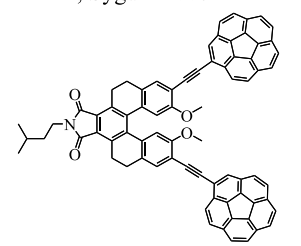

C, Chen 2017

2 units

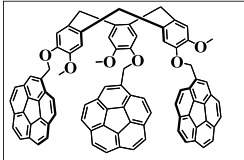

D, Sygula 2013

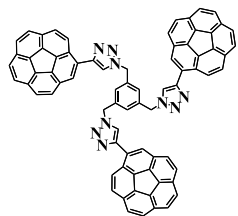

E, Álvarez 2015

3 units
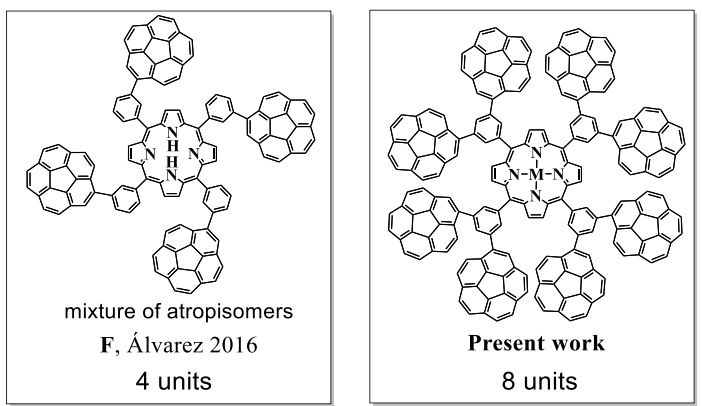

Figure 1. Development of systems bearing different numbers of corannulene units.

We have recently explored the use of porphyrin-based systems as molecular scaffolds for fullerene hosting. Although porphyrins and fullerenes can interact, the presence of only a single porphyrin core usually results in interactions with fullerenes that are too weak to be observed in solution. ${ }^{15}$ These systems are relatively rigid and allow for the active participation of the tether in the supramolecular interaction, and are therefore ideally suited to host fullerenes. We envisaged that a meso-substituted tetraaryl porphyrin core would be an ideal scaffold for supramolecular interactions, and prepared the meta-substituted porphyrin $\mathbf{F}^{14 \mathrm{k}}$ with four corannulene units. However, while this tetrakis-corannulene porphyrin clip was able to associate with $\mathrm{C}_{60}$, $\mathbf{F}$ was present as a difficult-to-analyze mixture of four atropisomers resulting from the orientation of the four corannulene units above and below the porphyrin plane. These atropisomers could not be separated, resulting in a complex system and marked decrease in $\mathrm{C}_{60}$ binding ability. In a recent work, we subsequently circumvented the formation of atropoisomers by introducing eight pyrene units at the meta positions of the tetraaryl porphyrin system. ${ }^{16}$ This resulted in a double tweezer with a remarkably high association for fullerenes, despite the poor shape complementarity between pyrene and fullerenes, due to the synergistic effect between the porphyrin tether and the pyrene units. As the combination of well-organized corannulene fragments and a porphyrin tether resulted in synergistic effects and good fullerene hosting ability, in the present work, we explore the possibility of introducing eight corannulene units on a single porphyrin core (Figure 1, Present work) and their impact on the fullerene affinity and selectivity of the new octapodal corannulene supramolecular platform (which contains the most corannulene moieties on a singlemolecule receptor to date). The effect of the association on the geometry of the double tweezer (allosteric effect) and its impact on a second association event, which determines whether the receptor will exhibit double or single tweezer behavior, is studied. This is an im- 
portant issue since the development of artificial and well-defined systems in which allosteric effects can control the association behavior, echoing more complex biological systems, is a great challenge.

\section{RESULTS AND DISCUSSION}

To obtain the octapodal corannulene target compound, we employed a 'corannulene LEGO brick' approach using a divergent synthesis in which a suitable porphyrin-based scaffold is first prepared to further allow the introduction of eight corannulene units. The metasubstituted octabromo-porphyrin $\mathbf{2 H - P O c t a B r}$ was selected as an ideal starting porphyrin core from which further elaboration of the porphyrin framework could be accomplished. 2 H-POctaBr presents eight bromine atoms in the meta positions of the tetraaryl mesosubstituted porphyrin (Scheme 1a), and therefore could be used in the palladium-catalyzed Suzuki reaction with the appropriate boronic ester of corannulene. Synthesis of $\mathbf{2 H - P O c t a B r}$ was accomplished using our previously reported microwave-assisted method. ${ }^{16}$ We next prepared 1-pinacol corannuleneboronate (BPin-Cor), which is the key 'LEGO' fragment for the introduction of corannulene to the system via Suzuki reactions at the eight bromines of $\mathbf{2 H - P O c t a B r}$. The borylation of corannulene to furnish Bpin-Cor was accomplished from 1-bromocorannulene (Br-Cor) via a microwave-assisted Miyaura reaction in just 80 min (Scheme 1b), which represented a significant improvement over the routine bench-top preparation (typically $24 \mathrm{~h}$ reflux in dioxane). Subsequently, the Suzuki reaction of 2HPOctaBr and Bpin-Cor was accomplished via a MW-assisted octuple Suzuki reaction $\left(150^{\circ} \mathrm{C}, 135 \mathrm{~min}\right.$, toluene) (Scheme 1c). In this manner, compound 2H-POctaCor was isolated in $15 \%$ total yield after optimization, which we considered quite satisfactory given the

eight reactions involved. The use of a MW reactor has been reported to be crucial in multiple $\mathrm{C}-\mathrm{C}$ coupling reactions in which the rapid buildup of byproducts might hinder product formation. ${ }^{17}$ Indeed, changing the cross-coupling partners in the Suzuki reaction (i.e. Brcorannulene and octaborylated porphyrin) led to a disappointing $3 \%$ yield. In this case, a range of impurities and incomplete reaction products (containing less than eight corannulene moieties) prevented us from obtaining 2 H-POctaCor in pure form. 
Scheme 1. Synthesis of 2H-POctaCor ${ }^{a}$

a)

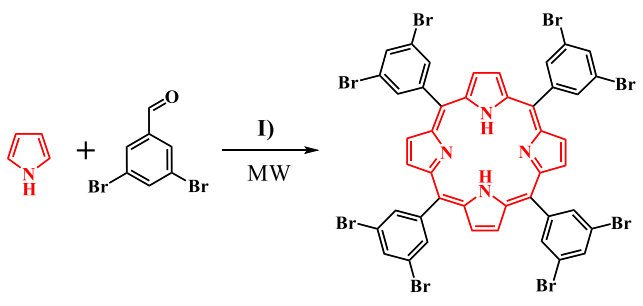

b)

2H-POctaBr

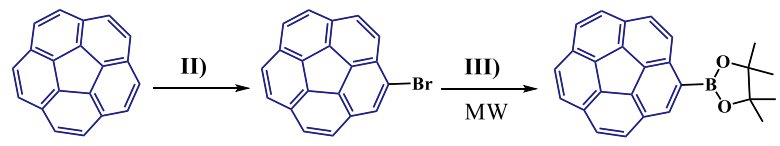

Cor

Br-Cor

Bpin-Cor

c)

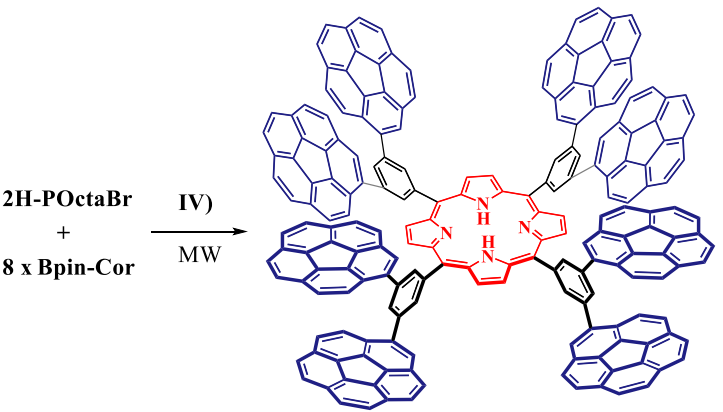

2H-POctaCor

${ }^{a}$ Reagents and conditions: (I) propionic acid, nitrobenzene, $\mathrm{MW}$; (II) N-Bromosuccinimide, $\mathrm{DCM}$; (III) $\mathrm{B}_{2}$ pin 2 , [PdCl $\left.(\mathrm{dppf})\right], \mathrm{AcOK}_{2}$ dioxane, $\mathrm{MW}$; (IV) $\left[\mathrm{PdCl}_{2}(\mathrm{dppf})\right]$, ${ }^{\mathrm{t}} \mathrm{BuONa}$, toluene, $\mathrm{MW}$

Despite its low solubility, the octapodal corannulene porphyrin $\mathbf{2 H}$-POctaCor was characterized by spectroscopic methods (see the Experimental Section). Further confirmation of the formation of $\mathbf{2 H - P O c t a C o r}$ was provided by high-resolution mass spectrometry, which showed the expected $[\mathrm{M}+\mathrm{H}]^{+}$peak at $\mathrm{m} / \mathrm{z} 2601.7586$ (calcd 2601.7619, see the Supporting Information, Figure. S20). The UV-Vis absorption spectra show the typical intense Soret band at $426 \mathrm{~nm}$ and the ${ }^{1} \mathrm{H}$ NMR spectrum of $\mathbf{2 H}$-POctaCor in chloroform- $d$ was remarkably simple due to the highly symmetrical nature of the compound. A characteristic upfield signal for the porphyrin NH protons is observed at $\delta=-2.50 \mathrm{ppm}$. Only one beta pyrrole proton resonance was observed, which along with the equivalence of the eight corannulene moieties, indicated an effective $\mathrm{D}_{4 \mathrm{~h}}$ symmetry in solution. Notably, the ${ }^{1} \mathrm{H}$ NMR signals are markedly broad and do not change significantly upon dilution (see the Supporting Information, Figure. S2). Although a certain degree of intermolecular $\pi$ - $\pi$ stacking is likely, this suggests that intramolecular $\pi-\pi$ interactions could also be occurring. ${ }^{14 \mathrm{~b}, 18}$

To further explore this possibility, compound $\mathbf{2 H - P O c t a C o r}$ was first optimized using a conformational screening by molecular mechanics and subsequently, full DFT optimization of the best candidates at the B97D3/6-31G(d,p) level of theory ${ }^{19}$ (see the Supporting Information for details). Interestingly, the lowest energy minimum corresponds to a conformer whose porphyrin core has been substantially 
distorted, giving rise to a saddle-like geometry (Figure 2). This situation stems from the highly attractive concave-convex stacking interactions between pairs of corannulene groups. The potential formation of conformers resulting from these interactions likely contributes to the broadening of the signals observed in the ${ }^{1} \mathrm{H}-\mathrm{NMR}$ spectrum. Figure $2 \mathrm{a}$, shows that $\pi-\pi$ interactions are established between pairs of corannulenes, leading to a 4+4 arrangement of the corannulene units below and above the distorted porphyrin plane in a "double picket fence" arrangement. This type of arrangement could potentially lead to the binding of two fullerenes. However, such corannulene $\pi-\pi$ interactions could conceivably produce a potential energy penalty for the adoption of an optimal structure for fullerene hosting by the molecule, as all the corannulene interactions must be overcome beforehand.

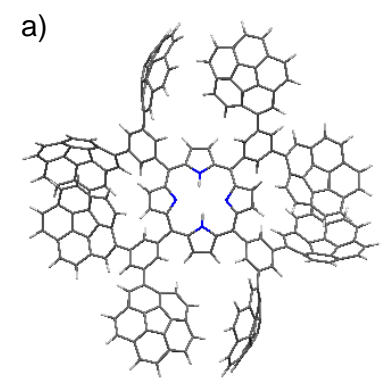

b)

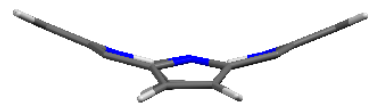

Figure 2. (a) Top view of the lowest energy minimum optimized structure of compound 2H-POctaCor and (b) side view of the porphyrin core.

To investigate these potential issues and study the supramolecular behavior and fullerene hosting ability of $2 \mathbf{H}$-POctaCor, we carried out titration experiments with $\mathrm{C}_{60}$ and $\mathrm{C}_{70}$ in toluene- $\mathrm{d}_{8}$. One particular facet we were interested in exploring was whether our octapodal corannulene-based system could allow the binding of two fullerenes (see idealized Scheme 1c). Due to the low solubility of $2 \mathbf{H}-\mathbf{P O c t a C o r}$ a host concentration of $[\mathrm{H}]_{0}=10^{-5} \mathrm{M}$ was selected. Upon the addition of 0.17 eq of $\mathrm{C}_{60}$, a shift in the ${ }^{1} \mathrm{H}$ NMR signals was observed, indicating supramolecular association between $\mathbf{2 H}$-POctaCor and $\mathrm{C}_{60}$. This shift was initially accompanied by further broadening of the signals (Figure 3 above). This was attributed to an intermediate-exchange regime ${ }^{20}$ between the free and bound guest on the NMR time scale, which is supported by the fact that towards the end of the titration (in the presence of an excess of $\mathrm{C}_{60}$ ) the signals again became sharper, since the equilibrium was then completely shifted towards the formation of the $\mathrm{C}_{60} @ \mathbf{2 H}$-POctaCor complex. The beta pyrrole proton resonance, which remained relatively sharp and well-defined throughout the process, was found to be a convenient signal to follow the titration (Figure 3 above).

Similar behavior was observed in the titration of $\mathbf{2 H}-\mathbf{P O c t a C o r}$ and $\mathrm{C}_{70}$ (Figure $\mathbf{3}$ below). Upon the addition of $\mathrm{C}_{70}$, a shift in the signals indicative of host-guest formation was observed, although in this case, much greater concomitant broadening of the signals was produced. Despite this, the beta pyrrole proton resonance could still be used as a good probe to follow the process (Figure 3 below). For both titration experiments, the nonlinear binding isotherms obtained could be fitted to a 1:1 model (Figure 3, insets). The calculated binding constant for $\mathrm{C}_{70}\left(K_{1}=2.13 \pm 0.1 \times 10^{5} \mathrm{M}^{-1}\right)$ was one order of magnitude larger than that of $\mathrm{C}_{60}\left(K_{1}=2.71 \pm 0.08 \times 10^{4} \mathrm{M}^{-1}\right)$.This shows than our supramolecular platform exhibits a certain degree of selectivity for $\mathrm{C}_{70}$ and that the interactions among the corannulene moieties in the absence of fullerene (Figure 2) do not apparently diminish its 
fullerene hosting ability. This is in contrast to the more flexible tris-corannulene systems $\mathbf{D}$ or $\mathbf{E}$ in Figure 1, for which these interactions resulted in very low affinities for $\mathrm{C}_{60}$. Importantly, despite the obvious potential of our octapodal corannulene system to act as a double tweezer (Scheme 1c), no evidence for a 1:2 model was observed. As noted in the introduction, cooperative effects are a key aspect for understanding recognition processes in supramolecular chemistry and play a central role in complex biological systems (i.e. in the recognition processes of proteins such as allosteric control). Both positive and negative cooperation (inhibition) effects play very important roles in biological systems. A well-known example of the latter is the coordination of cytidine triphosphate to the enzyme aspartate-transcarbamoylase, which induces a conformational change that produces an inactive conformation. ${ }^{21}$ Another iconic example is the coordination of $\mathrm{O}_{2}$ to hemoglobin. The coordination of the first molecule of $\mathrm{O}_{2}$ induces conformational changes that result in a larger binding affinity for the coordination of $\mathrm{O}_{2}$ to the remaining binding sites. ${ }^{22}$
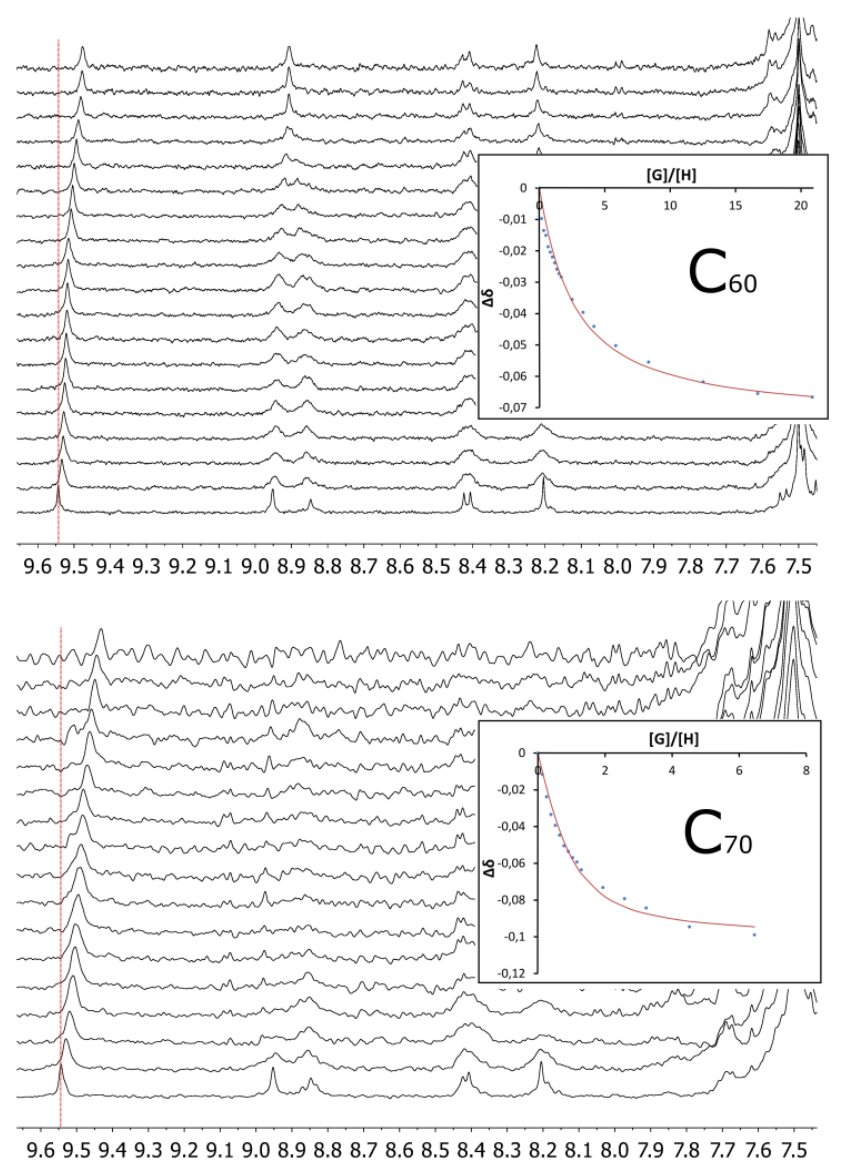

Figure 3. ${ }^{1} \mathrm{H}$ NMR spectra $\left(500 \mathrm{MHz}\right.$, toluene- $\left.\mathrm{d}_{8}\right)$ showing the chemical shift of the $\mathrm{H}_{2}$ proton of $\mathbf{2 H}$-PoctaCor upon the addition of aliquots of $\mathrm{C}_{60}$ (above) or $\mathrm{C}_{70}$ (below). Insets: Plots of the changes in the chemical shift against $[\mathrm{G}] /[\mathrm{H}]$, where $\mathrm{G}$ is $\mathrm{C}_{60}$ or $\mathrm{C}_{70}$ and $\mathrm{H}_{\text {is }}$ 2H-PoctaCor. The red line corresponds to the nonlinear fitting of $\Delta \delta$ for $\mathrm{H}_{2}$ to a 1:1 binding isotherm. Note: The dotted red line over the spectrum is guide for the eye.

In order to obtain further insight into this interesting phenomenon, DFT calculations were performed to determine the mechanism by which 1:1 rather than 1:2 binding stoichiometry was observed, and whether all the corannulene units are involved in the recognition pro- 
cess. Indeed, our octapodal corannulene system is ideally suited to study the possibility of cooperative effects in the fullerene recognition process. The structure of the inclusion complex C60@2H-POctaCor obtained by DFT is shown in Figure 4, (see the Supporting Information for details). As can be seen, the porphyrin core has a degree of flexibility; this flexibility not only allows the approach of the four corannulene moieties to $\mathrm{C}_{60}$ for an optimal interaction, but also allows the core itself to actively participate in the recognition process (see later). The ortho hydrogens of the phenylene substituents tend to point away from the fullerene molecule, maximizing the interaction of the corannulene units with the outer surface of $\mathrm{C}_{60}$. Thus, the structural arrangement is the result of the maximization of supramolecular binding, allowing better complementarity between both surfaces. This can be observed by the fact that all corannulene units on the same face of the porphyrin are arranged for an optimal interaction with the outer surface of the fullerene. Additionally, the contribution of the porphyrin core itself to this interaction is not negligible, as the distance between the core and the fullerene falls within the range of attractive dispersion contacts. These strong interactions lead to the compression of the corannulene arms of the active face of the porphyrin to effectively wrap the $\mathrm{C}_{60}$ surface.

The supramolecular bonding interactions between the host and $\mathrm{C}_{60}$ are most clearly illustrated on the basis of critical points. ${ }^{23}$ Figures $4 \mathbf{c}$ and $4 \mathbf{d}$ show five bowl-shaped attractive interactions between the fullerene and the molecular clip $2 \mathbf{H}$-PoctaCor. In addition to the four interactions from the four corannulene arms, an additional interaction with the porphyrin core is clearly observed. This demonstrates the excellent complementarity between $\mathrm{C}_{60}$ and our molecular platform, as revealed by the fact that the isosurface almost totally covers the fullerene surface. Additional interactions between the remaining corannulenes on the other face of the molecule are also observed, indicating that the intramolecular interactions among the four remaining corannulenes also contribute to the stabilization of this structural arrangement.

Our data indicate that in the presence of fullerene, an equilibrium is reached between free $\mathrm{C}_{60}$ and 1:1 $\mathrm{C}_{60} @ \mathbf{2 H}-\mathbf{P O c t a C o r}$ adducts $\left(K_{1}\right)$. This association deforms the geometry of $\mathbf{2 H - P O c t a C o r}$ in such a way that the second face of the porphyrin cannot effectively bind a second $\mathrm{C}_{60}$ fullerene. Figure 4a shows that concomitant to the organization of the active face of the porphyrin around $\mathrm{C}_{60}$ (compression), the arms of the other face expand significantly, leading to poor preorganization of the host for interaction with a second fullerene, as the four corannulene units of the inactive face are now too far away from each other to effectively interact with a second $\mathrm{C}_{60}$. 

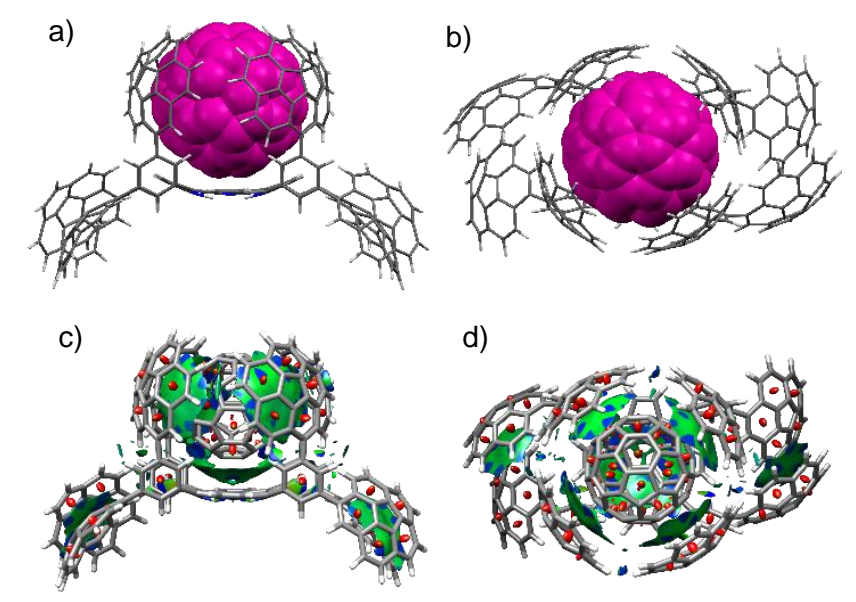

Figure 4. DFT-optimized structure of $\mathrm{C}_{60} @ 2$ H-PoctaCor. Side (a) and top (b) views of the optimized structure. Side (c) and top (d) views of NCI plots for the optimized structure of $\mathrm{C}_{60} @ 2 \mathbf{2 H}$-PoctaCor.

We also explored the effect of a second binding event. The structure of the inclusion complex $\left(\mathrm{C}_{60}\right)_{2} @ 2 \mathbf{H}-\mathbf{P O c t a C o r}$ was optimized by DFT calculations (see the Supporting Information). The data reveals that as expected, the hosting of one $\mathrm{C}_{60}$ in (C60)@2H-POctaCor hampers the efficient association of a second $\mathrm{C}_{60}$. Indeed, this results in a sub-optimal conformation of the receptor, in which the interaction between the first $\mathrm{C}_{60}$ and the porphyrin core is greatly reduced in order to partially cover the second $\mathrm{C}_{60}$ (see the Supporting Information for details). The acceptance of the first fullerene, therefore, leads to negative allosteric induction, preventing the binding of a second $\mathrm{C}_{60}$. This effect can be ascribed to the change in the conformation of the second binding face of the receptor upon the coordination of the first fullerene.

Metal coordination is known to lead to changes in the geometry of the porphyrin ring. In order to study whether the inhibitory conformational change of the current system upon association with a first $\mathrm{C}_{60}$ moiety could be prevented, we introduced $\mathrm{Zn}^{2+}$ in the porphyrin. The resulting metalloporphyrin, Zn-POctaCor, was expected to exhibit a reduced degree of flexibility compared to that of the porphyrin $\mathbf{2 H}$ -

POctaCor as a result of the metal coordination.

The introduction of a $\mathrm{Zn}^{2+}$ in the porphyrin was easily accomplished in a quantitative manner using a microwave-assisted method (see Scheme 2 and the Experimental Section). The ${ }^{1} \mathrm{H}$ NMR spectrum shows the disappearance of the inner $2 \mathrm{H}$ porphyrin protons, and the UV-Vis spectrum exhibited a small red-shift in the Soret band $(431 \mathrm{~nm})$ compared to that of 2 H-POctaCor (426 nm), suggesting that metal coordination slightly distorts the planarity of the porphyrin core..$^{24}$ 
Scheme 2. Synthesis of Zn-POctaCor ${ }^{a}$

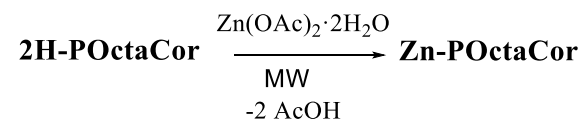

${ }^{a}$ Reagents and conditions: $\mathrm{Zn}(\mathrm{OAc})_{2} \cdot 2 \mathrm{H}_{2} \mathrm{O}, \mathrm{CHCl}_{3} /$ toluene, $\mathrm{MW}$

Titration of Zn-POctaCor with $\mathrm{C}_{60}$ and $\mathrm{C}_{70}$ revealed a shift in the signals accompanied with a very large broadening. Although the peak broadening made the analysis challenging, a 1:1 model could be observed in both cases (see the Supporting Information). The calculated binding constants, $\mathrm{K}_{1}=2.19 \pm 0.05 \times 10^{4} \mathrm{M}^{-1}$ and $\mathrm{K}_{1}=1.16 \pm 0.4 \times 10^{5} \mathrm{M}^{-1}$ for $\mathrm{C}_{60}$ and $\mathrm{C}_{70}$, respectively, are slightly smaller than those obtained for 2H-POctaCor, and also indicate selectivity for $\mathrm{C}_{70}$ over $\mathrm{C}_{60}$ (see Table $\mathbf{1}$ ).

Table 1. Summary of binding constants $\mathrm{K}_{1}\left(\mathrm{M}^{-1}\right)$ for $\mathbf{2 H}$-POctaCor and $\mathbf{Z n}$-POctaCor for different fullerenes in toluene-d 8

\begin{tabular}{ccc}
\hline & $\mathrm{C}_{60}$ & $\left.\mathrm{C}_{70}\right]$ \\
\hline 2H-POctaCor & $2.71 \pm 0.08 \times 10^{4}$ & $2.13 \pm 0.1 \times 10^{5}$ \\
Zn-POctaCor & $2.19 \pm 0.05 \times 10^{4}$ & $1.16 \pm 0.4 \times 10^{5}$ \\
\hline
\end{tabular}

These results suggest that although coordination to $\mathrm{Zn}^{2+}$ reduced the flexibility of the system somewhat, which in turn led to smaller binding constants, it did not completely prevent the expansion of the other porphyrin face upon the coordination of the fullerene. This structural arrangement would disfavor the coordination of a second fullerene, leading to the formation of the experimentally observed 1:1 fullerene adduct.

\section{CONCLUSIONS}

An octapodal corannulene porphyrin-based molecular clip and its Zn-complexed metalloporphyrin analogue have been prepared. This new molecular platform contains the largest number of corannulene units reported for a single molecule and show very strong associations as $\mathrm{C}_{60}$ and $\mathrm{C}_{70}$ hosts, with larger affinities for the latter, indicating selectivity for $\mathrm{C}_{70}$ over $\mathrm{C}_{60}$. Despite the presence of two potential binding sites, the system behaves as a single rather than a double tweezer, leading to the formation of 1:1 adducts with fullerene. DFT calculations indicate that the four corannulene moieties and the porphyrin core participate in the recognition process, resulting in very strong binding of $\mathrm{C}_{60}$ and a large conformational change in the molecular clip. This conformational change is transmitted to the second binding site, resulting in the expansion of its cavity and consequently, its deactivation. The allosteric effects observed in the novel octacorannulene "double picket fence" porphyrin could enable the accommodation of a larger host (such as a higher-order fullerene) in the expanded second binding site, resulting in a modular supramolecular platform that echoes allosteric regulation in biological systems. Work in our group is underway to study the interplay (compression/expansion) of the two faces to tailor the system for specific host/guest interactions. 


\section{EXPERIMENTAL SECTION}

\section{General Methods}

All reagents were purchased from commercial sources and used without further purification. Solvents were either used as purchased or dried according to procedures described elsewhere. ${ }^{25}$ Microwave reactions were carried out using an Anton Paar Monowave 300 Reactor. Column chromatography was carried out using silica gel 60 (particle size $0.040-0.063 \mathrm{~mm} ; 230-400 \mathrm{mesh}$ ) as the stationary phase, and TLC was performed on precoated silica gel plates $(0.25 \mathrm{~mm}$ thick, $60 \mathrm{~F} 254)$ and visualized under UV light and/or by immersion in anisaldehyde. NMR spectra and NMR titrations were recorded on $500 \mathrm{MHz}$ Agilent DD2 instruments equipped with a cold probe in the Laboratory of Instrumental Techniques (LTI) Research Facilities, University of Valladolid. ${ }^{1} \mathrm{H}$ and ${ }^{13} \mathrm{C}$ NMR chemical shifts $(\delta)$ are reported in parts per million (ppm) and are referenced to tetramethylsilane (TMS), using the residual solvent peak as an internal reference. Coupling constants $(J)$ are reported in Hz. Standard abbreviations are used to indicate multiplicity: $\mathrm{s}=$ singlet, $\mathrm{d}=$ doublet, $\mathrm{t}=$ triplet, $\mathrm{m}=$ multiplet. ${ }^{1} \mathrm{H}$ and ${ }^{13} \mathrm{C}$ peak assignments were performed using $2 \mathrm{D}$ NMR methods (DQFCOSY, band selective ${ }^{1} \mathrm{H}-{ }^{1} \mathrm{H}-\mathrm{ROESY}$, band selective ${ }^{1} \mathrm{H}_{-}{ }^{13} \mathrm{C}$ HSQC, band selective ${ }^{1} \mathrm{H}-{ }^{13} \mathrm{C}$ HMBC). Due to low solubility, some carbon signals were detected indirectly via ${ }^{1} \mathrm{H}_{-}{ }^{13} \mathrm{C}-\mathrm{HSQC} / \mathrm{HMBC}$ experiments. High resolution mass spectra were recorded at the mass spectrometry service of the Laboratory of Instrumental Techniques of the (LTI) University of Valladolid. A MALDI-TOF system (MALDI-TOF), the Bruker Autoflex Speed ( $\mathrm{N}_{2}$ laser: $337 \mathrm{~nm}$, pulse energy $100 \mu \mathrm{J}, 1 \mathrm{~ns}$; acceleration voltage: $19 \mathrm{kV}$, reflector positive mode) was used. Trans -2-[3-(4-tert-butylphenyl)-2methyl-2propenylidene]malonitrile (DCTB) and 1,8,9-anthracenetriol, 1,8-dihydroxy-9(10H)-anthracenone (dithranol) were used as matrixes. UV/Vis spectra were recorded using a Shimadzu UV-1603 with spectrophotometric grade solvents. UV/vis absorption spectral wavelengths $(\lambda)$ are reported in nanometers $(\mathrm{nm})$, and molar absorption coefficients $(\varepsilon)$ are reported in $\mathrm{M}^{-1} \mathrm{~cm}^{-1}$. Corannulene was obtained following the literature procedures. ${ }^{9 e}$ Synthesis and characterization of the compound 2 HPOctaBr was previously reported by our group. ${ }^{16}$

Br-Cor: Corannulene $(50 \mathrm{mg}, 0.199 \mathrm{mmol})$ and freshly recrystallized $\mathrm{N}$-bromosuccinimide $(37.3 \mathrm{mg}, 0.209 \mathrm{mmol})$ were placed into a $5 \mathrm{ml}$ roundbottom flask and dissolved in $690 \mu \mathrm{l}$ of dry DCM. The reaction was monitored using ${ }^{1} \mathrm{H}-\mathrm{NMR}$ spectroscopy until the corannulene signal disappeared. After stirring the mixture at $\mathrm{RT}$ for $21 \mathrm{~h}, 10 \mathrm{ml}$ of saturated $\mathrm{NH}_{4} \mathrm{Cl}$ was added to quench the reaction. The crude was treated with $10 \mathrm{ml}$ of $\mathrm{DCM}$ and placed into a separatory funnel. The organic phase was washed with $15 \mathrm{ml}$ of warm $\mathrm{H}_{2} \mathrm{O}$ twice, and the aqueous phase was extracted with $10 \mathrm{ml}$ of DCM. The solvent of the organic phase was removed under vacuum, and the crude was purified by column chromatography on silica gel (hexane) to obtain Br-Cor (48.4 mg, 74\%) as a fluffy yellow solid. The spectroscopic data were in agreement with the data reported in literature.9c

Bpin-Cor: Br-Cor (66 mg, $0.200 \mathrm{mmol})$, bis(pinacolato)diboron $(76.18 \mathrm{mg}, 0.300 \mathrm{mmol})$, [ $\left.\mathrm{PdCl}_{2}(\mathrm{dppf})\right](7.31 \mathrm{mg}, 0.01 \mathrm{mmol})$, AcOK (58.57 mg, $0.6 \mathrm{mmol}$ ) were mixed into a sealed vessel specifically designed for microwave irradiation, and placed into the microwave reactor inside a two-necked round-bottom flask in order to maintain the system under an inert atmosphere. Dry dioxane $(1.2 \mathrm{ml})$ was added to the microwave vessel. The mixture was stirred inside the microwave reactor at $165^{\circ} \mathrm{C}$ for $80 \mathrm{~min}$; the pressure reached 5.8 bar. Subsequently, the solvent was removed under low pres- 
sure and the crude was purified using column chromatography on silica gel; hexane/AcOEt gradient elution (20:1 - 15:1 - 10:1 - 5:1 - 3:1 -1:1 AcOEt) yielded Bpin-Cor (52.5 mg, 70\%) as a yellow oil. The spectroscopic data were in agreement with the data reported in literature. ${ }^{26}$

2H-POctaCor: $2 \mathrm{HPOctaBr}(10 \mathrm{mg}, 0.0080 \mathrm{mmol})$, Bpin-Cor $(26.7 \mathrm{mg}, 0.071 \mathrm{mmol}),\left[\mathrm{PdCl}_{2}(\mathrm{dppf})\right](9.3 \mathrm{mg}, 0.0128 \mathrm{mmol}) \mathrm{and}{ }^{\mathrm{t} B u O N a}(18.5$ $\mathrm{mg}, 0.192 \mathrm{mmol}$ ) were mixed in a sealed vessel specifically designed for microwave irradiation and put the microwave reactor inside a two-necked round-bottom flask in order to keep the system under an inert atmosphere. $1.4 \mathrm{ml}$ of dry toluene was added. The mixture was stirred inside the microwave reactor at $150^{\circ} \mathrm{C}$ for $135 \mathrm{~min}$; the pressure reached 3.8 bar. After cooling, the solvent was removed under vacuum, and the crude was purified by column chromatography on silica gel using hexane/AcOEt gradient elution $(3: 1-2: 1-1: 1)$ and $\mathrm{CHCl}_{3}$ to finally give a purple solid corresponding to $2 \mathrm{H}-\mathbf{P O c t a C o r}(3.1 \mathrm{mg}, 15 \%) .{ }^{1} \mathrm{H} \mathrm{NMR}\left(500 \mathrm{MHz}\right.$, chloroform-d) $\delta$ : $9.31\left(\mathrm{~s}, 8 \mathrm{H}, \mathrm{H}_{2}\right), 8.85\left(\mathrm{~s}, 8 \mathrm{H}, \mathrm{H}_{6}\right), 8.69\left(\mathrm{~s}, 4 \mathrm{H}, \mathrm{H}_{8}\right), 8.35-8.26(\mathrm{~m}, 16 \mathrm{H}$, $\mathrm{H}_{10}+\mathrm{H}_{11}$ ), 7.93-7.70 (m, 56H, $\left.\mathrm{H}_{12}+\mathrm{H}_{13}+\mathrm{H}_{14}+\mathrm{H}_{15}+\mathrm{H}_{16}+\mathrm{H}_{17}+\mathrm{H}_{18}\right)$, -2.50 (br, 2H, $\left.\mathrm{H}_{1}\right) .{ }^{13} \mathrm{C}\left\{{ }^{1} \mathrm{H}\right\}$ NMR (126 MHz, chloroform-d) 8: 136.4, 136.2, 135.8, $135.6\left(\mathrm{C}_{6}\right), 135.3,130.9,130.8\left(\mathrm{C}_{8}\right), 129.5,128.1-126.3\left(\mathrm{C}_{10}+\mathrm{C}_{11}+\mathrm{C}_{12}+\mathrm{C}_{13}+\mathrm{C}_{14}+\mathrm{C}_{15}+\mathrm{C}_{16}+\mathrm{C}_{17}+\mathrm{C}_{18}\right)$. HR-MS (MALDI-TOF): $m / z$ for $\mathrm{C}_{204} \mathrm{H}_{94} \mathrm{~N}_{4}[\mathrm{M}+\mathrm{H}]^{+}$calcd: 2601.7619 ; found: 2601.7586 (3.3 ppm error). UV/vis (toluene): $\lambda 426(\varepsilon=279556), 520(\varepsilon=12969), 544(\varepsilon=7205)$

Zn-POctaCor: $2 \mathrm{H}$-POctaCor $(2.1 \mathrm{mg}, 0.00080 \mathrm{mmol})$ and $\mathrm{Zn}(\mathrm{AcO})_{2} \cdot 2 \mathrm{H}_{2} \mathrm{O}(2.6 \mathrm{mg}, 0.012 \mathrm{mmol})$ were mixed in a sealed vessel specifically designed for microwave irradiation, and $1.5 \mathrm{ml} \mathrm{CHCl}_{3}$ and $1.5 \mathrm{ml}$ toluene were added. The mixture was stirred inside a microwave reactor at $120{ }^{\circ} \mathrm{C}$ for $90 \mathrm{~min}$; the pressure reached 4.7 bar. After cooling, the solvent was removed under vacuum, and the obtained solid was dissolved in $10 \mathrm{ml}$ of $\mathrm{CHCl}_{3}$, placed into a separatory funnel, and washed with $5 \mathrm{ml}$ of $\mathrm{H}_{2} \mathrm{O}$. The organic layer was removed under low pressure to give a purple solid corresponding to Zn-POctaCor (1.8 mg, 86\%). ${ }^{1} \mathrm{H}$ NMR (500 MHz, chloroform-d) $\delta: 9.41\left(\mathrm{~s}, 8 \mathrm{H}, \mathrm{H}_{2}\right), 8.84\left(\mathrm{~s}, 8 \mathrm{H}, \mathrm{H}_{6}\right), 8.66\left(\mathrm{~s}, 4 \mathrm{H}, \mathrm{H}_{8}\right), 8.34-8.19(\mathrm{~m}, 16 \mathrm{H}$, $\left.\mathrm{H}_{10}+\mathrm{H}_{11}\right), 7.91-7.65\left(\mathrm{~m}, 56 \mathrm{H}, \mathrm{H}_{12}+\mathrm{H}_{13}+\mathrm{H}_{14}+\mathrm{H}_{15}+\mathrm{H}_{16}+\mathrm{H}_{17}+\mathrm{H}_{18}\right)$. Due to the low solubility, carbon signals $(\mathrm{CH})$ were detected indirectly via an ${ }^{1} \mathrm{H}-$

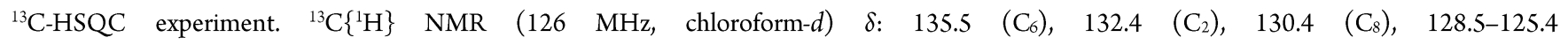
$\left(\mathrm{C}_{10}+\mathrm{C}_{11}+\mathrm{C}_{12}+\mathrm{C}_{13}+\mathrm{C}_{14}+\mathrm{C}_{15}+\mathrm{C}_{16}+\mathrm{C}_{17}+\mathrm{C}_{18}\right)$. HR-MS (MALDI-TOF): $m / z$ for $\mathrm{C}_{204} \mathrm{H}_{92} \mathrm{~N}_{4} \mathrm{Zn}[\mathrm{M}+\mathrm{H}]^{+}$calcd: 2663.6665 , found: 2663.6528 (13.7 ppm error). UV/vis (toluene): $\lambda 431(\varepsilon=202833), 552(\varepsilon=17205)$.

\section{ASSOCIATED CONTENT}

\section{Supporting Information}

The Supporting Information is available free of charge on the ACS Publications website. Methods and details, synthetic procedures and spectra of compounds are provided in PDF format.

\section{AUTHOR INFORMATION}

Corresponding Author

Celedonio M. Álvarez: GIR MIOMeT, IU CINQUIMA/Química Inorgánica, Facultad de Ciencias, Universidad de Valladolid, E47011, Valladolid, Spain.

E-mail: celedonio.alvarez@uva.es 
Raúl García-Rodríguez GIR MIOMeT, IU CINQUIMA/Química Inorgánica, Facultad de Ciencias, Universidad de Valladolid, E47011, Valladolid, Spain.

E-mail: raul.garcia.rodriguez@uva.es

Notes

The authors declare no competing financial interests.

\section{ACKNOWLEDGMENT}

We thank the Spanish Ministry of Science, Innovation and Universities (MCIU) for funding (project numbers PGC2018-096880-A-I00, MCIU/AEI/FEDER, UE and PGC2018-099470-B-I00, MCIU/AEI/FEDER, UE). R.G.-R. acknowledges the Spanish MINECO/AEI and the European Union (ESF) for a Ramon y Cajal contract (RYC-2015-19035). H.B. acknowledges the Alfonso Martin Escudero Foundation for a postdoctoral fellowship. We are also grateful to Eduardo Rodriguez-Gutiez for his support with NCIPlot calculations and its implementation in Chimera for visualization purposes.

\section{REFERENCES}

(1) (a) Lehn, J.-M. Supramolecular Chemistry—Scope and Perspectives Molecules, Supermolecules, and Molecular Devices (Nobel Lecture). Angew. Chem. Int. Ed. 1988, 27, 89-112. (b) Lehn, J.-M. From supramolecular chemistry towards constitutional dynamic chemistry and adaptive chemistry. Chem. Soc. Rev. 2007, 36, 151-160. (c) Lehn, J.-M. Perspectives in Chemistry-Steps towards Complex Matter. Angew. Chem. Int. Ed. 2013, 52, 2836-2850.

(2) (a) Whitty, A. Cooperativity and biological complexity. Nat. Chem. Biol. 2008, 4, 435. (b) Reichow, S. L.; Clemens, D. M.; Freites, J. A.; NémethCahalan, K. L.; Heyden, M.; Tobias, D. J.; Hall, J. E.; Gonen, T. Allosteric mechanism of water-channel gating by Ca2+-calmodulin. Nat. Struct. Mol. Biol. 2013, 20, 1085-1092.

(3) (a) Badjić, J. D.; Nelson, A.; Cantrill, S. J.; Turnbull, W. B.; Stoddart, J. F. Multivalency and Cooperativity in Supramolecular Chemistry. Acc. Chem. Res. 2005, 38, 723-732. (b) Hunter, C. A.; Anderson, H. L. What is Cooperativity? Angew. Chem. Int. Ed. 2009, 48, 7488-7499. (c) Gianfranco, E.; Luca, S. Allosteric, Chelate, and Interannular Cooperativity: A Mise au Point. Angew. Chem. Int. Ed. 2011, 50, 1762-1768. (d) von Krbek, L. K. S.; Schalley, C. A.; Thordarson, P. Assessing cooperativity in supramolecular systems. Chem. Soc. Rev. 2017, 46, 2622-2637.

(4) (a) Thordarson, P.; Bijsterveld, E. J. A.; Elemans, J. A. A. W.; Kasák, P.; Nolte, R. J. M.; Rowan, A. E. Highly Negative Homotropic Allosteric Binding of Viologens in a Double-Cavity Porphyrin. J. Am. Chem. Soc. 2003, 125, 1186-1187. (b) Thordarson, P.; Coumans, R. G. E.; Elemans, J. A. A. W.; Thomassen, P. J.; Visser, J.; Rowan, A. E.; Nolte, R. J. M. Allosterically Driven Multicomponent Assembly. Angew. Chem. Int. Ed. 2004, 43, 4755-4759. (c) Sato, H.; Tashiro, K.; Shinmori, H.; Osuka, A.; Murata, Y.; Komatsu, K.; Aida, T. Positive Heterotropic Cooperativity for Selective 
Guest Binding via Electronic Communications through a Fused Zinc Porphyrin Array. J. Am. Chem. Soc. 2005, 127, 13086-13087. (d) Christopher, K.; Arne, L. Artificial Allosteric Receptors. Chem. Eur. J. 2013, 19, 6162-6196.

(5) (a) Shen, Y.; Nakanishi, T. Fullerene assemblies toward photo-energy conversions. Phys. Chem. Chem. Phys. 2014, 16, 7199-7204. (b) Kirner, S.; Sekita, M.; Guldi, D. M. 25th Anniversary Article: 25 Years of Fullerene Research in Electron Transfer Chemistry. Adv. Mater. 2014, 26, 1482-1493. (c) Zieleniewska, A.; Lodermeyer, F.; Roth, A.; Guldi, D. M. Fullerenes - how 25 years of charge transfer chemistry have shaped our understanding of (interfacial) interactions. Chem. Soc. Rev. 2018, 47, 702-714. (d) Collavini, S.; Delgado, J. L. Fullerenes: the stars of photovoltaics. Sustainable Energy Fuels 2018, 2, 2480-2493.

(6) (a) Diederich, F.; Gómez-López, M. Supramolecular fullerene chemistry. Chem. Soc. Rev. 1999, 28, 263-277. (b) Martín, N.; Pérez, E. M. Molecular tweezers for fullerenes. Pure Appl. Chem. 2010, 82, 523-533. (c) Babu, S. S.; Mohwald, H.; Nakanishi, T. Recent progress in morphology control of supramolecular fullerene assemblies and its applications. Chem. Soc. Rev. 2010, 39, 4021-4035. (d) Canevet, D.; Pérez, E. M.; Martín, N. Wraparound Hosts for Fullerenes: Tailored Macrocycles and Cages. Angew. Chem. Int. Ed. 2011, 50, 9248-9259. (e) Hardouin-Lerouge, M.; Hudhomme, P.; Sallé, M. Molecular clips and tweezers hosting neutral guests. Chem. Soc. Rev. 2011, 40, 30-43. (f) Martín, N.; Nierengarten, J. F. In Supramolecular Chemistry of Fullerenes and Carbon Nanotubes; Wiley-VCH Verlag GmbH: Weinheim, Germany, 2012.

(7) (a) Rabideau, P. W.; Sygula, A. Buckybowls: Polynuclear Aromatic Hydrocarbons Related to the Buckminsterfullerene Surface. Acc. Chem. Res. 1996, 29, 235-242. (b) Tsefrikas, V. M.; Scott, L. T. Geodesic Polyarenes by Flash Vacuum Pyrolysis. Chem. Rev. 2006, 106, 4868-4884. (c) Wu, Y.T.; Siegel, J. S. Aromatic Molecular-Bowl Hydrocarbons: Synthetic Derivatives, Their Structures, and Physical Properties. Chem. Rev. 2006, 106, 4843-4867. (d) Kawase, T.; Kurata, H. Ball-, Bowl-, and Belt-Shaped Conjugated Systems and Their Complexing Abilities: Exploration of the Concave-Convex $\pi-\pi$ Interaction. Chem. Rev. 2006, 106, 5250-5273. (e) Sygula, A. Chemistry on a Half-Shell: Synthesis and Derivatization of Buckybowls. Eur. J. Org. Chem. 2011, 2011, 1611-1625. (f) Rajeshkumar, V.; Marc, C.; Fichou, D.; Stuparu, M. C. Synthesis and Properties of a Buckybowl/Buckyball Dyad. Synlett 2016, 27, 2101-2104. (g) Li, X.; Kang, F.; Inagaki, M. Buckybowls: Corannulene and Its Derivatives. Small 2016, 12, 3206-3223. (h) Saito, M.; Shinokubo, H.; Sakurai, H. Figuration of bowl-shaped $\pi$-conjugated molecules: properties and functions. Mater. Chem. Front. 2018, 2, 635-661.

(8) (a) Chen, R.; Lu, R.-Q.; Shi, P.-C.; Cao, X.-Y. Corannulene derivatives for organic electronics: From molecular engineering to applications. Chin. Chem. Lett. 2016, 27, 1175-1183. (b) Nestoros, E.; Stuparu, M. C. Corannulene: a molecular bowl of carbon with multifaceted properties and diverse applications. Chem. Commun. 2018, 54, 6503-6519. (c) Haupt, A.; Lentz, D. Tuning the Electron Affinity and Stacking Properties of Corannulene by Introduction of Fluorinated Thioethers. Chem. Asian J. 2018, 13, 3022-3026. (d) Gu, X.; Zhang, X.; Ma, H.; Jia, S.; Zhang, P.; Zhao, Y.; Liu, Q.; Wang, J.; Zheng, X.; Lam, J. W. Y.; Ding, D.; Tang, B. Z. Corannulene-Incorporated AIE Nanodots with Highly Suppressed Nonradiative Decay for Boosted Cancer Phototheranostics In Vivo. Adv. Mater. 2018, 30, 1801065. (e) Rice, A. M.; Dolgopolova, E. A.; Yarbrough, B. J.; Leith, G. A.; Martin, C. R.; Stephenson, K. S.; Heugh, R. A.; Brandt, A. J.; Chen, D. A.; Karakalos, S. G.; Smith, M. D.; Hatzell, K. B.; Pellechia, P. J.; Garashchuk, 
S.; Shustova, N. B. Stack the Bowls: Tailoring the Electronic Structure of Corannulene-Integrated Crystalline Materials. Angew. Chem. Int. Ed. 2018, $57,11310-11315$.

(9) (a) Barth, W. E.; Lawton, R. G. Dibenzo[ghi,mno]fluoranthene. J. Am. Chem. Soc. 1966, 88, 380-381. (b) Lawton, R. G.; Barth, W. E. Synthesis of corannulene. J. Am. Chem. Soc. 1971, 93, 1730-1745. (c) Seiders, T. J.; Elliott, E. L.; Grube, G. H.; Siegel, J. S. Synthesis of Corannulene and Alkyl Derivatives of Corannulene. J. Am. Chem. Soc. 1999, 121, 7804-7813. (d) Sygula, A.; Rabideau, P. W. A Practical, Large Scale Synthesis of the Corannulene System. J. Am. Chem. Soc. 2000, 122, 6323-6324. (e) Butterfield, A. M.; Gilomen, B.; Siegel, J. S. Kilogram-Scale Production of Corannulene. Org. Process Res. Dev. 2012, 16, 664-676.

(10) (a) Scott, L. T.; Hashemi, M. M.; Bratcher, M. S. Corannulene bowl-to-bowl inversion is rapid at room temperature. J. Am. Chem. Soc. 1992, 114, 1920-1921. (b) Seiders, T. J.; Baldridge, K. K.; Grube, G. H.; Siegel, J. S. Structure/Energy Correlation of Bowl Depth and Inversion Barrier in Corannulene Derivatives: Combined Experimental and Quantum Mechanical Analysis. J. Am. Chem. Soc. 2001, 123, 517-525. (c) Nishida, S.; Morita, Y.; Ueda, A.; Kobayashi, T.; Fukui, K.; Ogasawara, K.; Sato, K.; Takui, T.; Nakasuji, K. Curve-Structured Phenalenyl Chemistry: Synthesis, Electronic Structure, and Bowl-Inversion Barrier of a Phenalenyl-Fused Corannulene Anion. J. Am. Chem. Soc. 2008, 130, 14954-14955. (d) Yanney, M.; Fronczek, F. R.; Henry, W. P.; Beard, D. J.; Sygula, A. Cyclotrimerization of Corannulyne: Steric Hindrance Tunes the Inversion Barriers of Corannulene Bowls. Eur. J. Org. Chem. 2011, 2011, 6636-6639. (e) Juríček, M.; Strutt, N. L.; Barnes, J. C.; Butterfield, A. M.; Dale, E. J.; Baldridge, K. K.; Stoddart, J. F.; Siegel, J. S. Induced-fit catalysis of corannulene bowl-to-bowl inversion. Nat. Chem. 2014, 6, $222-228$.

(11) (a) Pérez, E. M.; Martín, N. Curves ahead: molecular receptors for fullerenes based on concave-convex complementarity. Chem. Soc. Rev. 2008, 37, 1512-1519. (b) Pérez, E. M.; Martín, N. $\pi-\pi$ interactions in carbon nanostructures. Chem. Soc. Rev. 2015, 44, 6425-6433. (c) Selmani, S.; Schipper, D. J. $\pi$-Concave Hosts for Curved Carbon Nanomaterials. Chem. Eur. J. 2019, 25, 6673-6692.

(12) (a) Wu, Y.-L.; Stuparu, M. C.; Boudon, C.; Gisselbrecht, J.-P.; Schweizer, W. B.; Baldridge, K. K.; Siegel, J. S.; Diederich, F. Structural, Optical, and Electrochemical Properties of Three-Dimensional Push-Pull Corannulenes. J. Org. Chem. 2012, 77, 11014-11026. (b) Stuparu, M. C. Rationally Designed Polymer Hosts of Fullerene. Angew. Chem. Int. Ed. 2013, 52, 7786-7790. (c) Lu, R.-Q.; Zheng, Y.-Q.; Zhou, Y.-N.; Yan, X.-Y.; Lei, T.; Shi, K.; Zhou, Y.; Pei, J.; Zoppi, L.; Baldridge, K. K.; Siegel, J. S.; Cao, X.-Y. Corannulene derivatives as non-fullerene acceptors in solution-processed bulk heterojunction solar cells. J. Mater.Chem. A 2014, 2, 20515-20519. (d) Steinauer, A.; Butterfield, A. M.; Linden, A.; Molina-Ontario, A.; Buck, D. C.; Cotta, R. W.; Echegoyen, L.; Baldridge, K. K.; Siegel, J. S. Tunable Photochemical/Redox Properties of (Phenylthio)ncorannulenes: Application to a Photovoltaic Device. J. Braz. Chem. Soc. 2016, 27, 1866-1871. (e) Li, J.; Terec, A.; Wang, Y.; Joshi, H.; Lu, Y.; Sun, H.; Stuparu, M. C. $\pi$-Conjugated Discrete Oligomers Containing Planar and Nonplanar Aromatic Motifs. J. Am. Chem. Soc. 2017, 139, 3089-3094. (f) Deng, Y.; Xu, B.; Castro, E.; Fernandez-Delgado, O.; Echegoyen, L.; Baldridge, K. K.; Siegel, J. S. Decakis(arylthio)corannulenes: Transferable Photochemical and Redox Parameters and Photovoltaic Device Performance. Eur. J. Org. Chem. 2017, 2017, 4338-4342. (g) Barát, V.; Budanović, M.; Halilovic, D.; Huh, J.; Webster, R. D.; Mahadevegowda, S. H.; Stuparu, M. C. A general approach to non-fullerene electron acceptors based on the corannulene motif. Chem. Commun. 2019, 55, 3113-3116. 
(13) (a) Dawe, L. N.; AlHujran, T. A.; Tran, H.-A.; Mercer, J. I.; Jackson, E. A.; Scott, L. T.; Georghiou, P. E. Corannulene and its penta-tert-butyl derivative co-crystallize 1:1 with pristine C60-fullerene. Chem. Commun. 2012, 48, 5563-5565. (b) Yamada, M.; Ohkubo, K.; Shionoya, M.; Fukuzumi, S. Photoinduced Electron Transfer in a Charge-Transfer Complex Formed between Corannulene and Li+@C60 by Concave-Convex $\pi-$ $\pi$ Interactions. J. Am. Chem. Soc. 2014, 136, 13240-13248.

(14) (a) Sygula, A.; Fronczek, F. R.; Sygula, R.; Rabideau, P. W.; Olmstead, M. M. A Double Concave Hydrocarbon Buckycatcher. J. Am. Chem. Soc. 2007, 129, 3842-3843. (b) Yanney, M.; Sygula, A. Tridental molecular clip with corannulene pincers: is three better than two? Tetrahedron Lett. 2013, 54, 2604-2607. (c) Le, V. H.; Yanney, M.; McGuire, M.; Sygula, A.; Lewis, E. A. Thermodynamics of Host-Guest Interactions between Fullerenes and a Buckycatcher. J. Phys. Chem. B 2014, 118, 11956-11964. (d) Álvarez, C. M.; García-Escudero, L. A.; García-Rodríguez, R.; MartínÁlvarez, J. M.; Miguel, D.; Rayón, V. M. Enhanced association for C70 over C60 with a metal complex with corannulene derivate ligands. Dalton Trans. 2014, 43, 15693-15696. (e) Yanney, M.; Fronczek, F. R.; Sygula, A. A 2:1 Receptor/C60 Complex as a Nanosized Universal Joint. Angew. Chem. Int. Ed. 2015, 54, 11153-11156. (f) Abeyratne Kuragama, P. L.; Fronczek, F. R.; Sygula, A. Bis-corannulene Receptors for Fullerenes Based on Klärner's Tethers: Reaching the Affinity Limits. Org. Lett. 2015, 17, 5292-5295. (g) Álvarez, C. M.; Aullón, G.; Barbero, H.; García-Escudero, L. A.; Martínez-Pérez, C.; Martín-Álvarez, J. M.; Miguel, D. Assembling Nonplanar Polyaromatic Units by Click Chemistry. Study of Multicorannulene Systems as Host for Fullerenes. Org. Lett. 2015, 17, 2578-2581. (h) Kumarasinghe, K. G. U. R.; Fronczek, F. R.; Valle, H. U.; Sygula, A. Biscorannulenoanthracene: An Angularly Fused Pentacene as a Precursor for Barrelene-Tethered Receptors for Fullerenes. Org. Lett. 2016, 18, 30543057. (i) Barbero, H.; Ferrero, S.; Álvarez-Miguel, L.; Gómez-Iglesias, P.; Miguel, D.; Álvarez, C. M. Affinity modulation of photoresponsive hosts for fullerenes: light-gated corannulene tweezers. Chem. Commun. 2016, 52, 12964-12967. (j) Álvarez, C. M.; Barbero, H.; Ferrero, S. Preparation of a Corannulene-functionalized Hexahelicene by Copper(I)-catalyzed Alkyne-azide Cycloaddition of Nonplanar Polyaromatic Units. J. Vis. Exp. 2016, 115, e53954. (k) Álvarez, C. M.; Barbero, H.; Ferrero, S.; Miguel, D. Synergistic Effect of Tetraaryl Porphyrins Containing Corannulene and Other Polycyclic Aromatic Fragments as Hosts for Fullerenes. Impact of C60 in a Statistically Distributed Mixture of Atropisomers. J. Org. Chem. 2016, 81, 6081-6086. (1) Yang, D.-C.; Li, M.; Chen, C.-F. A bis-corannulene based molecular tweezer with highly sensitive and selective complexation of C70 over C60. Chem. Commun. 2017, 53, 9336-9339. (m) Sygula, A. Corannulene-Adorned Molecular Receptors for Fullerenes Utilizing the $\pi-\pi$ Stacking of Curved-Surface Conjugated Carbon Networks. Design, Synthesis and Testing. Synlett 2016, 27, 2070-2080. (n) García-Calvo, V.; Cuevas, J. V.; Barbero, H.; Ferrero, S.; Álvarez, C. M.; González, J. A.; Díaz de Greñu, B.; García-Calvo, J.; Torroba, T. Synthesis of a Tetracorannulene-perylenediimide That Acts as a Selective Receptor for C60 over C70. Org. Lett. 2019, 21, 5803-5807.

(15) (a) Boyd, P. D. W.; Hodgson, M. C.; Rickard, C. E. F.; Oliver, A. G.; Chaker, L.; Brothers, P. J.; Bolskar, R. D.; Tham, F. S.; Reed, C. A. Selective Supramolecular Porphyrin/Fullerene Interactions1.J. Am. Chem. Soc. 1999, 121, 10487-10495. (b) Boyd, P. D. W.; Reed, C. A. Fullerene-Porphyrin Constructs. Acc. Chem. Res. 2005, 38, 235-242. (c) Tashiro, K.; Aida, T. Metalloporphyrin hosts for supramolecular chemistry of fullerenes. Chem. Soc. Rev. 2007, 36, 189-197. (d) Saegusa, Y.; Ishizuka, T.; Kojima, T.; Mori, S.; Kawano, M.; Kojima, T. Supramolecular Interaction of Fullerenes with a Curved $\pi$-Surface of a Monomeric Quadruply Ring-Fused Porphyrin. Chem. Eur. J. 2015, 21, 5302-5306. (e) Bromby, A. D.; Hogan, D. T.; 
Sutherland, T. C. Core expanded, 21,23-dithiadiacenaphtho[1,2-c]porphyrin interactions with [60]fullerene. New J. Chem. 2017, 41, 4802-4805. (f)

Yamada, M.; Murakami, G.; Kobayashi, S.; Maeda, Y. Enhancing solution-phase supramolecular interactions between monomeric porphyrins and

[60]fullerene by simple chemical modification. Tetrahedron Lett. 2017, 58, 4514-4518.

(16) Ferrero, S.; Barbero, H.; Miguel, D.; García-Rodríguez, R.; Álvarez, C. M. Dual-Tweezer Behavior of an Octapodal Pyrene Porphyrin-Based System as a Host for Fullerenes. J. Org. Chem. 2019, 84, 6183-6190.

(17) (a) Kappe, C. O. Controlled Microwave Heating in Modern Organic Synthesis. Angew. Chem. Int. Ed. 2004, 43, 6250-6284. (b) Sharma, N.; K. Sharma, U.; Van der Eycken, E. V. In Green Techniques for Organic Synthesis and Medicinal Chemistry; Zhang, W., Cue, B. W., Eds.; Wiley: New York, 2018, p 441-468.

(18) (a) Sygula, A.; Saebø, S. $\pi-\pi$ Stacking of curved carbon networks: The corannulene dimer. Int. J. Quantum Chem 2009, 109, 65-72. (b) MuckLichtenfeld, C.; Grimme, S.; Kobryn, L.; Sygula, A. Inclusion complexes of buckycatcher with C60 and C70. Phys. Chem. Chem. Phys. 2010, 12, 70917097. (c) Janowski, T.; Pulay, P.; Sasith Karunarathna, A. A.; Sygula, A.; Saebø, S. Convex-concave stacking of curved conjugated networks: Benchmark calculations on the corannulene dimer. Chem. Phys. Lett. 2011, 512, 155-160. (d) Topolinski, B.; Schmidt, B. M.; Kathan, M.; Troyanov, S. I.; Lentz, D. Corannulenylferrocenes: towards a 1D, non-covalent metal-organic nanowire. Chem. Commun. 2012, 48, 6298-6300. (e) Sygula, A.; Yanney, M.; Henry, W. P.; Fronczek, F. R.; Zabula, A. V.; Petrukhina, M. A. Inclusion Complexes and Solvates of Buckycatcher, a Versatile Molecular Host with Two Corannulene Pincers. Cryst. Growth Des. 2014, 14, 2633-2639.

(19) (a) Ditchfield, R.; Hehre, W. J.; Pople, J. A. Self-Consistent Molecular-Orbital Methods. IX. An Extended Gaussian-Type Basis for MolecularOrbital Studies of Organic Molecules. J. Chem. Phys. 1971, 54, 724-728. (b) Hehre, W. J.; Ditchfield, R.; Pople, J. A. Self-Consistent Molecular Orbital Methods. XII. Further Extensions of Gaussian-Type Basis Sets for Use in Molecular Orbital Studies of Organic Molecules. J. Chem. Phys. 1972, 56, 2257-2261. (c) Francl, M. M.; Pietro, W. J.; Hehre, W. J.; Binkley, J. S.; Gordon, M. S.; DeFrees, D. J.; Pople, J. A. Self-consistent molecular orbital methods. XXIII. A polarization-type basis set for second-row elements. J. Chem. Phys. 1982, 77, 3654-3665. (d) Grimme, S. Semiempirical GGA-type density functional constructed with a long-range dispersion correction. J. Comput. Chem. 2006, 27, 1787-1799. (e) Grimme, S.; Ehrlich, S.; Goerigk, L. Effect of the damping function in dispersion corrected density functional theory. J. Comput. Chem. 2011, 32, $1456-1465$.

(20) (a) Pons, M.; Millet, O. Dynamic NMR studies of supramolecular complexes. Prog. Nucl. Magn. Reson. Spectrosc. 2001, 38, 267-324. (b) Bain, A. D. Chemical exchange in NMR. Prog. Nucl. Magn. Reson. Spectrosc. 2003, 43, 63-103. (c) Kleckner, I. R.; Foster, M. P. An introduction to NMR-based approaches for measuring protein dynamics. Biochim. Biophys. Acta - Proteins Proteomics 2011, 1814, 942-968.

(21) (a) Blackburn, M. N.; Schachman, H. K. Allosteric regulation of aspartate transcarbamoylase. Effect of active site ligands on the reactivity of sulfhydryl groups of the regulatory subunits. Biochemistry 1977, 16, 5084-5091. (b) Endrizzi, J. A.; Beernink, P. T.; Alber, T.; Schachman, H. K. Binding of bisubstrate analog promotes large structural changes in the unregulated catalytic trimer of aspartate transcarbamoylase: Implications for allosteric regulation. Proc. Natl. Acad. Sci. 2000, 97, 5077-5082. 
(22) (a) Ackers, G. K.; Doyle, M. L.; Myers, D.; Daugherty, M. A. Molecular code for cooperativity in hemoglobin. Science 1992, 255, 54. (b) Eaton,

W. A.; Henry, E. R.; Hofrichter, J.; Mozzarelli, A. Is cooperative oxygen binding by hemoglobin really understood? Nat. Struct. Biol. 1999, 6, 351-358.

(c) Lukin, J. A.; Ho, C. The Structure-Function Relationship of Hemoglobin in Solution at Atomic Resolution. Chem. Rev. 2004, 104, 1219-1230.

(d) Nagatomo, S.; Nagai, M.; Kitagawa, T. A New Way To Understand Quaternary Structure Changes of Hemoglobin upon Ligand Binding On the Basis of UV-Resonance Raman Evaluation of Intersubunit Interactions. J. Am. Chem. Soc. 2011, 133, 10101-10110.

(23) (a) Johnson, E. R.; Keinan, S.; Mori-Sánchez, P.; Contreras-García, J.; Cohen, A. J.; Yang, W. Revealing Noncovalent Interactions. J. Am. Chem. Soc. 2010, 132, 6498-6506. (b) Contreras-García, J.; Johnson, E. R.; Keinan, S.; Chaudret, R.; Piquemal, J.-P.; Beratan, D. N.; Yang, W. NCIPLOT: A Program for Plotting Noncovalent Interaction Regions. J. Chem. Theory Comput. 2011, 7, 625-632.

(24) (a) Lemon, C. M.; Brothers, P. J.; Boitrel, B. Porphyrin complexes of the period 6 main group and late transition metals. Dalton Trans. 2011, 40, 6591-6609. (b) Kadish, K. M.; Smith, K. M.; Guilard, R. Handbook of Porphyrin Science (Volumes 21- 25); World Scientific Publishing Company, 2012; Vol. Volumes 21 - 25. (c) Valicsek, Z.; Horváth, O. Application of the electronic spectra of porphyrins for analytical purposes: The effects of metal ions and structural distortions. Microchem. J. 2013, 107, 47-62. (d) Senge, M. O.; MacGowan, S. A.; O'Brien, J. M. Conformational control of cofactors in nature - the influence of protein-induced macrocycle distortion on the biological function of tetrapyrroles. Chem. Commun. 2015, 51, 17031-17063.

(25) (a) Armarego, W. L. F.; Chai, C. L. L. Purification of Laboratory Chemicals, 6th; Butterworth-Heinemann: London, 2009. (b) Williams, D. B. G.; Lawton, M. Drying of Organic Solvents: Quantitative Evaluation of the Efficiency of Several Desiccants. J. Org. Chem. 2010, 75, 8351-8354.

(26) (a) Wegner, H. A.; Scott, L. T.; de Meijere, A. A New Suzuki-Heck-Type Coupling Cascade: Indeno[1,2,3]-Annelation of Polycyclic Aromatic Hydrocarbons. J. Org. Chem. 2003, 68, 883-887. (b) Da Ros, S.; Linden, A.; Baldridge, K. K.; Siegel, J. S. Boronic esters of corannulene: potential building blocks toward icosahedral supramolecules. Org. Chem. Front. 2015, 2, 626-633. 
Table of Contents artwork

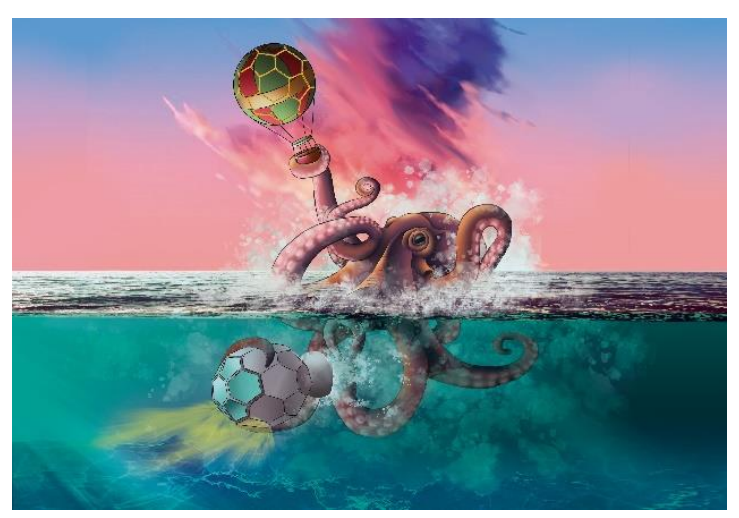




\subsection{ARTÍCULO III:}

Porphyrin-based systems containing polyaromatic fragments: decoupling the synergistic effects in aromatic-porphyrin-fullerene systems

RSC Adv., 2020, 10, 36164 - 36173 


\title{
Journal Name
}

\section{ARTICLE}

\section{Porphyrin-based systems containing polyaromatic fragments: decoupling the synergistic effects in aromatic-porphyrin-fullerene}

Received 00th January 20xx, Accepted 00th January 20xx

DOI: $10.1039 / \times 0 \times x 00000 x$

www.rsc.org/

\begin{abstract}
Sergio Ferrero, ${ }^{a}$ Héctor Barbero, ${ }^{a}$ Daniel Miguel, ${ }^{a}$ Raúl García-Rodríguez*a and Celedonio M. Álvarez*a

In this work, we report a two-step synthesis that allows the introduction of four pyrene or corannulene fragments at the para position of meso-tetraarylporphyrins using a microwave-assisted quadruple Suzuki-Miyaura reaction. Placing the PAHs at this position, further from the porphyrin core, avoids the participation of the porphyrin core in binding with fullerenes. The fullerene hosting ability of the four new molecular receptors was investigated by NMR titrations and DFT studies. Despite having two potential binding sites, the pyrene derivatives did not associate with $\mathrm{C}_{60}$ or $\mathrm{C}_{70}$. In contrast, the tetracorannulene derivatives bound $C_{60}$ and $C_{70}$, although with modest binding constants. In these novel para-substituted systems, the porphyrin core acts as a simple linker that does not participate in the binding process, which allows the system to be considered as two independent molecular tweezers; i.e., the first binding event is not transmitted to the second binding

site. This behavior can be considered a direct consequence of the decoupling of the porphyrin core from the binding event.
\end{abstract}

\section{Introduction}

The rational design and development of functional complex architectures capable of interacting with nanometer-sized carbon allotropes, ${ }^{1}$ especially fullerenes, in a supramolecular fashion is a challenging current topic. ${ }^{2}$ However, the rational design of efficient systems of this type is not always straightforward, since it depends on a delicate balance of favorable and unfavorable interactions, and requires an understanding of the different subtle factors at play. ${ }^{3}$

Among the fullerenes, buckminsterfullerene $\left(C_{60}\right)$, and to a lesser extent, $\mathrm{C}_{70}$, have attracted the most attention. The iconic $\mathrm{C}_{60}$ fullerene is constructed of 12 pentagonal rings and 20 hexagonal ones, which give rise to its unique hollow spherical symmetry ${ }^{4}$ and electronic and magnetic proprieties. ${ }^{5}$ However, as a result of its non-planar $\pi$-surface, engineering supramolecular interaction of $\mathrm{C}_{60}$ with typical planar benzenoid rings is difficult. Therefore, in order to achieve efficient supramolecular interactions with $\mathrm{C}_{60}$, a host must exhibit both effective preorganization and a wide complementary surface in order to maximise the area of the convex-concave interaction. ${ }^{3 a}$, $3 f, 6$ Among the curved polyaromatic hydrocarbons (PAHs), ${ }^{6 a, 7}$ corannulene has played a central role in fullerene recognition due to its excellent structural complementarity. ${ }^{8}$ However, pristine corannulene does not

\footnotetext{
a. GIR MIOMeT, IU CINQUIMA/Química Inorgánica, Facultad de Ciencias,

Universidad de Valladolid, E-47011 Valladolid, Spain

+ Electronic Supplementary Information (ESI) available: Methods and details, synthetic procedures and spectra of compounds are provided in PDF format. See
} DOI: $10.1039 / \mathrm{x} 0 \times x \times 00000 \mathrm{x}$ associate with $\mathrm{C}_{60}$ strongly enough for the adduct to be observed in solution. ${ }^{9}$ Therefore, the incorporation of corannulenes in different supramolecular frameworks is critical to achieve interactions with fullerene. ${ }^{10}$ Sygula's buckycatcher I, in which a cyclooctatetraene tether links two corannulene moieties, represented a breakthrough in the area. ${ }^{11}$ This molecular pincer was able to establish strong interactions with $\mathrm{C}_{60}$, sparking a search for other corannulene-based supramolecular architectures able to interact with $\mathrm{C}_{60}$. One obvious way to improve the interaction of a host with $\mathrm{C}_{60}$ is the introduction of more corannulene units. However, the seminal work by Sygula demonstrated that the introduction of more corannulene units might not necessarily improve the interaction with $\mathrm{C}_{60} .^{10 a}, 12$ This and subsequent studies highlighted the importance of not only the preorganization of the molecular pincer, but also more subtle factors such as the flexibility of the scaffold and the interplay of different binding events. ${ }^{13}$

We have turned our attention to porphyrin-based systems as ideal scaffolds for the formation of corannulene-based receptors for fullerenes. Porphyrins and fullerenes are known to interact; however, the interactions between a single porphyrin core and fullerenes are usually too weak to be detected in solution. ${ }^{14}$ We have shown that the introduction of four corannulene arms at the meta positions of a tetraaryl meso-substituted porphyrin leads to a "picket fence" molecular clip able to bind $\mathrm{C}_{60}$ (Fig 1a). ${ }^{15}$ However, the formation of four inseparable atropoisomers diminished the binding ability of the system and resulted in a difficult to analyse system. Nonetheless, this study highlighted the importance of the participation of the porphyrin core in the recognition process 
and inspired us to conduct subsequent studies based on this meta-substituted tetraaryl porphyrin scaffold. a) Picket fence

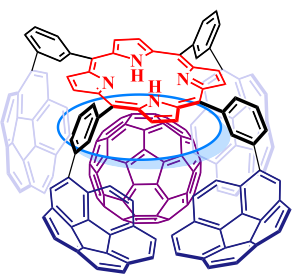

Mixture of Atropisomers

2H-Tetra(I) b) Double picket fence

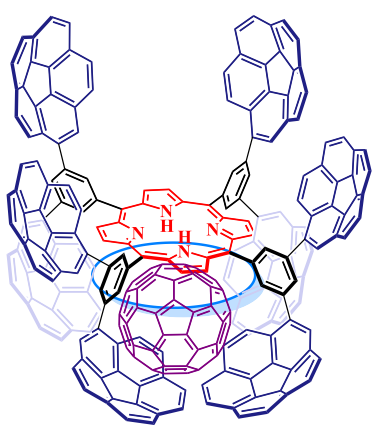

2H-Octa(II) c) Double "classical"- tweezer

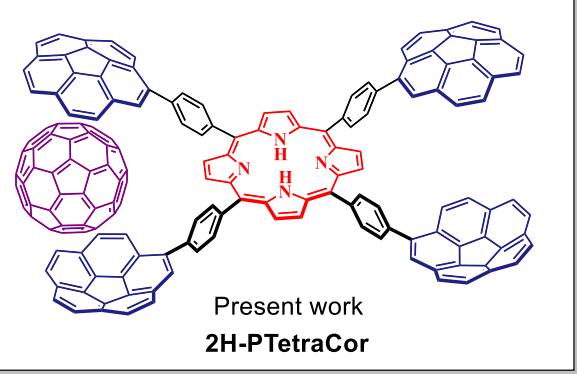

Fig. 1 Corannulene tetraaryl porphyrin-based systems. (a and b) Previously reported "picket fence" and double "picket fence" systems resulting from the introduction of four or eight corannulene arms at the meta positions. (c) Tetracorannulene-based double tweezer system via substitution at the para position described in the present work.

Note: The blue circle represents an idealized interaction of the guest with the porphyrin core in the meta substituted systems.

In order to prevent the formation of atropisomers, we first introduced eight pyrene units (i.e., in all meta positions), ${ }^{16}$ and, very recently eight corannulene units, ${ }^{17}$ at the meta positions of the tetraaryl porphyrin. Figure $1 \mathrm{~b}$ shows the resulting octapodal corannulene-based system, which features two binding sites as a result of the $4+4$ arrangement of the corannulene arms. Although the compound was obtained in very low yield, this new supramolecular platform displayed very high affinity for $\mathrm{C}_{60}$ due to the involvement of the four corannulene units, and, importantly, the participation of the porphyrin core. However, the active participation of the porphyrin core led to the expansion of the second active site, which in turn led to its deactivation, as indicated by DFT calculations. In other words, while beneficial in maximizing the interaction with the first $C_{60}$, the active participation of the porphyrin core led to a deactivating conformational change in the second binding site. Herein, we explore the introduction of corannulene units at the para-position of a meso-tetraarylporphyrin with the simple idea of preparing a double "classical"-tweezer-based supramolecular system with two potential binding sites (Fig. 1c). Introduction of the PAHs at the more remote para position in this new supramolecular scaffold should prevent cooperativity between the porphyrin core and the $\mathrm{PAH}$ pincers, and therefore provide a means to decouple the effect of porphyrin core in fullerene hosting.

\section{Results and discussion}

The preparation of $\mathbf{2 H}$-PTetraCor requires a porphyrin core that allows the easy introduction of four corannulene units at the para position of the tetraaryl meso-substituted porphyrin. We reasoned that the formation of such novel tetra-substituted systems could be accomplished via a tetra Suzuki reaction. In order to explore the feasibility of this synthetic scheme, we initially explored the formation of an analogous tetrapyrenebased scaffold (2H-PTetraPyr). Pyrene (Pyr) is less synthetically costly than corannulene and therefore offered a good starting point to test and optimize the synthetic route towards this new family of para-tetrasubstituted porphyrins. More importantly, 2H-PTetraPyr itself represents an additional frameworkscaffold for supramolecular studies on fullerene hosting.

A porphyrin with suitable reactive points in the para position is required for the construction of a more complex system via Suzuki reactions. Two alternatives were evaluated, based on the cross-coupling partners chosen for the Suzuki reaction. Route $A$ involves the preparation of $\mathbf{2 H}$-PTetraBpin with 1-bromopyrene as the cross-coupling partner, while Route $\mathrm{B}$ utilises $\mathbf{2} \mathbf{H}$ PTetraBr and 1-pinacol pyreneboronate (Pyr-Bpin) (Scheme 1). The synthesis of both porphyrin precursors was easily achieved by a microwave-assisted method starting from commercially available reagents. $\mathbf{2 H}-\mathbf{P T e t r a B r}$ and $\mathbf{2 H}-\mathbf{P T}$ TetraBpin precipitated out from the reaction mixture and were obtained in $36 \%$ and $18 \%$ yield, respectively. ${ }^{18}$ Initial attempts to introduce four pyrene substituents into the porphyrin framework using both routes A and B led to a mixture of products that was complex to analyse and separate, and included homocoupling by-products and products with less than four Pyr substituents. However, metallation of the porphyrins with $\mathrm{Zn}(\mathrm{OAc})_{2} \cdot 2 \mathrm{H}_{2} \mathrm{O}$ to give $\mathrm{Zn}-\mathrm{PTetraBr}$ and $\mathrm{Zn}$ PTetraBpin (step b in Scheme 1 , which can be easily accomplished in excellent yields, $90 \%$, see experimental part) dramatically improved the introduction of the Pyr groups. In this fashion, the pyrene-tetrasubstituted porphyrin Zn-PTetraPyr was easily accessible in remarkably good yield via route $B(80 \%$; $66 \%$ via route $\mathrm{A}$ ); this compound can be subsequently demetallated in virtually quantitative yield to produce $\mathbf{2 H}$ PTetraPyr, thus providing two pyrene-based scaffolds. 
Route A
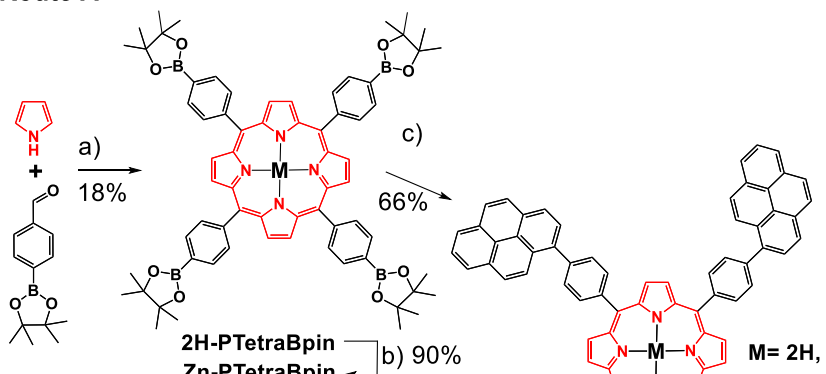
b) $90 \%$

Route B
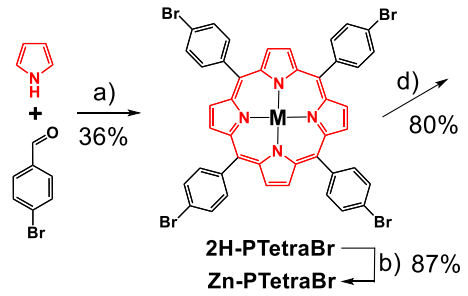

Scheme 1. Overview of the two synthetic routes evaluated for $\mathbf{2 H}$-PTetraPyr and $\mathrm{Zn}$-PTetraPyr. Reagents and conditions: (a) propionic acid, nitrobenzene, $\mathrm{MW}$ $200{ }^{\circ} \mathrm{C}$; (b) $\mathrm{Zn}(\mathrm{OAc})_{2} \cdot 2 \mathrm{H}_{2} \mathrm{O}, \mathrm{CHCl}_{3}, \mathrm{MW}, 120{ }^{\circ} \mathrm{C}$; (c) 1-Bromopyrene, $\left[\mathrm{PdCl}_{2}\right.$ (dppf)],

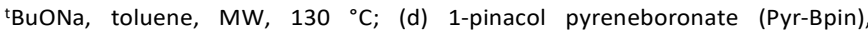
$\left[\mathrm{PdCl}_{2}(\mathrm{dppf})\right]$, tBuONa, toluene, $\mathrm{MW}, 130^{\circ} \mathrm{C}$; (e) $\mathrm{CF}_{3} \mathrm{CO}_{2} \mathrm{H}, \mathrm{CHCl}_{3}, \mathrm{RT}$

Having established and optimized the synthetic route for $\mathbf{2 H}-$ PTetraPyr, we turned our attention to introducing four corannulene units at the para positions of the porphyrin system using a similar microwave-assisted methodology. A method analogous to route B employing Cor-Bpin and $\mathbf{Z n - P T e t r a B r}$ was therefore selected. Zn-PTetraCor was obtained via this quadruple Suzuki reaction in $70 \%$ yield (Scheme 2). Quantitative demetallation furnished $\mathbf{2 H}$-PTetraCor, thus providing an additional supramolecular scaffold. This yield is particularly good within the context of such systems and bearing in mind that four corannulene arms are introduced (cf. with $\mathbf{2 H}$-Octa(II) (Fig. 1b), which was obtained in 15\%). The new tetracorannulene derivatives were characterized using UV-Vis, NMR, and HR-MS. The latter confirmed the formation of these compounds and showed the expected [M] ${ }^{+}$peak at $\mathrm{m} / \mathrm{z}$ 1606.4994 (calcd. 1606.4969) and 1668.4085 (calcd. 1668.4104), respectively, for 2H-PTetraCor and Zn-PTetraCor (see ESI Figure S62 and S64). In both cases, the ${ }^{1} \mathrm{H}$ NMR spectra in $\mathrm{CDCl}_{3}$ showed the equivalence of the four corannulene units and the presence of only one $\beta$-pyrrole proton, as expected for the effective $D_{4 h}$ symmetry in solution. In the case of $\mathbf{2 H}$ PTetraCor, a characteristic upfield-shifted broad signal was observed at $-2.52 \mathrm{ppm}$ for the $\mathrm{NH}$ groups. Remarkably, $\mathbf{2 H}$ PTetraCor and Zn-PTetraCor exhibited sharp signals over a range of concentrations. This is in contrast to $2 \mathrm{H}$-Octa(II), for which extensive broadening was observed due to intramolecular $\pi-\pi$ interactions between pairs of corannulene units (leading to the potential formation of conformers), and thus suggests that these interactions are not present in $\mathbf{2 H}$ PTetraCor and Zn-PTetraCor.
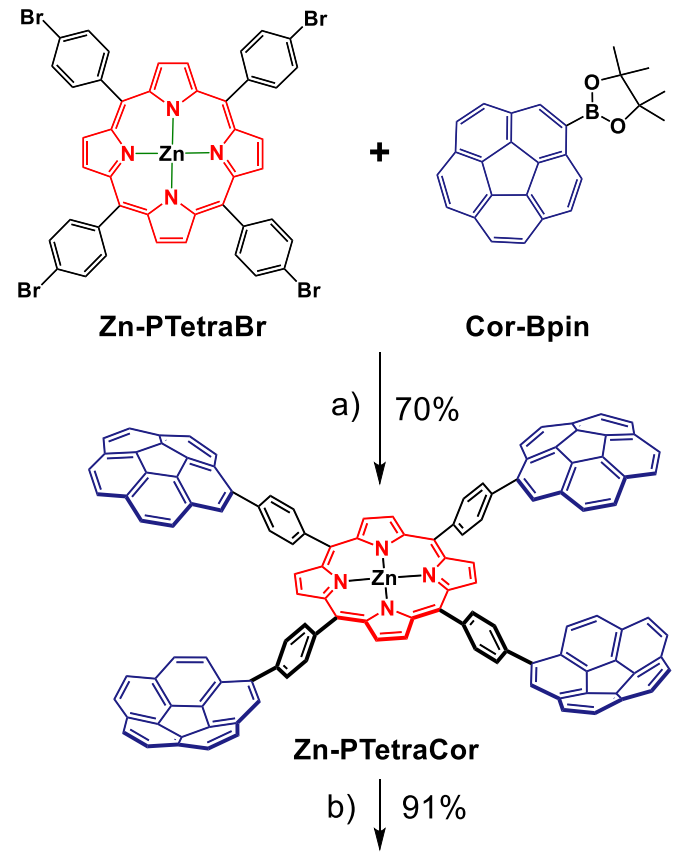

2H-PTetraCor

Scheme 2. Optimized synthetic route for the tetracorannulene porphyrin systems 2H-PTetraCor and Zn-PTetraCor. Reagents and conditions: (a) $\left[\mathrm{PdCl}_{2}\right.$ (dppf)], ${ }^{t} \mathrm{BuONa}$, toluene, $\mathrm{MW}, 130^{\circ} \mathrm{C}$; (b) $\mathrm{CF}_{3} \mathrm{CO}_{2} \mathrm{H}, \mathrm{CHCl}_{3}, \mathrm{RT}$.

2H-PTetraCor was investigated using DFT calculations, and Fig. 2 shows the most stable conformer (see ESI for details). In this structure, the four tetraaryl moieties are approximately perpendicular to the planar porphyrin core, which is consistent with previously reported X-ray structures for similar parasubstituted tetraaryl porphyrin systems. ${ }^{19}$ No $\pi-\pi$ intramolecular interactions between corannulene moieties are observed. This is in contrast to $\mathbf{2 H - O c t a ( I I ) , ~ i n ~ w h i c h ~ t h e ~}$ corannulene units could establish intramolecular interactions that had to be overcome prior to the inclusion of $\mathrm{C}_{60}$ and that were possible due to the bending of the porphyrin core, revealing its relatively flexible nature. ${ }^{17}$ In the case of $\mathbf{2 H}$ PTetraCor, the two corannulene moieties on each side of the porphyrin are preorganized for $\mathrm{C}_{60}$ interaction and adopt an approximately concave-concave conformation with two potential binding sites, as shown in Figure 2. The cleft formed by the two corannulene units is large enough (ca. $16 \AA$ ) to accommodate $\mathrm{C}_{60}$, suggesting that only a minor deformation of the system would be necessary to maximize its interaction with $\mathrm{C}_{60}$ (see later). It is also clear from the optimized structure that as expected, the porphyrin core is now far from the corannulene units, and therefore would not be expected to participate in the recognition process. Our new system is therefore predicted to behave like a "classic molecular tweezer", in which the porphyrin is a simple linker, in contrast to our previous reported meta-substituted "picket fence" systems, in which the active participation of the porphyrin resulted in large binding constants due to its synergetic effect (Fig. 1). 


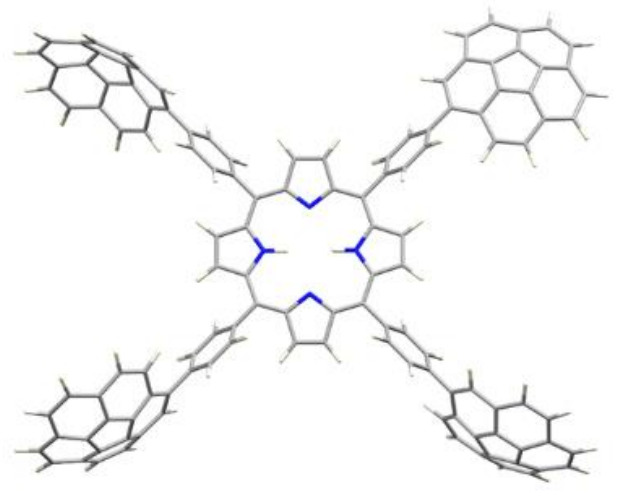

Fig. 2 Optimized structure of compound 2H-PTetraCor. $\alpha$ angles are close to $90^{\circ}$ ( $\alpha=$ $90.85^{\circ}$ ). Note: $\alpha$ is defined as the angle formed by the corannulene-derived meso substituents with the centroid of the porphyrin as the vertex (see later discussion and Figure 4).

In order to test these ideas and evaluate the decoupling of the porphyrin from the binding event, we next moved to study whether the new para-tetrasubstituted porphyrins could serve as supramolecular receptors for fullerenes, as suggested from DFT (Fig. 2). The pyrene-based systems Zn-PTetraPyr and $\mathbf{2 H}$ PTetraPyr did not show any evidence of interaction with $\mathrm{C}_{60}$ or $C_{70}$. Indeed, no change in their ${ }^{1} \mathrm{H} N M R$ chemical shifts was observed in toluene- $d_{8}$ after the addition of an excess of either of the fullerenes (10 equivalents). Although at first glance, this result is not unexpected, since planar PAHs are known to not exhibit supramolecular association with $\mathrm{C}_{60}$ due to their poor shape complementarity, it also suggests that the porphyrin core is not involved in the supramolecular recognition process in these para systems. In fact, in our previous work, meta-pyrenesubstituted porphyrins ${ }^{15-16}$ showed host-guest formation, which was partially attributed to the participation of the porphyrin core, resulting in a cooperative effect with the PAH units.

Moving to the tetracorannulene systems, $\mathbf{Z n - P T e t r a C o r}$ and $\mathbf{2 H}$ PTetraCor exhibited changes in their chemical shifts upon the addition of $\mathrm{C}_{60}$ or $\mathrm{C}_{70}$. This was indicative of supramolecular association with the fullerene, which was now favoured by the presence of corannulene units instead of pyrene, since the corannulene moieties are ideally placed for effective complementary concave-convex $\pi-\pi$ interactions with the $\mathrm{C}_{60}$ surface.

To further explore the supramolecular behaviour of these new molecular receptors, titration experiments were carried out between $\mathbf{Z n - P T e t r a C o r}$ or $\mathbf{2 H}$-PTetraCor and $\mathrm{C}_{60}$ in toluene- $\mathrm{d}_{8}$. In both cases, the addition of aliquots of $\mathrm{C}_{60}$ resulted in a clear change in their ${ }^{1} \mathrm{H}$ NMR chemical shifts, and several signals could be followed during the course of the titration, as shown in Fig. 3. The obtained nonlinear binding isotherms in the titrations of both receptors could be fitted to a 1:1 model (see insets in Fig. 3), yielding binding constants of $K_{1}=2.73 \pm 0.02 \times$ $10^{2}$ and $K_{1}=8.73 \pm 0.05 \times 10^{1}$, respectively, for Zn-PTetraCor and $\mathbf{2 H}$-PTetraCor. ${ }^{20}$ The results of titrations with $\mathrm{C}_{70}$ paralleled those obtained with $C_{60}$, and Table 1 summarizes the estimated binding constants obtained by fitting to a $1: 1$ system (however, the actual binding behaviour of these systems is believed to be more complex; see later discussion and ESI for details). While both Zn-PTetraCor and 2H-PTetraCor exhibited association with $\mathrm{C}_{70}$, the association constants were very similar to those obtained for $\mathrm{C}_{60}$ (i.e., these para-tetraaryl-porphyrins did not show discrimination between $\mathrm{C}_{70}$ or $\mathrm{C}_{60}$ ). Importantly, these constants are substantially smaller than those obtained for our $\mathbf{2 H}$-Tetra(I) or $\mathbf{2 H - O c t a ( I I ) , ~ i n ~ w h i c h ~ t h e ~ p o r p h y r i n ~ c o r e ~ a c t i v e l y ~}$ participated in the recognition process. In particular, they are approximately two orders of magnitude smaller in the case of binding to $\mathrm{C}_{60}$ (cf. $8.73 \pm 0.05 \times 10^{1}$ for $\mathbf{2 H}$-PTetraCor vs $5.4 \pm 0.2$ $\times 10^{3}$ (averaged value from atropisomers) for $2 \mathrm{H}$-tetra(I) and $2.71 \pm 0.08 \times 10^{4}$ for $\mathbf{2 H}$-Octa(II)). ${ }^{15,17}$ The relative difference is even greater for the association of $C_{70}$ (cf. $5.24 \pm 0.02 \times 10^{1}$ for 2H-PTetraCor vs $2.13 \pm 0.10 \times 10^{5}$ for $\mathbf{2 H}$-Octa(II)). ${ }^{17}$

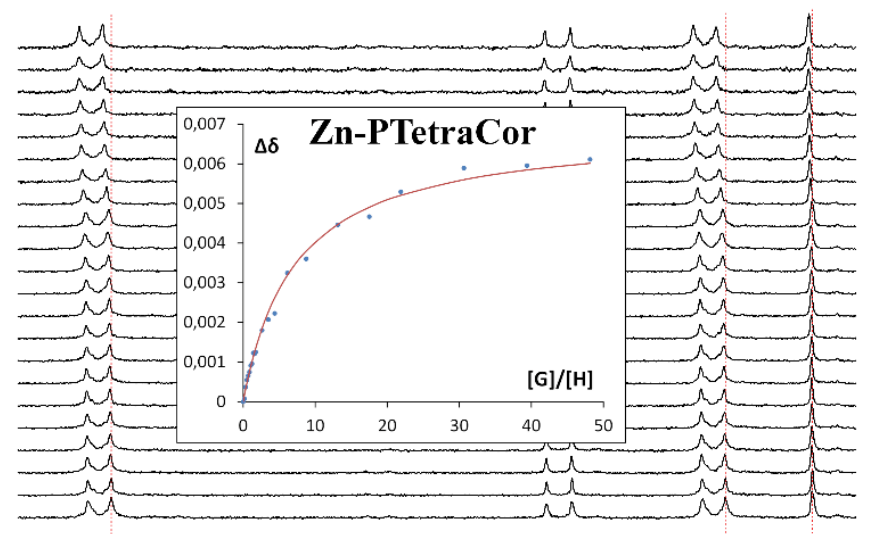

$\begin{array}{llllllllllllll}8.60 & 8.56 & 8.52 & 8.48 & 8.44 & 8.40 & 8.36 & 8.32 & 8.28 & 8.24 & 8.20 & 8.16 & 8.12 & 8.08\end{array}$

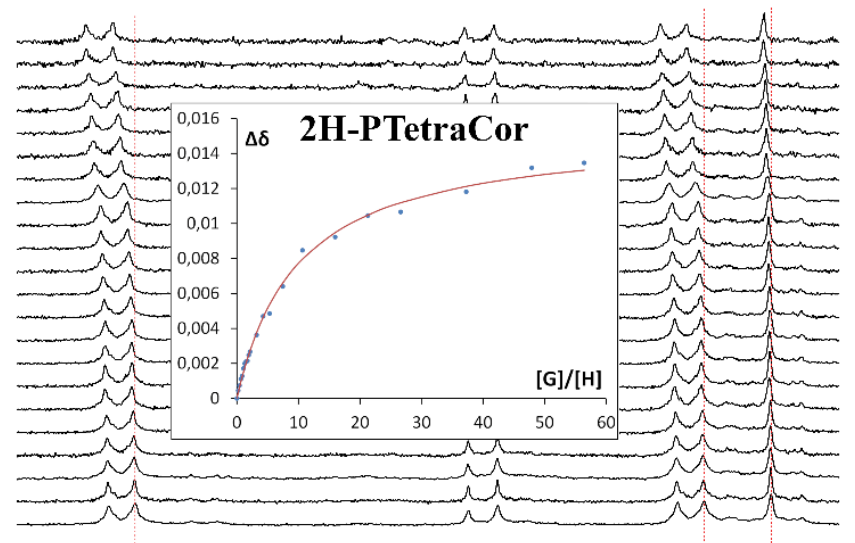

$\begin{array}{llllllllllll}8.46 & 8.42 & 8.38 & 8.34 & 8.30 & 8.26 & 8.22 & 8.18 & 8.14 & 8.10 & 8.06 & 8.02\end{array}$

Fig. $3^{1} \mathrm{H}$ NMR spectra $\left(500 \mathrm{MHz}\right.$, toluene- $\mathrm{d}_{8}$ ) showing the $\mathrm{H}_{6}, \mathrm{H}_{7}$, and $\mathrm{H}_{10}$ chemical shifts (see ESI for labelling scheme) of Zn-PTetraCor (top) and 2H-PTetraCor (bottom) upon the addition of aliquots of $\mathrm{C}_{60}$. Insets: Plots of the changes in chemical shift against $[\mathrm{G}] /[\mathrm{H}]$, where $\mathrm{G}$ (guest) is $\mathrm{C}_{60}$ and $\mathrm{H}$ (host) is Zn-PTetraCor or 2H-PTetraCor. The red line corresponds to the nonlinear fitting of $\Delta \delta$ for $\mathrm{H}_{6}$ to a $1: 1$ binding isotherm. $[\mathrm{H}]=10^{-4} \mathrm{M}$. The titration was carried out by adding known portions of a stock solution of $\mathrm{C}_{60}$ or $\mathrm{C}_{70}\left([\mathrm{G}]=10^{-3} \mathrm{M}\right)$.

Note: The dotted red line over the spectrum is a guide for the eye.

Table 1. Summary of apparent binding constants $\mathrm{K}_{\mathrm{a}}\left(\mathrm{M}^{-1}\right)$ of $\mathbf{2 H}-\mathbf{P T}$ TetraCor and $\mathbf{Z n}$ PTetraCor for different fullerenes obtained by fitting data from NMR titration in toluene- $d_{8}$ at $298 \mathrm{~K}$ to a $1: 1$ model.

\begin{tabular}{ccc}
\hline & $C_{60}$ & $C_{70}$ \\
\hline 2H-PTetraCor & $8.73 \pm 0.05 \times 10^{1}$ & $5.24 \pm 0.02 \times 10^{1}$ \\
\hline Zn-PTetraCor & $2.73 \pm 0.02 \times 10^{2}$ & $2.16 \pm 0.01 \times 10^{2}$ \\
\hline
\end{tabular}


Three main points can be extracted from these studies. a) Although metal coordination is known to greatly affect the conformation of the porphyrin ring, the binding constants for 2H-PTetraCor and Zn-PTetraCor are similar (Table 1), and, more importantly, relatively small compared to those of our previously reported meta-substituted porphyrin systems. These facts suggest that the porphyrin core has little-to-no involvement in the recognition process. b) Connected to this, the lack of discrimination between $C_{70}$ and $C_{60}$ in the present PTetraCor systems could also be traced, at least in part, to the lack of participation of the porphyrin core in the association event. c) Despite the presence of two potential binding sites in these tetracorannulene systems (see Fig. 2), the titration experiments indicate 1:1 association and provide little evidence of 1:2 adducts (i.e., both 2H-PTetraCor and Zn-PTetraCor apparently behave as single-tweezer molecular receptors for fullerenes).

To obtain further insight into the details of the recognition process of these novel para-substituted molecular receptors, we carried out computational DFT studies at the B97D3/6 $31+G(d, p)$ level of theory. ${ }^{21}$ The optimized geometries of $\mathrm{C}_{60} @ 2 \mathrm{H}-\mathrm{PT}$ TetraCor and $\mathrm{C}_{70} @ \mathbf{2 H}$-PTetraCor are depicted in Fig. 4. The average distances between the inner concave surface of the corannulene fragments and outer convex surface of the fullerenes in the computed structures of the adducts $\mathrm{C}_{60} @ \mathbf{2} \mathrm{H}$ PTetraCor and $\mathrm{C}_{70} @ 2 \mathrm{H}-\mathrm{PT}$ TetraCor fell within the usual range for favourable dispersion interactions $(\leq 3.5 \AA)^{22}$. The calculated interaction energies are $43.75 \mathrm{kcal} / \mathrm{mol}$ and $44.25 \mathrm{kcal} / \mathrm{mol}$, respectively (see ESI for details of the calculations). The very small difference between these energies $(0.50 \mathrm{kcal} / \mathrm{mol})$ indicates that $\mathbf{2 H}$-PTetraCor interacts almost identically with both fullerenes, which is in agreement with the experimentally observed lack of selectivity between $\mathrm{C}_{60}$ and $\mathrm{C}_{70}$ (see Table 1 ). In order to form the inclusion complexes, the two corannulene arms of one side of the molecule must reorganize slightly via C$\mathrm{C}$ bond rotation to align with the convex outer surface of the guest, and the fullerene must come into close enough proximity with the host to establish significant attractive interactions in a tweezer-like fashion. A slightly more open tweezer would be expected in the case of $\mathrm{C}_{70}$ to account for its eccentricity (Fig 4c). However, little deformation of the system is required to accommodate either $\mathrm{C}_{60}$ or $\mathrm{C}_{70}$. More specifically, the angle $(\alpha)$ formed by the corannulene-derived meso substituents with the centroid of the porphyrin as the vertex (see Fig. 4 a) is $90.85^{\circ}$ for 2H-PTetraCor. ${ }^{19}$ In order to interact with the fullerene, the two corannulene units move toward one another in a pincer fashion, resulting in a slight decrease in $\alpha\left(76.50^{\circ}\right.$ and $80.41^{\circ}$ for $\mathrm{C}_{60} @ 2 \mathrm{H}-\mathrm{PT}$ TetraCor and $\mathrm{C}_{70} @ 2 \mathrm{H}-\mathrm{PT}$ TetraCor, Fig. 4b and 4c, respectively), whereas the angle $\alpha$ formed by the two corannulene units not engaged in supramolecular binding remains almost unaltered $\left(90.71^{\circ}\right.$ and $90.68^{\circ}$, respectively, for C60@2H-PTetraCor and $\mathrm{C}_{70} @ \mathbf{2 H}-\mathrm{PT}$-traCor). That is, the first binding event (i.e., the small compression of one pincer) is not conformationally transmitted to the second binding site of the molecule. The deformation energy, i.e., the energy required for the host to adapt its conformation for fullerene binding, was very accessible and was estimated to be $5.55 \mathrm{kcal} / \mathrm{mol}$ and 3.78 $\mathrm{kcal} / \mathrm{mol}$ for the $\mathrm{C}_{60} @ 2 \mathrm{H}-\mathrm{PTetraCor}$ and $\mathrm{C}_{70} @ \mathbf{2 H}-\mathrm{PTetraCor}$ assemblies, respectively (see ESI for further information).

a)

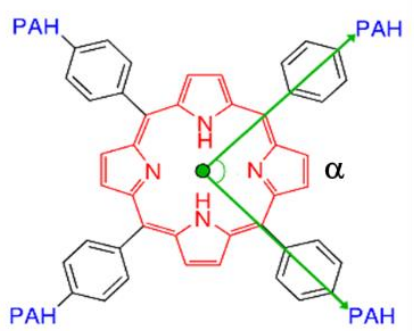

b)

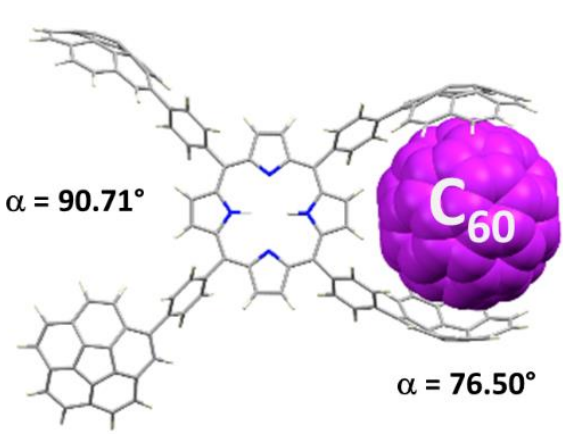

c)

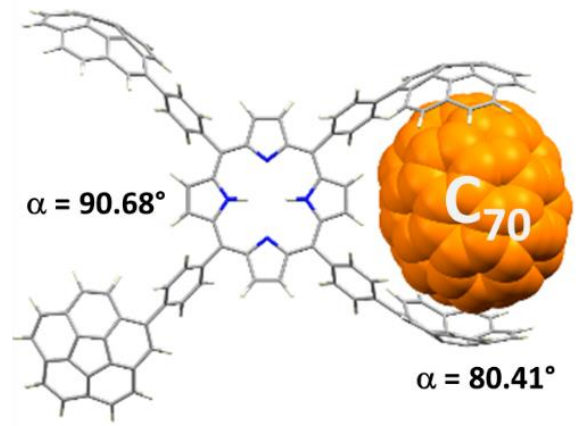

Fig. 4 Depiction of the angle ( $\alpha$ ) between the two meso substituents in the computed structures, where the green dot corresponds to the centroid of the porphyrin core and acts as the vertex (left). Computationally modelled structures of $\mathrm{C}_{60} @ \mathbf{2 H}$-PTetraCor (left) and $\mathrm{C}_{70} @ 2 \mathrm{H}-\mathrm{PT}$ TetraCor (right). Fullerenes are represented in spacefill style and colorized in purple and orange for $C_{60}$ and $C_{70}$, respectively.

We also studied the effect of the interaction with a second fullerene and optimized the adducts $\left(\mathrm{C}_{60}\right)_{2} @ 2 \mathrm{H}-\mathrm{PT}$ TetraCor and $\left(\mathrm{C}_{70}\right)_{2} @ \mathbf{2 H}$-PTetraCor, which were not observed experimentally, in order to estimate the deformation energies for the second binding event (see ESI for details). The calculated values of $9.04 \mathrm{kcal} / \mathrm{mol}$ and $7.41 \mathrm{kcal} / \mathrm{mol}$ are only slightly larger than those estimated for the association of one $\mathrm{C}_{60}$ or one $\mathrm{C}_{70}$, respectively. In other words, the association of the first fullerene does not substantially affect the second binding site, and they can be considered as two approximately independent binding sites. The small increase in deformation energy for the second event, along with the very modest binding constants (see Table 1 for $K_{1}$, and note that on purely statistical grounds, $\mathrm{K}_{2}$ would be 4 times lower than $\mathrm{K}_{1}$ for two completely independent sites) could help to rationalize the observed "apparent" 1:1 binding association by NMR titrations despite 
the fact that the two binding sites act approximately independently (i.e., not in an inhibitory fashion). ${ }^{23}$

Along with the previous discussion, DFT calculations revealed the effects of the lack of participation of the porphyrin core in the binding to fullerene. Decoupling the influence of the porphyrin tether from the molecular pincer formed by the corannulenes has profound implications for the current paratetrasubstituted porphyrin system. 1) The porphyrin core now acts merely as a linker and is not involved in the recognition process, resulting in lower binding energy and the loss of cooperativity between the porphyrin and the polyaromatic fragment. This is reflected in the comparatively lower binding constants observed experimentally. 2) A secondary effect connected to this is that the porphyrin does not transmit the information of the first binding event to the second binding site, and the system can be considered to consist of two independent pincers. This is in contrast to the large inhibitory effect observed for $\mathbf{2} \mathrm{H}$-Octa(II), in which the active participation of the porphyrin in $\mathrm{C}_{60}$ or $\mathrm{C}_{70}$ binding, although beneficial for attaining high affinities towards $\mathrm{C}_{60}$ and $\mathrm{C}_{70}$, strongly inhibited the binding of a second fullerene. In the $\mathbf{2 H}$-Octa(II) system, the involvement of the porphyrin resulted in the compression of one face of the porphyrin concomitant with the expansion of the second binding site (Fig. 1b). Finally, the lack of discrimination between $\mathrm{C}_{60}$ and $\mathrm{C}_{70}$ in the present systems most likely stems, at least in part, from the lack of participation of the porphyrin core in the binding, thus revealing more subtle implications than would be anticipated for the simple decoupling of the porphyrin from the binding event.

\section{Conclusions}

By using a synthetic strategy based on a quadruple Suzuki-Miyaura reaction, we were able to access mesotetraaryl substituted porphyrins in which four pyrene or corannulene fragments were installed relatively distant from the porphyrin core in the para positions. Both NMR titration experiments and density functional theory (DFT) calculations indicate that the porphyrin core is not involved in the binding event. While the tetrapyrene-porphyrin-based systems do not host fullerenes (either $\mathrm{C}_{60}$ or $\mathrm{C}_{70}$ ), the corannulene-based ones $\mathbf{2 H}$-PTetraCor and Zn-PTetraCor can act as "classical molecular tweezers" with two approximately independent pincers, as supported by DFT studies. The fact that this system exhibits apparent $1: 1$ association is attributed mainly to the very low binding constants rather than a strong inhibitory effect, in contrast to our previously reported meta-substituted "picket fence" system. Therefore, although detrimental in terms of fullerene binding ability, this "decoupling" of the porphyrin core can also present benefits, such as the prevention of large structural changes that inhibit the potential second binding event. These findings highlight the important role of the tether in the construction of complex supramolecular systems, along with the interplay of different binding events in the fullerene recognition process. We hope these results will lead to a better understanding of the complexity in porphyrin-based supramolecular systems and help to pave the way for the rational design of new and functional complex supramolecular platforms.

\section{Experimental}

General Methods: All reagents were purchased from commercial sources and used without further purification. Solvents were either used as received or dried according to procedures described elsewhere. ${ }^{24}$ Microwave reactions were carried out using an Anton Paar Monowave 300 Reactor. Column chromatography was carried out using silica gel 60 (particle size $0.040-0.063 \mathrm{~mm} ; 230-400$ mesh) as the stationary phase, and TLC was performed on precoated silica gel plates (0.25 mm thick, $60 \mathrm{~F} 254)$ and visualized under UV light and/or by immersion in anisaldehyde. NMR spectra were recorded on a $400 \mathrm{MHz}$ MR Agilent or $500 \mathrm{MHz}$ Agilent DD2 instrument equipped with a OneNMR probe. NMR titrations were recorded on $500 \mathrm{MHz}$ Agilent DD2 instruments equipped with a coldprobe in the Laboratory of Instrumental Techniques (LTI) Research Facilities, University of Valladolid. ${ }^{1} \mathrm{H}$ and ${ }^{13} \mathrm{C}$ NMR chemical shifts $(\delta)$ are reported in parts per million (ppm) and are referenced to tetramethylsilane (TMS) using the solvent residual peak as an internal reference. Coupling constants $(J)$ are reported in $\mathrm{Hz}$. Standard abbreviations are used to indicate multiplicity: $\mathrm{br}=$ broad, $\mathrm{s}=$ singlet, $\mathrm{d}=$ doublet, $\mathrm{t}=$ triplet, $\mathrm{m}=$ multiplet. ${ }^{1} \mathrm{H}$ and ${ }^{13} \mathrm{C}$ peak assignments were performed using 2D NMR methods $\left({ }^{1} \mathrm{H}-{ }^{1} \mathrm{H}\right.$ COSY, ${ }^{1} \mathrm{H}-{ }^{1} \mathrm{H}$ DQFCOSY, band-selective ${ }^{1} \mathrm{H}-{ }^{1} \mathrm{H}$-ROESY, band-selective ${ }^{1} \mathrm{H}-{ }^{13} \mathrm{C} \mathrm{HSQC}$, band selective ${ }^{1} \mathrm{H}-{ }^{13} \mathrm{C}$ $\mathrm{HMBC}$ ). Due to low solubility, some carbon signals were detected indirectly via ${ }^{1} \mathrm{H}-{ }^{13} \mathrm{C}-\mathrm{HSQC} / \mathrm{HMBC}$ experiments; in these cases, the abbreviation in is used. High-resolution mass spectra were recorded at the mass spectrometry service of the Laboratory of Instrumental Techniques of the University of Valladolid using a Bruker Autoflex Speed MALDI-TOF system $\left(\mathrm{N}_{2}\right.$ laser: $337 \mathrm{~nm}$, pulse energy $100 \mu \mathrm{J}, 1 \mathrm{~ns}$; acceleration voltage: $19 \mathrm{kV}$, reflector positive mode). Trans-2-[3-(4-tert-butylphenyl)2-methyl-2-propenylidene]malonitrile (DCTB), 1,8,9-anthracenetriol, and 1,8-dihydroxy-9(10H)-anthracenone (dithranol) were used as matrixes. UV/Vis spectra were recorded using a Shimadzu UV-1603 with spectrophotometric grade solvents. UV/vis absorption spectral wavelengths $(\lambda)$ are reported in nanometers $(\mathrm{nm})$, and molar absorption coefficients $(\varepsilon)$ are reported in $\mathrm{M}^{-1} \mathrm{~cm}^{-1}$. Corannulene, 1-pinacol corannuleneboronate (Cor-Bpin) and 1-pinacol pyreneboronate (Pyr-Bpin) were obtained following literature procedures. ${ }^{16-17,25}$

2H-PTetraBr: Pyrrole ( $278 \mu \mathrm{L}, 4 \mathrm{mmol}), \mathrm{p}$-bromobenzaldehyde (740 mg, $4 \mathrm{mmol}$ ), propionic acid (13 $\mathrm{mL}, 173 \mathrm{mmol}$ ), and nitrobenzene $(7 \mathrm{~mL}, 68 \mathrm{mmol})$ were mixed in a sealed vessel specifically designed for microwave irradiation. The mixture was stirred inside a microwave reactor at $200{ }^{\circ} \mathrm{C}$ for $15 \mathrm{~min}$. The resulting dark crude was stored in a refrigerator for two days, and then filtered using a Büchner funnel and washed with $\mathrm{MeOH}$. The obtained solid was placed in an oven under reduced pressure $\left(190{ }^{\circ} \mathrm{C}, 2 \mathrm{~h}, 50 \mathrm{mbar}\right)$ to remove residual nitrobenzene. Finally, the dark purple solid $\mathbf{2 H}-\mathbf{P T e t r a B r}$ was obtained (339 mg, 36\% yield). The spectroscopic data agreed with those reported in the literature. ${ }^{18 \mathrm{~b}}{ }^{1} \mathrm{H}$ NMR $(500 \mathrm{MHz}$, chloroform- $d$ ): $\delta 8.84\left(\mathrm{~s}, 8 \mathrm{H}, \mathrm{H}_{2}\right), 8.07\left(\mathrm{~d}, J=8.3 \mathrm{~Hz}, 8 \mathrm{H}, \mathrm{H}_{6}\right), 7.91$ $\left(\mathrm{d}, J=8.3 \mathrm{~Hz}, 8 \mathrm{H}, \mathrm{H}_{7}\right),-2.87\left(\mathrm{br}, 2 \mathrm{H}, \mathrm{H}_{1}\right) .{ }^{13} \mathrm{C}\left\{{ }^{1} \mathrm{H}\right\} \mathrm{NMR}(101 \mathrm{MHz}$, chloroform-d): $\delta 140.79\left(C_{5}\right), 135.78\left(C_{6}\right), 131.14\left(C_{2}\right), 129.95$ $\left(C_{7}\right), 122.61\left(C_{8}\right), 118.95\left(C_{4}\right)$. HR-MS (MALDI-TOF): $\mathrm{m} / \mathrm{z}$ for $\mathrm{C}_{44} \mathrm{H}_{26} \mathrm{Br}_{4} \mathrm{~N}_{4}$ [M] $^{+}$calcd: 929.8883, found: 929.8851 (3.2 ppm 
error). UV/vis (toluene): $\lambda 401(\varepsilon=76900), 421(\varepsilon=384900), 515$ $(\varepsilon=20100), 550(\varepsilon=9300), 592(\varepsilon=6300), 648(\varepsilon=4200)$.

Zn-PTetraBr: 2H-PTetraBr (114 mg, $0.12 \mathrm{mmol})$ and $\mathrm{Zn}(\mathrm{AcO})_{2}$ $2 \mathrm{H}_{2} \mathrm{O}$ (39 $\mathrm{mg}, 0.18 \mathrm{mmol}$ ) were mixed in a sealed vessel specifically designed for microwave irradiation, and $5.5 \mathrm{~mL}$ of $\mathrm{CHCl}_{3}$ was added. The mixture was stirred inside the microwave reactor at $120{ }^{\circ} \mathrm{C}$ for $150 \mathrm{~min}$. Subsequently, the crude was dissolved in $40 \mathrm{~mL}$ of $\mathrm{CHCl}_{3}$, placed in a separatory funnel, and washed with $20 \mathrm{~mL}$ of $\mathrm{H}_{2} \mathrm{O}$. The organic layer was removed under low pressure to give the purple solid Zn-PTetraBr (105 $\mathrm{mg}, 87 \%$ yield). The spectroscopic data agreed with those reported in the literature. ${ }^{18 \mathrm{~b}}{ }^{1} \mathrm{H} \mathrm{NMR}(500 \mathrm{MHz}$, chloroform- $d$ ): $\delta 8.94\left(\mathrm{~s}, 8 \mathrm{H}, \mathrm{H}_{2}\right), 8.07\left(\mathrm{~d}, J=8.3 \mathrm{~Hz}, 8 \mathrm{H}, \mathrm{H}_{6}\right), 7.90(\mathrm{~d}, J=8.3 \mathrm{~Hz}$ $\left.8 \mathrm{H}, \mathrm{H}_{7}\right) \cdot{ }^{13} \mathrm{C}\left\{{ }^{1} \mathrm{H}\right\}$ NMR (101 MHz, chloroform-d): $\delta 149.99\left(\mathrm{C}_{3}\right)$, $141.43\left(C_{5}\right), 135.66\left(C_{6}\right), 132.04\left(C_{2}\right), 129.80\left(C_{7}\right), 122.35\left(C_{8}\right)$, $119.93\left(\mathrm{C}_{4}\right)$. HR-MS (MALDI-TOF): $\mathrm{m} / \mathrm{z}$ for $\mathrm{C}_{44} \mathrm{H}_{24} \mathrm{Br}_{4} \mathrm{~N}_{4} \mathrm{Zn}[\mathrm{M}]^{+}$ calcd: 993.7964, found: 993.7985 (2.1 ppm error). UV/vis (toluene): $\lambda 401(\varepsilon=32500), 426(\varepsilon=162600), 551(\varepsilon=21500)$, $591(\varepsilon=5300)$.

2H-PTetraBpin: Pyrrole (173 $\mu \mathrm{L}, \quad 2.5 \quad \mathrm{mmol})$, 4formylphenylboronic acid-pinacol ester (580 mg, $2.5 \mathrm{mmol}$ ), propionic acid $(7 \mathrm{~mL}, 93 \mathrm{mmol})$, and nitrobenzene $(13 \mathrm{~mL}, 126$ $\mathrm{mmol}$ ) were mixed in a sealed vessel specifically designed for microwave irradiation. The mixture was stirred inside a microwave reactor at $200{ }^{\circ} \mathrm{C}$ for $15 \mathrm{~min}$. The dark crude was stored in a refrigerator for two days, and then filtered using a Büchner funnel and washed with hexane. The obtained solid was placed in an oven under reduced pressure $\left(180^{\circ} \mathrm{C}, 2 \mathrm{~h}, 50\right.$ mbar) to remove residual nitrobenzene. Finally, the dark purple solid 2H-PTetraBpin was obtained (127 mg, 18\% yield). The spectroscopic data agreed with those reported in the literature. ${ }^{18 \mathrm{a}}{ }^{1} \mathrm{H}$ NMR $(500 \mathrm{MHz}$, chloroform-d): $\delta 8.82(\mathrm{~s}, 8 \mathrm{H}$, $\left.\mathrm{H}_{2}\right), 8.22\left(\mathrm{~d}, J=8.0 \mathrm{~Hz}, 8 \mathrm{H}, \mathrm{H}_{6}\right), 8.18\left(\mathrm{~d}, J=8.0 \mathrm{~Hz}, 8 \mathrm{H}, \mathrm{H}_{7}\right), 1.50$ $\left(\mathrm{s}, 48 \mathrm{H}, \mathrm{H}_{10}\right),-2.81\left(\mathrm{br}, 2 \mathrm{H}, \mathrm{H}_{1}\right) .{ }^{13} \mathrm{C}\left\{{ }^{1} \mathrm{H}\right\}$ NMR $(101 \mathrm{MHz}$, chloroform- $d$ ): $\delta 145.03\left(C_{5}\right), 134.03\left(C_{6}\right), 132.97\left(C_{7}\right), 131.06$ $\left(C_{2}\right), 127.96\left(C_{8}\right), 120.06\left(C_{4}\right), 84.07\left(C_{9}\right), 25.03\left(C_{10}\right)$. HR-MS (MALDI-TOF): $\mathrm{m} / \mathrm{z}$ for $\mathrm{C}_{68} \mathrm{H}_{74} \mathrm{~B}_{4} \mathrm{~N}_{4} \mathrm{O}_{8}[\mathrm{M}]^{+}$calcd: 1118.5921 found: 1118.5958 (3.7 ppm error). UV/vis (toluene): $\lambda 401$ ( $\varepsilon=$ 74000), $422(\varepsilon=426600), 516(\varepsilon=20700), 551(\varepsilon=9600), 592$ $(\varepsilon=5500), 648(\varepsilon=3800)$

Zn-PTetraBpin: 2H-PTetraBpin (35 $\mathrm{mg}, 0.031 \mathrm{mmol}$ ) and $\mathrm{Zn}(\mathrm{AcO})_{2} 2 \mathrm{H}_{2} \mathrm{O}(55 \mathrm{mg}, 0.25 \mathrm{mmol})$ were mixed in a sealed vessel specifically designed for microwave irradiation, and $2 \mathrm{~mL}$ of $\mathrm{CHCl}_{3}$ was added. The mixture was stirred inside the microwave reactor at $137{ }^{\circ} \mathrm{C}$ for $55 \mathrm{~min}$. Subsequently, the crude was dissolved in $12 \mathrm{~mL}$ of $\mathrm{CHCl}_{3}$, placed in a separatory funnel, and washed with $10 \mathrm{~mL}$ of $\mathrm{H}_{2} \mathrm{O}$. The organic layer was removed under low pressure to give the purple solid $\mathbf{Z n}$ PTetraBpin ( $33 \mathrm{mg}, 90 \%$ yield). ${ }^{1} \mathrm{H}$ NMR ( $500 \mathrm{MHz}$, chloroformd): $\delta 8.92\left(\mathrm{~s}, 8 \mathrm{H}, \mathrm{H}_{2}\right), 8.23\left(\mathrm{~d}, J=8.0 \mathrm{~Hz}, 8 \mathrm{H}, \mathrm{H}_{6}\right), 8.19(\mathrm{~d}, J=8.0$ $\left.\mathrm{Hz}, 8 \mathrm{H}, \mathrm{H}_{7}\right), 1.50\left(\mathrm{~s}, 48 \mathrm{H}, \mathrm{H}_{10}\right) .{ }^{13} \mathrm{C}\left\{{ }^{1} \mathrm{H}\right\}$ NMR $(101 \mathrm{MHz}$, chloroform-d): $\delta 149.95\left(C_{3}\right), 145.68\left(C_{5}\right), 133.93\left(C_{6}\right), 132.86$ $\left(C_{7}\right), 131.98\left(C_{2}\right), 127.74\left(C_{8}-i n\right), 121.07\left(C_{4}\right), 84.05\left(C_{9}\right), 25.03$ $\left(\mathrm{C}_{10}\right)$. HR-MS (MALDI-TOF): $\mathrm{m} / \mathrm{z}$ for $\mathrm{C}_{68} \mathrm{H}_{72} \mathrm{~B}_{4} \mathrm{~N}_{4} \mathrm{O}_{8} \mathrm{Zn}[\mathrm{M}]^{+}$calcd: 1180.5058, found: 1180.5036 (-2.2 ppm error). UV/vis (toluene): $\lambda 401(\varepsilon=29800), 425(\varepsilon=399100), 551(\varepsilon=17400)$, $591(\varepsilon=4300)$.

Zn-PTetraPyr: Zn-PTetraBr (13 mg, $0.013 \mathrm{mmol}), 1$-pinacol pyreneboronate (Pyr-Bpin) (19 mg, $0.058 \mathrm{mmol}$ ), $\left[\mathrm{PdCl}_{2}\right.$ (dppf)] (7.6 $\mathrm{mg}, 0.010 \mathrm{mmol}$ ), and ${ }^{t} \mathrm{BuONa}(15 \mathrm{mg}, 0.15 \mathrm{mmol})$ were placed in a sealed vessel specifically designed for microwave irradiation, which was placed inside a two-necked round- bottom flask in order to keep the system under an inert atmosphere. $1.4 \mathrm{~mL}$ of dry toluene and $36 \mu \mathrm{L}$ of pyridine were added. The mixture was stirred inside the microwave reactor at $130^{\circ} \mathrm{C}$ for $60 \mathrm{~min}$. After cooling, the solvent was removed under vacuum, and the crude was purified by column chromatography on silica gel using hexane/AcOEt gradient elution (3:1-2:1-1:1) and $\mathrm{CHCl}_{3}$ to finally give $\mathbf{Z n - P T e t r a P y r}$ as a purple solid $(15 \mathrm{mg}$, $80 \%$ yield). ${ }^{1} \mathrm{H}$ NMR (500 MHz, chloroform- $d$ ): $\delta 9.33\left(\mathrm{~s}, 8 \mathrm{H}, \mathrm{H}_{2}\right)$, $8.70\left(\mathrm{~d}, J=9.2 \mathrm{~Hz}, 4 \mathrm{H}, \mathrm{H}_{10}\right), 8.54\left(\mathrm{~d}, J=7.7 \mathrm{~Hz}, 8 \mathrm{H}, \mathrm{H}_{6}\right), 8.44(\mathrm{~d}, J$ $\left.=7.7 \mathrm{~Hz}, 4 \mathrm{H}, \mathrm{H}_{17}\right), 8.42\left(\mathrm{~d}, J=7.7 \mathrm{~Hz}, 4 \mathrm{H}, \mathrm{H}_{18}\right), 8.318 .26(\mathrm{~m}, 12 \mathrm{H}$, $\left.\mathrm{H}_{11}+\mathrm{H}_{12}+\mathrm{H}_{14}\right), 8.24\left(\mathrm{~d}, J=8.9 \mathrm{~Hz}, 4 \mathrm{H}, \mathrm{H}_{16}\right), 8.20(\mathrm{~d}, J=8.9 \mathrm{~Hz}$, $\left.4 \mathrm{H}, \mathrm{H}_{15}\right), 8.14-8.08\left(\mathrm{~m}, 12 \mathrm{H}, \mathrm{H}_{7}+\mathrm{H}_{13}\right) .{ }^{13} \mathrm{C}\left\{{ }^{1} \mathrm{H}\right\} \mathrm{NMR}(126 \mathrm{MHz}$, chloroform-d): $\delta 150.36\left(C_{3}\right), 142.12\left(C_{5}\right), 140.22\left(C_{8}\right), 137.61$ $\left(C_{9}\right), 134.70\left(C_{6}\right), 132.19\left(C_{2}\right), 131.56\left(C_{21}\right), 131.43\left(C_{q}\right), 131.08$ $\left(C_{20}\right), 130.79\left(C_{22}\right), 128.76\left(C_{7}\right), 128.05\left(C_{19}\right), 127.98\left(C_{18}\right), 127.75$ $\left(C_{11}\right), 127.52\left(C_{15}+C_{16}\right), 126.07\left(C_{13}\right), 125.46\left(C_{10}\right), 125.20\left(C_{12}\right.$ or $\left.C_{14}\right), 125.03\left(C_{23}\right), 124.93\left(C_{12}\right.$ or $\left.C_{14}\right), 124.88\left(C_{17}\right), 120.90\left(C_{4}\right)$. HR-MS (MALDI-TOF): $\mathrm{m} / \mathrm{z}$ for $\mathrm{C}_{108} \mathrm{H}_{60} \mathrm{~N}_{4} \mathrm{Zn}$ [M] ${ }^{+}$calcd: 1476.4115, found: 1476.4116 (0.1 ppm error). UV/vis (toluene): $\lambda 345(\varepsilon=72400), 404(\varepsilon=28100), 430(\varepsilon=379300), 552(\varepsilon=$ $17600), 592(\varepsilon=6400)$.

2H-PTetraPyr: Zn-PTetraPyr (12 $\mathrm{mg}, 0.0081 \mathrm{mmol})$ was dissolved in $1.5 \mathrm{~mL}$ of $\mathrm{CHCl}_{3}$, and $1 \mathrm{~mL}$ of $\mathrm{CF}_{3} \mathrm{COOH}$ was then added. The initial deep red solution turned green after the addition of the acid. The mixture was stirred at room temperature for $4 \mathrm{~h}$. Subsequently, it was diluted with $10 \mathrm{~mL}$ of $\mathrm{CHCl}_{3}$, and a saturated solution of $\mathrm{Na}_{2} \mathrm{CO}_{3}$ in water was added portion-wise with vigorous stirring until the evolution of gas ceased and the organic layer had become deep red again. This layer was separated from the aqueous phase and washed three times with water $(10 \mathrm{~mL})$. The organic layer was removed under low pressure to give the purple solid 2H-PTetraPyr (11 mg, 96\% yield). ${ }^{1} \mathrm{H}$ NMR (500 MHz, chloroform-d): $\delta 9.23\left(\mathrm{~s}, 8 \mathrm{H}, \mathrm{H}_{2}\right), 8.68$ $\left(\mathrm{d}, J=9.2 \mathrm{~Hz}, 4 \mathrm{H}, \mathrm{H}_{10}\right), 8.54\left(\mathrm{~d}, J=7.7 \mathrm{~Hz}, 8 \mathrm{H}, \mathrm{H}_{6}\right), 8.44(\mathrm{~d}, J=7.7$ $\left.\mathrm{Hz}, 4 \mathrm{H}, \mathrm{H}_{17}\right), 8.41\left(\mathrm{~d}, J=7.7 \mathrm{~Hz}, 4 \mathrm{H}, \mathrm{H}_{18}\right), 8.32-8.25\left(\mathrm{~m}, 12 \mathrm{H}, \mathrm{H}_{11}\right.$ $\left.+\mathrm{H}_{12}+\mathrm{H}_{14}\right), 8.24\left(\mathrm{~d}, J=8.8 \mathrm{~Hz}, 4 \mathrm{H}, \mathrm{H}_{16}\right), 8.20(\mathrm{~d}, J=8.8 \mathrm{~Hz}, 4 \mathrm{H}$, $\left.\mathrm{H}_{15}\right), 8.15-8.08\left(\mathrm{~m}, 12 \mathrm{H}, \mathrm{H}_{7}+\mathrm{H}_{13}\right),-2.48\left(\mathrm{br}, 2 \mathrm{H}, \mathrm{H}_{1}\right) .{ }^{13} \mathrm{C}\left\{{ }^{1} \mathrm{H}\right\}$ NMR $\left(126 \mathrm{MHz}\right.$, chloroform-d): $\delta 141.18\left(\mathrm{C}_{5}\right), 140.66\left(\mathrm{C}_{8}\right)$, $137.44\left(C_{9}\right), 134.84\left(C_{6}\right), 131.59\left(C_{21}\right), 131.32\left(C_{q}\right), 131.11\left(C_{20}\right)$, $130.88\left(C_{22}\right), 129.03\left(C_{7}\right), 128.76\left(C_{19}\right), 127.96\left(C_{18}\right), 127.83\left(C_{11}\right)$, $127.63\left(C_{15}\right), 127.53\left(C_{16}\right), 126.13\left(C_{13}\right), 125.40\left(C_{10}\right), 125.29\left(C_{12}\right.$ or $\left.C_{14}\right), 125.23\left(C_{23}\right), 125.05\left(C_{24}\right), 125.01\left(C_{12}\right.$ or $\left.C_{14}\right), 124.91$ $\left(\mathrm{C}_{17}\right), 120.15\left(\mathrm{C}_{4}\right)$. HR-MS (MALDI-TOF): $\mathrm{m} / \mathrm{z}$ for $\mathrm{C}_{108} \mathrm{H}_{62} \mathrm{~N}_{4}[\mathrm{M}]^{+}$ calcd: 1414.4980 , found: 1414.5022 (4.2 ppm error). UV/vis (toluene): $\lambda 349(\varepsilon=16900), 411(\varepsilon=16000), 426(\varepsilon=53100)$, $518(\varepsilon=8600), 552(\varepsilon=8000), 595(\varepsilon=7000), 656(\varepsilon=6500)$.

Zn-PTetraCor: Zn-PTetraBr (9 mg, $0.0090 \mathrm{mmol})$, 1-pinacol corannuleneboronate (Cor-Bpin) (17 mg, $0.045 \mathrm{mmol}$ ), $\left[\mathrm{PdCl}_{2}(\mathrm{dppf})\right](5.8 \mathrm{mg}, 0.0079 \mathrm{mmol})$, and ${ }^{\mathrm{t}} \mathrm{BuONa}(11 \mathrm{mg}, 0.11$ $\mathrm{mmol}$ ) were mixed in a sealed vessel specifically designed for microwave irradiation, which was placed inside a two-necked round-bottom flask in order to keep the system under an inert atmosphere. $1.4 \mathrm{~mL}$ of dry toluene and $36 \mu \mathrm{L}$ of pyridine were added. The mixture was stirred inside the microwave reactor at $130^{\circ} \mathrm{C}$ for $60 \mathrm{~min}$. After cooling, the solvent was removed under vacuum and the crude was purified by column chromatography on silica gel using hexane/AcOEt gradient elution (3:1-2:1-1:1) and $\mathrm{CHCl}_{3}$ to finally give the purple solid $\mathbf{Z n}$-PTetraCor (10 mg, $70 \%$ yield). ${ }^{1} \mathrm{H}$ NMR (500 MHz, chloroform-d): $\delta 9.26\left(\mathrm{~s}, 8 \mathrm{H}, \mathrm{H}_{2}\right)$, $8.50\left(\mathrm{~d}, J=8.0 \mathrm{~Hz}, 8 \mathrm{H}, \mathrm{H}_{6}\right), 8.29\left(\mathrm{~s}, 4 \mathrm{H}, \mathrm{H}_{10}\right), 8.26(\mathrm{~d}, J=8.9 \mathrm{~Hz}$, $\left.4 \mathrm{H}, \mathrm{H}_{18}\right), 8.25\left(\mathrm{~d}, J=8.0 \mathrm{~Hz}, 8 \mathrm{H}, \mathrm{H}_{7}\right), 8.01\left(\mathrm{~d}, J=8.6 \mathrm{~Hz}, 4 \mathrm{H}, \mathrm{H}_{11}\right)$, $7.98\left(\mathrm{~d}, J=8.9 \mathrm{~Hz}, 4 \mathrm{H}, \mathrm{H}_{17}\right), 7.95\left(\mathrm{~d}, J=8.6 \mathrm{~Hz}, 4 \mathrm{H}, \mathrm{H}_{12}\right), 7.93-$ 
$7.88\left(\mathrm{~m}, 16 \mathrm{H}, \mathrm{H}_{13}+\mathrm{H}_{14}+\mathrm{H}_{15}+\mathrm{H}_{16}\right) \cdot{ }^{13} \mathrm{C}\left\{{ }^{1} \mathrm{H}\right\} \mathrm{NMR}(126 \mathrm{MHz}$, chloroform-d) $\delta: 150.35\left(C_{3}\right), 142.20\left(C_{q}-i n\right), 141.51\left(C_{5}-i n\right)$, $138.92\left(C_{8}-i n\right), 136.47\left(C_{q}\right), 136.31\left(C_{q}\right), 136.00\left(C_{q}\right), 135.50\left(C_{26}\right)$, $134.99\left(C_{6}\right), 132.27\left(C_{2}\right), 130.97\left(C_{q}\right), 129.83\left(C_{19}-i n\right), 128.20\left(C_{7}\right)$, $127.63\left(C_{17}\right), 127.43\left(C_{12}\right), 127.36\left(C_{x}\right), 127.18\left(C_{x}+C_{18}\right), 127.09$ $\left(C_{x}+C_{11}\right), 127.06\left(C_{x}\right), 126.27\left(C_{10}\right)$. Being $C_{x}=C_{13}$ or $C_{14}$ or $C_{15}$ or

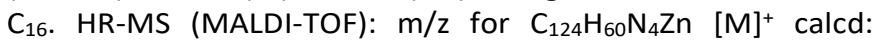
1668.4104, found: 1668.4085 (-1.9 ppm error). UV/vis (toluene): $\lambda 404(\varepsilon=13400), 430(\varepsilon=89300), 553(\varepsilon=9800), 591$ $(\varepsilon=7700)$.

Note: Zn-PTetraCor could also be prepared, albeit in lower yield (56\%), using Zn-PTetraBpin and Cor-Br as the coupling partners (i.e., by a synthetic route similar to route $A$ in Scheme 1 ).

2H-PTetraCor: $\mathrm{Zn}$-PTetraCor ( $8 \mathrm{mg}, 0.0048 \mathrm{mmol}$ ) was dissolved in $2.0 \mathrm{~mL}$ of $\mathrm{CHCl}_{3}$, and $1 \mathrm{~mL}$ of $\mathrm{CF}_{3} \mathrm{COOH}$ was then added. The initial deep red solution turned green after the addition of the acid. The mixture was stirred at room temperature for $4 \mathrm{~h}$. Subsequently, it was diluted with $10 \mathrm{~mL}$ of $\mathrm{CHCl}_{3}$, and a saturated solution of $\mathrm{Na}_{2} \mathrm{CO}_{3}$ in water was added portion-wise with vigorous stirring until the evolution of gas ceased and the organic layer had become deep red again. This layer was separated from the aqueous phase and washed three times with water $(10 \mathrm{~mL})$. The organic layer was removed under low pressure to give the purple solid 2H-PTetraCor $(7 \mathrm{mg}, 91 \%$ yield). ${ }^{1} \mathrm{H}$ NMR $\left(500 \mathrm{MHz}\right.$, chloroform-d): $\delta 9.15\left(\mathrm{~s}, 8 \mathrm{H}, \mathrm{H}_{2}\right), 8.50$ $\left(\mathrm{d}, J=8.0 \mathrm{~Hz}, 8 \mathrm{H}, \mathrm{H}_{6}\right), 8.28\left(\mathrm{~s}, 4 \mathrm{H}, \mathrm{H}_{10}\right), 8.26(\mathrm{~d}, J=8.0 \mathrm{~Hz}, 8 \mathrm{H}$, $\left.\mathrm{H}_{7}\right), 8.25\left(\mathrm{~d}, J=8.8 \mathrm{~Hz}, 4 \mathrm{H}, \mathrm{H}_{18}\right), 8.01\left(\mathrm{~d}, J=8.6 \mathrm{~Hz}, 4 \mathrm{H}, \mathrm{H}_{11}\right), 7.98$ $\left(\mathrm{d}, J=8.8 \mathrm{~Hz}, 4 \mathrm{H}, \mathrm{H}_{17}\right), 7.95\left(\mathrm{~d}, J=8.6 \mathrm{~Hz}, 4 \mathrm{H}, \mathrm{H}_{12}\right), 7.93-7.88(\mathrm{~m}$, $\left.16 \mathrm{H}, \mathrm{H}_{13}+\mathrm{H}_{14}+\mathrm{H}_{15}+\mathrm{H}_{16}\right),-2.52\left(\mathrm{br}, 2 \mathrm{H}, \mathrm{H}_{1}\right) .{ }^{13} \mathrm{C}\left\{{ }^{1} \mathrm{H}\right\}$ NMR $(126$ $\mathrm{MHz}$, chloroform-d): $\delta 141.45\left(\mathrm{C}_{5}\right), 139.2\left(\mathrm{C}_{8}-\right.$ in $), 136.50\left(\mathrm{C}_{23}\right.$ or $\left.C_{25}\right), 136.33\left(C_{q}\right), 136.00\left(C_{q}-i n\right), 135.90\left(C_{q}-i n\right), 135.53\left(C_{26}\right)$, $135.16\left(C_{6}\right), 130.97\left(C_{q}\right), 130.88\left(C_{q}\right), 129.75\left(C_{19}\right), 128.35\left(C_{7}\right)$, $127.67\left(C_{17}\right), 127.53\left(C_{12}\right), 127.40\left(C_{x}\right), 127.20\left(C_{x}+C_{18}\right), 127.12$ $\left(C_{x}+C_{11}\right), 127.02\left(C_{x}\right), 126.34\left(C_{10}\right), 120.00\left(C_{4}-i n\right)$. Being $C_{x}=C_{13}$ or $\mathrm{C}_{14}$ or $\mathrm{C}_{15}$ or $\mathrm{C}_{16}$. HR-MS (MALDI-TOF): $\mathrm{m} / \mathrm{z}$ for $\mathrm{C}_{124} \mathrm{H}_{62} \mathrm{~N}_{4}[\mathrm{M}]^{+}$ calcd: 1606.4969 , found: 1606.4994 (2.5 ppm error). UV/vis (toluene): $\lambda 404(\varepsilon=12200), 426(\varepsilon=38500), 518(\varepsilon=8100), 555$ ( $\varepsilon=7600), 595(\varepsilon=7100), 651(\varepsilon=7100)$.

\section{Conflicts of interest}

There are no conflicts to declare.

\section{Acknowledgements}

We thank the Spanish Ministry of Science, Innovation and Universities (MCIU) for funding (project numbers PGC2018096880-A-I00, MCIU/AEI/FEDER, UE and PGC2018-099470-B100, MCIU/AEI/FEDER, UE). R.G.-R. acknowledges the Spanish MINECO/AEI and the European Union (ESF) for a Ramon y Cajal contract (RYC-2015-19035). H.B. acknowledges the Alfonso Martín Escudero Foundation for a postdoctoral fellowship.

\section{Notes and references}

1. (a) Z. Li, Z. Liu, H. Sun and C. Gao, Chem. Rev., 2015, 115, 7046-7117; (b) V. Georgakilas, J. A. Perman, J. Tucek and R. Zboril, Chem. Rev., 2015, 115, 4744-4822; (c) Y. Segawa, H. Ito and K. Itami, Nat. Rev. Mater., 2016, 1, 15002. (a) L. Moreira, J. Calbo, R. M. Krick Calderon, J. Santos, B. M. Illescas, J. Aragó, J.-F. Nierengarten, D. M. Guldi, E. Ortí and N. Martín, Chem. Sci., 2015, 6, 4426-4432; (b) X.-S. Ke, T. Kim, J. T. Brewster, V. M. Lynch, D. Kim and J. L. Sessler, J. Am. Chem. Soc., 2017, 139, 4627-4630; (c) D. Lu, G. Zhuang, H. Wu, S. Wang, S. Yang and P. Du, Angew. Chem. Int. Ed., 2017, 56, 158-162; (d) X. Lu, T. Y. Gopalakrishna, Y. Han, Y. Ni, Y. Zou and J. Wu, J. Am. Chem. Soc., 2019, 141, 5934-5941; (e) V. Martínez-Agramunt, T. Eder, H. Darmandeh, G. Guisado-Barrios and E. Peris, Angew. Chem. Int. Ed., 2019, 58, 5682-5686; (f) G. Zango, M. Krug, S. Krishna, V. Mariñas, T. Clark, M. V. Martinez-Diaz, D. M. Guldi and T. Torres, Chem. Sci., 2020, 11, 3448-3459.

3. (a) E. M. Pérez and N. Martín, Chem. Soc. Rev., 2008, 37, 1512-1519; (b) S. S. Babu, H. Mohwald and T. Nakanishi, Chem. Soc. Rev., 2010, 39, 4021-4035; (c) D. Canevet, E. M. Pérez and N. Martín, Angew. Chem. Int. Ed., 2011, 50, 9248-9259; (d) C. García-Simón, M. Costas and X. Ribas, Chem. Soc. Rev., 2016, 45, 40-62; (e) S. Toyota and E. Tsurumaki, Chem. Eur. J., 2019, 25, 6878-6890; (f) S. Selmani and D. J. Schipper, Chem. Eur. J., 2019, 25, 66736692.

4. (a) H. W. Kroto, J. R. Heath, S. C. O'Brien, R. F. Curl and R. E. Smalley, Nature, 1985, 318, 162-163; (b) W. Krätschmer, L. D. Lamb, K. Fostiropoulos and D. R. Huffman, Nature, 1990, 347, 354-358; (c) R. C. Haddon, Science, 1993, 261, 1545-1550; (d) H. W. Kroto, Angew. Chem. Int. Ed. Engl., 1997, 36, 1578-1593.

5. (a) R. C. Haddon, L. E. Brus and K. Raghavachari, Chem. Phys. Lett., 1986, 125, 459-464; (b) D. M. Guldi and M. Prato, Acc. Chem. Res., 2000, 33, 695-703; (c) S. Kirner, M. Sekita and D. M. Guldi, Adv. Mater., 2014, 26, 1482-1493; (d) A. Zieleniewska, F. Lodermeyer, A. Roth and D. M. Guldi, Chem. Soc. Rev., 2018, 47, 702-714.

6. (a) T. Kawase and H. Kurata, Chem. Rev., 2006, 106, 52505273; (b) E. M. Pérez and N. Martín, Chem. Soc. Rev., 2015, 44, 6425-6433.

7. (a) P. W. Rabideau and A. Sygula, Acc. Chem. Res., 1996, 29, 235-242; (b) Y.-T. Wu and J. S. Siegel, Chem. Rev., 2006, 106, 4843-4867; (c) V. M. Tsefrikas and L. T. Scott, Chem. Rev., 2006, 106, 4868-4884; (d) L. T. Scott, Chem. Soc. Rev., 2015, 44, 6464-6471; (e) X.-Q. Hou, Y.-T. Sun, L. Liu, S.-T. Wang, R.-L. Geng and X.-F. Shao, Chin. Chem. Lett., 2016, 27, 1166-1174; (f) M. Saito, H. Shinokubo and H. Sakurai, Mater. Chem. Front., 2018, 2, 635-661; (g) M. A. Majewski and M. Stępień, Angew. Chem. Int. Ed., 2019, 58, 86-116. (a) L. T. Scott, M. M. Hashemi and M. S. Bratcher, J. Am. Chem. Soc., 1992, 114, 1920-1921; (b) M. Juríček, N. L. Strutt, J. C. Barnes, A. M. Butterfield, E. J. Dale, K. K. Baldridge, J. F. Stoddart and J. S. Siegel, Nat. Chem., 2014, 6, 222-228; (c) C. Dubceac, A. S. Filatov, A. V. Zabula, A. Y. Rogachev and M. A. Petrukhina, Chem. Eur. J., 2015, 21, 14268-14279; (d) E. Nestoros and M. C. Stuparu, Chem. Commun., 2018, 54, 6503-6519; (e) M. A. Petrukhina, Dalton Trans., 2019, 48, 5125-5130; (f) A. Haupt and D. Lentz, Chem. Eur. J., 2019, 25, 3440-3454.

9. (a) H. Becker, G. Javahery, S. Petrie, P. C. Cheng, H. Schwarz, L. T. Scott and D. K. Bohme, J. Am. Chem. Soc., 1993, 115, 11636-11637; (b) A. Sygula and S. Saebø, Int. J. Quantum Chem, 2009, 109, 65-72; (c) P. A. Denis, Chem. Phys. Lett., 2011, 516, 82-87. 
10. (a) A. Sygula, Synlett, 2016, 27, 2070-2080; (b) H. Barbero, S. Ferrero, A. Sacristán-Martín and C. Alvarez, in Advances in Chemistry Research. Volume 42, Nova Science Publishers, New York, 2017, vol. 42, ch. 4, pp. 165-204.

11. (a) A. Sygula, F. R. Fronczek, R. Sygula, P. W. Rabideau and M. M. Olmstead, J. Am. Chem. Soc., 2007, 129, 3842-3843; (b) V. H. Le, M. Yanney, M. McGuire, A. Sygula and E. A. Lewis, J. Phys. Chem. B, 2014, 118, 11956-11964.

12. M. Yanney and A. Sygula, Tetrahedron Lett., 2013, 54, 2604-2607.

13. (a) C. M. Álvarez, L. A. García-Escudero, R. GarcíaRodríguez, J. M. Martín-Álvarez, D. Miguel and V. M. Rayón, Dalton Trans., 2014, 43, 15693-15696; (b) C. M. Álvarez, G. Aullón, H. Barbero, L. A. García-Escudero, C. Martínez-Pérez, J. M. Martín-Álvarez and D. Miguel, Org. Lett., 2015, 17, 2578-2581; (c) H. Barbero, S. Ferrero, L. Álvarez-Miguel, P. Gómez-Iglesias, D. Miguel and C. M. Álvarez, Chem. Commun., 2016, 52, 12964-12967; (d) V. García-Calvo, J. V. Cuevas, H. Barbero, S. Ferrero, C. M. Álvarez, J. A. González, B. Díaz de Greñu, J. García-Calvo and T. Torroba, Org. Lett., 2019, 21, 5803-5807.

14. (a) P. D. W. Boyd, M. C. Hodgson, C. E. F. Rickard, A. G. Oliver, L. Chaker, P. J. Brothers, R. D. Bolskar, F. S. Tham and C. A. Reed, J. Am. Chem. Soc., 1999, 121, 10487-10495; (b) P. D. W. Boyd and C. A. Reed, Acc. Chem. Res., 2005, 38, 235-242; (c) K. Tashiro and T. Aida, Chem. Soc. Rev., 2007, 36, 189-197; (d) Y. Saegusa, T. Ishizuka, T. Kojima, S. Mori, M. Kawano and T. Kojima, Chem. Eur. J., 2015, 21, 53025306; (e) M. Yamada, G. Murakami, S. Kobayashi and Y. Maeda, Tetrahedron Lett., 2017, 58, 4514-4518.

15. C. M. Álvarez, H. Barbero, S. Ferrero and D. Miguel, J. Org. Chem., 2016, 81, 6081-6086.

16. S. Ferrero, H. Barbero, D. Miguel, R. García-Rodríguez and C. M. Álvarez, J. Org. Chem., 2019, 84, 6183-6190.

17. S. Ferrero, H. Barbero, D. Miguel, R. García-Rodríguez and C. M. Álvarez, J. Org. Chem., 2020, 85, 4918-4926.

18. (a) S. Wan, F. Gándara, A. Asano, H. Furukawa, A. Saeki, S. K. Dey, L. Liao, M. W. Ambrogio, Y. Y. Botros, X. Duan, S. Seki, J. F. Stoddart and O. M. Yaghi, Chem. Mater., 2011, 23, 4094-4097; (b) X. Liu, Y. Xu, Z. Guo, A. Nagai and D. Jiang, Chem. Commun., 2013, 49, 3233-3235.

19. (a) H.-B. Acta Crystallographica Section CZhao, L. Chen, B.Y. Wang, J.-X. Liao and Y.-J. Xu, Acta Cryst. C, 2013, 69, 651653; (b) N. Sheng, S. Zong, W. Cao, J. Jiang, Z. Wang and Y. Cui, ACS Appl. Mater. Interfaces, 2015, 7, 19718-19725; (c) P. Kuś, J. Kusz and M. Książek, J. Chem. Crystallogr., 2020, 50, 21-27.

(a) P. Thordarson, Chem. Soc. Rev., 2011, 40, 1305-1323;

(b) D. Brynn Hibbert and P. Thordarson, Chem. Commun. 2016, 52, 12792-12805.

21. (a) R. Ditchfield, W. J. Hehre and J. A. Pople, J. Chem. Phys., 1971, 54, 724-728; (b) W. J. Hehre, R. Ditchfield and J. A. Pople, J. Chem. Phys., 1972, 56, 2257-2261; (c) M. M. Francl, W. J. Pietro, W. J. Hehre, J. S. Binkley, M. S. Gordon, D. J. DeFrees and J. A. Pople, J. Chem. Phys., 1982, 77, 3654 3665; (d) M. J. Frisch, J. A. Pople and J. S. Binkley, J. Chem. Phys., 1984, 80, 3265-3269; (e) S. Grimme, J. Comput. Chem., 2006, 27, 1787-1799; (f) S. Grimme, S. Ehrlich and L. Goerigk, J. Comput. Chem., 2011, 32, 1456-1465.

22. (a) C. Muck-Lichtenfeld, S. Grimme, L. Kobryn and A. Sygula, Phys. Chem. Chem. Phys., 2010, 12, 7091-7097; (b) P. A. Denis, RSC Adv., 2013, 3, 25296-25305; (c) D. Josa, J.
Rodríguez-Otero, E. M. Cabaleiro-Lago, L. A. Santos and T. C. Ramalho, J. Phys. Chem. A, 2014, 118, 9521-9528.

23. The modest strength of the binding constants makes it difficult to determine the exact stoichiometry for the association constant, and therefore it cannot be unambiguously established. Our data is consistent with a 1:2 interaction in which both binding sites act independently with little-to-no involvement of the porphyrin core in the recognition process, and therefore, the observed 1:1 binding association could be described as "apparent". In this regard, we note that although zinc from the porphyrin core is known to bind $C_{60}$ or $C_{70}$ (see references below) we do not have any evidence of this interaction operating in our metalloporphyrins. (a) L. Moreira, J. Calbo, B. M. Illescas, J. Aragó, I. Nierengarten, B. Delavaux-Nicot, E. Ortí, N. Martín and J.-F. Nierengarten, Angew. Chem. Int. Ed., 2015, 54, 1255-1260; (b) L. Moreira, J. Calbo, J. Aragó, B. M. Illescas, I. Nierengarten, B. Delavaux-Nicot, E. Ortí, N. Martín and J.-F. Nierengarten, J. Am. Chem. Soc., 2016, 138, 15359-15367.

24. (a) W. L. F. Armarego and C. L. L. Chai, Purification of Laboratory Chemicals, 6th, Butterworth-Heinemann, London, 2009; (b) D. B. G. Williams and M. Lawton, J. Org. Chem., 2010, 75, 8351-8354.

25. A. M. Butterfield, B. Gilomen and J. S. Siegel, Org. Process Res. Dev., 2012, 16, 664-676. 
8. BIBLIOGRAFÍA Y NOTAS 


\section{BIBLIOGRAFÍA Y NOTAS}

${ }^{1}$ (a) J. M. Lehn, Supramolecular Chemistry: Concepts and Perspectives, VCH-Wiley, Weinheim, 1995; (b) G. R. Desiraju, Nature, 2001, 412, 397-400; (c) J. W. Steed, J. L. Atwood, Supramolecular Chemistry, 2nd Edition, John Wiley \& Sons, New York, 2009; (d) R. M. Izatt, J. S. Bradshaw, S. R. Izatt, R. G. Harrison, Macrocyclic and Supramolecular Chemistry: How IzattChristensen Award Winners Shaped the Field, Wiley, Oxford, UK, 2016.

2J. M. Lehn, Pure Appl. Chem., 1978, 50, 871-892.

${ }^{3}$ (a) B. Dietrich, J. M. Lehn, J. P. Sauvage, Tetrahedron Lett., 1969, 10, 2885-2888; (b) B. Dietrich, J. M. Lehn, J. P. Sauvage, Tetrahedron Lett., 1969, 10, 2889-2892.

${ }^{4}$ E. Fischer, Ber. Dt. Chem. Ges., 1894, 27, 2985-2993.

${ }^{5}$ (a) C. J. Pedersen, J. Am. Chem. Soc., 1967, 89, 2495-2496; (b) C. J. Pedersen, J. Am. Chem. Soc., 1967, 89, 7017-7036; (c) J. M. Lehn, in Alkali Metal Complexes with Organic Ligands, Springer, Berlin, Heidelberg, 1973, pp. 1-69; (d) D. J. Cram, J. M. Cram, Science, 1974, 183, 803.

${ }^{6}$ H.-J. Schneider, Angew. Chem. Int. Ed., 2009, 48, 3924-3977.

${ }^{7}$ D. Philp, J. F. Stoddart, Angew. Chem. Int. Ed. Engl., 1996, 35, 1154-1196.

${ }^{8}$ (a) J. D. Watson, F. H. C. Crick, Nature, 1953, 171, 737-738; (b) M. H. F. Wilkins, A. R. Stokes, H. R. Wilson, Nature, 1953, 171, 738-740; (c) R. E. Franklin, R. G. Gosling, Nature, 1953, 171, 740741; (d) C. K. McLaughlin, G. D. Hamblin, H. F. Sleiman, Chem. Soc. Rev., 2011, 40, 5647-5656.

${ }^{9}$ (a) N. H. Evans, P. D. Beer, Angew. Chem. Int. Ed., 2014, 53, 11716-11754; (b) P. A. Gale, J. T. Davis, R. Quesada, Chem. Soc. Rev., 2017, 46, 2497-2519.

${ }^{10}$ (a) K. A. Dill, Biochemistry, 1990, 29, 7133-7155; (b) A. C. Steven, W. Baumeister, L. N. Johnson, R. N. Perham, Molecular Biology of Assemblies and Machines, Garland Science, New York, 2016.

${ }^{11}$ (a) J. D. Badjić, A. Nelson, S. J. Cantrill, W. B. Turnbull, J. F. Stoddart, Acc. Chem. Res., 2005, 38, 723-732; (b) C. A. Hunter, H. L. Anderson, Angew. Chem. Int. Ed., 2009, 48, 7488-7499; (c) L. K. S. von Krbek, C. A. Schalley, P. Thordarson, Chem. Soc. Rev., 2017, 46, 2622-2637.

${ }^{12}$ (a) G. K. Ackers, M. L. Doyle, D. Myers, M. A. Daugherty, Science, 1992, 255, 54; (b) W. A. Eaton, E. R. Henry, J. Hofrichter, A. Mozzarelli, Nat. Struct. Biol., 1999, 6, 351-358; (c) J. A. Lukin, C. Ho, Chem. Rev., 2004, 104, 1219-1230; (d) S. Nagatomo, M. Nagai, T. Kitagawa, J. Am. Chem. Soc., 2011, 133, 10101-10110.

${ }^{13}$ (a) C. J. Pedersen, Angew. Chem. Int. Ed. Engl., 1988, 27, 1021-1027; (b) D. J. Cram, Angew. Chem. Int. Ed. Engl., 1988, 27, 1009-1020; (c) J.-M. Lehn, Angew. Chem. Int. Ed., 1988, 27, 89112.

${ }^{14}$ (a) J.-P. Sauvage, Angew. Chem. Int. Ed., 2017, 56, 11080-11093; (b) J. F. Stoddart, Angew. Chem. Int. Ed., 2017, 56, 11094-11125; (c) B. L. Feringa, Angew. Chem. Int. Ed., 2017, 56, 1106011078.

${ }^{15}$ (a) M. M. J. Treacy, T. W. Ebbesen, J. M. Gibson, Nature, 1996, 381, 678-680; (b) C. Lee, X. Wei, J. W. Kysar, J. Hone, Science, 2008, 321, 385-388; (c) D. M. Guldi, V. Sgobba, Chem. Commun., 2011, 47, 606-610; (d) D. Jariwala, V. K. Sangwan, L. J. Lauhon, T. J. Marks, M. C. Hersam, Chem. Soc. Rev., 2013, 42, 2824-2860; (e) F. R. Baptista, S. A. Belhout, S. Giordani, S. J. Quinn, Chem. Soc. Rev., 2015, 44, 4433-4453; (f) A. J. Clancy, M. K. Bayazit, S. A. Hodge, N. T. Skipper, C. A. Howard, M. S. P. Shaffer, Chem. Rev., 2018, 118, 7363-7408.

${ }^{16}$ (a) V. Georgakilas, J. A. Perman, J. Tucek, R. Zboril, Chem. Rev., 2015, 115, 4744-4822; (b) Z. Li, Z. Liu, H. Sun, C. Gao, Chem. Rev., 2015, 115, 7046-7117; (c) Y. Segawa, H. Ito, K. Itami, Nat. Rev. Mater., 2016, 1, 15002.

${ }^{17}$ (a) H. W. Kroto, J. R. Heath, S. C. O'Brien, R. F. Curl, R. E. Smalley, Nature, 1985, 318, $162-$ 163; (b) A. Hirsch, M. Brettreich, Fullerenes: Chemistry and Reactions, Wiley-VCH, Weinheim, 2004; (c) N. Martín, Chem. Commun., 2006, 2093-2104.

${ }^{18}$ (a) S. Iijima, Nature, 1991, 354, 56-58; (b) S. Niyogi, M. A. Hamon, H. Hu, B. Zhao, P. Bhowmik, R. Sen, M. E. Itkis, R. C. Haddon, Acc. Chem. Res., 2002, 35, 1105-1113; (c) S. Reich, C. 
Thomsen, J. Maultzsch, Carbon Nanotubes-Basic Concepts and Physical Properties, Wiley-VCH, Weinheim, 2004.

${ }^{19}$ (a) K. S. Novoselov, A. K. Geim, S. V. Morozov, D. Jiang, Y. Zhang, S. V. Dubonos, I. V. Grigorieva, A. A. Firsov, Science, 2004, 306, 666-669; (b) M. J. Allen, V. C. Tung, R. B. Kaner, Chem. Rev., 2010, 110, 132-145; (c) W. Choi, L. Jo-won, Graphene: synthesis and applications, CRC Press, 2011.

${ }^{20}$ (a) F. Banhart, J. Kotakoski, A. V. Krasheninnikov, ACS Nano, 2011, 5, 26-41; (b) Y. Wei, J. Wu, H. Yin, X. Shi, R. Yang, M. Dresselhaus, Nat. Mater., 2012, 11, 759-763.

${ }^{21}$ (a) W. Krätschmer, L. D. Lamb, K. Fostiropoulos, D. R. Huffman, Nature, 1990, 347, $354-$ 358; (b) R. Taylor, J. P. Hare, A. a. K. Abdul-Sada, H. W. Kroto, J. Chem. Soc., Chem. Commun., 1990, 1423-1425.

${ }^{22}$ J. R. Heath, S. C. O'Brien, Q. Zhang, Y. Liu, R. F. Curl, F. K. Tittel, R. E. Smalley, J. Am. Chem. Soc., 1985, 107, 7779-7780.

${ }^{23}$ H. W. Kroto, Nature, 1987, 329, 529-531.

${ }^{24}$ L. Euler, Novi Commentarii academiae scientiarum Petropolitanae, 1758, 4, 109-140.

${ }^{25} \mathrm{~F}$. Cozzi, W. H. Powell, C. Thilgen, Pure Appl. Chem., 2005, 77, 843-923.

${ }^{26}$ (a) R. F. Curl, Angew. Chem. Int. Ed. Engl., 1997, 36, 1566-1576; (b) H. W. Kroto, Angew. Chem. Int. Ed. Engl., 1997, 36, 1578-1593; (c) R. E. Smalley, Angew. Chem. Int. Ed. Engl., 1997, 36, 1594-1601.

${ }^{27}$ (a) N. S. Sariciftci, L. Smilowitz, A. J. Heeger, F. Wudl, Science, 1992, 258, 1474-1476; (b) L. W. Tutt, A. Kost, Nature, 1992, 356, 225-226; (c) L. Echegoyen, L. E. Echegoyen, Acc. Chem. Res., 1998, 31, 593-601; (d) D. M. Guldi, M. Prato, Acc. Chem. Res., 2000, 33, 695-703; (e) S. Collavini, J. L. Delgado, Sustainable Energy Fuels, 2018, 2, 2480-2493.

${ }^{28}$ (a) D. M. Guldi, Chem. Commun., 2000, 321-327; (b) S. Kirner, M. Sekita, D. M. Guldi, Adv. Mater., 2014, 26, 1482-1493; (c) A. Zieleniewska, F. Lodermeyer, A. Roth, D. M. Guldi, Chem. Soc. Rev., 2018, 47, 702-714.

${ }^{29}$ (a) J. L. Segura, N. Martín, D. M. Guldi, Chem. Soc. Rev., 2005, 34, 31-47; (b) S. Günes, H. Neugebauer, N. S. Sariciftci, Chem. Rev., 2007, 107, 1324-1338; (c) Y. Shen, T. Nakanishi, Phys. Chem. Chem. Phys., 2014, 16, 7199-7204; (d) M. Rudolf, S. V. Kirner, D. M. Guldi, Chem. Soc. Rev., 2016, 45, 612-630.

${ }^{30}$ (a) S. Stevenson, G. Rice, T. Glass, K. Harich, F. Cromer, M. R. Jordan, J. Craft, E. Hadju, R. Bible, M. M. Olmstead, K. Maitra, A. J. Fisher, A. L. Balch, H. C. Dorn, Nature, 1999, 401, 55-57; (b) A. A. Popov, S. Yang, L. Dunsch, Chem. Rev., 2013, 113, 5989-6113; (c) S. Yang, T. Wei, F. Jin, Chem. Soc. Rev., 2017, 46, 5005-5058; (d) T. Wang, C. Wang, Small, 2019, 15, 1901522.

${ }^{31}$ (a) R. C. Haddon, Acc. Chem. Res., 1992, 25, 127-133; (b) M. Capone, M. Fabrizio, C. Castellani, E. Tosatti, Science, 2002, 296, 2364-2366.

32 (a) R. S. Ruoff, D. S. Tse, R. Malhotra, D. C. Lorents, J. Phys. Chem., 1993, 97, 3379-3383; (b) K. N. Semenov, N. A. Charykov, V. A. Keskinov, A. K. Piartman, A. A. Blokhin, A. A. Kopyrin, J. Chem. Eng. Data, 2010, 55, 13-36.

${ }^{33}$ (a) F. Diederich, M. Gómez-López, Chem. Soc. Rev., 1999, 28, 263-277; (b) E. M. Pérez, N. Martín, Chem. Soc. Rev., 2008, 37, 1512-1519; (c) S. S. Babu, H. Mohwald, T. Nakanishi, Chem. Soc. Rev., 2010, 39, 4021-4035; (d) N. Martín, E. M. Pérez, Pure Appl. Chem., 2010, 82, 523-533; (e) D. Canevet, E. M. Pérez, N. Martín, Angew. Chem. Int. Ed., 2011, 50, 9248-9259; (f) S. Selmani, D. J. Schipper, Chem. Eur. J., 2019, 25, 6673-6692; (g) S. Toyota, E. Tsurumaki, Chem. Eur. J., 2019, 25, 6878-6890.

${ }^{34}$ (a) Y. Chen, T. Marszalek, T. Fritz, M. Baumgarten, M. Wagner, W. Pisula, L. Chen, K. Müllen, Chem. Commun., 2017, 53, 8474-8477; (b) S. Grätz, D. Beyer, V. Tkachova, S. Hellmann, R. Berger, X. Feng, L. Borchardt, Chem. Commun., 2018, 54, 5307-5310; (c) K. Xu, J. I. Urgel, K. Eimre, M. Di Giovannantonio, A. Keerthi, H. Komber, S. Wang, A. Narita, R. Berger, P. Ruffieux, C. A. Pignedoli, J. Liu, K. Müllen, R. Fasel, X. Feng, J. Am. Chem. Soc., 2019, 141, 7726-7730.

${ }^{35}$ (a) K. Suzuki, K. Takao, S. Sato, M. Fujita, J. Am. Chem. Soc., 2010, 132, 2544-2545; (b) T. M. Figueira-Duarte, K. Müllen, Chem. Rev., 2011, 111, 7260-7314; (c) T. Wöhrle, I. Wurzbach, J. 
Kirres, A. Kostidou, N. Kapernaum, J. Litterscheidt, J. C. Haenle, P. Staffeld, A. Baro, F. Giesselmann, S. Laschat, Chem. Rev., 2016, 116, 1139-1241; (d) F. Würthner, C. R. Saha-Möller, B. Fimmel, S. Ogi, P. Leowanawat, D. Schmidt, Chem. Rev., 2016, 116, 962-1052.

${ }^{36}$ (a) W. P. Ronald, J. Toxicol. Cut. \& Ocular Toxicol., 2000, 19, 55-67; (b) W. M. Baird, L. A. Hooven, B. Mahadevan, Environ.Mol.Mutagen., 2005, 45, 106-114.

${ }^{37}$ A. Laurent, Ann. Chim. Phys., 1837, 66, 136.

${ }^{38}$ X. Feng, J.-Y. Hu, C. Redshaw, T. Yamato, Chem. Eur. J., 2016, 22, 11898-11916.

${ }^{39}$ (a) J. R. Moffat, D. K. Smith, Chem. Commun., 2011, 47, 11864-11866; (b) D. Mandal, T. Kar, P. K. Das, Chem. Eur. J., 2014, 20, 1349-1358; (c) O. Karagollu, M. Gorur, F. Gode, B. Sennik, F. Yilmaz, Macromol. Chem. Phys., 2015, 216, 939-949; (d) Y. Sun, Y. Wu, C. Yu, L. Zhang, G. Song, Z. Yao, ACS Appl. Nano Mater., 2019, 2, 3453-3458.

${ }^{40}$ (a) V. L. Malinovskii, D. Wenger, R. Häner, Chem. Soc. Rev., 2010, 39, 410-422; (b) A. O. Krasheninina, S. D. Novopashina, K. E. Apartsin, G. A. Venyaminova, Molecules, 2017, 22, 2108.

${ }^{41}$ Algunos ejemplos seleccionados: (a) Y.-L. Zhao, J. F. Stoddart, Acc. Chem. Res., 2009, 42, 1161-1171; (b) J. A. Mann, J. Rodríguez-López, H. D. Abruña, W. R. Dichtel, J. Am. Chem. Soc., 2011, 133, 17614-17617; (c) D. Parviz, S. Das, H. S. T. Ahmed, F. Irin, S. Bhattacharia, M. J. Green, ACS Nano, 2012, 6, 8857-8867; (d) C. B. KC, G. N. Lim, F. D'Souza, Angew. Chem. Int. Ed., 2015, 54, 5088-5092; (e) A. López-Moreno, E. M. Pérez, Chem. Commun., 2015, 51, 5421-5424; (f) A. de Juan, A. López-Moreno, J. Calbo, E. Ortí, E. M. Pérez, Chem. Sci., 2015, 6, 7008-7014; (g) M. Garrido, J. Calbo, L. Rodríguez-Pérez, J. Aragó, E. Ortí, M. A. Herranz, N. Martín, Chem. Commun., 2017, 53, 12402-12405; (h) B. K. Billing, Mayank, P. K. Agnihotri, N. Singh, Analyst, 2018, 143, 3343-3352; (i) M. Garrido, M. K. Volland, P. W. Münich, L. Rodríguez-Pérez, J. Calbo, E. Ortí, M. Á. Herranz, N. Martín, D. M. Guldi, J. Am. Chem. Soc., 2020, 142, 1895-1903.

${ }^{42}$ (a) K. Mulla, H. Shaik, D. W. Thompson, Y. Zhao, Org. Lett., 2013, 15, 4532-4535; (b) M. Park, K.-I. Hong, M. Kang, T.-W. Kim, H. Lee, W.-D. Jang, K.-U. Jeong, ACS Nano, 2019, 13, 61016112.

${ }^{43}$ (a) T. K. Ronson, A. B. League, L. Gagliardi, C. J. Cramer, J. R. Nitschke, J. Am. Chem. Soc., 2014, 136, 15615-15624; (b) T. K. Ronson, W. Meng, J. R. Nitschke, J. Am. Chem. Soc., 2017, 139, 9698-9707; (c) V. Martínez-Agramunt, D. G. Gusev, E. Peris, Chem. Eur. J., 2018, 24, 1480214807; (d) V. Martínez-Agramunt, T. Eder, H. Darmandeh, G. Guisado-Barrios, E. Peris, Angew. Chem. Int. Ed., 2019, 58, 5682-5686; (e) V. Martínez-Agramunt, E. Peris, Inorg. Chem., 2019, 58, 11836-11842.

${ }^{44}$ (a) R. A. Pascal, Chem. Rev., 2006, 106, 4809-4819; (b) M. Ball, Y. Zhong, Y. Wu, C. Schenck, F. Ng, M. Steigerwald, S. Xiao, C. Nuckolls, Acc. Chem. Res., 2015, 48, 267-276.

${ }^{45}$ (a) M. Gingras, Chem. Soc. Rev., 2013, 42, 1051-1095; (b) M. Rickhaus, M. Mayor, M. Juríček, Chem. Soc. Rev., 2017, 46, 1643-1660; (c) E. Nestoros, M. C. Stuparu, Chem. Commun., 2018, 54, 6503-6519.

${ }^{46}$ M. S. Newman, D. Lednicer, J. Am. Chem. Soc., 1956, 78, 4765-4770.

${ }^{47}$ (a) W. E. Barth, R. G. Lawton, J. Am. Chem. Soc., 1966, 88, 380-381; (b) R. G. Lawton, W. E. Barth, J. Am. Chem. Soc., 1971, 93, 1730-1745.

${ }^{48}$ K. Yamamoto, T. Harada, M. Nakazaki, T. Naka, Y. Kai, S. Harada, N. Kasai, J. Am. Chem. Soc., 1983, 105, 7171-7172.

${ }^{49}$ G. Mehta, S. R. Shahk, K. Ravikumarc, J. Chem. Soc., Chem. Commun., 1993, 1006-1008.

${ }^{50}$ (a) P. W. Rabideau, A. Sygula, Acc. Chem. Res., 1996, 29, 235-242; (b) L. T. Scott, H. E. Bronstein, D. V. Preda, R. B. M. Ansems, M. S. Bratcher, S. Hagen, Pure \& Appl. Chem., 1999, 71, 209-219; (c) V. M. Tsefrikas, L. T. Scott, Chem. Rev., 2006, 106, 4868-4884.

${ }^{51}$ (a) A. Borchardt, A. Fuchicello, K. V. Kilway, K. K. Baldridge, J. S. Siegel, J. Am. Chem. Soc., 1992, 114, 1921-1923; (b) M. A. Petrukhina, K. W. Andreini, J. Mack, L. T. Scott, J. Org. Chem., 2005, 70, 5713-5716; (c) S. Grabowsky, M. Weber, Y.-S. Chen, D. Lentz, M. Schmidt Bernd, M. Hesse, P. Luger, Z. Naturforsch. B, 2010, 65, 452.

${ }^{52}$ J. C. Hanson, C. E. Nordman, Acta Crystallogr. Sect. B, 1976, 32, 1147-1153. 
${ }^{53}$ (a) R. C. Haddon, L. T. Scott, Pure Appl. Chem., 1986, 58, 137-142; (b) R. C. Haddon, Acc. Chem. Res., 1988, 21, 243-249; (c) R. C. Haddon, J. Am. Chem. Soc., 1990, 112, 3385-3389.

${ }^{54}$ M. A. Petrukhina, Y. Sevryugina, A. Y. Rogachev, E. A. Jackson, L. T. Scott, Angew. Chem. Int. Ed., 2006, 45, 7208-7210.

${ }^{55}$ F. J. Lovas, R. J. McMahon, J.-U. Grabow, M. Schnell, J. Mack, L. T. Scott, R. L. Kuczkowski, J. Am. Chem. Soc., 2005, 127, 4345-4349.

${ }^{56}$ (a) L. T. Scott, M. M. Hashemi, M. S. Bratcher, J. Am. Chem. Soc., 1992, 114, 1920-1921; (b) A. Sygula, A. H. Abdourazak, P. W. Rabideau, J. Am. Chem. Soc., 1996, 118, 339-343; (c) T. J. Seiders, K. K. Baldridge, E. L. Elliott, G. H. Grube, J. S. Siegel, J. Am. Chem. Soc., 1999, 121, $7439-$ 7440; (d) T. J. Seiders, K. K. Baldridge, G. H. Grube, J. S. Siegel, J. Am. Chem. Soc., 2001, 123, $517-$ 525; (e) M. Yanney, F. R. Fronczek, W. P. Henry, D. J. Beard, A. Sygula, Eur. J. Org. Chem., 2011, 2011, 6636-6639; (f) M. Juríček, N. L. Strutt, J. C. Barnes, A. M. Butterfield, E. J. Dale, K. K. Baldridge, J. F. Stoddart, J. S. Siegel, Nat. Chem., 2014, 6, 222-228.

${ }^{57}$ (a) C. Dubceac, A. S. Filatov, A. V. Zabula, A. Y. Rogachev, M. A. Petrukhina, Chem. Eur. J., 2015, 21, 14268-14279; (b) L. T. Scott, Chem. Soc. Rev., 2015, 44, 6464-6471.

${ }^{58}$ (a) R.-Q. Lu, W. Xuan, Y.-Q. Zheng, Y.-N. Zhou, X.-Y. Yan, J.-H. Dou, R. Chen, J. Pei, W. Weng, X.-Y. Cao, RSC Adv., 2014, 4, 56749-56755; (b) R. Chen, R.-Q. Lu, P.-C. Shi, X.-Y. Cao, Chin. Chem. Lett., 2016, 27, 1175-1183; (c) X. Li, D. Sun, X. Li, D. Zhu, Z. Jia, J. Jiao, K. Wang, D. Kong, X. Zhao, L. Xu, Q. Zhao, D. Chen, X. Feng, Biomater. Sci., 2017, 5, 849-859; (d) X. Gu, X. Zhang, H. Ma, S. Jia, P. Zhang, Y. Zhao, Q. Liu, J. Wang, X. Zheng, J. W. Y. Lam, D. Ding, B. Z. Tang, Adv. Mater., 2018, 30, 1801065; (e) A. M. Rice, E. A. Dolgopolova, B. J. Yarbrough, G. A. Leith, C. R. Martin, K. S. Stephenson, R. A. Heugh, A. J. Brandt, D. A. Chen, S. G. Karakalos, M. D. Smith, K. B. Hatzell, P. J. Pellechia, S. Garashchuk, N. B. Shustova, Angew. Chem. Int. Ed., 2018, 57, 11310-11315; (f) M. Saito, H. Shinokubo, H. Sakurai, Mater. Chem. Front., 2018, 2, 635-661; (g) S. Du, H. Wang, Y. Yang, X. Feng, X. Shao, C. Chipot, W. Cai, J. Phys. Chem. C, 2019, 123, 922-930; (h) X. Guo, D. Lu, D. Zhang, J. Deng, X. Zhang, Z. Wang, L. Xiao, Y. Zhao, Mater. Sci. Eng. C, 2020, 106, 110227.

${ }^{59}$ Citas en el interior: (a) B. M. Schmidt, D. Lentz, Chem. Lett., 2014, 43, 171-177; (b) A. Haupt, D. Lentz, Chem. Eur. J., 2019, 25, 3440-3454.

${ }^{60}$ (a) N. J. Sumner, S. N. Spisak, A. S. Filatov, A. Y. Rogachev, A. V. Zabula, M. A. Petrukhina, Organometallics, 2014, 33, 2874-2878; (b) A. V. Zabula, S. N. Spisak, A. S. Filatov, A. Y. Rogachev, M. A. Petrukhina, Acc. Chem. Res., 2018, 51, 1541-1549; (c) M. A. Petrukhina, Dalton Trans., 2019, 48, 5125-5130.

${ }^{61}$ (a) J. Li, A. Y. Rogachev, Phys. Chem. Chem. Phys., 2016, 18, 11781-11791; (b) J. Li, G. da Silva Ramos, A. Yu Rogachev, J. Comput. Chem., 2016, 37, 2266-2278; (c) S. Liu, A. Y. Rogachev, ChemPhysChem, 2018, 19, 2579-2588.

${ }^{62}$ (a) H. B. Lee, P. R. Sharp, Organometallics, 2005, 24, 4875-4877; (b) H. Choi, C. Kim, K.-M. Park, J. Kim, Y. Kang, J. Ko, J. Organomet. Chem., 2009, 694, 3529-3532; (c) R. Maag, B. H. Northrop, A. Butterfield, A. Linden, O. Zerbe, Y. M. Lee, K.-W. Chi, P. J. Stang, J. S. Siegel, Org. Biomol. Chem., 2009, 7, 4881-4885; (d) M. Yamada, S. Tashiro, R. Miyake, M. Shionoya, Dalton Trans., 2013, 42, 3300-3303; (e) J. W. Facendola, M. Seifrid, J. Siegel, P. I. Djurovich, M. E. Thompson, Dalton Trans., 2015, 44, 8456-8466; (f) R. D. Adams, P. Dhull, M. Pennachio, M. A. Petrukhina, M. D. Smith, Chem. Eur. J., 2019, 25, 4234-4239.

${ }^{63}$ (a) P. A. Vecchi, C. M. Alvarez, A. Ellern, R. J. Angelici, A. Sygula, R. Sygula, P. W. Rabideau, Angew. Chem. Int. Ed., 2004, 43, 4497-4500; (b) P. A. Vecchi, C. M. Alvarez, A. Ellern, R. J. Angelici, A. Sygula, R. Sygula, P. W. Rabideau, Organometallics, 2005, 24, 4543-4552; (c) M. A. Petrukhina, L. T. Scott, Dalton Trans., 2005, 2969-2975; (d) M. A. Petrukhina, Angew. Chem. Int. Ed., 2008, 47, 1550-1552; (e) A. S. Filatov, M. A. Petrukhina, Coord. Chem. Rev., 2010, 254, 22342246.

${ }^{64}$ (a) P. W. Rabideau, A. H. Abdourazak, H. E. Folsom, Z. Marcinow, A. Sygula, R. Sygula, J. Am. Chem. Soc., 1994, 116, 7891-7892; (b) G. Mehta, G. Panda, Tetrahedron Lett., 1997, 38, 2145-2148. 
${ }^{65}$ (a) L. T. Scott, M. M. Hashemi, D. T. Meyer, H. B. Warren, J. Am. Chem. Soc., 1991, 113, 7082-7084; (b) L. T. Scott, P.-C. Cheng, M. M. Hashemi, M. S. Bratcher, D. T. Meyer, H. B. Warren, J. Am. Chem. Soc., 1997, 119, 10963-10968.

${ }^{66}$ (a) A. Borchardt, K. Hardcastle, P. Gantzel, J. S. Siegel, Tetrahedron Lett., 1993, 34, 273276; (b) T. J. Seiders, K. K. Baldridge, J. S. Siegel, J. Am. Chem. Soc., 1996, 118, 2754-2755; (c) T. J. Seiders, E. L. Elliott, G. H. Grube, J. S. Siegel, J. Am. Chem. Soc., 1999, 121, 7804-7813.

${ }^{67}$ (a) A. Sygula, P. W. Rabideau, J. Am. Chem. Soc., 2000, 122, 6323-6324; (b) G. Xu, A. Sygula, Z. Marcinow, P. W. Rabideau, Tetrahedron Lett., 2000, 41, 9931-9934; (c) A. Sygula, G. Xu, Z. Marcinow, P. W. Rabideau, Tetrahedron, 2001, 57, 3637-3644.

${ }^{68}$ A. M. Butterfield, B. Gilomen, J. S. Siegel, Org. Process Res. Dev., 2012, 16, 664-676.

${ }^{69}$ (a) A. Girard, G. Sandulesco, Helv. Chim. Acta, 1936, 19, 1095-1107; (b) H. B. Henbest, Nature, 1946, 158, 950-950.

${ }^{70}$ (a) H. A. Reisch, M. S. Bratcher, L. T. Scott, Org. Lett., 2000, 2, 1427-1430; (b) Z. Marcinow, A. Sygula, A. Ellern, P. W. Rabideau, Org. Lett., 2001, 3, 3527-3529; (c) H. A. Wegner, L. T. Scott, A. de Meijere, J. Org. Chem., 2003, 68, 883-887; (d) D. Kim, J. L. Petersen, K. K. Wang, Org. Lett., 2006, 8, 2313-2316; (e) C.-N. Feng, Y.-C. Hsieh, Y.-T. Wu, Chem. Rec., 2015, 15, 266-279.

${ }^{71}$ E. M. Pérez, N. Martín, Chem. Soc. Rev., 2015, 44, 6425-6433.

${ }^{72}$ (a) H. Becker, G. Javahery, S. Petrie, P. C. Cheng, H. Schwarz, L. T. Scott, D. K. Bohme, J. Am. Chem. Soc., 1993, 115, 11636-11637; (b) A. Sygula, S. Saebø, Int. J. Quantum Chem, 2009, 109, 65-72; (c) P. A. Denis, Chem. Phys. Lett., 2011, 516, 82-87; (d) T. Janowski, P. Pulay, A. A. Sasith Karunarathna, A. Sygula, S. Saebø, Chem. Phys. Lett., 2011, 512, 155-160.

${ }^{73}$ M. Yamada, K. Ohkubo, M. Shionoya, S. Fukuzumi, J. Am. Chem. Soc., 2014, 136, $13240-$ 13248.

${ }^{74}$ M. R. Kennedy, L. A. Burns, C. D. Sherrill, J. Phys. Chem. A, 2012, 116, 11920-11926.

${ }^{75}$ L. N. Dawe, T. A. AlHujran, H.-A. Tran, J. I. Mercer, E. A. Jackson, L. T. Scott, P. E. Georghiou, Chem. Commun., 2012, 48, 5563-5565.

${ }^{76}$ Y. Wang, Y. Li, W. Zhu, J. Liu, X. Zhang, R. Li, Y. Zhen, H. Dong, W. Hu, Nanoscale, 2016, 8, 14920-14924.

${ }^{77}$ W. Xiao, D. Passerone, P. Ruffieux, K. Aitt-Mansour, O. Gröning, E. Tosatti, J. S. Siegel, R. Fasel, J. Am. Chem. Soc., 2008, 130, 4767-4771.

${ }^{78}$ S. Lampart, L. M. Roch, A. K. Dutta, Y. Wang, R. Warshamanage, A. D. Finke, A. Linden, K. K. Baldridge, J. S. Siegel, Angew. Chem., 2016, 128, 14868-14872.

${ }^{79}$ S. Mizyed, P. E. Georghiou, M. Bancu, B. Cuadra, A. K. Rai, P. Cheng, L. T. Scott, J. Am. Chem. Soc., 2001, 123, 12770-12774.

${ }^{80}$ (a) M. Bancu, A. K. Rai, P. Cheng, R. D. Gilardi, L. T. Scott, Synlett, 2004, 2004, 173-176; (b) P. E. Georghiou, A. H. Tran, S. Mizyed, M. Bancu, L. T. Scott, J. Org. Chem., 2005, 70, 6158-6163.

${ }^{81}$ C. Mejuto, L. Escobar, G. Guisado-Barrios, P. Ballester, D. Gusev, E. Peris, Chem. Eur. J., 2017, 23, 10644-10651.

${ }^{82}$ A. Sygula, R. Sygula, A. Ellern, P. W. Rabideau, Org. Lett., 2003, 5, 2595-2597.

${ }^{83}$ A. Sygula, F. R. Fronczek, R. Sygula, P. W. Rabideau, M. M. Olmstead, J. Am. Chem. Soc., 2007, 129, 3842-3843.

${ }^{84}$ (a) C. Muck-Lichtenfeld, S. Grimme, L. Kobryn, A. Sygula, Phys. Chem. Chem. Phys., 2010, 12, 7091-7097; (b) V. H. Le, M. Yanney, M. McGuire, A. Sygula, E. A. Lewis, J. Phys. Chem. B, 2014, 118, 11956-11964; (c) A. Sygula, M. Yanney, W. P. Henry, F. R. Fronczek, A. V. Zabula, M. A. Petrukhina, Cryst. Growth Des., 2014, 14, 2633-2639.

${ }^{85}$ M. Yanney, F. R. Fronczek, A. Sygula, Angew. Chem. Int. Ed., 2015, 54, 11153-11156.

${ }^{86}$ P. Job, Anal. Chim. Appl., 1928, 9, 113-203.

${ }^{87}$ K. G. U. R. Kumarasinghe, F. R. Fronczek, H. U. Valle, A. Sygula, Org. Lett., 2016, 18, 30543057.

${ }^{88}$ P. L. Abeyratne Kuragama, F. R. Fronczek, A. Sygula, Org. Lett., 2015, 17, 5292-5295.

${ }^{89}$ C. M. Álvarez, L. A. García-Escudero, R. García-Rodríguez, J. M. Martín-Álvarez, D. Miguel, V. M. Rayón, Dalton Trans., 2014, 43, 15693-15696. 
${ }^{90}$ H. Barbero, S. Ferrero, L. Álvarez-Miguel, P. Gómez-Iglesias, D. Miguel, C. M. Álvarez, Chem. Commun., 2016, 52, 12964-12967.

${ }^{91}$ D.-C. Yang, M. Li, C.-F. Chen, Chem. Commun., 2017, 53, 9336-9339.

${ }^{92}$ M. Yanney, A. Sygula, Tetrahedron Lett., 2013, 54, 2604-2607.

${ }^{93}$ C. M. Álvarez, G. Aullón, H. Barbero, L. A. García-Escudero, C. Martínez-Pérez, J. M. MartínÁlvarez, D. Miguel, Org. Lett., 2015, 17, 2578-2581.

${ }^{94}$ C. M. Álvarez, H. Barbero, S. Ferrero, D. Miguel, J. Org. Chem., 2016, 81, 6081-6086.

${ }_{95}^{95}$ V. García-Calvo, J. V. Cuevas, H. Barbero, S. Ferrero, C. M. Álvarez, J. A. González, B. Díaz de Greñu, J. García-Calvo, T. Torroba, Org. Lett., 2019, 21, 5803-5807.

${ }^{96}$ M. C. Stuparu, J. Polym. Sci., Part A: Polym. Chem., 2012, 50, 2641-2649.

${ }^{97}$ M. C. Stuparu, Angew. Chem. Int. Ed., 2013, 52, 7786-7790.

${ }^{98}$ (a) S. Saito, A. Osuka, Angew. Chem. Int. Ed., 2011, 50, 4342-4373; (b) M. Toganoh, H. Furuta, Chem. Commun., 2012, 48, 937-954; (c) C. G. Claessens, D. González-Rodríguez, M. S. Rodríguez-Morgade, A. Medina, T. Torres, Chem. Rev., 2014, 114, 2192-2277; (d) B. Szyszko, L. Latos-Grażyński, Chem. Soc. Rev., 2015, 44, 3588-3616; (e) B. Szyszko, M. J. Białek, E. PacholskaDudziak, L. Latos-Grażyński, Chem. Rev., 2017, 117, 2839-2909.

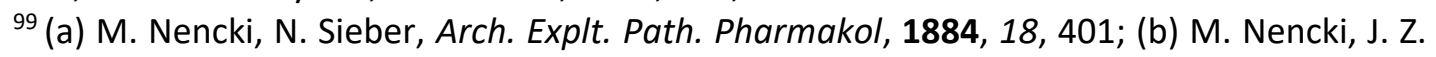
Zaleski, Z. Physiol. Chem., 1901, 34, 997.

${ }^{100}$ W. Küster, Z. Physiol. Chem., 1912, 82, 463-483.

${ }^{101}$ (a) H. Fischer, J. Klarer, Liebigs Ann. Chem., 1926, 440, 181-201; (b) H. Fischer, K. Zeile, Liebigs Ann. Chem., 1929, 468, 98-116.

102 (a) A. R. Battersby, C. J. R. Fookes, G. W. J. Matcham, E. McDonald, Nature, 1980, 285, 17 21; (b) A. R. Battersby, Nat. Prod. Rep., 2000, 17, 507-526.

${ }^{103}$ C. J. Reedy, B. R. Gibney, Chem. Rev., 2004, 104, 617-650.

104 (a) I. G. Denisov, T. M. Makris, S. G. Sligar, I. Schlichting, Chem. Rev., 2005, 105, 22532278; (b) O. M. Senge, A. A. Ryan, A. K. Letchford, A. S. MacGowan, T. Mielke, Symmetry, 2014, $6,781-843$.

105 (a) H. W. Baik, R. M. Russell, Annu. Rev. Nutr., 1999, 19, 357-377; (b) M. J. Koury, P. Ponka, Annu. Rev. Nutr., 2004, 24, 105-131.

${ }^{106}$ (a) K. M. Kadish, K. M. Smith, R. Guilard, Handbook of Porphyrin Science: with Applications to Chemistry, Physics, Materials Science, Engineering, Biology and Medicine, World Scientific Publishing Company, Singapore, 2010; (b) H. Dong, H. Zhu, Q. Meng, X. Gong, W. Hu, Chem. Soc. Rev., 2012, 41, 1754-1808; (c) L.-L. Li, E. W.-G. Diau, Chem. Soc. Rev., 2013, 42, 291-304; (d) S. H. A. M. Leenders, R. Gramage-Doria, B. de Bruin, J. N. H. Reek, Chem. Soc. Rev., 2015, 44, 433-448; (e) Y. Ding, W.-H. Zhu, Y. Xie, Chem. Rev., 2017, 117, 2203-2256.

${ }^{107}$ G. P. Moss, Eur. J. Biochem., 1988, 178, 277-328.

${ }^{108}$ C. M. Lemon, P. J. Brothers, B. Boitrel, Dalton Trans., 2011, 40, 6591-6609.

${ }^{109}$ M. J. Webb, N. Bampos, Chem. Sci., 2012, 3, 2351-2366.

${ }^{110}$ (a) K. M. Barkigia, M. D. Berber, J. Fajer, C. J. Medforth, M. W. Renner, K. M. Smith, J. Am. Chem. Soc., 1990, 112, 8851-8857; (b) K. M. Kadish, F. D'Souza, A. Villard, M. Autret, E. Van Caemelbecke, P. Bianco, A. Antonini, P. Tagliatesta, Inorg. Chem., 1994, 33, 5169-5170; (c) J. A. Shelnutt, X.-Z. Song, J.-G. Ma, S.-L. Jia, W. Jentzen, C. J. Medforth, C. J. Medforth, Chem. Soc. Rev., 1998, 27, 31-42; (d) R. E. Haddad, S. Gazeau, J. Pécaut, J.-C. Marchon, C. J. Medforth, J. A. Shelnutt, J. Am. Chem. Soc., 2003, 125, 1253-1268; (e) M. O. Senge, S. A. MacGowan, J. M. O'Brien, Chem. Commun., 2015, 51, 17031-17063; (f) M. Roucan, M. Kielmann, S. J. Connon, S. S. R. Bernhard, M. O. Senge, Chem. Commun., 2018, 54, 26-29.

${ }^{111}$ (a) M. Bröring, Angew. Chem. Int. Ed., 2011, 50, 2436-2438; (b) J. I. Wu, I. Fernández, P. v. R. Schleyer, J. Am. Chem. Soc., 2013, 135, 315-321.

112 (a) E. D. Becker, R. B. Bradley, J. Chem. Phys., 1959, 31, 1413-1414; (b) J. Ellis, A. H. Jackson, G. W. Kenner, J. Lee, Tetrahedron Lett., 1960, 1, 23-27; (c) E. D. Becker, R. B. Bradley, C. J. Watson, J. Am. Chem. Soc., 1961, 83, 3743-3748. 
113 (a) M. Gouterman, J. Chem. Phys., 1959, 30, 1139-1161; (b) M. Gouterman, J. Mol. Spectrosc., 1961, 6, 138-163; (c) M. Gouterman, G. H. Wagnière, L. C. Snyder, J. Mol. Spectrosc., 1963, 11, 108-127.

${ }^{114}$ (a) C. B. Storm, Y. Teklu, J. Am. Chem. Soc., 1972, 94, 1745-1747; (b) R. J. Abraham, G. E. Hawkes, K. M. Smith, Tetrahedron Lett., 1974, 15, 1483-1486.

${ }^{115}$ R. J. Abraham, H. Pearson, K. M. Smith, J. Am. Chem. Soc., 1976, 98, 1604-1606.

${ }^{116}$ (a) P. Rothemund, J. Am. Chem. Soc., 1935, 57, 2010-2011; (b) P. Rothemund, J. Am. Chem. Soc., 1936, 58, 625-627.

${ }^{117}$ (a) A. D. Adler, F. R. Longo, W. Shergalis, J. Am. Chem. Soc., 1964, 86, 3145-3149; (b) A. D. Adler, F. R. Longo, J. D. Finarelli, J. Goldmacher, J. Assour, L. Korsakoff, J. Org. Chem., 1967, 32, 476-476.

118 (a) J. S. Lindsey, H. C. Hsu, I. C. Schreiman, Tetrahedron Lett., 1986, 27, 4969-4970; (b) J. S. Lindsey, I. C. Schreiman, H. C. Hsu, P. C. Kearney, A. M. Marguerettaz, J. Org. Chem., 1987, 52, 827-836.

${ }^{119}$ (a) A. M. d. A. R. Gonsalves, J. M. T. B. Varejão, M. M. Pereira, J. Heterocycl. Chem., 1991, 28, 635-640; (b) K. M. Smith, New J. Chem., 2016, 40, 5644-5649.

${ }^{120}$ M. O. Senge, Chem. Commun., 2011, 47, 1943-1960.

${ }^{121}$ (a) P. Lidström, J. Tierney, B. Wathey, J. Westman, Tetrahedron, 2001, 57, 9225-9283; (b) C. O. Kappe, Angew. Chem. Int. Ed., 2004, 43, 6250-6284; (c) N. Sharma, U. K. Sharma, E. V. Van der Eycken, in Green Techniques for Organic Synthesis and Medicinal Chemistry, eds. W. Zhang and B. W. Cue, Wiley, New York, 2018, ch. 17, pp. 441-468.

122 (a) S. M. S. Chauhan, B. B. Sahoo, K. A. Srinivas, Synth. Commun., 2001, 31, 33-37; (b) B. F. O. Nascimento, M. Pineiro, A. M. d. A. Rocha Gonsalves, M. Ramos Silva, A. Matos Beja, J. A. Paixão, J. Porphyrins Phthalocyanines, 2007, 11, 77-84; (c) R. De Paula, M. A. F. Faustino, D. C. G. A. Pinto, M. G. P. M. S. Neves, J. A. S. Cavaleiro, J. Heterocycl. Chem., 2008, 45, 453-459; (d) M. Pineiro, Curr. Org. Synth., 2014, 11, 89-109.

${ }^{123}$ (a) Y. Sun, T. Drovetskaya, R. D. Bolskar, R. Bau, P. D. W. Boyd, C. A. Reed, J. Org. Chem., 1997, 62, 3642-3649; (b) P. D. W. Boyd, M. C. Hodgson, C. E. F. Rickard, A. G. Oliver, L. Chaker, P. J. Brothers, R. D. Bolskar, F. S. Tham, C. A. Reed, J. Am. Chem. Soc., 1999, 121, 10487-10495.

${ }^{124}$ (a) D. Sun, F. S. Tham, C. A. Reed, L. Chaker, P. D. W. Boyd, J. Am. Chem. Soc., 2002, 124, 6604-6612; (b) Y.-B. Wang, Z. Lin, J. Am. Chem. Soc., 2003, 125, 6072-6073; (c) P. D. W. Boyd, C. A. Reed, Acc. Chem. Res., 2005, 38, 235-242.

125 (a) M. M. Olmstead, D. A. Costa, K. Maitra, B. C. Noll, S. L. Phillips, P. M. Van Calcar, A. L. Balch, J. Am. Chem. Soc., 1999, 121, 7090-7097; (b) T. Ishii, N. Aizawa, M. Yamashita, H. Matsuzaka, T. Kodama, K. Kikuchi, I. Ikemoto, Y. Iwasa, J. Chem. Soc., Dalton Trans., 2000, 44074412; (c) P. Bhyrappa, K. Karunanithi, Inorg. Chem., 2010, 49, 8389-8400; (d) P. Bhyrappa, U. K. Sarangi, B. Varghese, Eur. J. Inorg. Chem., 2014, 2014, 5646-5650; (e) M. Roy, M. M. Olmstead, A. L. Balch, Cryst. Growth Des., 2019, 19, 6743-6751.

${ }^{126}$ (a) Y. Saegusa, T. Ishizuka, T. Kojima, S. Mori, M. Kawano, T. Kojima, Chem. Eur. J., 2015, 21, 5302-5306; (b) M. Yamada, G. Murakami, S. Kobayashi, Y. Maeda, Tetrahedron Lett., 2017, $58,4514-4518$.

${ }^{127}$ K. Tashiro, T. Aida, J.-Y. Zheng, K. Kinbara, K. Saigo, S. Sakamoto, K. Yamaguchi, J. Am. Chem. Soc., 1999, 121, 9477-9478.

${ }^{128}$ (a) H. Uno, M. Furukawa, A. Fujimoto, H. Uoyama, H. Watanabe, T. Okujima, H. Yamada, S. Mori, M. Kuramoto, T. Iwamura, N. Hatae, F. Tani, N. Komatsu, J. Porphyrins Phthalocyanines, 2011, 15, 951-963; (b) C. García-Simón, M. Costas, X. Ribas, Chem. Soc. Rev., 2016, 45, 40-62; (c) L. Moreira, J. Calbo, J. Aragó, B. M. Illescas, I. Nierengarten, B. Delavaux-Nicot, E. Ortí, N. Martín, J.-F. Nierengarten, J. Am. Chem. Soc., 2016, 138, 15359-15367; (d) N. Fukui, T. Kim, D. Kim, A. Osuka, J. Am. Chem. Soc., 2017, 139, 9075-9088; (e) S. Xue, D. Kuzuhara, N. Aratani, H. Yamada, Org. Lett., 2019, 21, 2069-2072; (f) S. Mori, N. Kawamoto, H. Uno, ChemPlusChem, 2019, 84, 686-693. 
${ }^{129}$ (a) K. Tashiro, T. Aida, Chem. Soc. Rev., 2007, 36, 189-197; (b) D. V. Konarev, S. S. Khasanov, R. N. Lyubovskaya, Coord. Chem. Rev., 2014, 262, 16-36; (c) L. Moreira, J. Calbo, B. M. Illescas, J. Aragó, I. Nierengarten, B. Delavaux-Nicot, E. Ortí, N. Martín, J.-F. Nierengarten, Angew. Chem. Int. Ed., 2015, 54, 1255-1260; (d) P. Mondal, S. P. Rath, Coord. Chem. Rev., 2020, 405, 213117.

${ }^{130}$ (a) D. M. Guldi, Chem. Soc. Rev., 2002, 31, 22-36; (b) H. Imahori, S. Fukuzumi, Adv. Funct. Mater., 2004, 14, 525-536; (c) H. Imahori, Org. Biomol. Chem., 2004, 2, 1425-1433; (d) D. Gust, T. A. Moore, A. L. Moore, Acc. Chem. Res., 2009, 42, 1890-1898; (e) F. D'Souza, O. Ito, Chem. Commun., 2009, 4913-4928; (f) J.-F. Nierengarten, Eur. J. Inorg. Chem., 2019, 2019, 4865-4878.

${ }^{131}$ (a) W. L. F. Armarego, C. L. L. Chai, Purification of Laboratory Chemicals, 6th, ButterworthHeinemann, London, 2009; (b) D. B. G. Williams, M. Lawton, J. Org. Chem., 2010, 75, 8351-8354.

${ }^{132}$ (a) G. K. Anderson, M. Lin, A. Sen, E. Gretz, in Inorg. Synth., ed. R. J. Angelici, John Wiley \& Sons, New York, 1990, vol. 28, pp. 60-63; (b) C. Nataro, S. M. Fosbenner, J. Chem. Educ., 2009, $86,1412-1415$.

${ }^{133}$ (a) N. Miyaura, A. Suzuki, Chem. Rev., 1995, 95, 2457-2483; (b) S. Kotha, K. Lahiri, D. Kashinath, Tetrahedron, 2002, 58, 9633-9695; (c) S. E. Hooshmand, B. Heidari, R. Sedghi, R. S. Varma, Green Chem., 2019, 21, 381-405.

${ }^{134}$ A. J. J. Lennox, G. C. Lloyd-Jones, Chem. Soc. Rev., 2014, 43, 412-443.

${ }^{135}$ T. D. W. Claridge, High-Resolution NMR Techniques in Organic Chemistry, 3rd ed., Elsevier, Boston, 2016.

${ }^{136}$ T. Parella, Magn. Reson. Chem., 1998, 36, 467-495.

${ }^{137}$ (a) R. D. Boyer, R. Johnson, K. Krishnamurthy, J. Magn. Reson., 2003, 165, 253-259; (b) R. Crouch, R. D. Boyer, R. Johnson, K. Krishnamurthy, Magn. Reson. Chem., 2004, 42, 301-307; (c) H. Hu, K. Krishnamurthy, Magn. Reson. Chem., 2008, 46, 683-689.

${ }^{138}$ M. A. Smith, H. Hu, A. J. Shaka, J. Magn. Reson., 2001, 151, 269-283.

${ }^{139}$ C. Gaillet, C. Lequart, P. Debeire, J.-M. Nuzillard, J. Magn. Reson., 1999, 139, 454-459.

${ }^{140} \bar{E}$. Kupce, R. Freeman, J. Magn. Reson. Ser. A, 1995, 117, 246-256.

${ }^{141}$ (a) H. Ajie, M. M. Alvarez, S. J. Anz, R. D. Beck, F. Diederich, K. Fostiropoulos, D. R. Huffman, W. Kraetschmer, Y. Rubin, et al., J. Phys. Chem., 1990, 94, 8630-8633; (b) F. Diederich, R. L. Whetten, Acc. Chem. Res., 1992, 25, 119-126.

${ }^{142}$ A. Beer, Annalen der Physik, 1852, 162, 78-88.

${ }^{143}$ M. J. Frisch, G. W. Trucks, H. B. Schlegel, G. E. Scuseria, M. A. Robb, J. R. Cheeseman, G. Scalmani, V. Barone, G. A. Petersson, H. Nakatsuji, X. Li, M. Caricato, A. V. Marenich, J. Bloino, B. G. Janesko, R. Gomperts, B. Mennucci, H. P. Hratchian, J. V. Ortiz, A. F. Izmaylov, J. L. Sonnenberg, Williams, F. Ding, F. Lipparini, F. Egidi, J. Goings, B. Peng, A. Petrone, T. Henderson, D. Ranasinghe, V. G. Zakrzewski, J. Gao, N. Rega, G. Zheng, W. Liang, M. Hada, M. Ehara, K. Toyota, R. Fukuda, J. Hasegawa, M. Ishida, T. Nakajima, Y. Honda, O. Kitao, H. Nakai, T. Vreven, K. Throssell, J. A. Montgomery Jr., J. E. Peralta, F. Ogliaro, M. J. Bearpark, J. J. Heyd, E. N. Brothers, K. N. Kudin, V. N. Staroverov, T. A. Keith, R. Kobayashi, J. Normand, K. Raghavachari, A. P. Rendell, J. C. Burant, S. S. Iyengar, J. Tomasi, M. Cossi, J. M. Millam, M. Klene, C. Adamo, R. Cammi, J. W. Ochterski, R. L. Martin, K. Morokuma, O. Farkas, J. B. Foresman, D. J. Fox, Gaussian 16 Rev. C.01, Wallingford, CT, 2016.

${ }^{144}$ C. F. Macrae, I. Sovago, S. J. Cottrell, P. T. A. Galek, P. McCabe, E. Pidcock, M. Platings, G. P. Shields, J. S. Stevens, M. Towler, P. A. Wood, J. Appl. Cryst., 2020, 53.

145 (a) D.A. Case, I.Y. Ben-Shalom, S.R. Brozell, D.S. Cerutti, T.E. Cheatham, III, V.W.D. Cruzeiro, T.A. Darden, R.E. Duke, D. Ghoreishi, M.K. Gilson, H. Gohlke, A.W. Goetz, D. Greene, R Harris, N. Homeyer, S. Izadi, A. Kovalenko, T. Kurtzman, T.S. Lee, S. LeGrand, P. Li, C. Lin, J. Liu, T. Luchko, R. Luo, D.J. Mermelstein, K.M. Merz, Y. Miao, G. Monard, C. Nguyen, H. Nguyen, I. Omelyan, A. Onufriev, F. Pan, R. Qi, D.R. Roe, A. Roitberg, C. Sagui, S. Schott-Verdugo, J. Shen, C.L. Simmerling, J. Smith, R. Salomon-Ferrer, J. Swails, R.C. Walker, J. Wang, H. Wei, R.M. Wolf, X. Wu, L. Xiao, D.M. York and P.A. Kollman (2018), AMBER 2018, University of California, San Francisco; (b) D. A. Case, T. E. Cheatham III, T. Darden, H. Gohlke, R. Luo, K. M. Merz Jr, A. 
Onufriev, C. Simmerling, B. Wang, R. J. Woods, J. Comput. Chem., 2005, 26, 1668-1688; (c) R. Salomon-Ferrer, D. A. Case, R. C. Walker, Wiley Interdiscip. Rev.:Comput. Mol. Sci., 2013, 3, 198210.

${ }^{146}$ (a) S. Grimme, J. Comput. Chem., 2006, 27, 1787-1799; (b) S. Grimme, S. Ehrlich, L. Goerigk, J. Comput. Chem., 2011, 32, 1456-1465.

${ }^{147}$ (a) R. Ditchfield, W. J. Hehre, J. A. Pople, J. Chem. Phys., 1971, 54, 724-728; (b) W. J. Hehre, R. Ditchfield, J. A. Pople, J. Chem. Phys., 1972, 56, 2257-2261; (c) M. M. Francl, W. J. Pietro, W. J. Hehre, J. S. Binkley, M. S. Gordon, D. J. DeFrees, J. A. Pople, J. Chem. Phys., 1982, 77, 36543665.

148 J. J. P. Stewart, J. Mol. Model., 2007, 13, 1173-1213.

${ }^{149}$ G. Scalmani, M. J. Frisch, J. Chem. Phys., 2010, 132, 114110.

${ }^{150}$ M. J. Frisch, J. A. Pople, J. S. Binkley, J. Chem. Phys., 1984, 80, 3265-3269.

151 (a) S. F. Boys, F. Bernardi, Mol. Phys., 1970, 19, 553-566; (b) S. Simon, M. Duran, J. J. Dannenberg, J. Chem. Phys., 1996, 105, 11024-11031; (c) T. Van Mourik, A. K. Wilson, K. A. Peterson, D. E. Woon, T. H. Dunning, in Adv. Quantum Chem., eds. J. R. Sabin, M. C. Zerner, E. Brändas, S. Wilson, J. Maruani, Y. G. Smeyers, P. J. Grout and R. McWeeny, Academic Press, 1998, vol. 31, pp. 105-135; (d) K. N. Kirschner, J. B. Sorensen, J. P. Bowen, J. Chem. Educ., 2007, 84, 1225-1229.

${ }^{152}$ (a) E. R. Johnson, S. Keinan, P. Mori-Sánchez, J. Contreras-García, A. J. Cohen, W. Yang, J. Am. Chem. Soc., 2010, 132, 6498-6506; (b) J. Contreras-García, E. R. Johnson, S. Keinan, R. Chaudret, J.-P. Piquemal, D. N. Beratan, W. Yang, J. Chem. Theory Comput., 2011, 7, 625-632.

${ }^{153}$ E. F. Pettersen, T. D. Goddard, C. C. Huang, G. S. Couch, D. M. Greenblatt, E. C. Meng, T. E. Ferrin, J. Comput. Chem., 2004, 25, 1605-1612.

${ }^{154}$ Rodríguez-Guerra Pedregal, J. Development and Application of a Computational Platform for Complex Molecular Design, Universitat Autònoma de Barcelona, 2018. ISBN 9788449082382. https://ddd.uab.cat/record/9788449201498.(https://github.com/insilichem/tangram nciplot).

155 La elección y justificación de la concentración de Host (anfitrión) y Guest (huésped) en cada caso está detallado en la parte experimental de cada artículo.

${ }^{156}$ (a) L. Fielding, Tetrahedron, 2000, 56, 6151-6170; (b) P. Thordarson, Chem. Soc. Rev., 2011, 40, 1305-1323; (c) P. Thordarson, in Supramolecular Chemistry: From Molecules to Nanomaterials, eds. P. A. Gale and J. W. Steed, John Wiley \& Sons, Chichester, UK, 2012, vol. 2, pp. 239-274; (d) D. Brynn Hibbert, P. Thordarson, Chem. Commun., 2016, 52, 12792-12805.

${ }^{157}$ F. Ulatowski, K. Dąbrowa, T. Bałakier, J. Jurczak, J. Org. Chem., 2016, 81, 1746-1756.

${ }^{158}$ M. O. Senge, Chem. Commun., 2006, 243-256.

159 J. P. Hare, H. W. Kroto, R. Taylor, Chem. Phys. Lett., 2013, 589, 57-60.

${ }^{160}$ (a) C. Zhang, Q. Wang, H. Long, W. Zhang, J. Am. Chem. Soc., 2011, 133, 20995-21001; (b) Y. Shi, K. Cai, H. Xiao, Z. Liu, J. Zhou, D. Shen, Y. Qiu, Q.-H. Guo, C. Stern, M. R. Wasielewski, F. Diederich, W. A. Goddard, J. F. Stoddart, J. Am. Chem. Soc., 2018, 140, 13835-13842.

${ }^{161}$ B. Topolinski, B. M. Schmidt, M. Kathan, S. I. Troyanov, D. Lentz, Chem. Commun., 2012, 48, 6298-6300.

162 (a) M. Pons, O. Millet, Prog. Nucl. Magn. Reson. Spectrosc., 2001, 38, 267-324; (b) A. D. Bain, Prog. Nucl. Magn. Reson. Spectrosc., 2003, 43, 63-103; (c) I. R. Kleckner, M. P. Foster, Biochim. Biophys. Acta - Proteins Proteomics, 2011, 1814, 942-968.

163 (a) M. N. Blackburn, H. K. Schachman, Biochemistry, 1977, 16, 5084-5091; (b) J. A. Endrizzi, P. T. Beernink, T. Alber, H. K. Schachman, Proc. Natl. Acad. Sci., 2000, 97, 5077-5082.

${ }^{164}$ (a) S. Wan, F. Gándara, A. Asano, H. Furukawa, A. Saeki, S. K. Dey, L. Liao, M. W. Ambrogio, Y. Y. Botros, X. Duan, S. Seki, J. F. Stoddart, O. M. Yaghi, Chem. Mater., 2011, 23, 4094-4097; (b) X. Liu, Y. Xu, Z. Guo, A. Nagai, D. Jiang, Chem. Commun., 2013, 49, 3233-3235.

165 Zn-PTetraCor también puede prepararse usando como productos de partida ZnPTetraBpin y Br-Cor (Esquema 9, similar Ruta A). En este caso el rendimiento es del $56 \%$. 
${ }^{166}$ (a) H.-B. Acta Crystallographica Section CZhao, L. Chen, B.-Y. Wang, J.-X. Liao, Y.-J. Xu, Acta Cryst. C, 2013, 69, 651-653; (b) N. Sheng, S. Zong, W. Cao, J. Jiang, Z. Wang, Y. Cui, ACS Appl. Mater. Interfaces, 2015, 7, 19718-19725; (c) P. Kuś, J. Kusz, M. Książek, J. Chem. Crystallogr., 2020, 50, 21-27. En estas estructuras de rayos $X$, en sistemas para sustituidos, el valor de alfa es próximo a $90^{\circ}\left(91.62^{\circ}-88.46^{\circ}\right)$ como el observado en la estructura optimizada $2 \mathrm{H}$-PTetraCor.

167 (a) P. A. Denis, RSC Adv., 2013, 3, 25296-25305; (b) D. Josa, J. Rodríguez-Otero, E. M. Cabaleiro-Lago, L. A. Santos, T. C. Ramalho, J. Phys. Chem. A, 2014, 118, 9521-9528.

168 En centros receptores independientes o no cooperativos el valor de $K_{2}$ es 4 veces inferior al valor de $K_{1}$, por motivos puramente estadísticos. Por tanto, dado los valores relativamente pequeños de $K_{1}$ (Tabla 6) la determinación experimental de $K_{2}$, aún menor, es muy complicada. 